\title{
(1)
}

UNIVERSIDAD PERUANA DE CIENCIAS APLICADAS

FACULTAD DE INGENIERÍA

PROGRAMA ACADÉMICO DE INGENIERÍA INDUSTRIAL

\section{PROYECTO DE VIABILIDAD PARA IMPLEMENTAR \\ UN SISTEMA DE GENERACIÓN DE ENERGÍA RENOVABLE EN LAS ESTACIONES DE LA LÍNEA 1 DEL TREN ELÉCTRICO DE LIMA}

\section{TESIS}

para optar el grado académico de Ingeniero Industrial

\section{AUTORES}

Concha Reátegui, Pablo Renato (0000-0003-1934-5386)

Zamalloa Rubina, Rodrigo Fernando (0000-0001-9354-0687)

\section{ASESOR DE TESIS}

Quispe Santivañez, Grimaldo Wilfredo (0000-0001-6168-8935) 


\section{Dedicatoria}

Este proyecto no pudo llevarse a cabo sin el constante e incondicional apoyo de todos nuestros seres queridos, amigos, familiares, profesores y otros. Además, las entidades que nos brindaron soporte desde un principio, tales como AATE, UPC y Shell. A todos ellos les dedicamos este trabajo de investigación. 


\section{TABLA DE CONTENIDO}

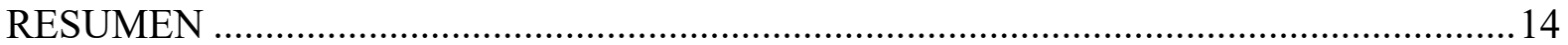

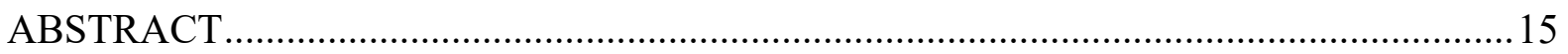

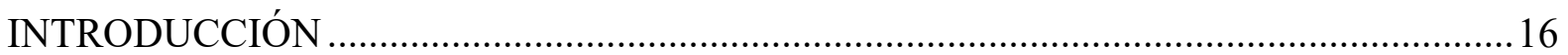

CAPÍTULO 1: ESTADO DEL ARTE Y MARCO TEÓRICO ................................................ 19

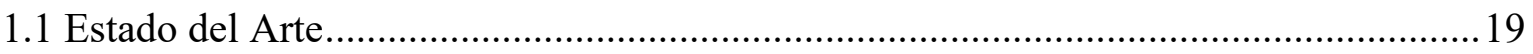

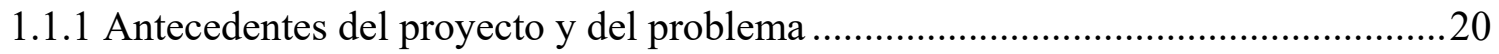

1.1.1.1 Autoridad Autónoma del Sistema Eléctrico de Transporte Masivo de Lima y

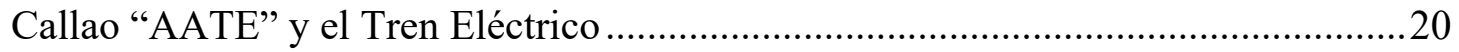

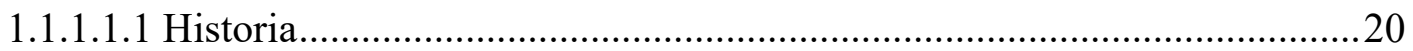

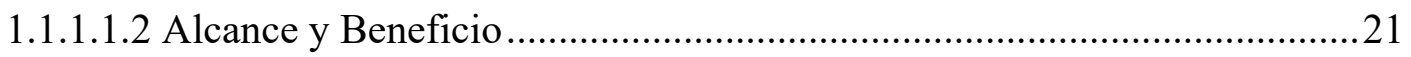

1.1.1.1.3 Detalles del Proyecto “Tren Eléctrico en Lima Perú” .............................24

1.1.1.1.4 Conclusiones e Importancia del Tren Eléctrico de Lima.........................24

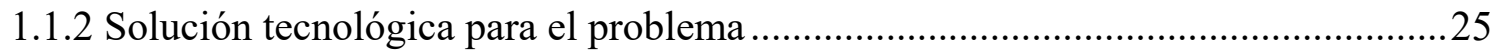

1.1.2.1 Energy Harvesting "Recolección de Energía" ..............................................25

1.1.2.1.1 Clasificación de los Energy Harvesters "Recolectores de Energía" .........27

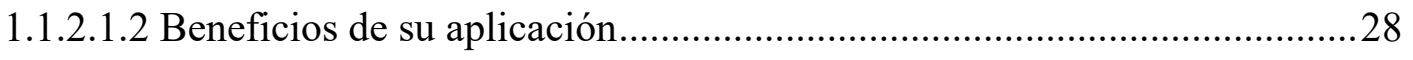

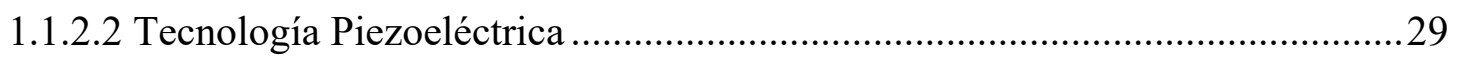

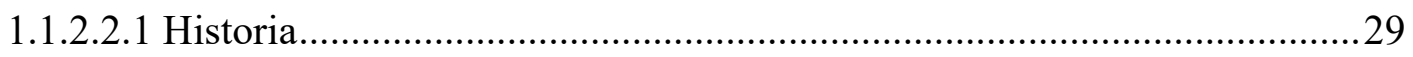

1.1.2.2.2 Fundamentos de la Piezoelectricidad .......................................................

1.1.2.2.3 Modelo eléctrico de materiales piezoeléctricos ......................................34

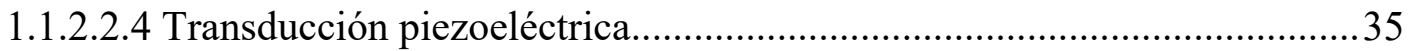

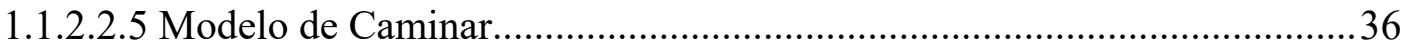

1.1.2.2.6 Evolución de la tecnología piezoeléctrica............................................... 37

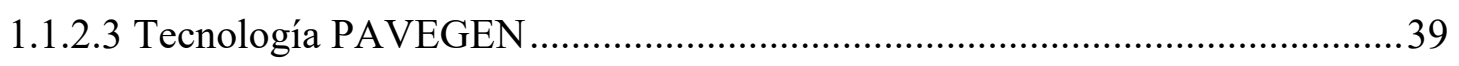

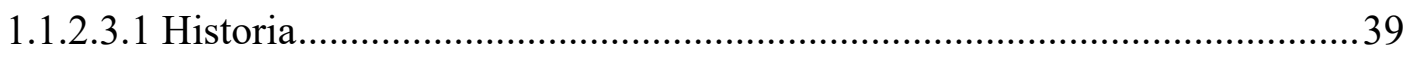

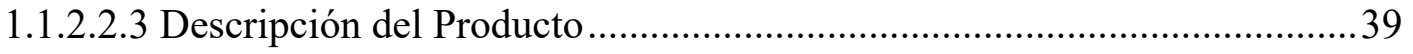

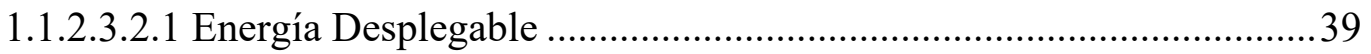

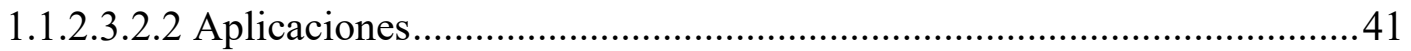

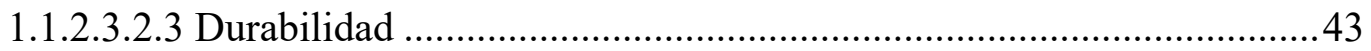

1.1.2.3.2.4 Almacenamiento y distribución de la energía.....................................47

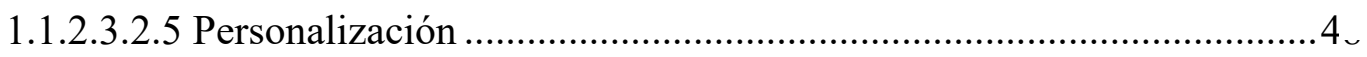

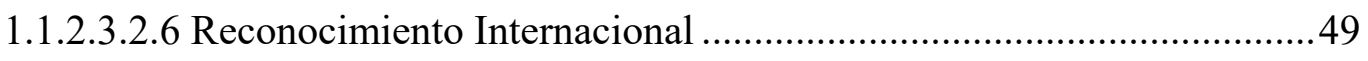




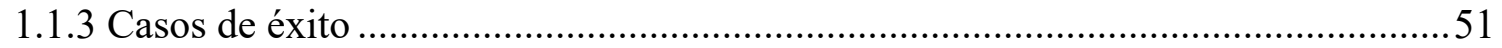

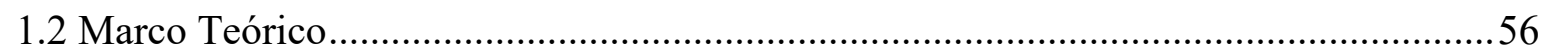

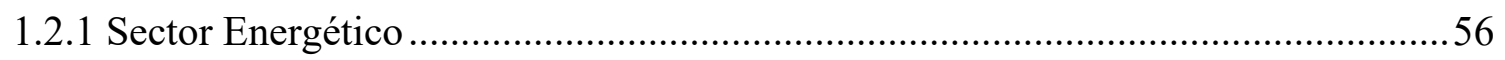

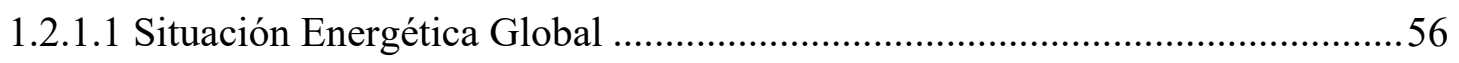

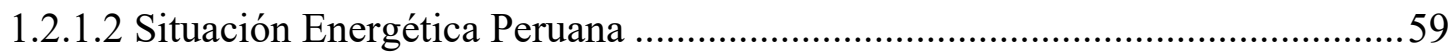

1.2.2 Simulación Montecarlo en Software Arena..........................................................65

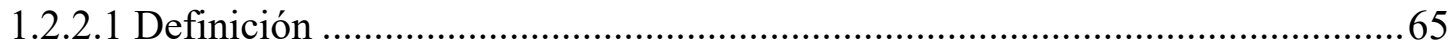

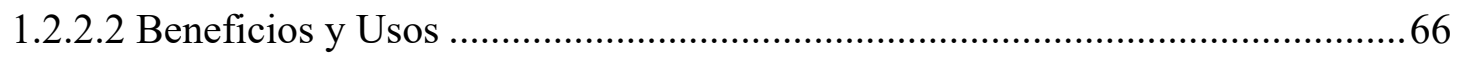

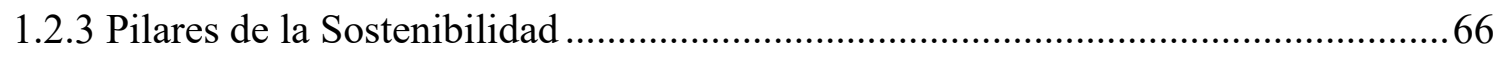

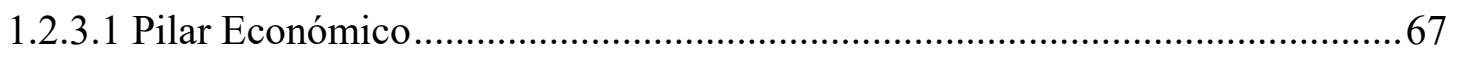

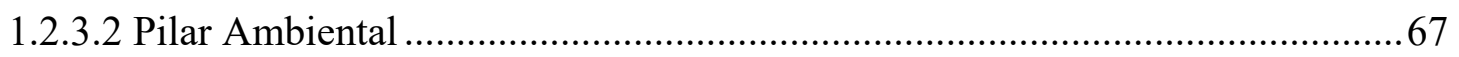

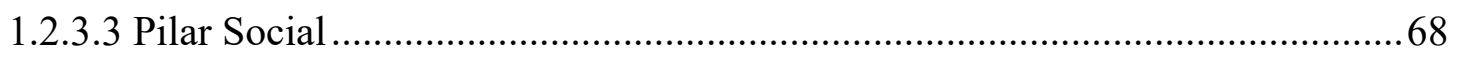

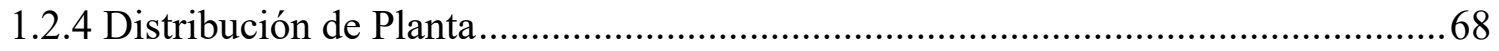

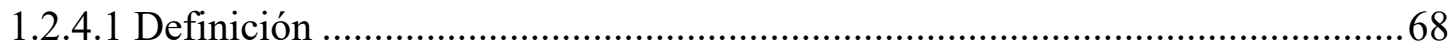

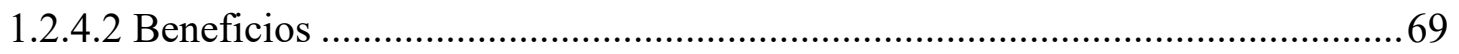

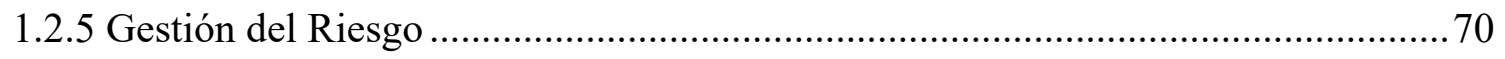

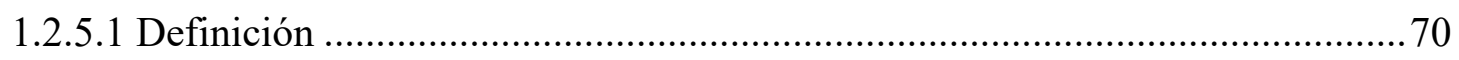

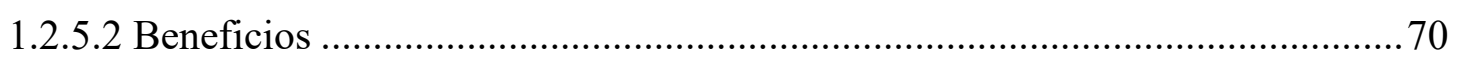

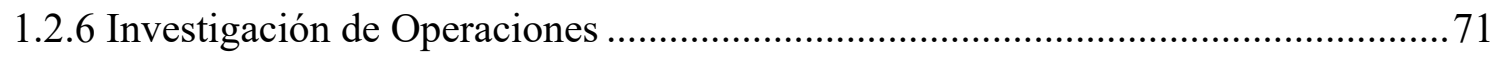

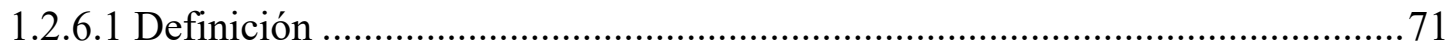

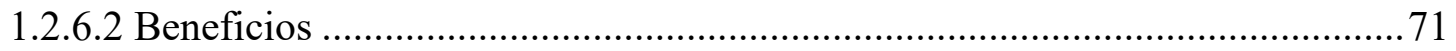

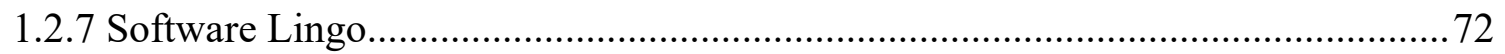

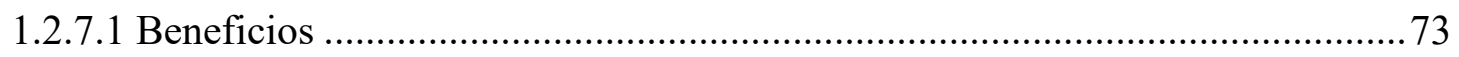

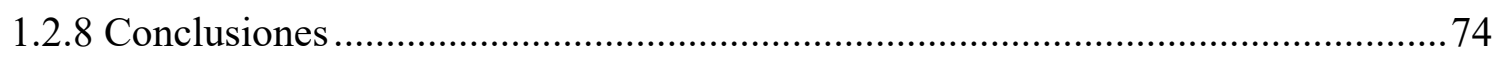

CAPÍTULO 2: DIAGNÓSTICO E IDENTIFICACIÓN DEL PROBLEMA ..........................76

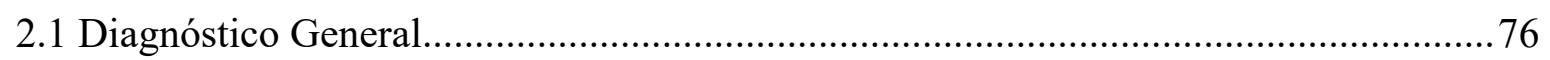

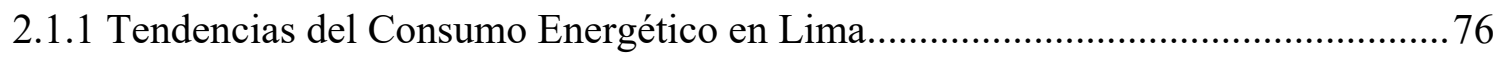

2.1.2 El Estado Peruano frente a las Energías Renovables............................................ 77

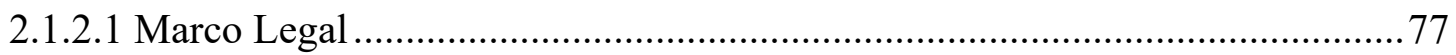

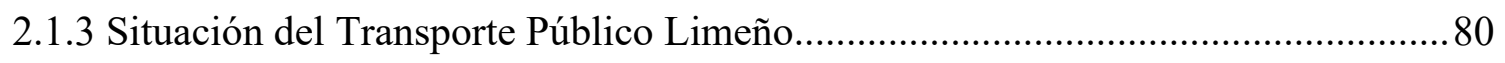

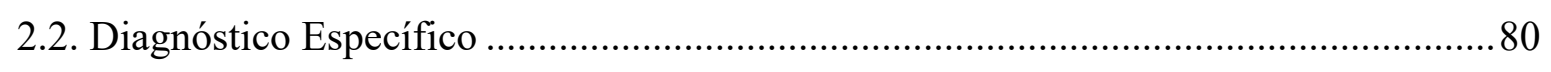

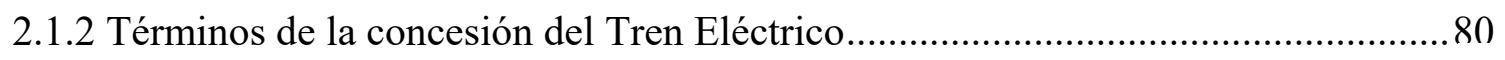

2.2.2 Afluencia de personas en las estaciones del tren eléctrico .................................... o J 


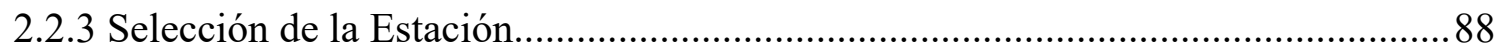

2.2.4 Consumo eléctrico de la Estación La Cultura.......................................................8

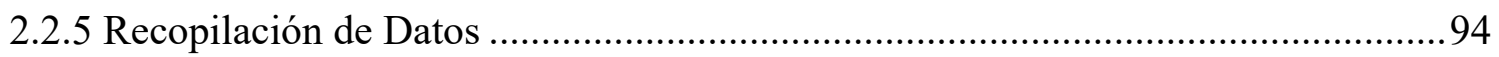

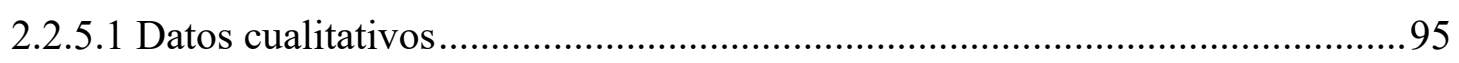

2.2.5.1.1 Análisis FODA de AATE ....................................................................95

2.2.5.1.2 Entrevista personal a miembros de AATE.............................................96

2.2.5.1.3 Identificación de STAKEHOLDERS .................................................... 97

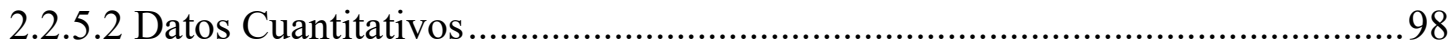

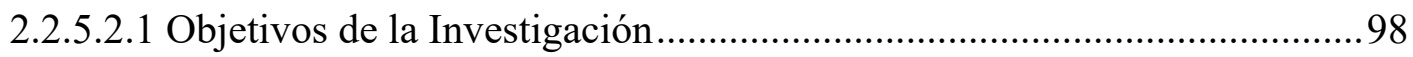

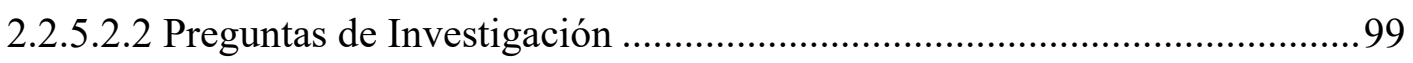

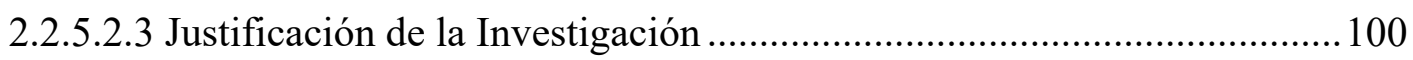

2.2.5.2.4 Tamaño de Muestra a considerar ........................................................... 100

2.2.5.2.5 Reporte de resultados del análisis cuantitativo ..................................... 101

2.2.5.3 Confrontación de la encuesta Cualitativa con la Cuantitativa .......................114

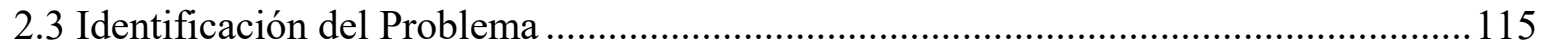

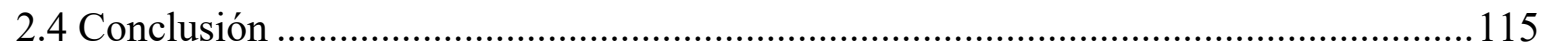

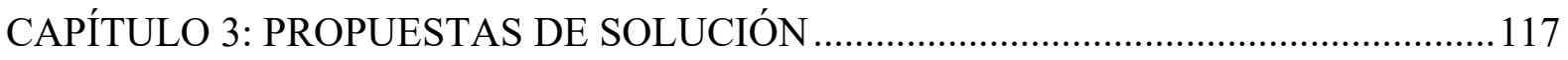

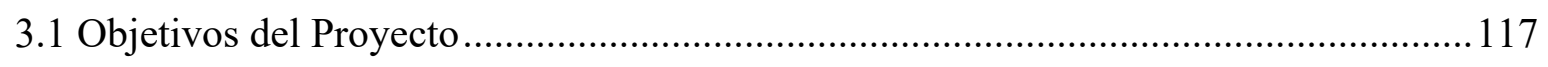

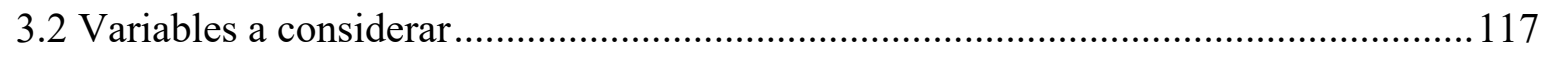

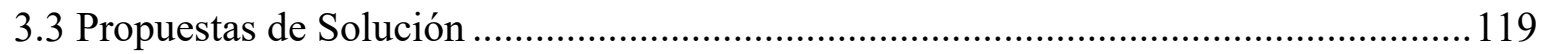

3.3.1 Propuesta 1: Implementación de un sistema de generación de Energía Renovable

3.3.1.1 Evaluación de Proveedores ..................................................................... 119

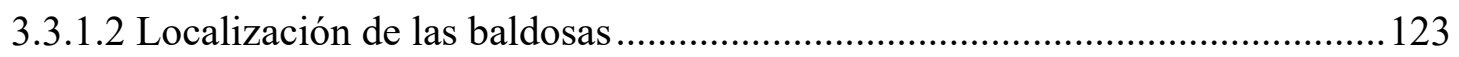

3.3.1.3 Cálculo del Lote óptimo de Baldosas a instalar en la Estación ......................132

3.3.1.4 Cálculo de beneficios de la Implementación ................................................139

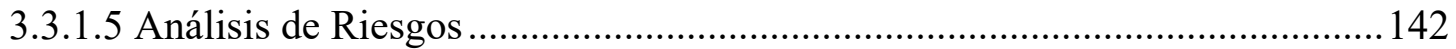

3.3.2 Propuesta 2: Cambio de luminaria en la estación ..................................................147

3.3.3 Selección de Propuestas de Solución......................................................................151

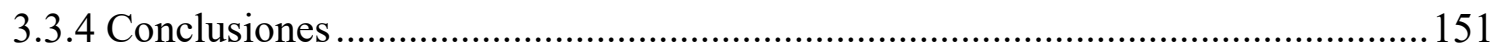

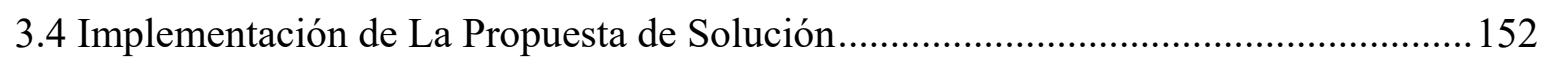

3.4.1 Diseño Arquitectónico ............................................................................. $]^{\text {En }}$

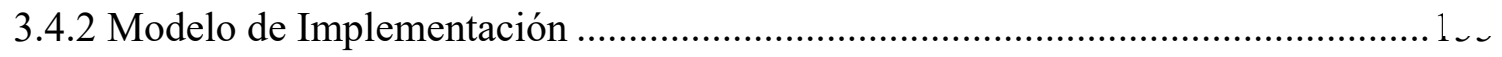


3.4.3 Requerimientos y Procedimientos Civiles ........................................................... 159

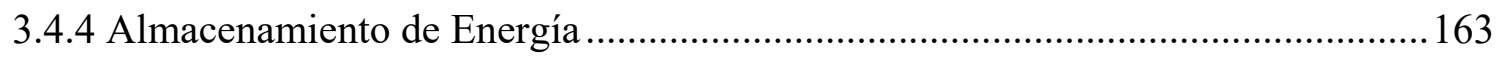

3.4.5 Mantenimiento de las Baldosas PAVEGEN ........................................................... 165

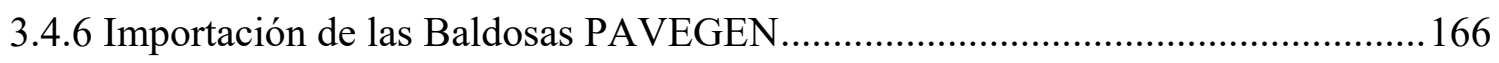

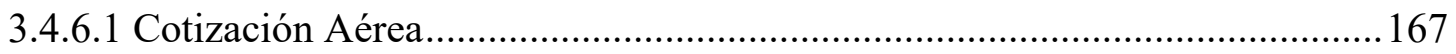

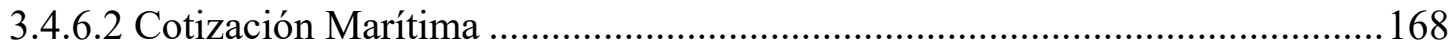

3.4.6.3 Evaluación y Selección del Medio de Transporte..........................................169

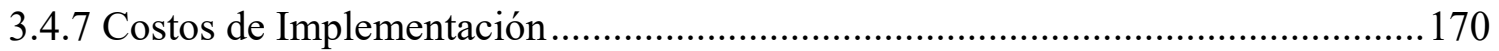

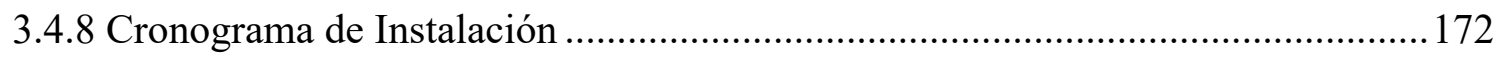

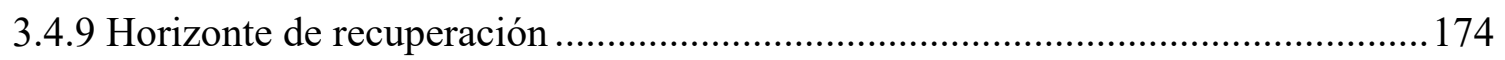

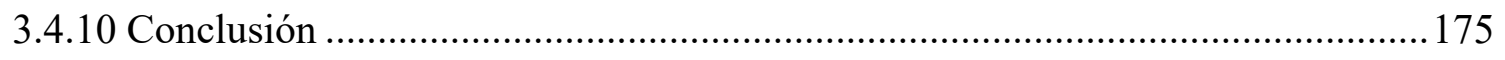

CAPÍTULO 4: VALIDACIÓN DE LA PROPUESTA DE SOLUCIÓN ..............................176

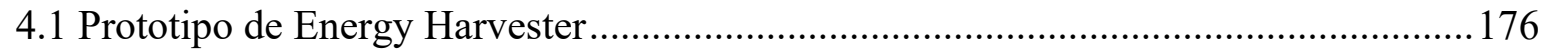

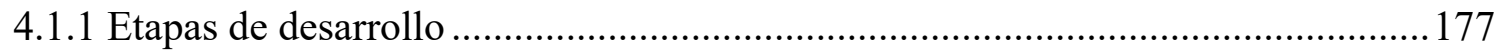

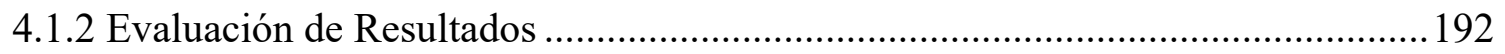

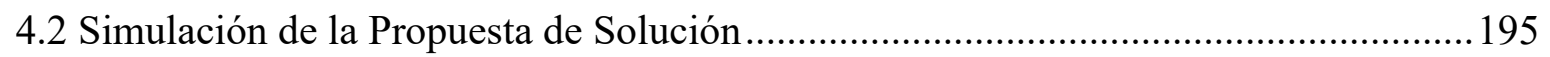

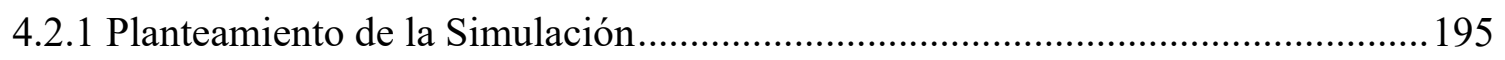

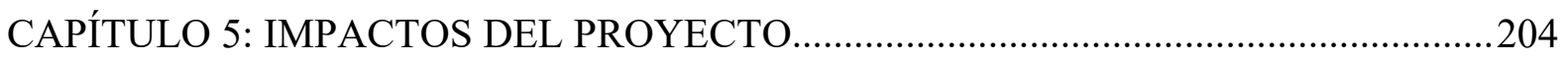

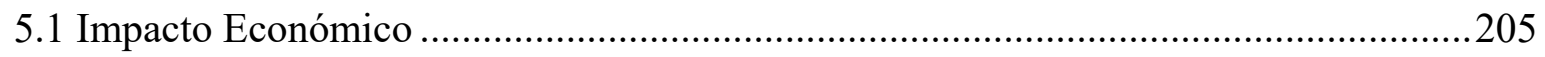

5.1.1 Ahorros Generados por la instalación de la tecnología piezoeléctrica .................205

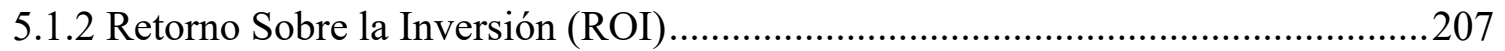

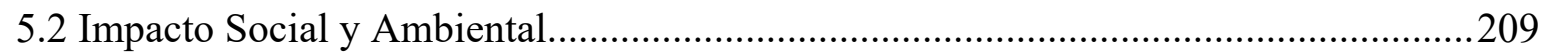

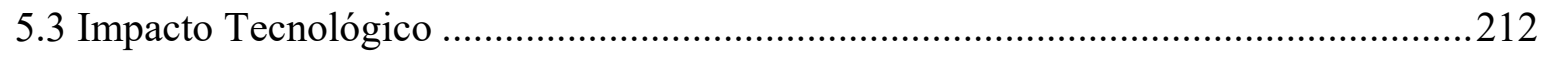

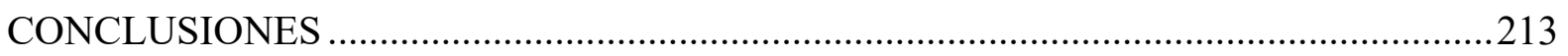

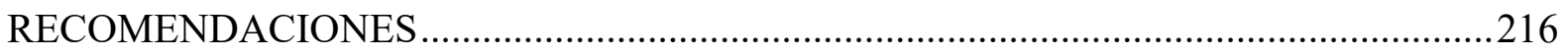

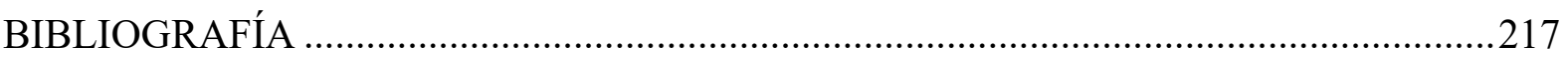

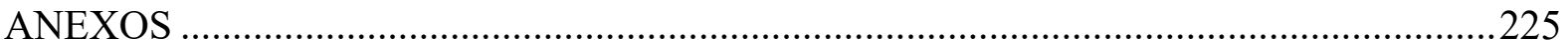




\section{ÍNDICE DE TABLAS}

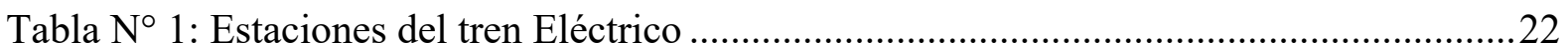

Tabla N 2: Condiciones de la Concesión con Graña y Montero 2013 ....................................81

Tabla $\mathrm{N}^{\circ}$ 3: Balance económico del contrato de la Concesión con G\&M ...............................82

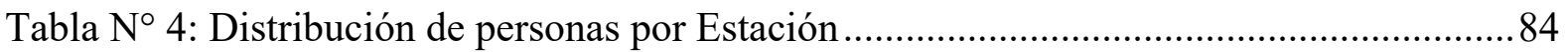

Tabla $N^{\circ}$ 5: Afluencia Promedio diaria de pasajeros en la Estación La Cultura durante el año

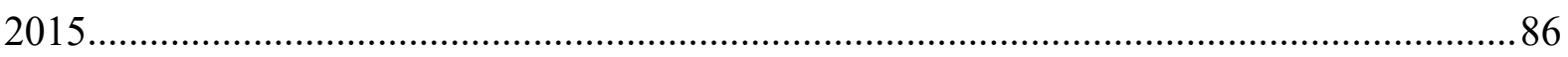

Tabla N ${ }^{\circ}$ 6: Afluencia Mensual y Anual de la Estación La Cultura .......................................87

Tabla N ${ }^{\circ}$ : Tarifa para la venta de Energía Eléctrica ...........................................................91

Tabla Nº 8: Consumo Eléctrico Estación La Cultura ............................................................91

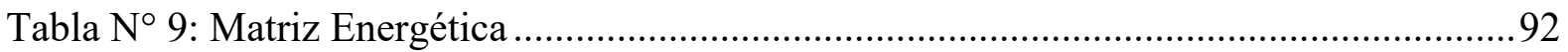

Tabla N 10: Consumo Eléctrico Estación La Cultura .............................................................93

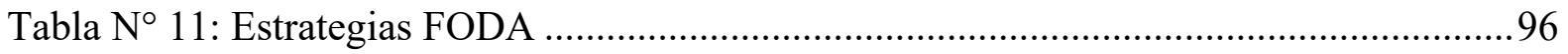

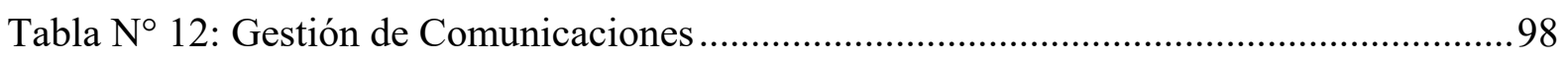

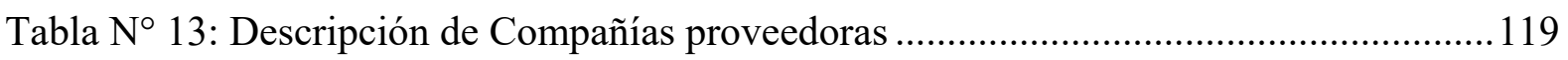

Tabla N 14: Calificación de las Compañías .......................................................................... 122

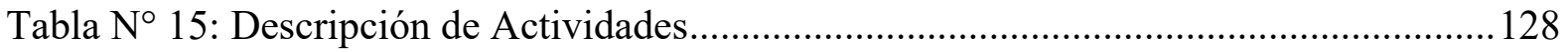

Tabla $\mathrm{N}^{\circ}$ 16: Distancia promedio de las pisadas de los peruanos .........................................133

Tabla $\mathrm{N}^{\circ}$ 17: Cálculo de Ahorros en los tres escenarios con 6 Pasos aprovechados por Usuario 139

Tabla $\mathrm{N}^{\circ}$ 18: Cálculo de Ahorros en los tres escenarios con 7 Pasos aprovechados por Usuario 140

Tabla N 19: Cálculo de Ahorros en los tres escenarios con 8 Pasos aprovechados por Usuario 140

Tabla $\mathrm{N}^{\circ}$ 20: Costos y ahorros Energéticos Estación la Cultura .......................................... 142

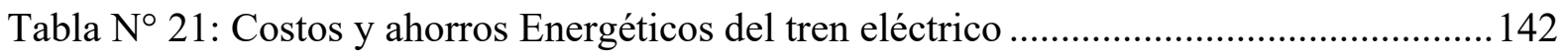

Tabla $\mathrm{N}^{\circ}$ 22: Porcentaje de Ahorro del Déficit del Estado.................................................. 142

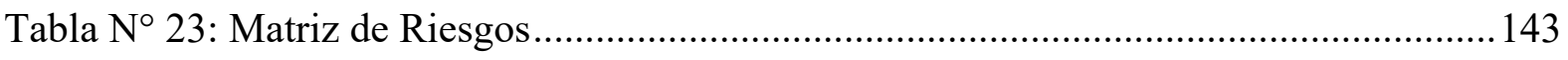

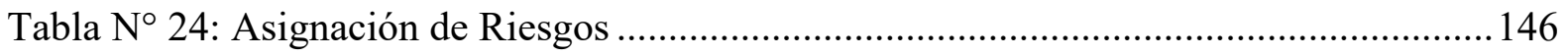

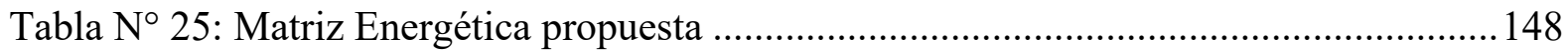

Tabla $\mathrm{N}^{\circ}$ 26: Variación del consumo energético S. Actual VS Propuesta .............................150 
Tabla $\mathrm{N}^{\circ}$ 27: Variación del consumo energético S. Actual VS Propuesta 150

Tabla N $\mathrm{N}^{\circ} 28$ : Costos de Implementación del Proyecto ......................................................... 170

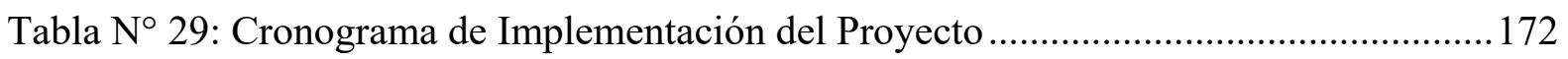

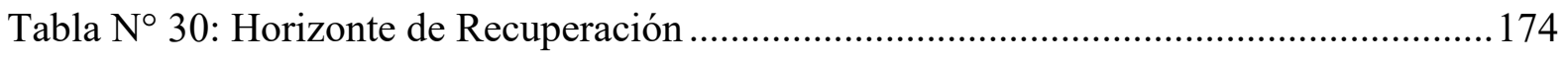

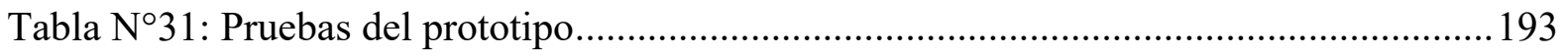

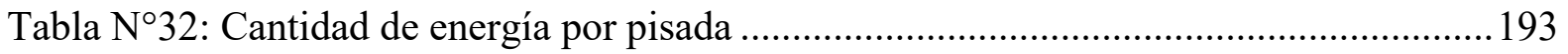

Tabla N³3: Energía Promedio generada por el prototipo .................................................... 194

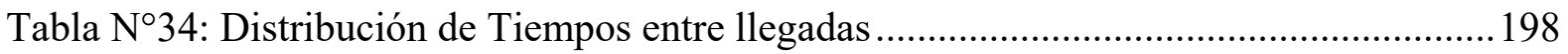

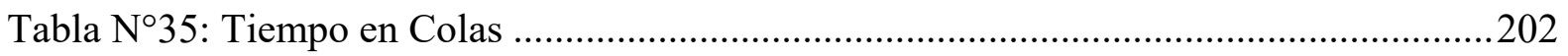

Tabla N³6: Cálculo de Ahorros en la Estación la Cultura 6 Pasos aprovechados por Usuario .206

Tabla N³7: Cálculo de Ahorros en la Estación la Cultura 7 Pasos aprovechados por Usuario .206

Tabla N³8: Cálculo de Ahorros en la Estación la Cultura 8 Pasos aprovechados por Usuario .207

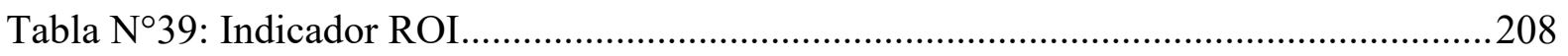

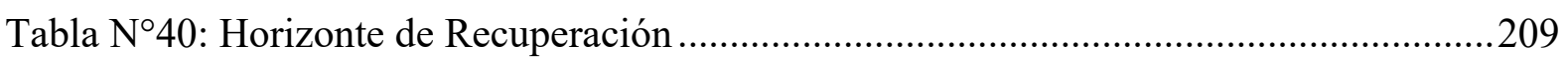




\section{ÍNDICE DE FIGURAS}

Figura $N^{\circ}$ 1: Distribución de Estaciones del Tren Eléctrico en Lima. .23

Gráfica $N^{\circ} 1$ : Cantidad de publicaciones sobre Energy Harvesting entre 1963-2013 ....26

Gráfica $N^{\circ}$ 2: Cantidad de publicaciones sobre Energy Scavenging entre 1963-2013 ....26

Figura $\mathrm{N}^{\circ}$ 2: Diferentes fuentes de energía y sus respectivos transductores para su conversión a energía eléctrica

Figura $\mathrm{N}^{\circ}$ 3: Efecto piezoeléctrico directo e inverso 31

Figura $\mathrm{N}^{\circ}$ 4: Estructura cristalina de una cerámica piezoeléctrica antes y después de ser polarizada (Pb: Plomo, O2: Oxígeno, Ti: Titanio, Zr: Circonio) 32

Figura $N^{\circ}$ 5: Proceso de polarización (a) Antes de la polarización los dominios polares se encuentran orientados aleatoriamente. (b) Un gran campo eléctrico DC es aplicado para la polarización. (c) Al quitar el campo eléctrico, la polarización remanente permanece 33 Figura $\mathrm{N}^{\circ}$ 6: Comportamiento de un material piezoeléctrico en aplicación con sensor o actuador (a)Dirección de polarización. (b)Campo eléctrico aplicado con la misma polaridad que el de polarización. (c)Campo eléctrico aplicado con la polaridad opuesta al de polarización. (d)Compresión aplicada en la dirección de polarización. (e)Tracción aplicada en la dirección de polarización. .34

Figura $N^{\circ}$ 7: Principio de Funcionamiento del Transductor piezoeléctrico.....................36

Figura $N^{\circ}$ 8: Modelo de caminar como Péndulo invertido ................................................37

Figura $N^{\circ}$ 9: Gráficas de aprovechamiento de energía por tipo....................................40

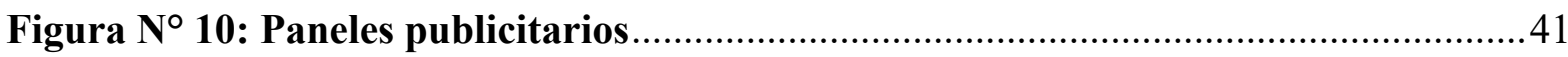

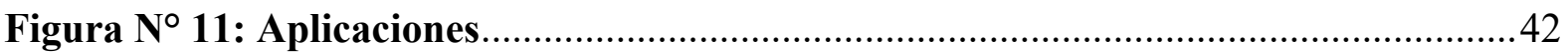

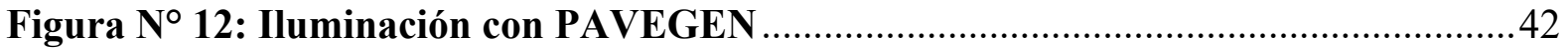

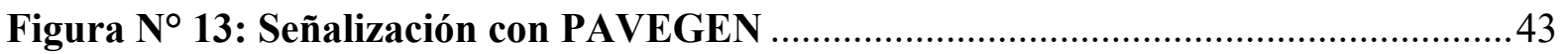

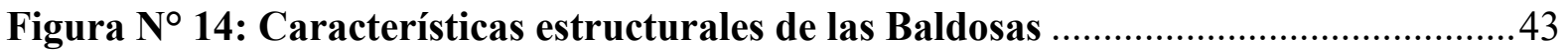

Figura $N^{\circ}$ 15: Sobrecarga en las baldosas PAVEGEN .................................................... 44

Figura $\mathbf{N}^{\circ}$ 16: Simulación y prueba de presión en las Baldosas ......................................45

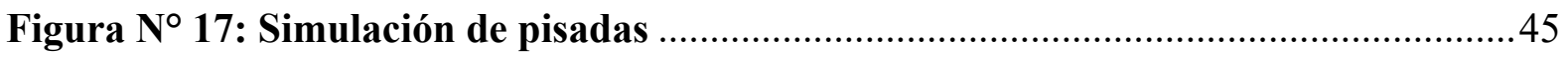

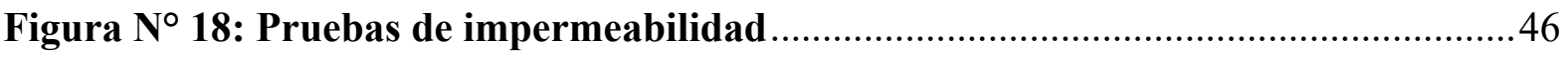

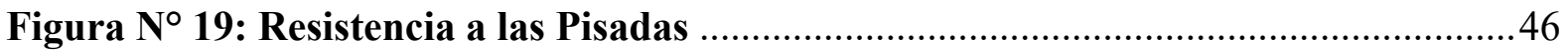

Figura $N^{\circ}$ 20: Diagrama de flujo del sistema de carga de batería 
Figura $\mathrm{N}^{\circ}$ 21: Diagrama de flujo del sistema eléctrico. .48

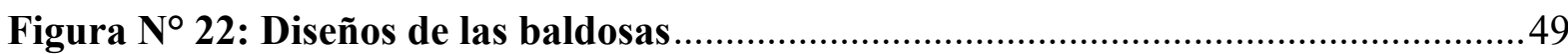

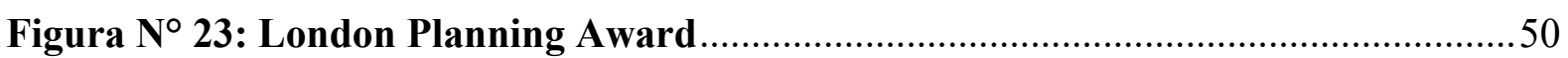

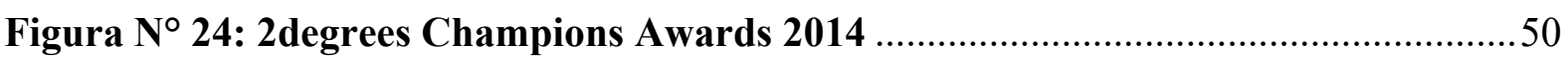

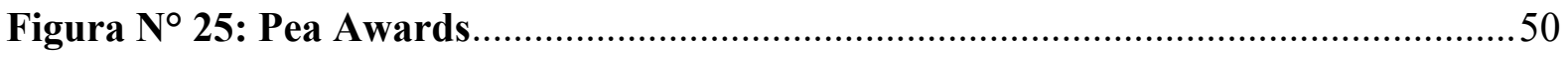

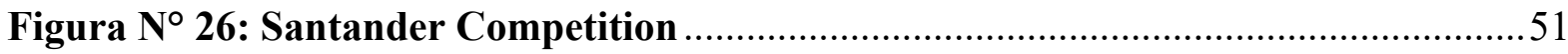

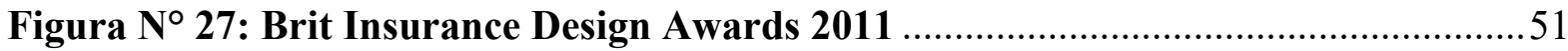

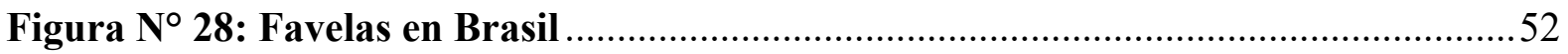

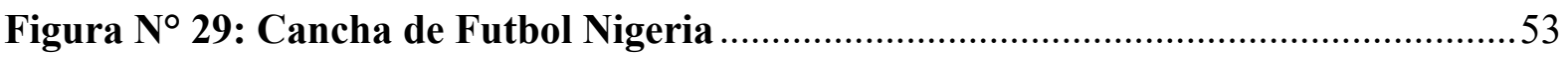

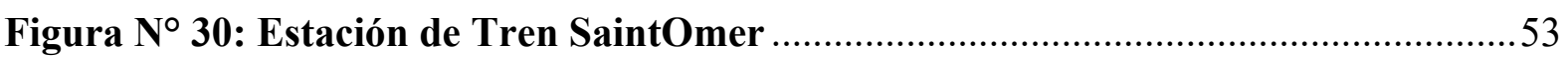

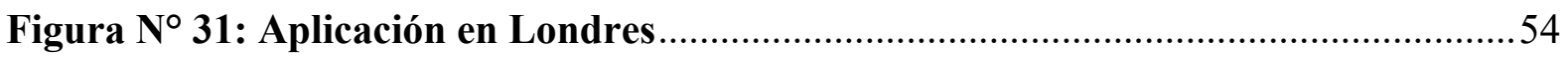

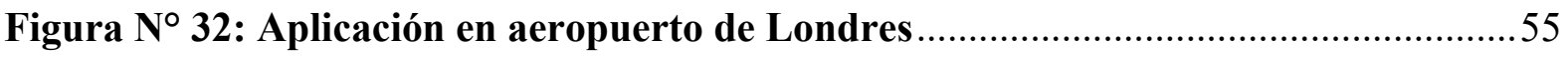

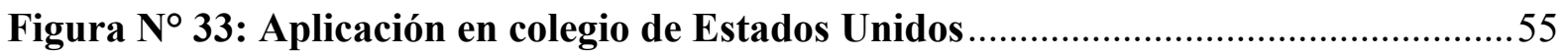

Figura $N^{\circ}$ 34: Evolución de la población y de la energía empleada por el ser humano ..56

Gráfica $N^{\circ}$ 3: Petróleo Escenario Business as usual ..........................................................58

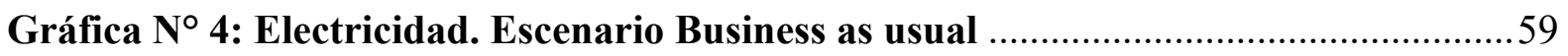

Gráfica N ${ }^{\circ}$ 5: VAR\% Mensual Interanual de Generación Eléctrica vs PBI...................60

Gráfica N ${ }^{\circ}$ 6: Proyección del Consumo Final de Energía (TJ)......................................60

Gráfica $N^{\circ}$ 7: Crecimiento del consumo final de Hidrocarburos Líquidos.....................61

Gráfica No 8: Crecimiento de la demanda de Gas Natural.............................................62

Gráfica No 9: Proyección de la Máxima Demanda 2014-2025 .........................................62

Gráfica $N^{\circ}$ 10: Producción de electricidad por fuente (2013-2025)-1 ..............................63

Gráfica $N^{\circ}$ 11: Producción de electricidad por fuente (2013-2025) - Escenario PBI 4,5\%

Gráfica $N^{\circ}$ 12: Producción de electricidad por fuente (2013-2025) - Escenario PBI 6,5\%

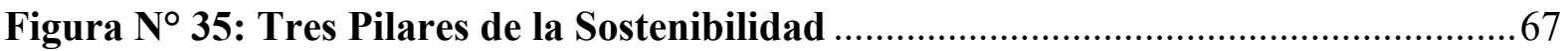

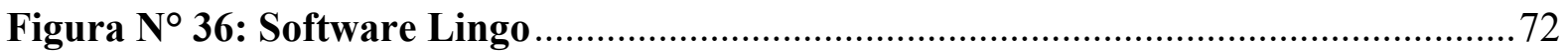

Gráfica $N^{\circ}$ 13: Tendencia del crecimiento energético 2003-2025 …................................77

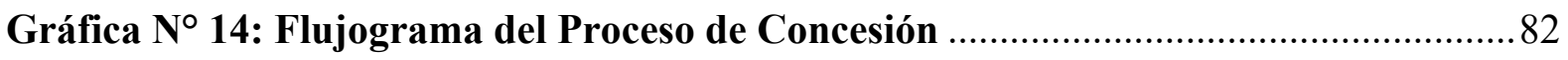

Gráfica $N^{\circ}$ 15: Afluencia de Gente en las Estaciones del Tren Eléctrico .........................83

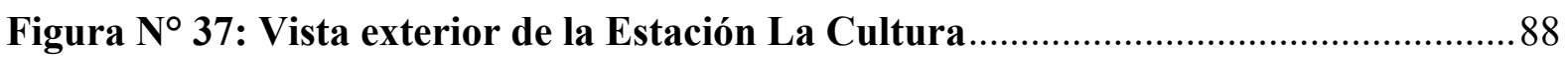

Figura $N^{\circ}$ 38: Entrada de la Estación La Cultura ..................................................... ${ }^{80}$ 


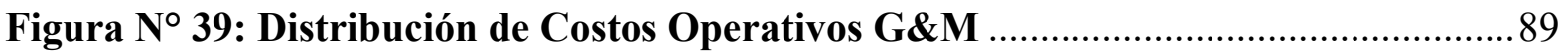

Gráfica $N^{\circ}$ 16: Consumo energético por horario Situación Actual..................................94

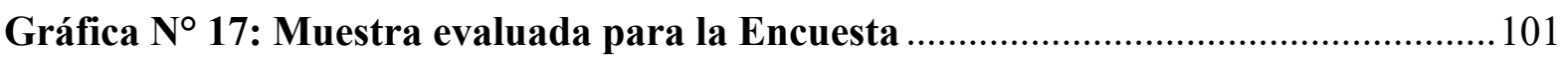

Gráfica № 18: ¿Tiene conocimiento del servicio de transporte público del Tren Eléctrico

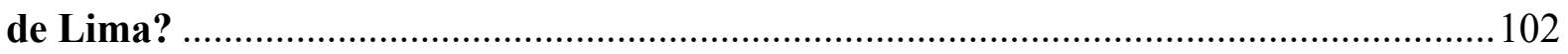

Gráfica $N^{\circ}$ 19: ¿Alguna vez ha utilizado el Tren Eléctrico en Lima Perú? ................... 103

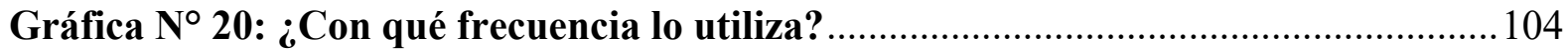

Gráfica $N^{\circ}$ 21: ¿Qué opina usted del actual costo del pasaje del Tren Eléctrico de Lima (S/.1.50), considerando el servicio que brinda?

Gráfica $N^{\circ}$ 22: ¿Qué opina usted del actual costo del pasaje del Tren Eléctrico de Lima (S/.1.50), considerando el servicio que brinda? - 15-23 años 106 Gráfica $N^{\circ}$ 23: ¿Qué opina usted del actual costo del pasaje del Tren Eléctrico de Lima (S/.1.50), considerando el servicio que brinda? - 24-35 años 106

Gráfica $N^{\circ}$ 24: ¿Qué opina usted del actual costo del pasaje del Tren Eléctrico de Lima (S/.1.50), considerando el servicio que brinda? - 36-45 años

Gráfica $N^{\circ}$ 25: ¿Qué opina usted del actual costo del pasaje del Tren Eléctrico de Lima (S/.1.50), considerando el servicio que brinda? - 46 años a más 107

Gráfica N ${ }^{\circ}$ 26: ¿Ha escuchado sobre las energías Renovables? .................................... 108

Gráfica $N^{\circ}$ 27: ¿Está a favor del uso de Energías Renovables?

Gráfica N 28: ¿Estaría de acuerdo en el uso de Energías Renovables en la ciudad? ...109 Gráfica $N^{\circ}$ 29: ¿Cree usted que los ciudadanos de Lima tienen una cultura de ahorro de energía?

Gráfica $N^{\circ}$ 30: ¿Considera que la ciudad de Lima esta propensa a una crisis energética en los próximos 10 años?

Gráfica $N^{\circ}$ 31: ¿Considera que la ciudad de Lima está atravesando una crisis energética actualmente?.

Gráfica $N^{\circ}$ 32: ¿Considera que la ciudad de Lima tiene problemas de contaminación ambiental?

Gráfica $N^{\circ}$ 33: Calificación de proveedores

Figura $\mathrm{N}^{\circ}$ 40: Distribución física de la Estación La Cultura

Figura $N^{\circ}$ 41: Rutas disponibles en la Estación La Cultura para la utilización del Tren Eléctrico 125

Figura $N^{\circ}$ 42: Flujo de atención al cliente en las estaciones $1^{n}$ 
Figura $N^{\circ}$ 43: Flujo de atención al cliente en la Estación La Cultura con Baldosas ......130

Figura $N^{\circ}$ 44: Modelo de Programación Lineal en LINGO............................................ 135

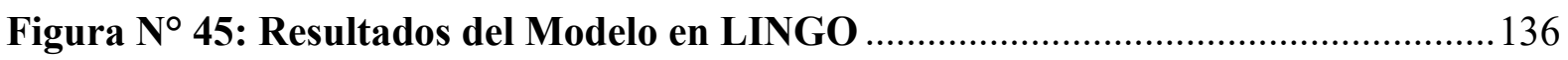

Gráfica $N^{\circ}$ 34: Consumo energético por horario Situación Actual VS Propuesta ........ 149

Figura $N^{\circ}$ 46: Dimensiones de las baldosas PAVEGEN............................................ 153

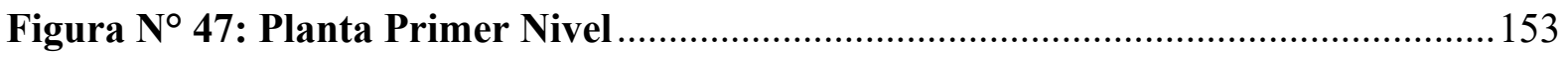

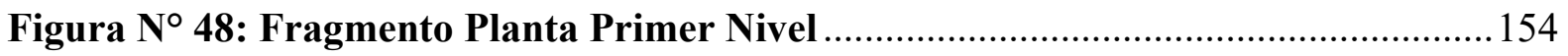

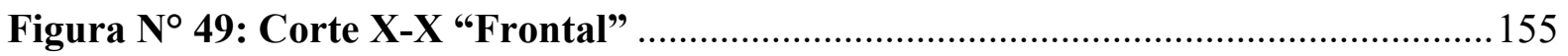

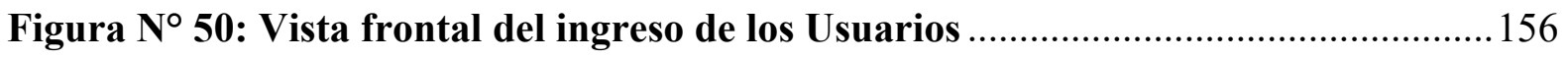

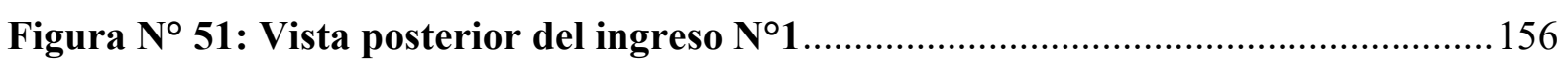

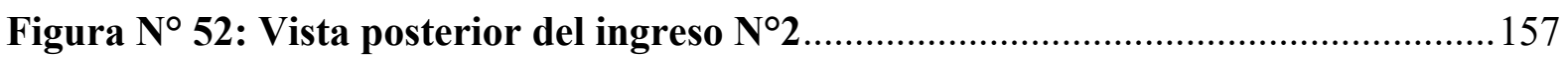

Figura $N^{\circ}$ 53: Usuarios utilizando las Baldosas PAVEGEN ..................................... 158

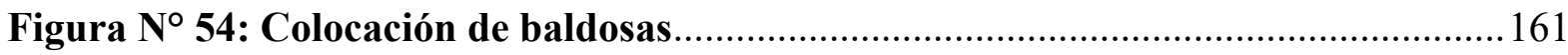

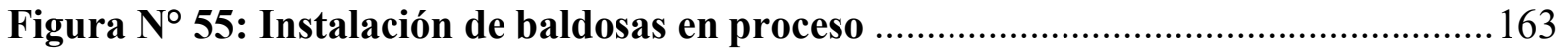

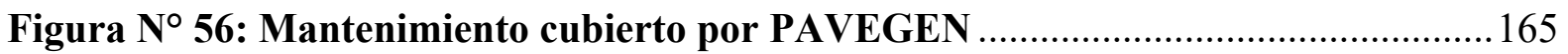

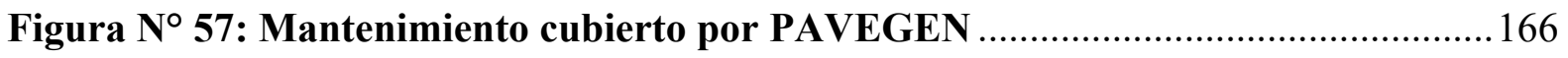

Figura $N^{\circ}$ 58: Costos de Importación para la Partida Arancelaria “8541.60.00.00” .... 167

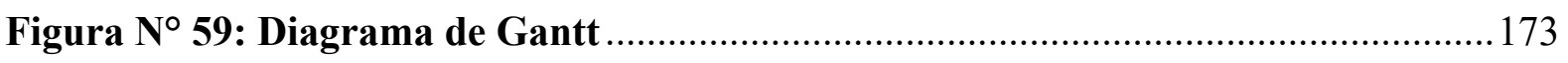

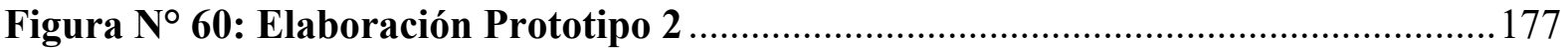

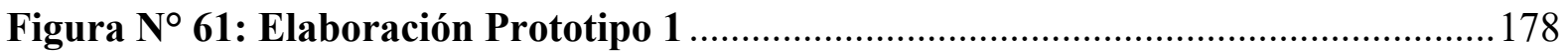

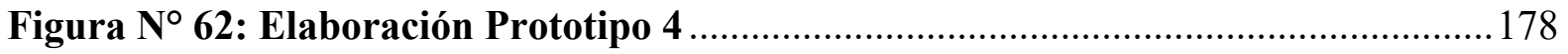

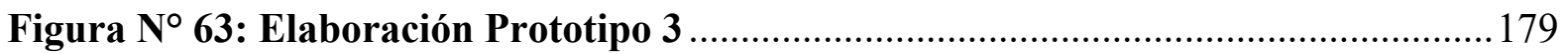

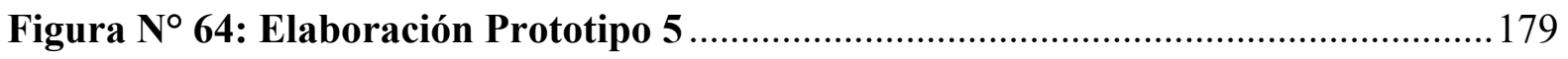

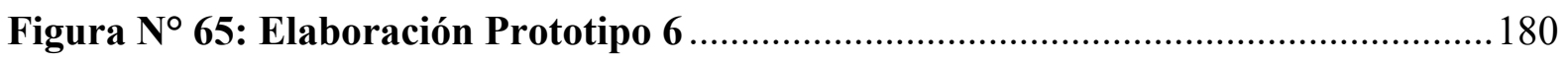

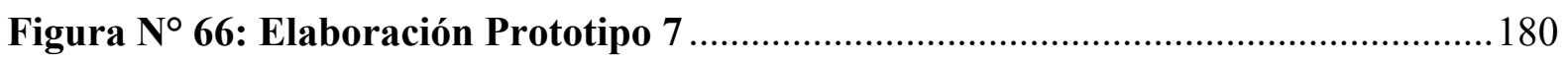

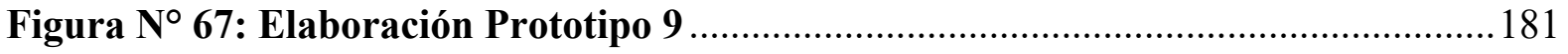

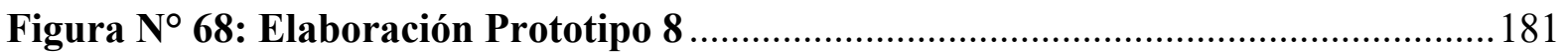

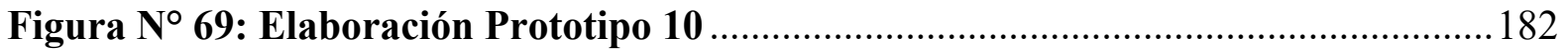

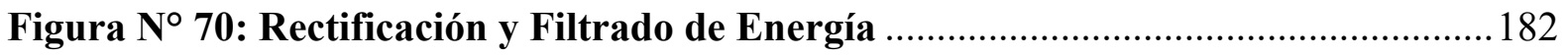

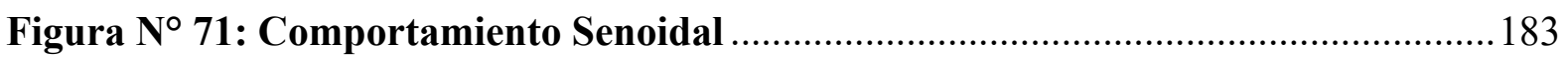

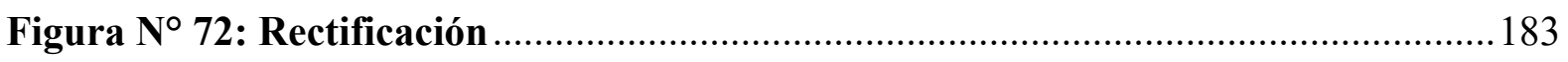

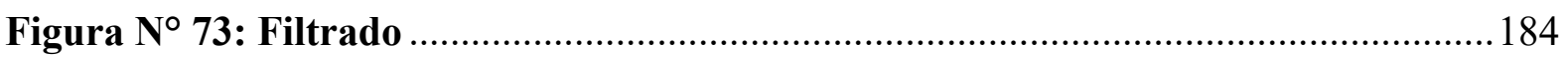

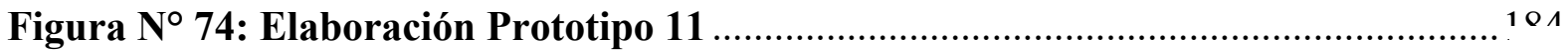




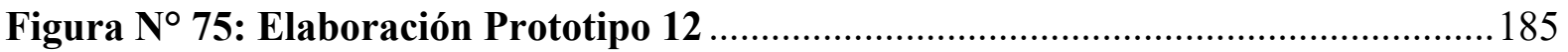

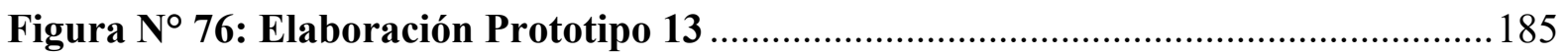

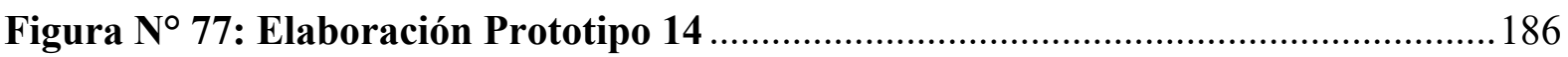

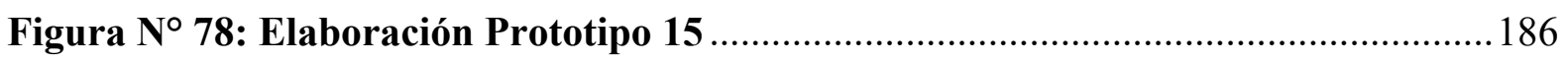

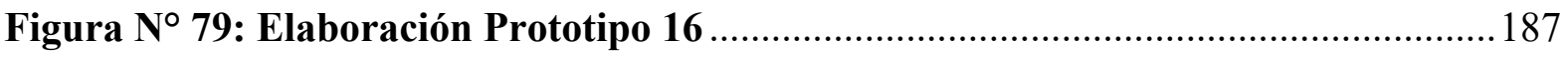

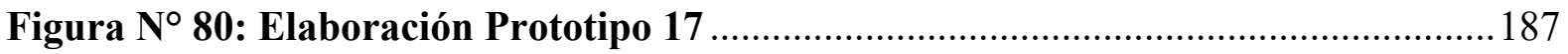

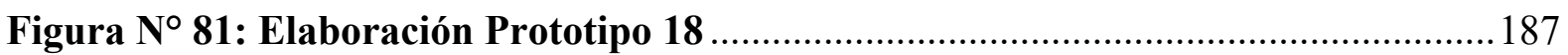

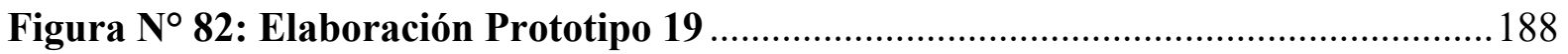

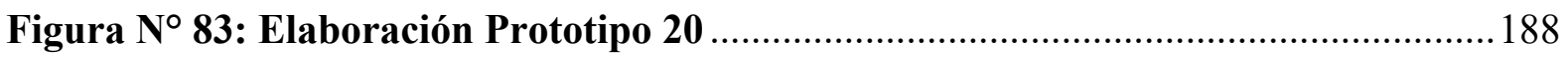

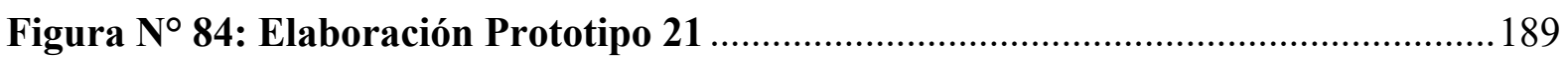

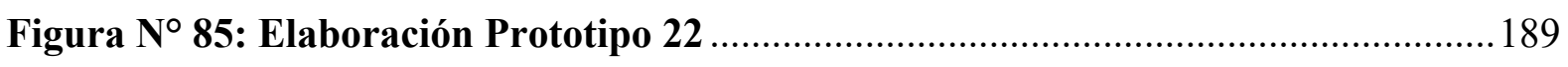

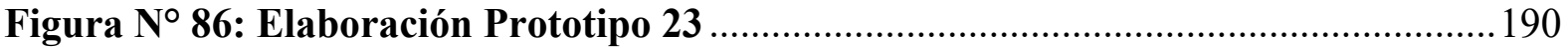

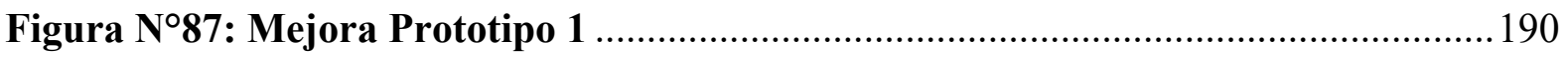

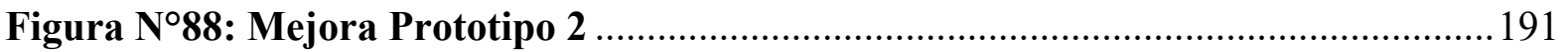

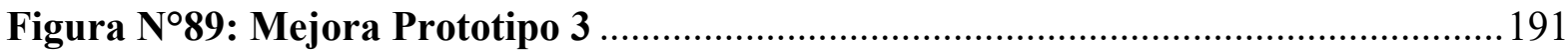

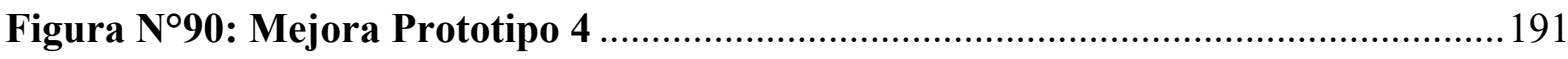

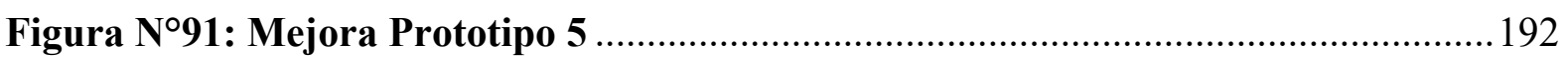

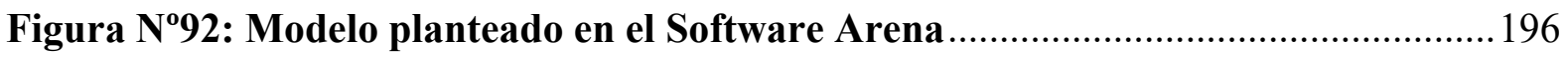

Figura Nº3: Distribución del tiempo de llegada de los clientes ..................................197

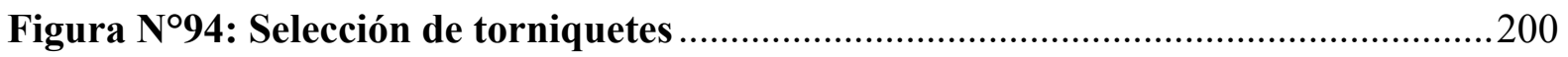

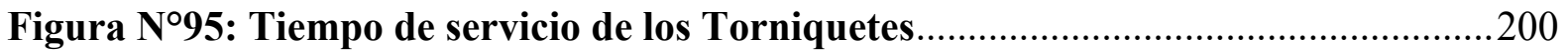

Gráfico N³5: Conocimiento de la sociedad sobre tipos de energía................................204

Gráfico $N^{\circ} 36$ : ¿Ha escuchado sobre las energías Renovables ? .................................210

Gráfico $N^{\circ} 37$ : ¿Estaría de acuerdo en el uso de Energías Renovables en la ciudad ? 211 


\section{RESUMEN}

En este artículo se expondrá la implementación de un sistema de generación de energía renovable en una estación del tren eléctrico de Lima, Perú, basado en la tecnología piezoeléctrica. Mediante la implementación de las baldosas piezoeléctricas PAVEGEN se ha logrado aprovechar la energía cinética del caminar de más de 29,000 personas que transitan diariamente por una de sus estaciones, logrando generar ahorros energéticos entre $451 \mathrm{MWh}$ y 1000 MWh al año, los cuales están valorizados en $\quad$ S/ 132,000 y S/ 322,000 respectivamente. De esta forma, se logró reducir los costos energéticos en una proporción estimada entre un $32,82 \%$ y un $80.28 \%$; consecuentemente, se redujo el déficit de 27 millones de soles anuales subvencionados por el Estado Peruano para mantener operativo este medio de transporte. Se ha contemplado el diseño arquitectónico, la modelación y el dimensionamiento, los requerimientos y procedimientos civiles, la importación y los costos de implementación. La inversión total de este proyecto tiene un periodo de recuperación menor a dos años. Por lo tanto, puede ser el punto de partida para masificar proyectos de este ámbito en el Perú y Latinoamérica, ya que es auto sostenible e innovador.

Palabras clave : Energía Renovable, Piezoelectricidad, PAVEGEN 


\section{ABSTRACT}

This research project presents the implementation of a renewable energy generation system based on piezo technology at an electric train station located in Lima, Peru. By implementing the piezoelectric tiles PAVEGEN, we have managed to harness the kinetic energy from the walk of more than 29,000 people that pass daily through one of its stations, achieving power savings between $451 \mathrm{MWh}$ and $1000 \mathrm{MWh}$ per year, which are valued in S/ 132,00 and S/ 322,000 respectively. Thus, it was possible to reduce the energetic cost in proportion between $32.82 \%$ and $80.28 \%$; consequently, the deficit of 27 million Soles, which are annually subsidized by the Peruvian government to keep on the operation of this transport, was reduced. This project has included architectural design, modeling and dimensioning, requirements and civil procedures, import and implementation costs. The total investment of this project has a recovery period smaller than two years. Therefore, it can be the starting point to promote projects in this field in Peru and Latin America, as it is sustainable and innovative.

Keywords: Renewable Energy, Piezoelectricity, PAVEGEN 


\section{INTRODUCCIÓN}

El presente trabajo es una investigación, que tiene como finalidad evaluar la factibilidad de implementar un sistema de generación de energía renovable en las estaciones de la Línea 1 del Tren Eléctrico de Lima. El objetivo de este análisis es reducir los costos energéticos de las estaciones, disminuir la contaminación ambiental que se genera indirectamente al utilizar energía no renovable, brindando así un mejor servicio a los pasajeros y mejorando la imagen de la empresa ante la sociedad.

Actualmente, la población peruana, al igual que la población mundial, es una sociedad consumista que depende de la energía proveniente de los combustibles fósiles, los cuales proporcionan un $87 \%$ de la energía total consumida por la población mundial. A consecuencia de esto, los combustibles fósiles están destinados a agotarse en un futuro cada vez más cercano, pues, la humanidad utiliza cada día más energía proveniente de ellos por sus hábitos consumistas, las necesidades que se crean día a día y la falta de promoción y generación de energía renovable a nivel mundial. El nivel de consumo de estos recursos es mayor a su capacidad de regeneración, lo cual determinará su agotamiento en un futuro cada vez más próximo.

El consumo energético de una población se encuentra muy ligado tanto a su crecimiento económico como a su crecimiento demográfico. El crecimiento demográfico peruano de los últimos años ha sido de $1.13 \%$, lo cual equivale a un promedio anual de 325 mil habitantes. Por otro lado, el crecimiento promedio anual del PBI se ha encontrado entre $4 \%$ y $5 \%$, lo que contribuye a un mayor consumo energético de la sociedad peruana.

Como se puede ver, tanto el sector económico como la sociedad peruana en sí, se encuentran en continuo crecimiento, lo cual conllevará a una mayor demanda de energía eléctrica y una posible crisis energética en un futuro no muy lejano. Si se continúa con el sistema actual, el cual consiste en la generación de esta energía mediante el uso de combustibles no renovables y contaminantes, estos combustibles se agotarán y la contaminación ambiental aumentará lo cual traerá consecuencias negativas para la sociedad. 
En este proyecto, se plantea la utilización de un sistema de generación de energía renovable, el cual consiste en la utilización de la tecnología piezoeléctrica. Esta tecnología aprovecha la energía cinética de las personas "los pasos de su caminar" para generar energía renovable de una forma económica, ecológica y rentable. La peculiaridad del servicio brindado por el tren eléctrico, lo cual contribuye y lo hace idóneo para realizar este proyecto, es que cuentan con una afluencia de 323,000 personas diarias distribuidas en 26 estaciones. Al contar con una gran afluencia de gente, esta permitirá un mejor aprovechamiento de la tecnología a instalar, ya que se podrá aprovechar una mayor cantidad de energía cinética que en otros lugares o establecimientos.

Además de reducir los costos energéticos de las estaciones del tren eléctrico, también se busca fomentar la utilización de energía renovable por la población limeña, fomentar la cultura del ahorro energético y así tratar de evitar una posible crisis energética futura.

Este proyecto está estructurado en base a 6 capítulos, en los cuales se tratarán diversos temas, con un objetivo definido para cada uno.

El Capítulo 1 se centrará en desarrollar un preámbulo de la situación energética actual del país y del mundo y el marco teórico necesario para entender la metodología, las herramientas y la terminología a usar en este proyecto de investigación, y la situación actual energética.

El Capítulo 2 se encargará de realizar un diagnóstico general y específico, tanto interno como externo de AATE, para así identificar y definir el problema a tratar en este proyecto de investigación, lo cual permitirá proponer un par de soluciones para luego ser analizadas.

En el Capítulo 3, después de haber identificado el problema a tratar en el Capítulo 2, se diseñará y sugerirá una propuesta de solución, la cual se basará en la implementación y el uso de la piezoelectricidad como medio de generación de energía renovable y el uso de herramientas de ingeniería, para conseguir una propuesta bien elaborada y fundamentada detalle a detalle.

En el Capítulo 4, se validarán los entregables de los capítulos anteriores, de manera que se pueda validar las hipótesis generales y especificas planteadas, y a la vez la propuesta de solución expuesta en el capítulo 3 mediante el juicio de expertos en la materia, pruebas estadísticas, modelos de simulación y estudios realizados en el transcurso de este proyecto. 
En los últimos 2 capítulos, (5 y 6), se identificarán y validarán los impactos económicos, sociales y ambientales que traerán consigo este proyecto, y se presentarán las conclusiones y recomendaciones en base a todo el proyecto de investigación realizado. 


\section{CAPÍTULO 1: ESTADO DEL ARTE Y MARCO TEÓRICO}

\subsection{Estado del Arte}

Este proyecto de Investigación se basa en la aplicación de la tecnología piezoeléctrica en las estaciones del tren eléctrico, un servicio de transporte sumamente frecuentando y utilizado por muchas personas en los diversos puntos de la ciudad. En este caso, se tratará la Línea 1 del Tren eléctrico de la ciudad de lima, ya que se ha convertido en un medio de transporte trascendente para la sociedad limeña.

Esta tecnología es muy utilizada actualmente, pero poco reconocida, ya que se encuentra en varios dispositivos que se utilizan día a día, pero las personas en general desconocen su existencia. Por ejemplo, se utiliza la tecnología piezoeléctrica en la fabricación de parlantes, audífonos, bocinas, micrófonos, tocadiscos, generadores de ultrasonidos, etc. Estos dispositivos funcionan gracias a esta tecnología, la cual aprovecha las vibraciones para generar impulsos eléctricos.

Este tipo de energía es producida por un estrés mecánico capaz de alimentar circuitos eléctricos pequeños, o sistemas mayores, dependiendo del tamaño del piezoeléctrico y su tecnología. Actualmente, existen baldosas piezoeléctricas las cuales son capaces de aprovechar la energía cinética de las personas "la fuerza generada con el caminar de las mismas" y transformarla en energía eléctrica para poder utilizarla en la alimentación de diversos dispositivos eléctricos de los establecimientos en los cuales se encuentren instaladas.

A continuación, para tener un panorama base sobre el proyecto de investigación y la tecnología que se planea implementar, se tratará sobre la historia y la situación actual de la Línea 1 del tren eléctrico de Lima; los Energy Harvester o recolectores de energía, los cuales engloban a la tecnología piezoeléctrica y finalmente la historia, funcionamiento y evolución de la piezoelectricidad a lo largo de los años.

Este proyecto de investigación se basa en la línea 1 del tren eléctrico de la ciudad de Lima, la cual es de suma importancia para su población por los diversos beneficios que esta brinda a sus 
ciudadanos, ya que es un transporte seguro, rápido y sobre todo moderno. Sin embargo, este servicio de transporte en la actualidad no es sostenible, ya que el dinero recabado por los pasajes de los usuarios no logra cubrir los costos operacionales; por ello, el Estado peruano se ve obligado a subsidiar el pago de sus operaciones para el bienestar de la sociedad.

\subsubsection{Antecedentes del proyecto y del problema}

\subsubsection{Autoridad Autónoma del Sistema Eléctrico de Transporte Masivo de Lima y Callao "AATE" y el Tren Eléctrico}

\subsection{Historia}

La institución AATE fue creada mediante el Decreto Supremo $N^{\circ}$ 001-86-MIPRE de fecha 20 de febrero de 1986 con el nombre de Autoridad Autónoma del Proyecto Especial Sistema Eléctrico de Transporte Masivo de Lima y Callao (AATE). Cuatro años después, se transfirió la administración de la AATE a la Presidencia del Consejo de Ministros y posteriormente fue transferida al Ministerio de Transportes, Comunicaciones, Vivienda y Construcción a través del Decreto Supremo No172-91-PCM. Desde 1997, se constituyó la Unidad Ejecutora 011 Sistema Eléctrico de Transporte Masivo.

Años después, el 1 de Junio del 2001, la administración de AATE fue transferida a la Municipalidad Metropolitana de Lima, constituyéndose en un organismo descentralizado de dicho municipio.

El 12 de Junio del 2004, se declaró la necesidad pública de la continuación de la ejecución del Sistema Eléctrico de Transporte Masivo de Lima y Callao, lo que desencadeno la liberación de impuestos a la importación de bienes que serían destinados directamente a la ejecución de la Línea 1 del Tren Eléctrico. ( AATE, 2013,p.3)

El primer tramo del tren Eléctrico fue inaugurado en 1990 durante el gobierno de Alan García, pero solo recorría $9.2 \mathrm{~km}$ desde Villa El Salvador hasta San Juan de Miraflores. Su funcionamiento fue detenido, ya que no era comercialmente viable por falta de público. 


\subsection{Alcance y Beneficio}

En cuanto al alcance y a los beneficios brindados por la institución AATE y la Línea 1 del Tren Eléctrico son un poco distintos por sus distintos objetivos a largo plazo. En primer lugar, se tratarán los alcances y beneficios de la institución AATE y posteriormente los de la Línea 1 del Tren Eléctrico de Lima.

\section{AATE:}

\section{- Alcance:}

Esta institución se encarga de la proyección, planificación, ejecución y administración de la infraestructura ferroviaria correspondiente a la Red Básica del Metro de Lima, según el Decreto Supremo N ${ }^{0}$ 032-2011-MTC, a través de la elaboración de proyectos y/o estudios de supervisión y ejecución de las obras civiles y electromecánicas realizadas con responsabilidad e inclusión social. (AATE, 2013, p.1-5). Actualmente, solo se encuentra construida la Línea 1 del Tren Eléctrico, pero se planifica a futuro construir un total de 6 Líneas ferroviarias a través de Lima para poder transportar a la población de una manera más eficiente, veloz, segura y económica. Actualmente, ya se ha evaluado y se está llevando a cabo la planificación para la construcción de la Línea 2 del Tren Eléctrico, la cual será construida subterráneamente y unirá los distritos de Ate y Callao.

"Ese es el compromiso de la AATE: Optimizar la movilidad de la población de manera sostenible, con calidad y responsabilidad social para todos los ciudadanos de Lima y Callao" (AATE, 2013, p.1)

\section{- Beneficios:}

ATTE se encarga de velar por el buen funcionamiento de este medio de transporte, ya que, actualmente, se encuentra concesionado y este podría ser mal administrado por la empresa Graña y Montero; de esta forma, la población limeña y los objetivos del Tren Eléctrico se verían perjudicados negativamente.

Por otro lado, contar con una institución encargada de planificar la modernización de los medios de transporte limeño es sumamente beneficioso para poder así mejorar la calidad de vida de los peruanos, reducir la contaminación emitida por el parque automotor y brindar 
oportunidades de trabajo y transporte a toda la población sin discriminar ningún sector social.

\section{Línea 1 del Tren Eléctrico:}

\section{- Alcance:}

El servicio del tren eléctrico está dirigido a toda la población limeña con el objetivo de brindarles un mejor medio de transporte para reducir sus tiempos de desplazamiento, asegurar su seguridad, brindarles beneficios económicos, etc. La Línea 1 del tren Eléctrico está constituida por 26 estaciones, las cuales unen 8 distritos y van desde Villa El Salvador hasta Bayovar. A continuación, se podrá observar la lista de las 26 estaciones que conforman este servicio de transporte y su respectivo mapa en la ciudad de Lima.

Tabla $N^{\circ}$ 1: Estaciones del tren Eléctrico

\begin{tabular}{|c|l|r|l|}
\hline $\mathbf{N}^{\circ}$ & \multicolumn{1}{|c|}{ Distrito } & $\mathbf{N}^{\circ}$ & \multicolumn{1}{|c|}{ Distrito } \\
\hline 1 & Villa El Salvador & 14 & Nicolás Arriola \\
\hline 2 & Parque Industrial & 15 & Gamarra \\
\hline 3 & Pumacahua & 17 & Miguel Grau \\
\hline 4 & Villa María & 18 & Parque Maestro \\
\hline 5 & María Auxiliadora & 19 & Caja de Agua \\
\hline 6 & San Juan & 20 & Pirámide del Sol \\
\hline 7 & Atocongo & 21 & Los Jardines \\
\hline 8 & Jorge Chávez & 22 & Los Postes \\
\hline 9 & Ayacucho & 23 & San Carlos \\
\hline 10 & Los Cabitos & 24 & San Martín \\
\hline 11 & Angamos & 25 & Santa Rosa \\
\hline 12 & San Borja Sur & 26 & Bayovar \\
\hline 13 & La Cultura & & \\
\hline
\end{tabular}

Fuente: AATE 
Figura $N^{\circ}$ 1: Distribución de Estaciones del Tren Eléctrico en Lima

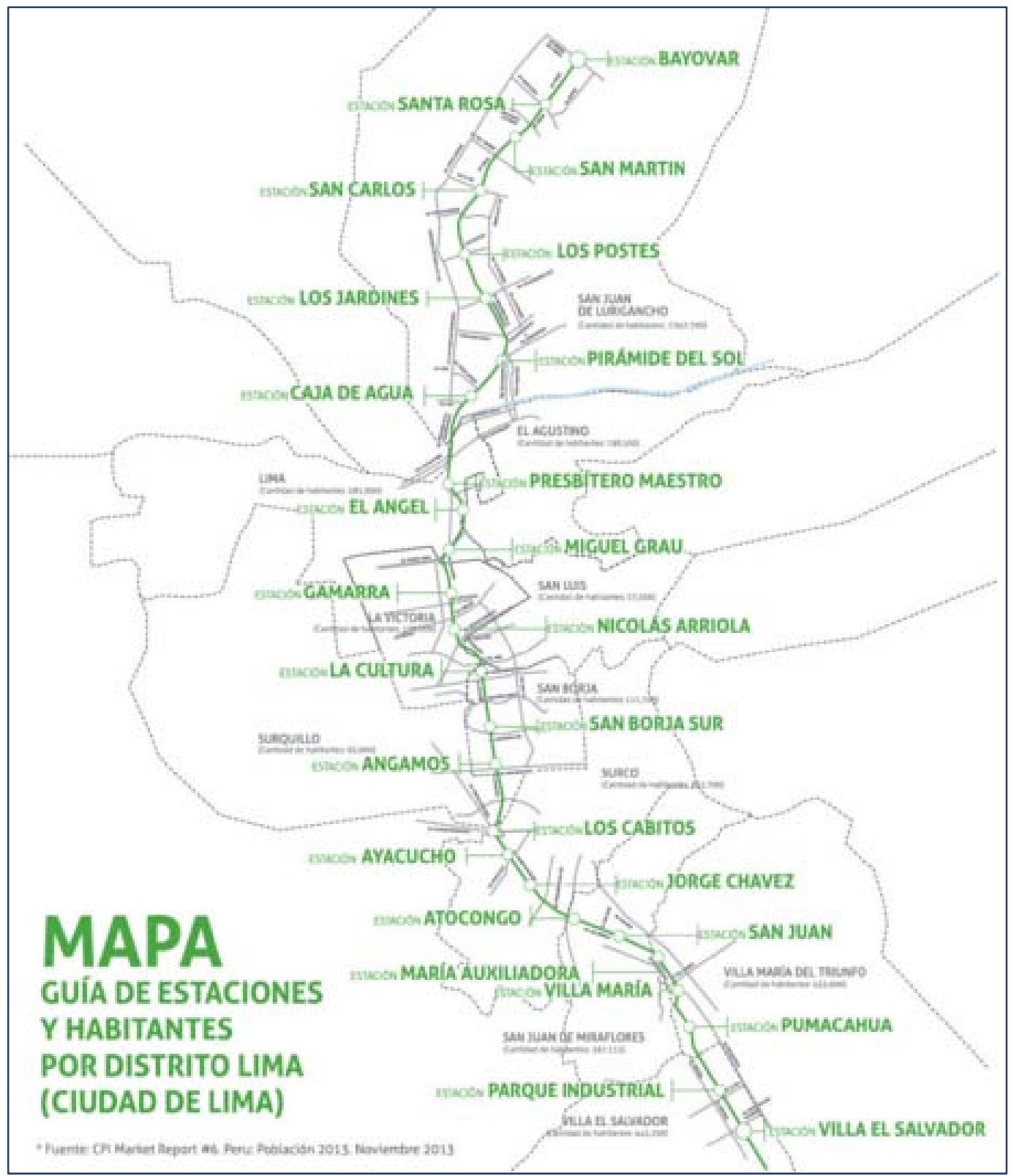

Fuente: AATE

- Beneficios:

Brinda un transporte de buena calidad a la población limeña, asegurándose de que beneficie tanto a la población como al medio ambiente.

En primer lugar, la población se ve beneficiada, ya que un tramo, que se demora 4 horas en ser recorrido por buses y microbuses, el Tren Eléctrico lo recorre en 52 minutos. Por otro lado, el pasaje para utilizar es económico, ya que los adultos pagan S/. 1.50 y los estudiantes y colegiales pagan solo S/. 0.75. Como se puede ver, es un servicio de 
transporte veloz, económico y más seguro que transportarse en los buses y microbuses de la ciudad de Lima.

\subsection{Detalles del Proyecto "Tren Eléctrico en Lima Perú"}

Este proyecto fue iniciado en el primer gobierno de Alan García (1985-1990), inaugurando el primer tramo el 28 de Abril de 1990. Este tramo abarcaba desde Villa el Salvador hasta San Juan de Miraflores. Pese a tener 30 vagones disponibles y 7 estaciones, se tuvieron que detener las operaciones, ya que el proyecto no era rentable por falta de pasajeros y alcance.

Al pasar muchos años, en el 2009 durante el segundo gobierno de Alan García, el Ministerio de Transportes y Comunicaciones retomó el proyecto con el fin de culminar el primer tramo y poder ampliar su recorrido hasta la estación de Miguel Grau localizada en el centro de la ciudad de Lima. Esta ampliación fue iniciada el 2 de Marzo del 2010 a cargo de las constructores Odebrecht y Graña y Montero (G\&M). Esta ampliación fue culminada el 11 de Julio del 2011 e inició sus operaciones comerciales el 5 de Enero del 2012, cubriendo 21.48 kilómetros, contando con 16 estaciones y cubriendo 8 distritos en total.

Paralelamente a la culminación del tramo 1, se realizó una licitación para obtener la concesión de operación y el mantenimiento de toda la Línea 1 (primer y segundo tramo), por un periodo de 30 años, saliendo ganador el Consorcio Tren de Lima conformado por G\&M y la argentina Ferrovías.

La construcción del segundo y último tramo de la Línea 1 del tren eléctrico fue iniciada en San Juan de Lurigancho y culminada el 12 de Mayo del 2014. De esta manera, la Línea 1 del tren eléctrico fue completada, convirtiéndose así en una línea de metro elevado con una extensión de 34.6 kilómetros y 26 estaciones. Las operaciones del último tramo fueron iniciadas el 25 de Julio del 2014. (Wikipedia, <<Línea1 1 (Metro de Lima>>, 2015)

\subsection{Conclusiones e Importancia del Tren Eléctrico de Lima}

El correcto funcionamiento de la Línea 1 del Tren Eléctrico de Lima, es de suma importancia para la población limeña, ya que, no solo reduce los tiempos de transporte para los usuarios, como fue mencionado líneas arriba, sino que también les brinda la posibilidad de movilizarse de una manera más cómoda y segura. 
Actualmente, la operación y el mantenimiento de la Línea 1 se encuentran concesionados por las empresas Graña y Montero y la argentina Ferrovías, las cuales se encargan de que el tren eléctrico funcione con normalidad y logre satisfacer las necesidades de sus usuarios.

Según información brindada por la empresa AATE, la cual será especificada en los siguientes capítulos, se sabe que las operaciones de este medio de transporte son subvencionadas por el Estado peruano, ya que el dinero recaudado con los pasajes no alcanza a cubrir los costos operativos. Por este motivo, se están buscando diferentes alternativas para reducir los costos de operación, y así mejorar la rentabilidad, logrando un proyecto sostenible. En el siguiente subcapítulo, se hablará sobre los Energy Harvesters, los cuales son recolectores de energía que pueden contribuir en la reducción de los costos energéticos de la estación del tren eléctrico.

\subsubsection{Solución tecnológica para el problema}

\subsubsection{Energy Harvesting "Recolección de Energía"}

Los Energy Harvesters (recolectores de energía) hacen referencia a varios tipos de sistemas encargados de la recuperación, la reutilización y el aprovechamiento de los diferentes tipos de energía que se encuentran en nuestro entorno y usualmente no son aprovechados o simplemente se desperdician; estos sistemas, también conocidos como Energy Scavenging (barrido de energía), utilizan la energía solar, térmica, eólica, el ruido, las vibraciones, entre otras, para realizar el proceso de transformación y convertirla en energía eléctrica. El principal objetivo de esta tecnología es proveer una fuente remota de energía eléctrica y/o la recarga de dispositivos de almacenamiento, tales como baterías, condensadores y capacitores, alcanzando de esta manera un impacto ecológico importante debido a que ayuda a reducir los residuos químicos que se producen al sustituir estos dispositivos de almacenamiento tradicionales.

La evolución tecnológica y las tendencias que ésta ha experimentado en los últimos veinte años, han traído consigo una serie de cambios de gran relevancia; principalmente, en la construcción de un sinnúmero de dispositivos electrónicos. Dicha evolución ha generado modificaciones significativas en el tamaño de éstos y en su consumo de potencia, reduciendo ambos en gran escala. (L. Mateu y F. Moll, 2005, p. 359-373.). Es por esto que con el pasar de los años los Energy Harvesters han sido un punto de investigación cada vez más amplio y con una temática que llama mayor interés en la sociedad actual. 
En las siguientes gráficas, se puede observar claramente cómo es que las investigaciones referentes a estos temas han presentado un crecimiento acelerado en los últimos 10 años.

Gráfica $N^{\circ}$ 1: Cantidad de publicaciones sobre Energy Harvesting entre 1963-2013

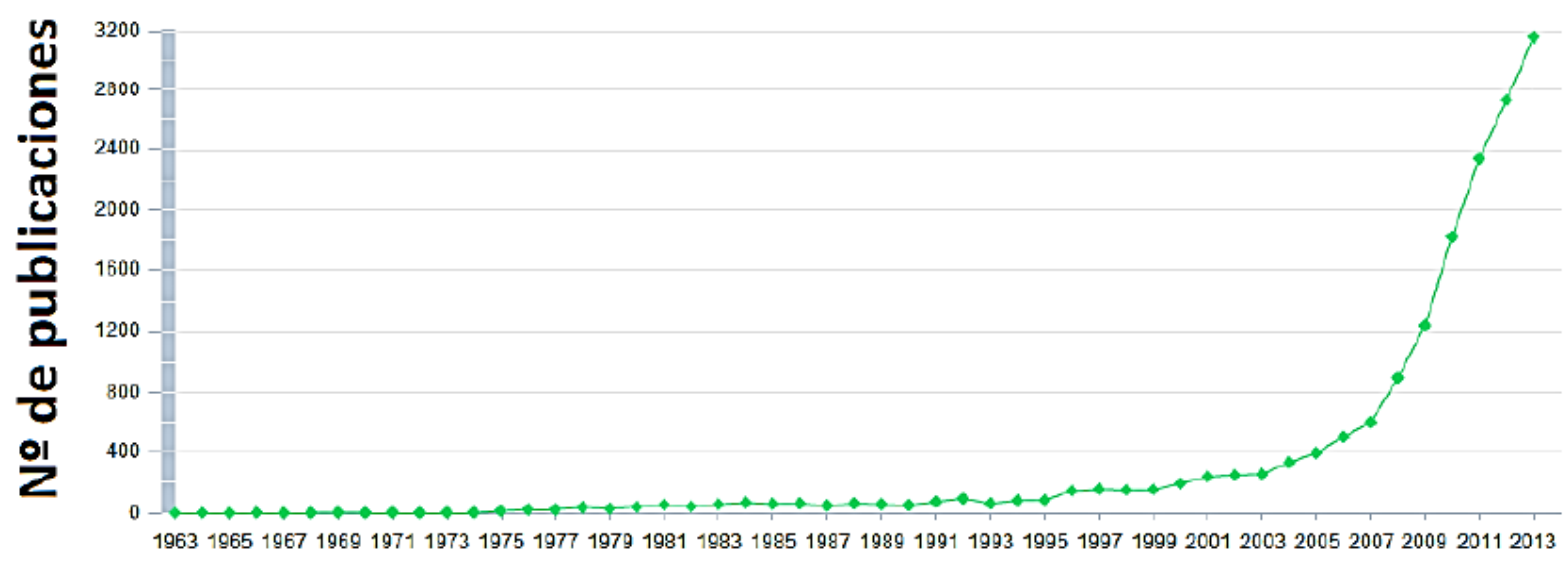

Año

\section{Fuente: SCOPUS}

\section{Gráfica $N^{\circ}$ 2: Cantidad de publicaciones sobre Energy Scavenging entre 1963-2013}

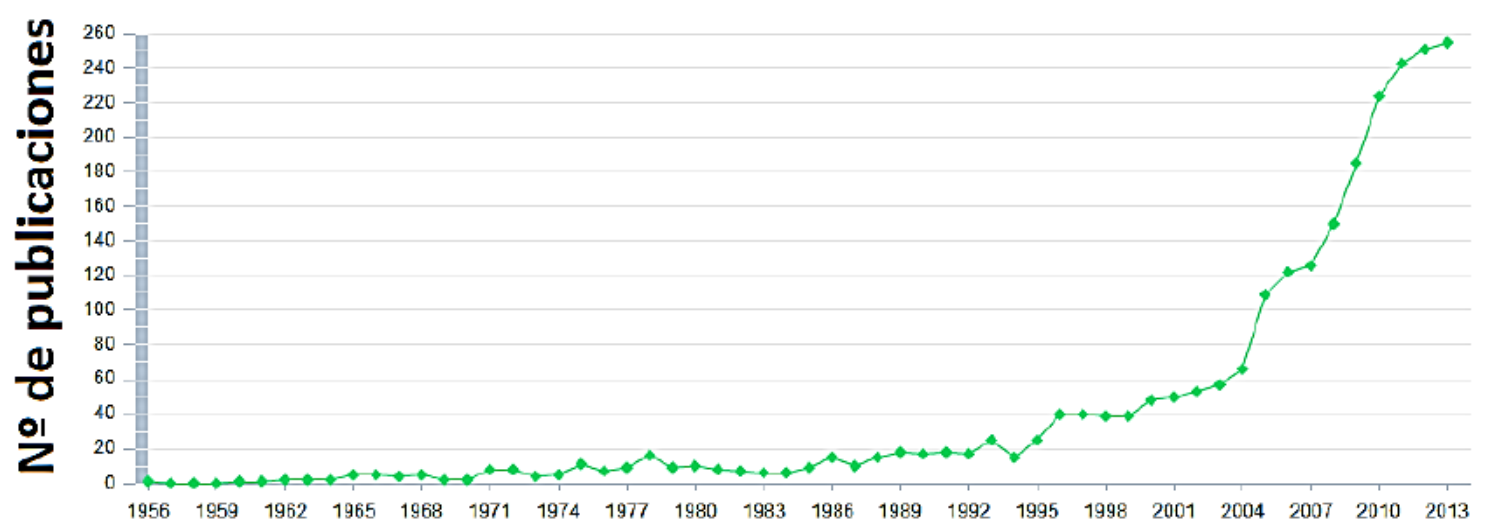

\section{Año}

\section{Fuente: Scopus}

Esto refleja cómo es que los Energy Harvesters cada vez son más considerados en las investigaciones en el mundo y como es que estos temas toman más relevancia e interés en las 
personas que buscan utilizar energía limpia a base del simple aprovechamiento de nuestro entorno.

\subsection{Clasificación de los Energy Harvesters "Recolectores de Energía"}

En cualquier parte de nuestro entorno podemos encontrar diferentes y diversas formas de energía interactuando que pasan desapercibidas a simple vista; sin embargo, desde la perspectiva de los Energy Harvesters son fuentes latentes para la generación de energía y no son aprovechadas.

Existen muchos tipos de energía que pueden ser aprovechadas por los Energy Harvesters para su funcionamiento. A continuación, se mostrará la clasificación dada por Penella y Gasulla (M. T. Penella y M. Gasulla, 2007, p. 1-5.) de los diferentes tipos de Energy Harvesters, la cual surge a raíz de la descripción realizada por Thomas, Qidwai y Kellogg (J. P. Thomas, M. A. Qidwai, y J. C. Kellogg, J., 2006, p. 1494-1509.) de las diversas fuentes de energía no biológicas que pueden transformarse en energía eléctrica para el uso de sistemas eléctricos remotos.

Figura $\mathrm{N}^{\circ}$ 2: Diferentes fuentes de energía y sus respectivos transductores para su conversión a energía eléctrica

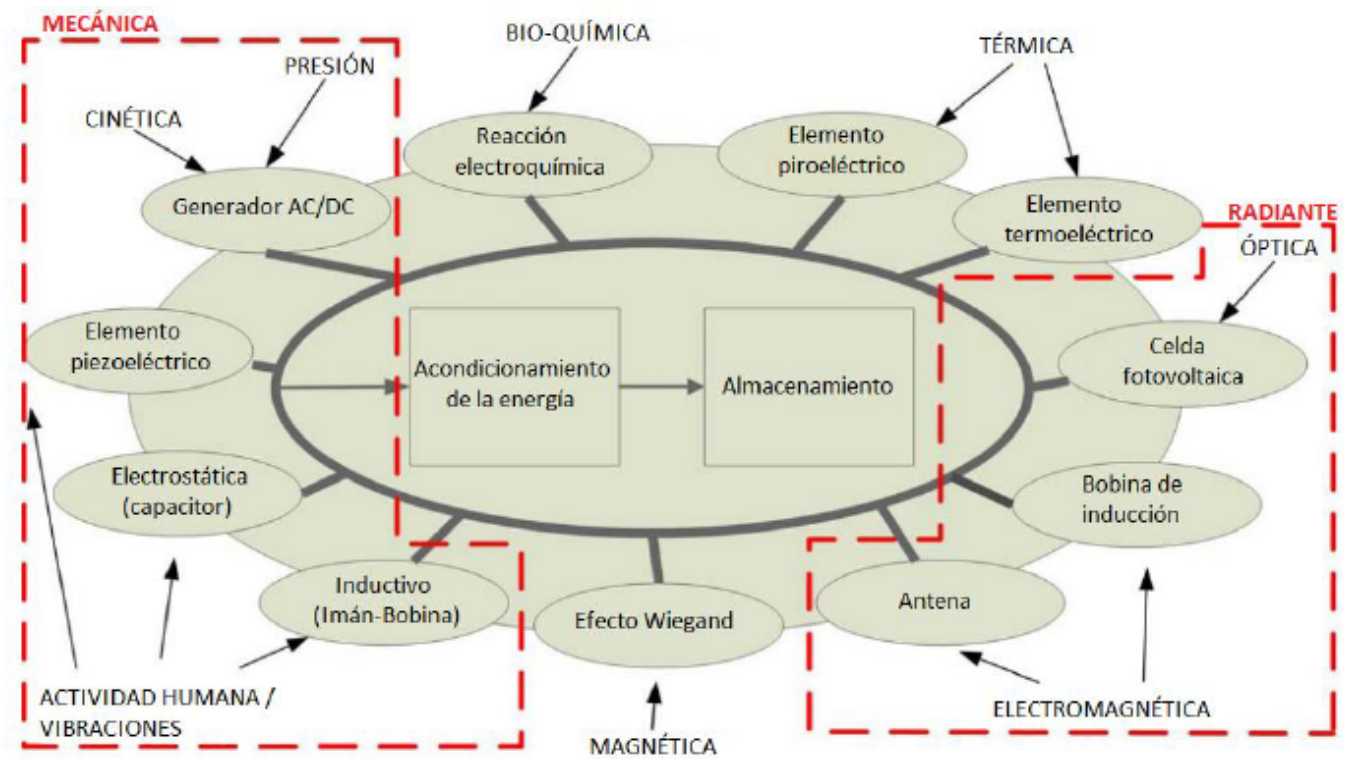

Fuente: M.T Penella y M. Gasulla 
Esta clasificación muestra los diferentes Energy Harvesters de acuerdo al tipo de energía que usan para su funcionamiento y relaciona cada uno de ellos con su respectivo transductor; de esta manera se distinguen 5 principales grupos:

- Los mecánicos: Dentro de los mecánicos, se encuentran los que usan la presión, la cinética, las vibraciones y las diversas actividades humanas como fuente principal de obtención de energía, la cual es transformada mediante generadores DC/AC, elementos piezoeléctricos, electrostáticos o inductivos.

- Los magnéticos: Dentro de los magnéticos, encontramos aquellos que aprovechan el efecto Wiegand, el cual consiste en la conmutación de la magnetización de la zona central de un hilo ferromagnético cuando este es sometido a un campo magnético externo intenso.

- Los radiantes: Dentro de los radiantes, como su mismo nombre lo indica, aprovechan la radiación tanto electromagnética como óptica para generar energía eléctrica a partir de celdas fotovoltaicas, inducción de bobinas y antenas.

- Los térmicos: En este grupo se encuentran aquellos que usan elementos piroeléctricos y termoeléctricos para su generación.

- Los bioquímicos: Dentro de los bioquímicos, encontramos aquellos que requieren de reacciones electroquímicas para su generación.

\subsection{Beneficios de su aplicación}

Los principales beneficios de la aplicación de los Energy Harvesters son:

- Aprovechamiento del entorno como fuente de generación de energía.

- Reutilización de recursos para la generación de energía.

- Autonomía y auto-sostenibilidad de dispositivos, espacios o establecimientos en base al suministro de energía renovable.

- Cuidado del medio ambiente en función de la reducción de la contaminación generada por el uso de energías convencionales. 
- Reducción de los costos energéticos en base a la implementación de dispositivos de Energy Harvesting.

- Creación de conciencia y mejores hábitos de consumo en la sociedad.

\subsubsection{Tecnología Piezoeléctrica}

\subsection{Historia}

La palabra piezo viene del griego "piezein" que significa presionar. La historia del desarrollo de la piezoelectricidad data de hace más de 130 años y desde su descubrimiento el interés por este fenómeno incremento rápidamente, convirtiéndose a finales del siglo XIX en un nuevo campo de investigación. En 1880, los hermanos franceses Pierre y Jacques Curie descubrieron que algunos materiales como el cuarzo, la turmalina, la blenda o esfalerita y el topacio entre otros, sometidos a presiones o esfuerzos mecánicos eran acompañados por una macroscópica polarización y por lo tanto desarrollaban superficies cargadas eléctricamente. A raíz de esto, este efecto fue llamado efecto piezo, a la electricidad producida por el fenómeno se le dio el nombre de piezoelectricidad y a los materiales en los cuales se presentaba el fenómeno se les denominaron piezoeléctricos. Un año después del descubrimiento hecho por los hermanos Curie, el físico Gabriel Lippmann predijo el efecto contrario en éstos, partiendo de consideraciones termodinámicas: un piezoeléctrico sometido a una carga eléctrica podría generar deformaciones mecánicas en el material, lo cual fue probado experimentalmente por los hermanos franceses. A este fenómeno se le denomino "efecto piezo-inverso".

En 1917 se realizó la primera aplicación práctica usando piezoeléctricos cuando el físicomatemático francés Paul Langevin propuso el uso del eco ultrasónico para el desarrollo de un dispositivo que pueda detectar objetos bajo el agua (Hidrófono), éste fue construido en base a una placa de cuarzo puesta entre dos láminas de acero, el cual emitía y recibía ondas de baja frecuencia $(\mathrm{KHz})$. La evolución y eficacia de dicho dispositivo obligó su inclusión y uso generalizado en submarinos, por lo que fue inminente la invención de nuevos sistemas que se valían del efecto piezoeléctrico para su funcionamiento, ejemplo de esto son los micrófonos, los audífonos, los dispositivos para la grabación de sonido y diferentes dispositivos de medición de vibraciones, fuerzas y aceleraciones.

En 1944 en el Lebedev Physical Institute perteneciente a la USSR (Union of Soviet Socialist Republics), los investigadores B. M. Wool y I.P. Goldman estudiaron el desarrollo de 
piezoeléctricos sintéticos, desenvolviendo así el primer método de sintetización de una piezocerámica o cerámica piezoeléctrica de titanato de bario (BaTiO3). Posteriormente, en Estados Unidos, se continuó por esta misma línea de investigación desarrollando la piezocerámica de titanato circonato de plomo más conocida como PZT por sus siglas en inglés. A partir de estas invenciones se continuó con la investigación y en 1969 Kawaidescubre descubre un fuerte efecto piezoeléctrico en un nuevo material, el polímero polifluoruro de vinilideno o fluoruro de polivilideno (PVDF) lo que llevó a muchos otros nuevos desarrollos aprovechando la flexibilidad del material.

En la actualidad, los avances en base a la tecnología piezoeléctrica incluyen materiales inteligentes para el control de vibraciones, aplicaciones aeronáuticas y aeroespaciales de superficies y estructuras flexibles, sensores robóticos y otros novedosos prototipos de Energy Harvesters que están despertando la atención del mundo.

\subsection{Fundamentos de la Piezoelectricidad}

Los materiales piezoeléctricos tienen la propiedad de presentar una polarización eléctrica al generarle una deformación mecánica y viceversa, es decir, generan una deformación mecánica al aplicarle una carga eléctrica. Cuando un material piezoeléctrico se somete a una compresión o a una presión positiva este adquiere polaridad. Si la presión es sustituida por un estiramiento (es decir, un cambio de signo de la presión) el signo de la polaridad eléctrica se invierte, también. Entonces el efecto piezoeléctrico es la respuesta eléctrica que un material tiene frente a un valor positivo o negativo de presión mecánica aplicada entre sus extremos.

Por un lado, existe un comportamiento que se conoce como efecto directo, en el cual el material piezoeléctrico actúa como sensor; mientras que por otro lado existe otro llamado efecto inverso y en este caso el material piezoeléctrico tiene el comportamiento de un actuador. (E. Minazara, D. Vasic, y F. Costa, 2008). La Figura 3 muestra la representación de ambos efectos, los cuales son una característica que poseen todos los cristales ferroeléctricos. Este comportamiento se presenta principalmente en temperaturas inferiores a la temperatura de $\mathrm{Curie}^{1}$, ya que a temperaturas mayores el material pierde las propiedades piezoeléctricas y muestra un comportamiento dieléctrico normal.

\footnotetext{
${ }^{1}$ La temperatura de Curie Tc para los cristales piezoeléctricos, es la temperatura a la cual éstos cambian de un estado polarizado a baja temperatura a un estado no polarizado a temperatura alta, destruyendo el efecto ferro eléctrico debido a la agitación térmica.
} 


\section{Figura $N^{\circ}$ 3: Efecto piezoeléctrico directo e inverso}

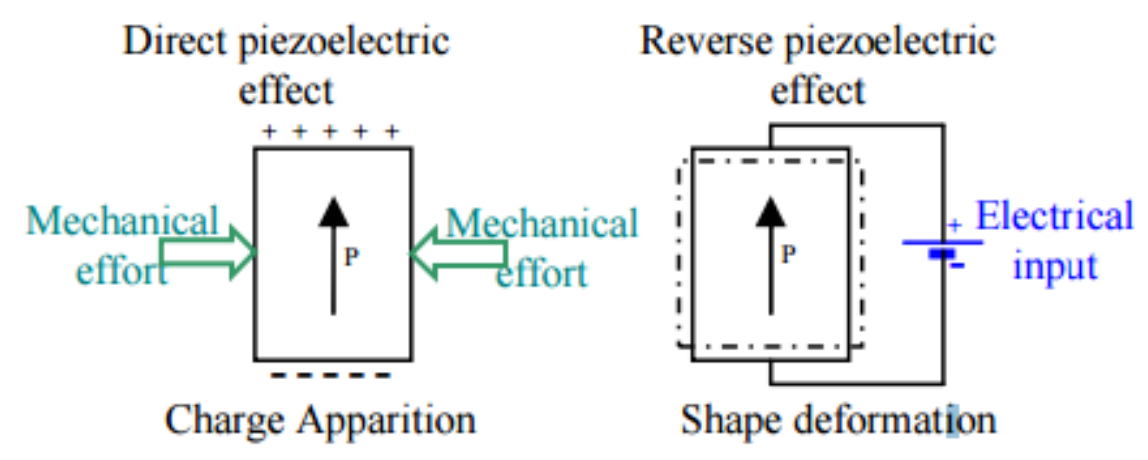

Fuente: E.Minazara, D.Vasic y F.Costa (2008)

Una cerámica piezoeléctrica está compuesta por una masa de cristales de perovskita. Cada cristal se compone por un pequeño ion de metal tetravalente dispuesto dentro de una cuadrícula de un gran ion de metal divalente y oxígeno tal como se ve en la Figura 4. Para la preparación de una cerámica piezoeléctrica, polvos muy finos de óxidos metálicos son mezclados en proporciones específicas, posteriormente estos polvos son mezclados con un aglutinante orgánico y el resultado de dicha mezcla es dispuesto en formas específicas (discos, barras, placas, etc.), las cuales son sometidas a altas temperaturas durante un tiempo determinado. Como resultado de este proceso, las partículas de polvo sinterizado y el material, forman una estructura cristalina muy densa que a continuación es enfriada y de ser necesario cortada, finalmente los electrodos son aplicados en las superficies adecuadas de la estructura. (S. O. R. Moheimani y A. J. Fleming, 2006, p. 9-35.) 
Figura $\mathrm{N}^{\circ} 4$ : Estructura cristalina de una cerámica piezoeléctrica antes y después de ser polarizada (Pb: Plomo, O2: Oxígeno, Ti: Titanio, Zr: Circonio)

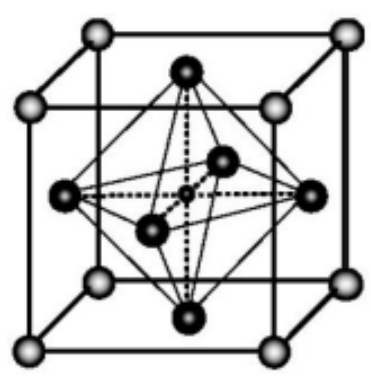

$\mathrm{OPb}$

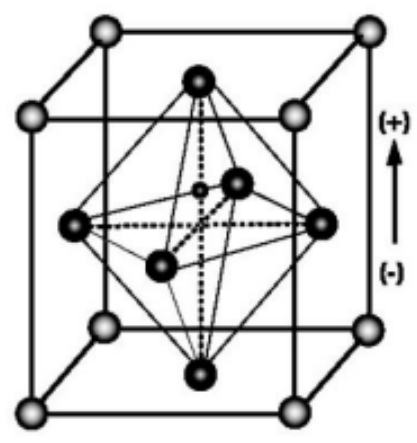

$\mathrm{O}^{2}$ Oxígeno $\bullet \mathrm{Ti}, \mathrm{Zr}$,

Fuente: S. O. R. Moheimani y A. J. Fleming (2006)

Una estructura cristalina con propiedades piezoeléctricas tiene definidos algunos parámetros para cuantificar su respuesta. Un parámetro importante es el “one-wayness" o región donde se determina el signo de la presión ejercida. En el efecto contrario, la misma one-wayness determina el signo de la deformación cuando un campo eléctrico se aplica al cristal.

Una presión ejercida a dos cristales piezoeléctricos produce una deformación de su estado molecular ocasionando un choque entre átomos. Cuando se comprime el cristal, los átomos ionizados (cargados) presentes en la estructura de cada celda de formación del cristal se desplazan, provocando la polarización eléctrica de ella. Debido a la regularidad de la estructura cristalina, y como los efectos de deformación de la celda suceden en todas las celdas del cuerpo del cristal, estas cargas se suman y se produce una acumulación de carga eléctrica, produciendo una diferencia de potencial eléctrico entre determinadas caras del cristal en las cuales se ejerce la presión.

De las 32 clases cristalinas existen 20 que poseen one-wayness. En las demás no existe forma de determinar la dirección de la compresión o la polaridad, ya que estos materiales no se polarizan significativamente.

El efecto de la aplicación de un voltaje para deformar un cristal no es siempre reciproco, este depende de la estructura del cristal por la deformación puede ser pura o en diferentes ángulos con respecto al campo eléctrico. Esto se ve evidenciado en la siguiente imagen. 
Figura $N^{\circ}$ 5: Proceso de polarización (a) Antes de la polarización los dominios polares se encuentran orientados aleatoriamente. (b) Un gran campo eléctrico DC es aplicado para la polarización. (c) Al quitar el campo eléctrico, la polarización remanente permanece

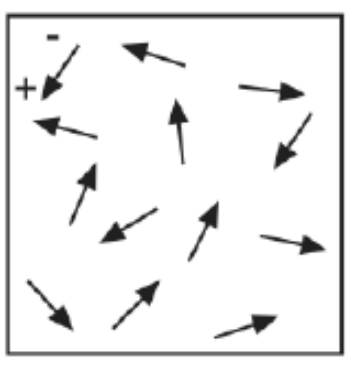

(a)

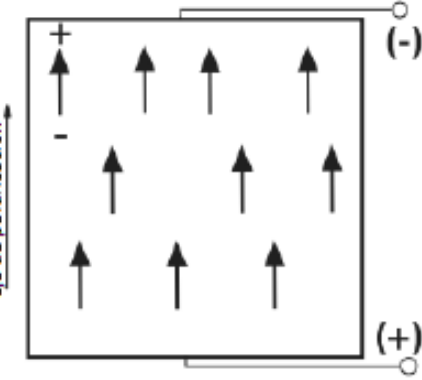

(b)

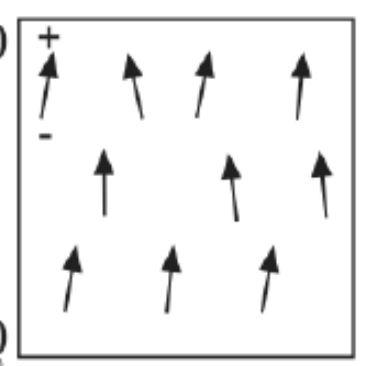

(c)

Fuente: S. O. R. Moheimani y A. J. Fleming (2006)

Las propiedades de una piezocerámica polarizada, tanto para el efecto directo (sensor) como para el inverso (actuador), se ven evidenciadas en la Figura 6. Para el efecto inverso, cuando se le aplica un campo eléctrico en la dirección opuesta a la de polarización, la cerámica sufre una contracción en la dirección de polarización, disminuyendo así el tamaño de su diámetro (Figura 6b). Cuando el campo eléctrico es aplicado en el mismo sentido que el de polarización, la cerámica se expande en dirección perpendicular a la dirección de polarización, aumentando su diámetro (Figura 6c). En cuanto al efecto directo, cuando se aplica una fuerza que comprime la piezocerámica en la dirección de polarización o se ejerce una tracción perpendicular a la misma, ésta genera una diferencia de potencial con la misma polaridad con la que fue polarizada (Figura 6d), mientras que si una tracción mecánica es aplicada en la dirección de polarización o una compresión es aplicada perpendicularmente a la dirección de polarización, éstas generarán un voltaje con la polaridad opuesta a la de polarización. (S. O. R. Moheimani y A. J. Fleming, 2006, p. 9-35) 
Figura $N^{\circ}$ 6: Comportamiento de un material piezoeléctrico en aplicación con sensor o actuador (a)Dirección de polarización. (b)Campo eléctrico aplicado con la misma polaridad que el de polarización. (c)Campo eléctrico aplicado con la polaridad opuesta al de polarización. (d)Compresión aplicada en la dirección de polarización. (e)Tracción aplicada en la dirección de polarización.

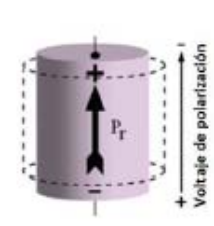

(a)

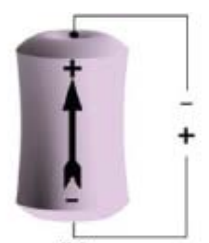

(b)

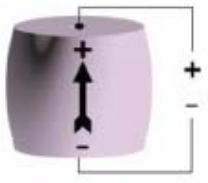

(c)

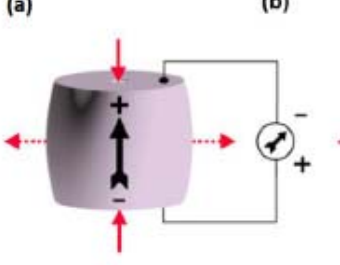

(d)

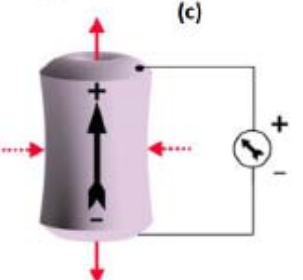

(e)

Fuente: R. S. Dahiya y M. Valle (2013)

\subsection{Modelo eléctrico de materiales piezoeléctricos}

El efecto piezoeléctrico es reversible, es decir que la aplicación de un potencial eléctrico a un cristal piezoeléctrico produce deformación. Los piezoeléctricos son dispositivos de alta impedancia, por esto solo pueden suministrar corrientes muy pequeñas (Jiménez, 1995).

Las tensiones mecánicas que aparecen en un dieléctrico isótropo que se encuentra en un campo eléctrico constituyen un efecto que es cuadrático respecto del campo. Este mismo efecto se observa en los cristales. Sin embargo, para ciertos tipos de simetrías de la estructura cristalina esta dependencia tiene un carácter esencialmente distinto. Las tensiones internas que aparecen en los cristales son aproximadamente lineales con el campo. Despreciando las contribuciones de orden mayor, como se muestra en la siguiente ecuación (Honoré \& Mininni, 1996).

$$
\varepsilon=d \times E
$$

Donde " $\varepsilon$ " es el tensor de deformaciones, " $d$ " es el tensor piezoeléctrico y "E" es el campo eléctrico. 
De la misma forma, frente a deformaciones del dieléctrico aparece un campo lineal con las tensiones mecánicas internas, como se indica en la ecuación (Honoré \&Mininni, 1996).

$$
P=d \times \sigma
$$

Donde " $P$ ” es el vector polarización y " $\sigma$ " el tensor de tensiones. Este fenómeno es llamado efecto piezoeléctrico (Honoré \& Mininni, 1996).

\subsection{Transducción piezoeléctrica}

La generación de energía eléctrica, a partir de energía procedente del entorno, ha permitido aprovechar en los últimos años el efecto piezoeléctrico en la alimentación de dispositivos de baja potencia (Roundy, Wright, \& Rabaey, 2002). Los materiales piezoeléctricos se pueden utilizar como un medio para transformar las vibraciones del entorno en energía eléctrica, está puede ser almacenada o utilizada para alimentar otros dispositivos como microscopía, scanner de espejo rápido, sintonización de láser, dispositivos micro dispensadores, estimulación de audio fisiología, entre otros. Con el reciente aumento de los dispositivos de escala micro, la generación de energía piezoeléctrica puede proporcionar una alternativa conveniente a las fuentes de energía tradicionales que se utilizan para operar ciertos tipos de sensores, actuadores, y dispositivos MEMS (Sodano \& Inman, 2005).

Los materiales piezoeléctricos poseen la capacidad de generar energía eléctrica cuando se ven sujetos a un esfuerzo mecánico (efecto piezoeléctrico directo). Éstos también ven afectada su forma, si en el caso inverso, (efecto piezoeléctrico inverso) se ven sometidos a una carga eléctrica (Escalera Siles, 2012).

En la figura 7 se observa que cuando una fuerza externa es aplicada a un transductor piezoeléctrico, una parte del trabajo mecánico realizado se almacena como energía potencial elástica, y otra parte en el campo eléctrico asociado con la polarización inducida del material. Si se proporciona un patrón de conducción externo a través de la carga, resulta una corriente que neutraliza la carga neta. (Mitcheson, Yeatman, Rao, Holmes, \& Green, 2008). 
Figura N 7: Principio de Funcionamiento del Transductor piezoeléctrico

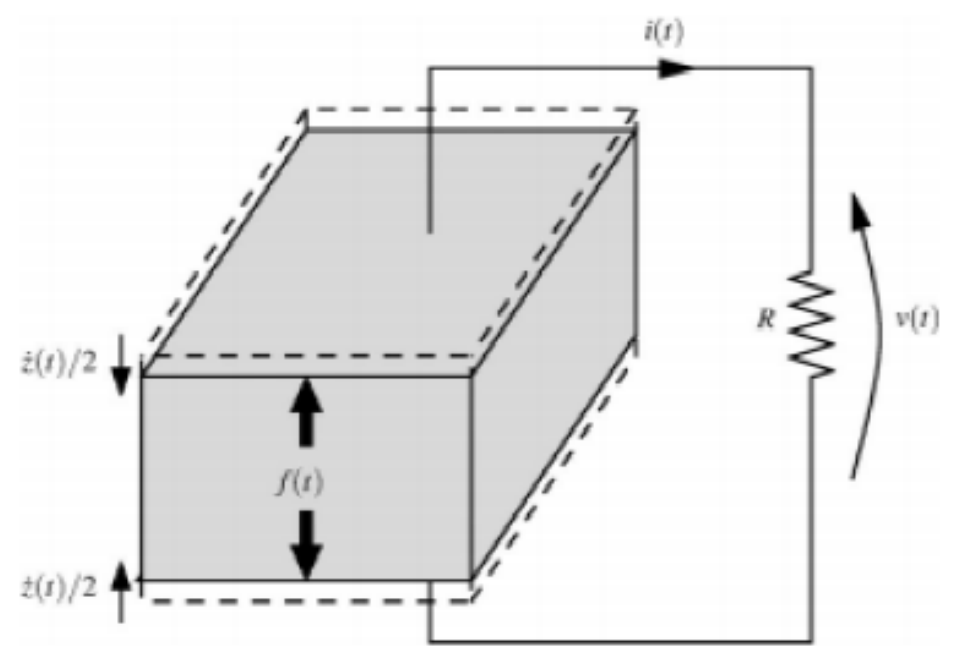

Fuentes: Mitcheson, Yeatman, Rao, Holmes, y Green (2008)

\subsection{Modelo de Caminar}

El movimiento humano está controlado por el sistema neuro-muscular. El caminar es un ejemplo básico de los movimientos humanos, esté puede ser entendido como un proceso mecánico pasivo (Garcia, Ruina, Coleman, \& Chatterjee, 2010). Caminar es un movimiento que se realiza para desplazarse en el que intervienen los pies, piernas y rodillas; el modelo generalmente aceptado para esta actividad está dado por el modelo del péndulo invertido, ya que la pierna de apoyo se comporta como un péndulo invertido en movimiento sobre el pie postura, y la pierna en movimiento como un péndulo regular de oscilar alrededor de la cadera. (Kuo, Donelan, \& Ruina, 2005).

En la figura 8 se muestra el diagrama esquemático del modelo del péndulo invertido simple en el caminar, que no requiere energía para el movimiento pendular, sino más bien para redirigir el centro de masa (CDM) del cuerpo entre los pasos. En el momento del soporte individual (cuando solo una pierna hace contacto con el suelo), el péndulo rígido conserva su energía mecánica y el CDM puede ser mantenido sin ninguna fuerza muscular. Las fases del soporte individual son separadas consecutivamente con la fase de soporte doble (comenzando con el golpe del talón) cuando una pierna de apoyo es sustituida por la otra. 
Figura Nº 8: Modelo de caminar como Péndulo invertido

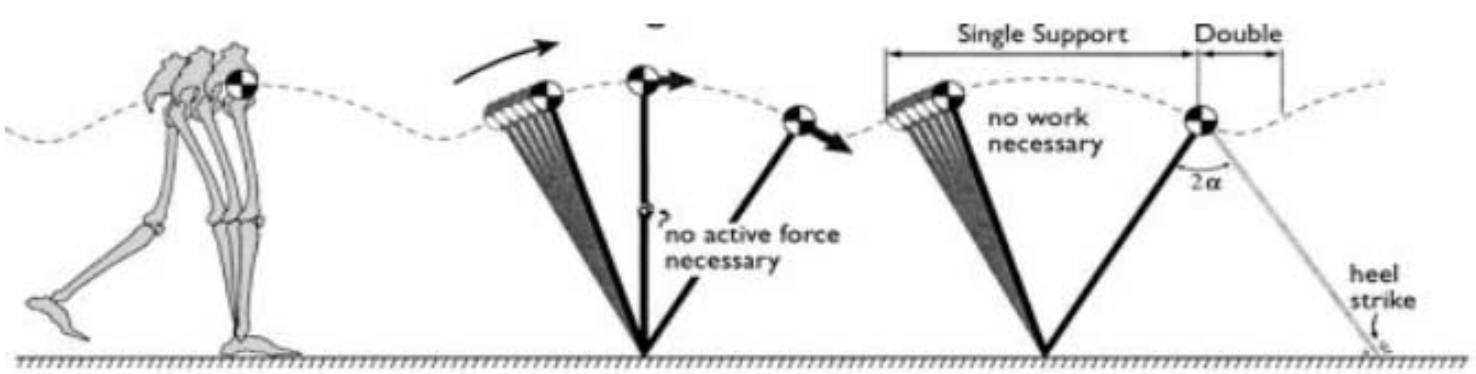

Figura 2 Modelo del caminar como Péndulo invertido. (Kuo, Donelan, \& Ruina, 2005)

Fuente: Kuo, Donelan y Ruina (2005)

\subsection{Evolución de la tecnología piezoeléctrica}

A continuación, se presenta un resumen cronológico de los descubrimientos y hechos destacables que acontecieron con respecto a la tecnología piezoeléctrica.

\begin{tabular}{|c|c|}
\hline Tiempo & Hecho o descubrimiento destacable \\
\hline $\begin{array}{c}\text { SIGLO } \\
\text { XIX }\end{array}$ & $\begin{array}{l}\text { - Comprensión de las estructuras cristalinas. } \\
\text { - Manómetro piezoeléctrico. Para la medición de las grandes } \\
\text { diferencias de potencial. } \\
\text { - Tira doble de cuarzo. Este dispositivo puede servir como } \\
\text { un electrómetro piezoeléctrico. } \\
\text { - Piezoeléctrico de cuarzo. Sirve para la medición de } \\
\text { capacitancias, voltajes, y el efecto piro - y piezoeléctrico } \\
\text { de la radioactividad. }\end{array}$ \\
\hline 1917 & - Detector de ultrasonidos submarinos. \\
\hline $\begin{array}{l}1920- \\
1940\end{array}$ & - Resonadores de cuarzo. \\
\hline $\begin{array}{c}\text { Después } \\
\text { de la } \\
\text { Primera } \\
\text { Guerra } \\
\text { mundial. }\end{array}$ & $\begin{array}{l}\text { - Micrófonos, acelerómetros, transductores ultrasónicos, } \\
\text { actuadores doblador elemento, el fonógrafo pick-ups, } \\
\text { filtros de señal, etc. }\end{array}$ \\
\hline
\end{tabular}




\begin{tabular}{|l|l|}
\hline \multirow{2}{*}{$1950-$} & $\begin{array}{l}\text { Filtros de señal piezocerámicos, que abordó las } \\
\text { necesidades que surgen en la televisión, la radio y los } \\
\text { mercados de equipos de comunicaciones. }\end{array}$ \\
\hline 1980 & $\begin{array}{l}\text { Zumbadores de audio, transductores de ultrasonidos de } \\
\text { aire y dispositivos de filtro de la SIERRA. }\end{array}$ \\
\hline 2006 & $\begin{array}{l}\text { La empresa East Japan Railway Company intento producir } \\
\text { electricidad a gran escala colocando dispositivos } \\
\text { piezoeléctricos en las compuertas de las entradas al metro. }\end{array}$ \\
\hline 10 de & $\begin{array}{l}\text { Una discoteca holandesa llamada Watt implemento } \\
\text { dispositivos piezoeléctricos para producir energía en su } \\
\text { pista de baile. }\end{array}$ \\
\hline 2008 & Este proyecto se llamó Sustainable Dance Floor \\
\hline 2009 & $\begin{array}{l}\text { Dispositivo para generar electricidad a partir del tráfico de } \\
\text { vehículos, trenes y peatones fue creado por la empresa } \\
\text { Israelí INNOWATTECH. }\end{array}$ \\
\hline \multirow{2}{*}{ Laurence Kemball-Cook presento y participo con su } \\
tecnología peizoeléctrica en un concurso atrayendo gran \\
atención de inversionistas, lo cual lo llevo a crear su propia \\
empresa PAVEGEN
\end{tabular}




\subsubsection{Tecnología PAVEGEN}

\subsection{Historia}

En el año 2009 Laurence Kemball-Cook (Fundador y dueño de PAVEGEN) fue contratado por la Compañía de Energía EON, para hallar una forma de iluminar una calle de Londres mediante el uso de energía solar y energía eólica. Al tratar de hallar esta solución, se dio cuenta que no había forma de poder cumplir con este objetivo, ya que habían muchas sombras en la ciudad y no se iba a poder recolectar la suficiente energía como para poder iluminar toda la calle. En ese momento, se le ocurrió que la solución se encontraba bajo sus pies, ya que podía aprovechar la energía cinética de las personas para poder generar energía. A partir de ese momento, fundo la compañía PAVEGEN, pero le tomo muchos años en poder desarrollar la tecnología adecuada para aprovechar adecuadamente las pisadas y la caminata de las personas. Al inicio, ningún inversionista se interesó en sus baldosas, ya que no habían sido puestas en acción en las calles de la sociedad. Un día inesperado, Laurence K. instaló las baldosas ilegalmente para tomarles fotos como si fuera su primer proyecto de instalación. Posterior a la publicación de estas imágenes, Westfield fue el primer patrocinador de esta compañía. (Hickey, Sh., 2015). PAVEGEN inició con un capital de $\$ 800,000.00$ dólares proporcionados por su familia, amigos y el banco de inversión Renaissance Capital Partners.

Al crear el producto, se logró conseguir que cada pisada en la baldosa genere 7 Watts de energía, de los cuales el 5\% se utiliza para iluminar el logo LED de las propias baldosas, y el 95\% restante utilizado al instante o almacenado para un uso posterior. (Grose, T. 2012)

\subsection{Descripción del Producto}

\subsection{1 Energía Desplegable}

Los hábitos de las personas no cambian, pero el tiempo lo hace. Pavegen produce energía en nuestras ciudades cuando otras energías renovables luchan por hacerlo. 
Figura No 9: Gráficas de aprovechamiento de energía por tipo
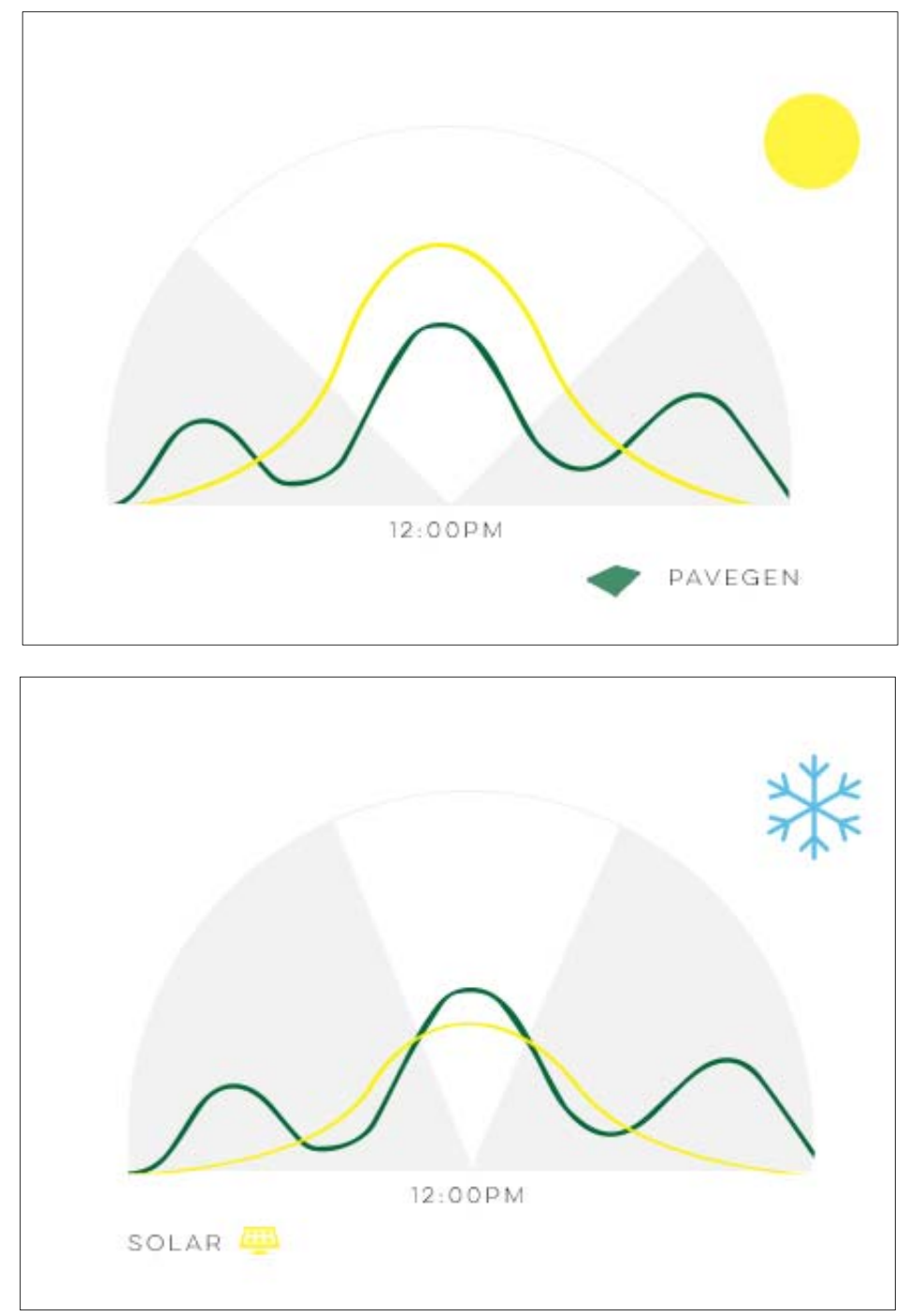

Fuente: PAVEGEN

La tecnología Pavegen se puede implementar en escala dentro de cualquier ciudad de todo el mundo. El espacio de bienes raíces potencial para instalar las baldosas Pavegen es interminable, mientras que las alternativas eólicas y solares están limitadas por el espacio, las sombras de los edificios, y el constante cambio del clima.

Pavegen puede producir energía continua durante todo el día y en cualquier estación del año, lo que demuestra cómo la energía obtenida por las pisadas es la última fuente de energía en el núcleo de nuestras ciudades del futuro. 


\subsection{Aplicaciones}

Las baldosas PAVEGEN son utilizadas principalmente para generar energía renovable mediante el aprovechamiento de la energía cinética brindada por los peatones. Además, también sirve para recolectar data exacta de la afluencia de personas por el área instalada, la cual puede ser utilizada por la empresa, en la cual se encuentren instaladas, para proponer mejoras en sus servicios, localización de publicidades, locales estratégicos, etc.

La energía generada por estas baldosas puede ser utilizada en una gran variedad de aplicaciones como:

- Iluminación o energización de paneles publicitarios.

\section{Figura $N^{\circ} 10$ : Paneles publicitarios}

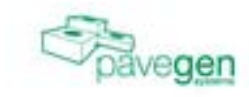

\section{Fuente: PAVEGEN}

- Almacenar la energía recolectada en baterías para poder suministrar energía a los enchufes de las instalaciones, para cargar teléfonos, energizar computadoras, radios, monitores, televisores, etc. 


\section{Figura $N^{\circ}$ 11: Aplicaciones}

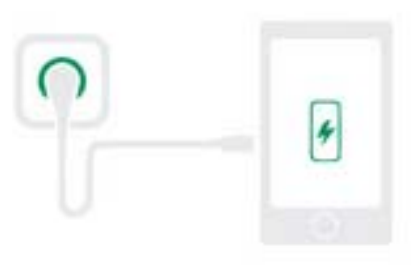

\section{Fuente: PAVEGEN}

- Iluminación Pública o Privada

Dependiendo de la designación y derivación de la energía recolectada, se puede iluminar tanto las propiedades en las cuales se encuentren instaladas estas baldosas, o las zonas públicas dependiendo del dueño y objetivo de estos productos.

Figura $N^{\circ}$ 12: Iluminación con PAVEGEN

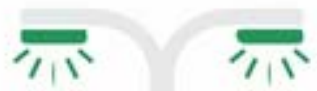

\section{Fuente: PAVEGEN}

- Iluminación de Caminos

Especialmente en los aeropuertos y establecimientos en los cuales se requiera indicar el camino constantemente a los peatones, se utiliza la energía recolectada por estas baldosas en iluminar las paredes de los pasadizos, en los cuales se encuentran LED's para indicar el camino correcto a los pasajeros. (Pavegen, 2015). 


\section{Figura $N^{\circ}$ 13: Señalización con PAVEGEN}

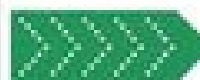

\section{Fuente: PAVEGEN}

\subsection{3 Durabililidad}

La tecnología y el producto PAVEGEN están diseñado para funcionar en los ambientes más extremos conocidos por el ser humano. Además, las baldosas también han sido evaluadas en una serie de pruebas específicas para conocer su durabilidad, resistencia e impermeabilidad.

\section{Prueba de Carga:}

En el 2012, las baldosas PAVEGEN fueron puestas a prueba de estructuración para certificar su correcta construcción y resistencia ante diversas cargas.

Figura $N^{\circ}$ 14: Características estructurales de las Baldosas

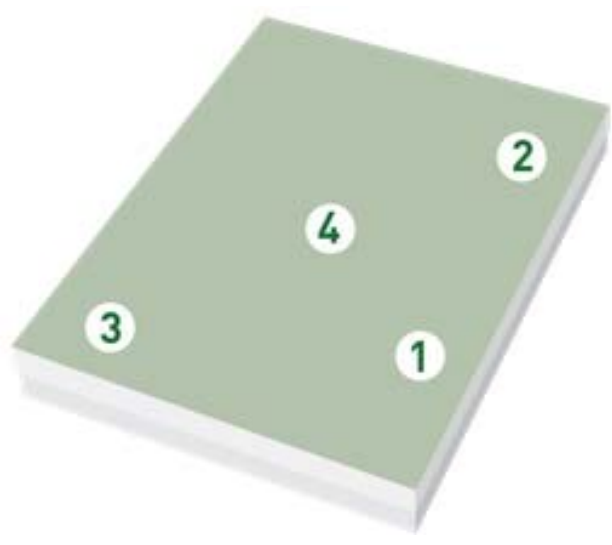

Fuente: PAVEGEN 
1- Borde frontal con barras estructurales de soporte.

2- Área sin soporte estructural "zona más delicada".

3- Borde lateral con barras estructurales. "zona con mayor flexibilidad.

4- Área central.

Después de haberles realizado diversas pruebas de resistencia a las baldosas se obtuvieron los siguientes resultados.

a) Carga muerta $3 \mathrm{kN} / \mathrm{m}$ - Equivale a $810 \mathrm{~N}$ en $25 \mathrm{~mm} \mathrm{X} 25 \mathrm{~mm}$.

b) Carga en movimiento $7 \mathrm{kN} / \mathrm{m}-1.89 \mathrm{kN}$ cada $25 \mathrm{~mm} \mathrm{X} 25 \mathrm{~mm}$.

c) Carga simulada de $3.68 \mathrm{kN} / \mathrm{m}$ - Simulación de un carro promedio a través de $185 \mathrm{~mm}$ X $70 \mathrm{~mm}$.

d) Prueba de impacto del salto de una persona de $80 \mathrm{Kg}$, desde una altura de 1 metro sobre el centro de las baldosas.

\section{Prueba de Sobrecarga}

a) Se usó una placa de $100 \mathrm{~mm} \times 75 \mathrm{~mm}$ para probar la resistencia a 2 toneladas. La prueba fue exitosa.

Figura $N^{\circ}$ 15: Sobrecarga en las baldosas PAVEGEN

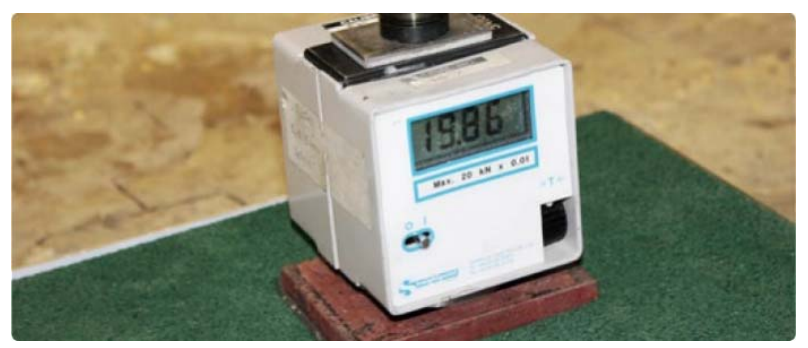

Fuente: PAVEGEN 
b) La segunda prueba simulo la presión ejercido por los zapatos con tacos en punta, la cual soporto hasta $15 \mathrm{kN}$ sin ningún impacto en las baldosas.

Figura $N^{\circ}$ 16: Simulación y prueba de presión en las Baldosas

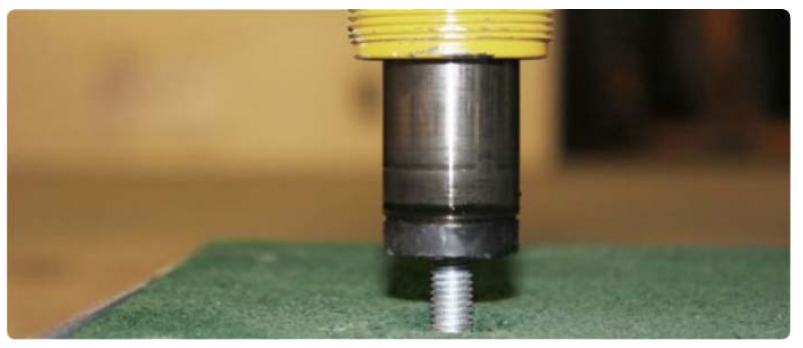

\section{Fuente: PAVEGEN}

c) La tercera prueba simuló 1,000,000 de pisadas continuas de seres humanos.

Figura $N^{\circ}$ 17: Simulación de pisadas

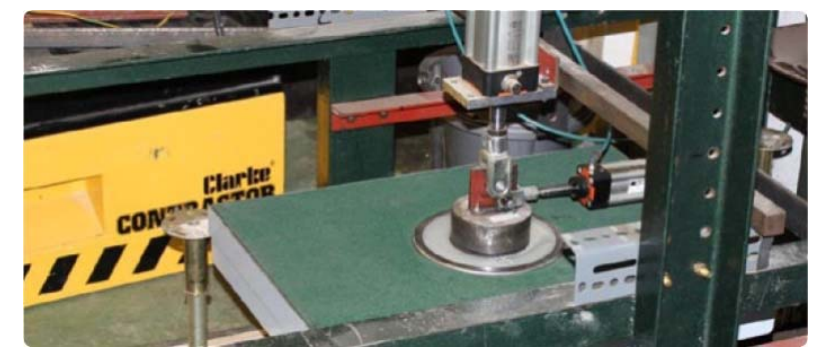

Fuente: PAVEGEN

\section{Impermeabilidad}

Las baldosas han sido sumergidas en una piscina a una profundidad de $1.2 \mathrm{~m}$ para asegurarse de que sean totalmente impermeables y funcionen adecuadamente sin importar la humedad de su exterior. 
Figura $N^{\circ}$ 18: Pruebas de impermeabilidad
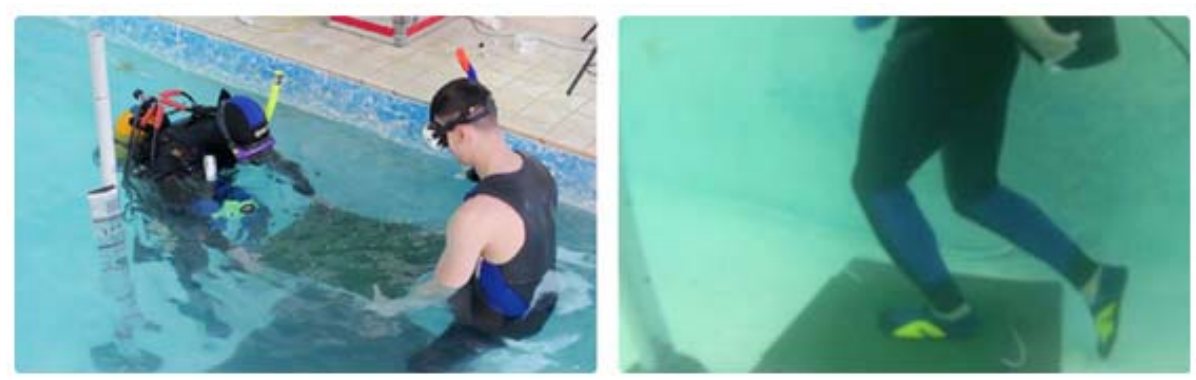

\section{Fuente: PAVEGEN}

\section{Resistencia a las Pisadas}

En el 2013 las baldosas fueron probadas y comprimidas por más de 3 millones de pisadas y funcionan continuamente a la perfección. (Pavegen, 2015). Posteriormente, KemballCook comento que su duración actual es de más de 5 años y buscan que esta sea mayor a 20 años.(Grose, T., 2012)

Figura $N^{\circ}$ 19: Resistencia a las Pisadas

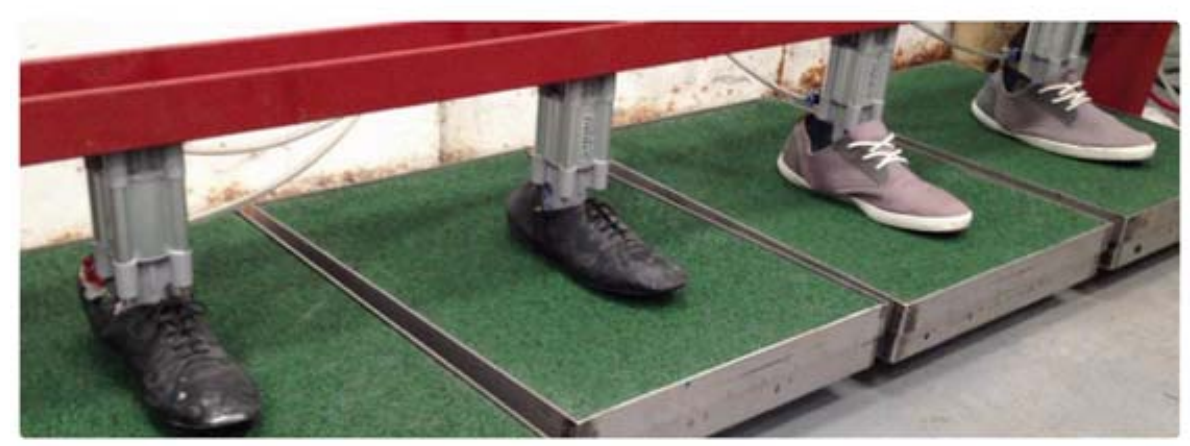

Fuente: PAVEGEN 


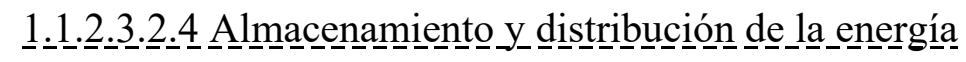

\section{Almacenamiento inteligente}

Figura $\mathrm{N}^{\circ}$ 20: Diagrama de flujo del sistema de carga de batería

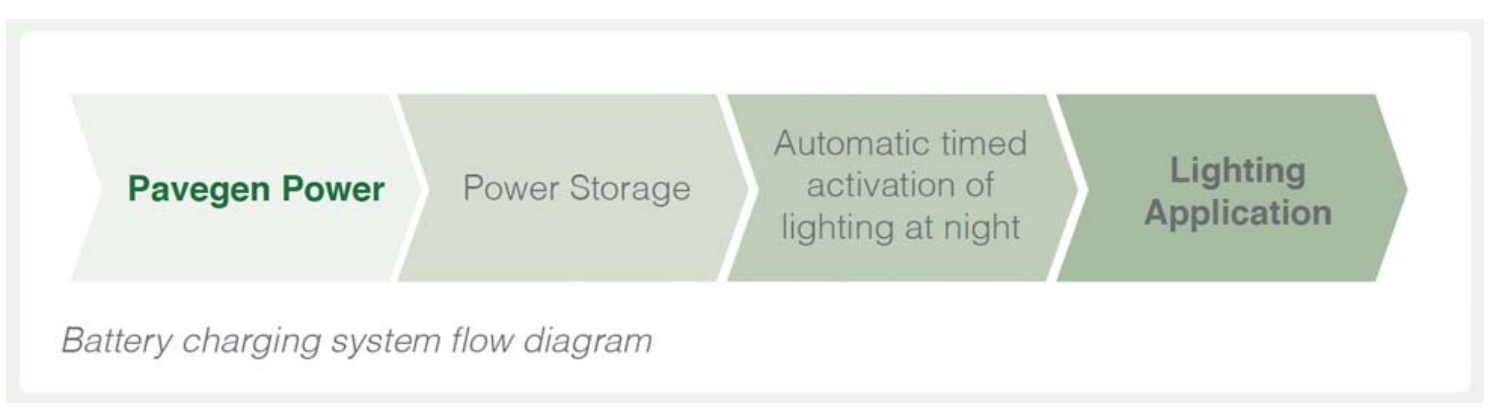

Fuente: PAVEGEN

El diagrama anterior representa el sistema de carga de batería implementados por Pavegen. A medida que la energía se genera durante el día por las baldosas, se almacena en súper condensadores listos para su uso por las luces en la noche. La activación de las luces será automática, lo que garantiza que no se desperdicia la iluminación de la zona antes de la noche.

\section{Energía Inteligente}

El equipo Pavegen ha desarrollado y mejorado la forma en que se utiliza la electricidad después de haber sido generada a partir de las baldosas. La tecnología de energía inteligente permite que las baldosas puedan suministrar su energía con una mayor gama de aplicaciones a través de la distribución inteligente de energía entre la energía renovable de Pavegen y la energía de la red. 


\section{Figura $N^{\circ}$ 21: Diagrama de flujo del sistema eléctrico}

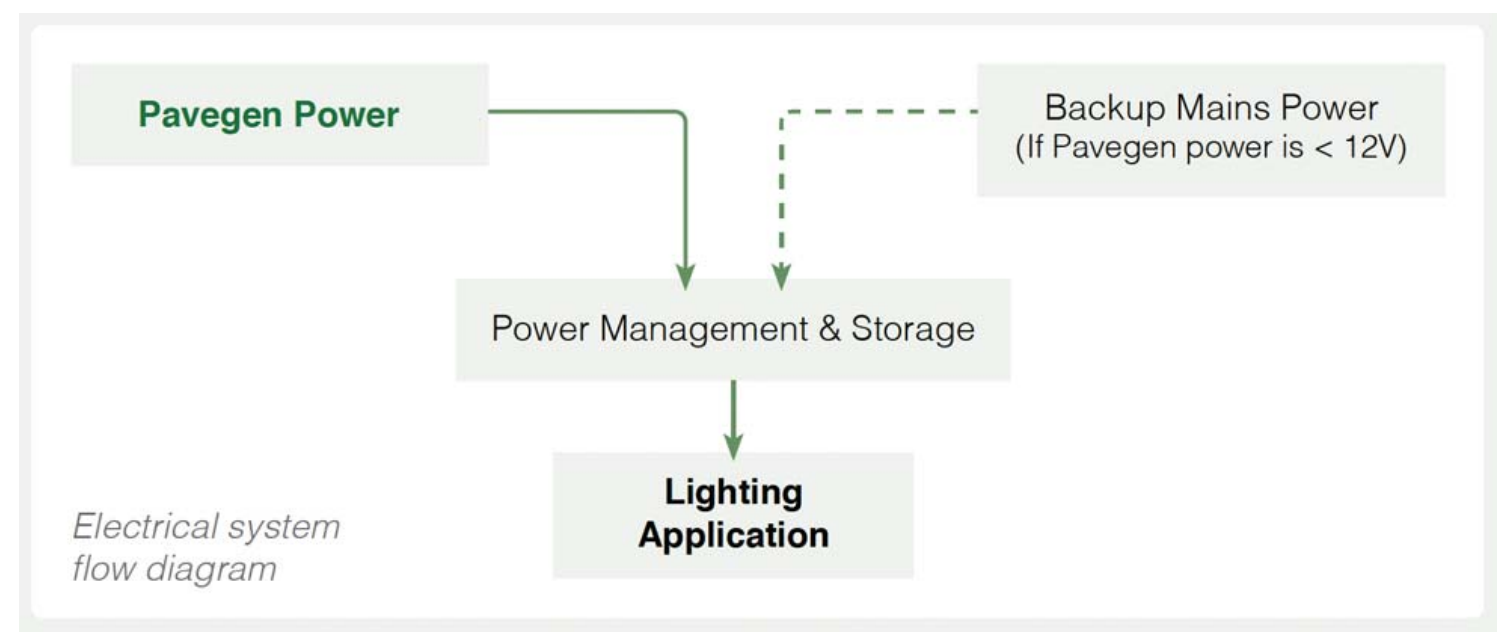

\section{Fuente: PAVEGEN}

El diagrama anterior representa el sistema eléctrico que ha de aplicarse con la instalación de las baldosas. La electricidad generada por las unidades Pavegen se almacena en baterías, que luego se utilizan para suministrarla en cualquiera que se la aplicación. La electricidad de la red se utilizará para complementar la alimentación siempre y cuando la batería cae por debajo de un límite establecido.

\subsection{2.5 Personalización}

La personalización del aspecto de cada una de estas baldosas es muy variada, logrando así que puedan ser utilizadas en diversos establecimientos, tanto públicos como privados. Estos pueden asemejar pisos de oficina como parquét, alfombras, cerámicos, etc. También tienen la presentación principal de PAVEGEN, las cuales incluyen una luz LED en el medio de la baldosa para que la gente pueda identificarse con la energía que está generando y puedan contribuir más alegremente con este sistema de energía renovable.

En la siguiente imagen, se podrán ver los diversos acabados con los que pueden contar cada una de estas baldosas. (Pavegen, 2015) 
Figura $N^{\circ}$ 22: Diseños de las baldosas

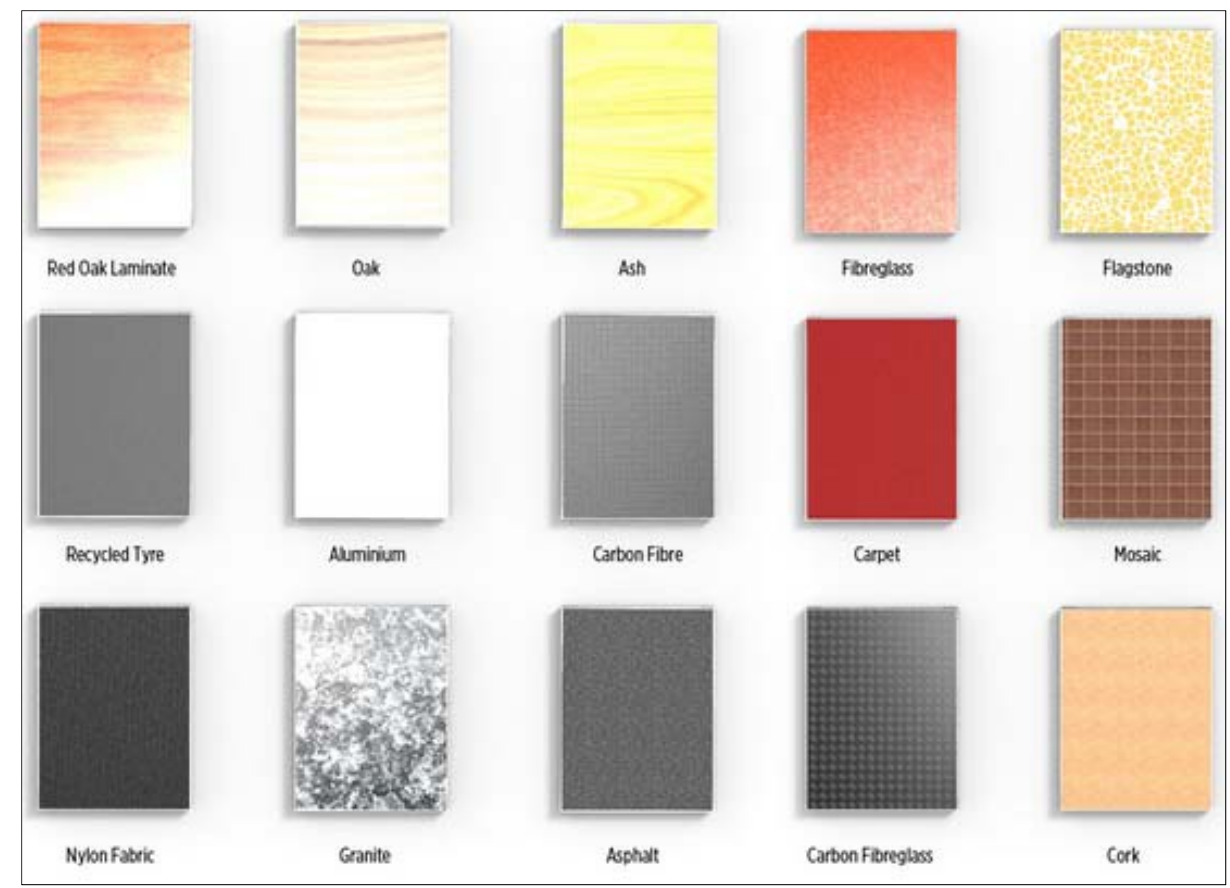

Fuente: PAVEGEN

\section{1._1.2.3.2.6 Reconocimiento_Internacional}

Durante su trayectoria, la empresa PAVEGEN y Laurence Kemball-Cook han recibido muchos premios por su destacado funcionamiento, y la idea innovadora que se fue generada por Laurence Kemball-Cook. A continuación, se podrán observar algunos de los premios obtenidos por la empresa y por el mismo diseñador de esta tecnología. (Pavegen, 2015)

- London PlanningAwards, 11 de Febrero del 2015

El Proyecto contemplaba el rediseño de los túneles subterráneos para implementarlos con las baldosas PAVEGEN y generar energía para la iluminación de los mismos y suministrar de energía ciertos accesorios para que la gente pueda cargar sus teléfonos celulares. 


\section{Figura $N^{\circ}$ 23: London Planning Award}

LONDON

PLANNING

AWARDS

\section{Fuente: PAVEGEN}

\section{- 2degrees Awards, 4 de Marzo del 2014}

Este premio se debió a la contribución con el manejo de la energía y las emisiones de carbono al medio ambiente. Un sistema de energía renovable súper innovador que generará un gran cambio en la sociedad.

Figura $N^{\circ} 24:$ 2degrees Champions Awards 2014

$$
\text { 2degrees Champions Awards } 2014
$$

\section{Fuente: PAVEGEN}

\section{- PEA Awards Champions, 2014}

Este premio fue entregado a PAVEGEN por su idea innovadora de Reducir o salvar energía "ENERGY SAVING IDEA".

Figura No 25: Pea Awards

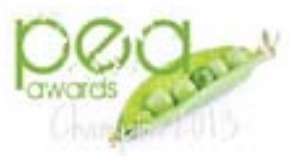

Fuente: PAVEGEN 
- Santander Entrepreneurship Award, 2012

Laurence Kemball-Cook fue condecorado con este premio por construir baldosas que convierten la energía cinética de las pisadas de las personas en energía renovable que puede ser usada en aplicaciones que requieran bajo consumo energético, iluminación, publicidad y aplicaciones de sonido.

Figura $N^{\circ}$ 26: Santander Competition

\section{$\$$ Santander}

\section{Fuente: PAVEGEN}

- Best Insurance Design of the Year Award, 2011

Pavegen fue nominado como producto del año 2011, compitiendo contra el Ipad de Apple, y la secadora de manos Dyson Airblade. (Pavegen, 2015)

Figura Nº 27: Brit Insurance Design Awards 2011

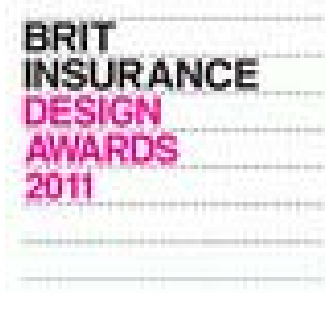

Fuente: PAVEGEN

\subsubsection{Casos de éxito}

Desde el año 2009, posterior a la fundación de la empresa PAVEGEN, se han instalados las baldosas en diversos lugares, los cuales eran transitados regularmente, con el fin de ahorrar 
costos de energía y fomentar la energía renovable para alargar la vida del planeta y reducir el consumo de combustibles fósiles. Actualmente, en Reino Unido y Europa se han llevado a cabo casi 30 proyectos de PAVEGEN tanto permanentes como temporales. (Grose,T., 2012)

Uno de los más importantes se llevó a cabo en cooperación con la empresa SHELL, donde se instaló una cancha de futbol, que funciona mediante energía renovable, en una favela localizada en Brasil. Esto se realizó, ya que se les quería brindar un lugar seguro y accesible a todos los niños y adolescentes de la favela para que pudieran jugar durante el día y la noche sin tener miedo de poder ser asaltados o asesinados.

Como se puede ver en las imágenes, el simple hecho de poder aprovechar la energía renovable generada por cada persona de esta favela, les ha dado la gran facilidad de poder contar con una cancha iluminada sin tener que pagar por la electricidad consumida.

\section{Figura $N^{\circ}$ 28: Favelas en Brasil}

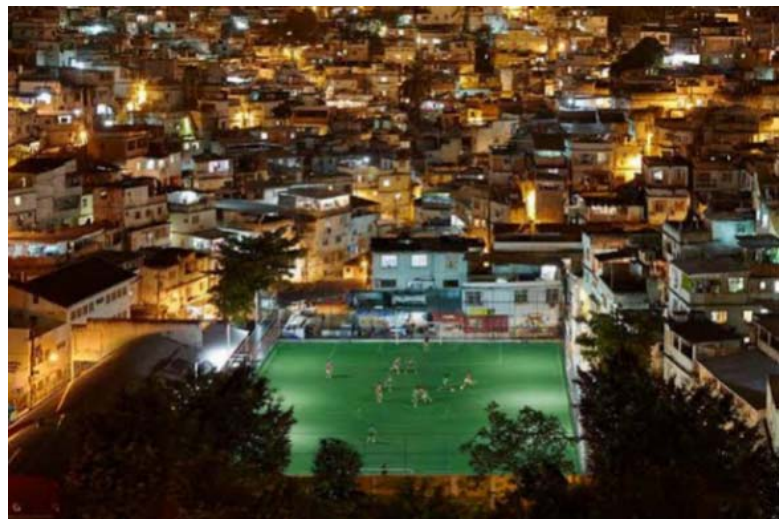

Fuente: PAVEGEN

Asimismo, en diciembre del 2015 PAVEGEN, de la mano nuevamente con Shell y con Akon crearon la primera cancha que se alimenta de energía renovable en África con la instalación de 100 baldosas en Lagos, Nigeria. 
Figura $N^{\circ}$ 29: Cancha de Futbol Nigeria

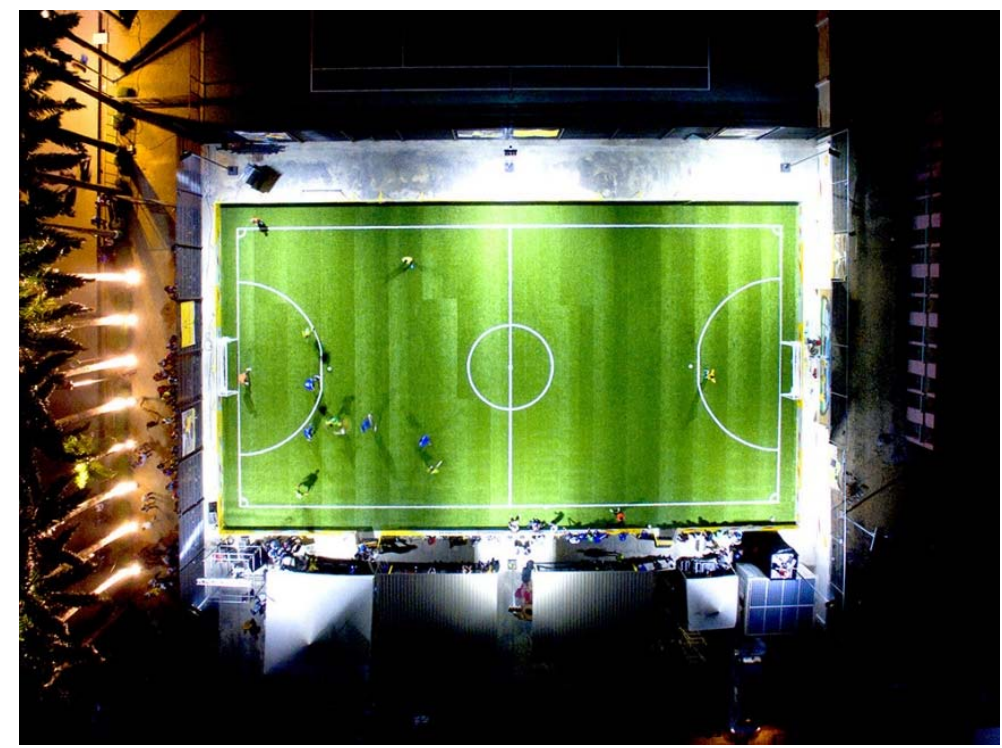

Fuente: PAVEGEN

Esta es la segunda cancha que funciona con esta tecnología y marca el octavo proyecto instalado con corporaciones multinacionales.

De la misma manera, se han instalado baldosas PAVEGEN en la estación de tren Saint Omer, Francia el 14 de Marzo del 2014. Diariamente, por esta estación transitan aproximadamente 5,000 personas, las cuales, en conjunto con las baldosas instaladas, generarán un ahorro del $30 \%$ del consumo eléctrico mensual de la estación. Como se puede ver, es una tecnología sumamente eficiente, la cual permitirá a las empresas reducir sus costos de eléctricos y colaborar con la reducción de la contaminación global.

Figura $N^{\circ}$ 30: Estación de Tren SaintOmer

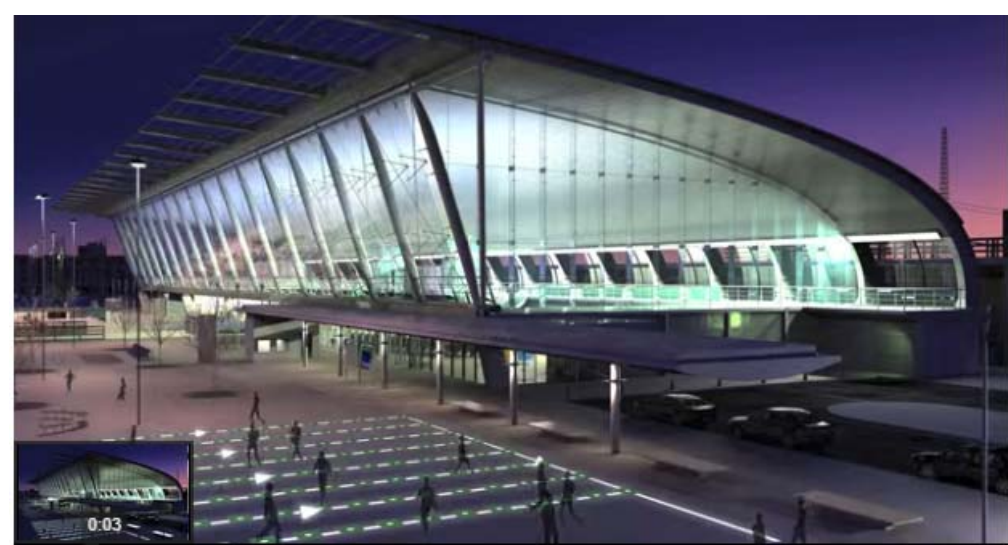


Asimismo, durante los Juegos Olímpicos de Londres, la británica Pavegen instaló 12 baldosas en uno de los transitados corredores de acceso al Parque Olímpico. Como resultado, esas plataformas recibieron 12 millones de pisadas que generaron suficiente energía para cargar 10,000 teléfonos celulares por una hora o hacerse cargo del $50 \%$ de la iluminación de un escenario deportivo. Luego, durante la Maratón de París se instalaron 176 azulejos en 25 metros cuadrados cerca de la meta en los Campos Elíseos. Con la energía generada se iluminó los paneles en el área del evento.

Así como estos ejemplos, existen otros más, motivo por el cual consideramos que es un gran momento para introducir dicha tecnología al Perú. (Pavegen, 2015)

Figura $N^{\circ}$ 31: Aplicación en Londres

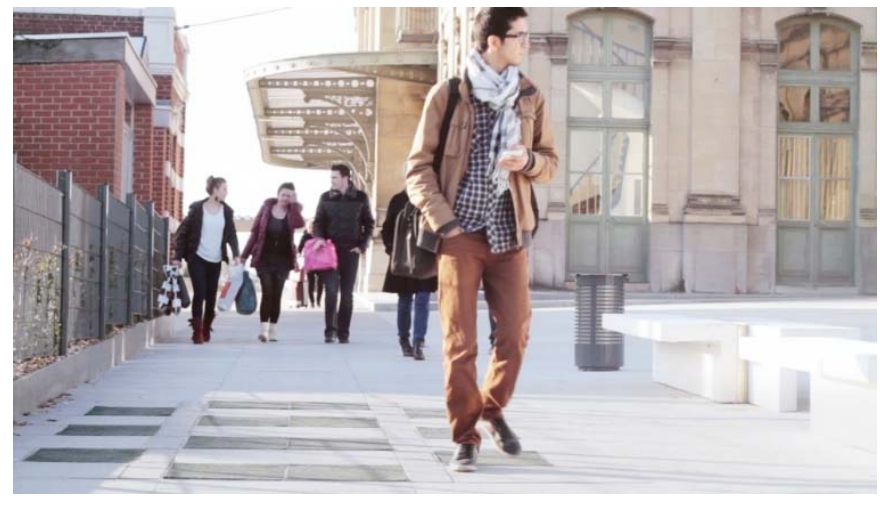

Fuente: PAVEGEN

Otro proyecto fue cuando, en el 2012, se instalaron 51 baldosas PAVEGEN en el aeropuerto Heathrow al oeste de Londres, en donde se iluminaron los pasadizos por los que caminaban los viajeros, brindaron data al aeropuerto que 18.4 millones pasajeros transitaban el área. De esta manera, el aeropuerto se puede reorganizar para colocar puestos comerciales en las áreas más transitadas, instalar más baldosas para seguir ahorrando energía, colocar publicidad electrónica por los pasadizos más transitados, etc. 
Figura $N^{\circ}$ 32: Aplicación en aeropuerto de Londres

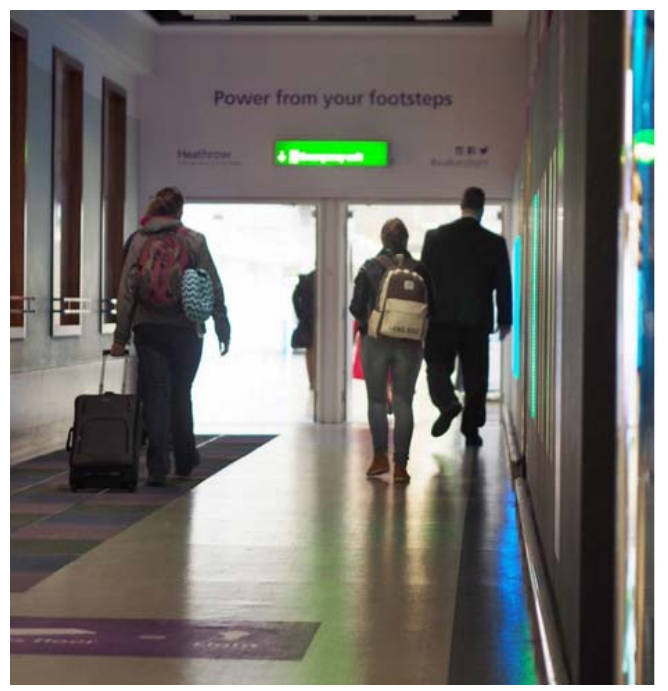

Fuente: PAVEGEN

Como último ejemplo, se instalaron 8 baldosas PAVEGEN en el colegio secundario Bloomington High School South, Indiana, EE.UU. Mediante la instalación de estas baldosas en la entrada principal del colegio, se pudo recabar información sobre la cantidad de estudiantes que asistían día a día, se generó energía renovable para ser utilizada en estaciones para cargar teléfonos celulares. La instalación de esta tecnología innovadora generó que sea comentada y publicada inmediatamente por todos sus estudiantes, ya que estaban colaborando con el medio ambiente y era algo innovador que no había sido tratado ni mencionado anteriormente.

Figura $N^{\circ}$ 33: Aplicación en colegio de Estados Unidos

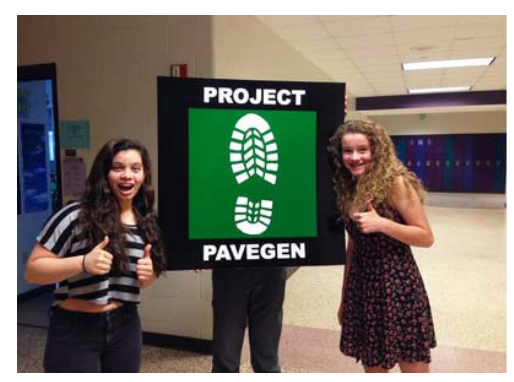

Fuente: PAVEGEN 


\subsection{Marco Teórico}

\subsubsection{Sector Energético}

\subsubsection{Situación Energética Global}

El actual sistema energético global está pasando por un momento sumamente complicado, ya que, uno de los mayores problemas de la humanidad es el abastecimiento de energía. Esto se debe principalmente al modo de vida consumista de las personas, lo cual está causando problemas ambientales gravísimos que pueden ocasionar impactos irreversibles y estamos al límite de lo que la Tierra puede soportar.

El creciente consumo de combustibles fósiles como principal fuente de energía, no solo es nocivo, si no también, está generando una dependencia de la sociedad ante estos en su vida cotidiana. Actualmente el $87 \%$ de nuestro consumo de energía primaria viene del carbón, petróleo, gas natural y uranio, y sabemos que todos ellos son combustibles no renovables. (Mediavilla, M., 2010) Todo esto no es algo de lo que debamos sorprendernos, todo es parte de una tendencia que se ha venido desarrollando desde el principio de los tiempos y se ha ido atenuando con el pasar de los años a pasos agigantados.

Si desde el Neolítico hasta principios del siglo XX la población pasó de 10 a 1600 millones, en sólo el siglo XX ha crecido hasta 6000 millones. Y el crecimiento de la energía consumida es todavía más espectacular. Si la energía utilizada creció entre 200 y 2000 Watts por persona al día entre el Neolítico y el siglo XX, en este último siglo pasó a 12000 Watts, de forma que en ambos se ha doblado aproximadamente dos veces y media, sólo que el primero es un periodo de 9000 años y el otro de sólo cien. La siguiente gráfica muestra lo espectacular de este crecimiento y lo tremendamente rápido que ha sido comparado con la historia de la humanidad.

Figura $N^{\circ}$ 34: Evolución de la población y de la energía empleada por el ser humano 


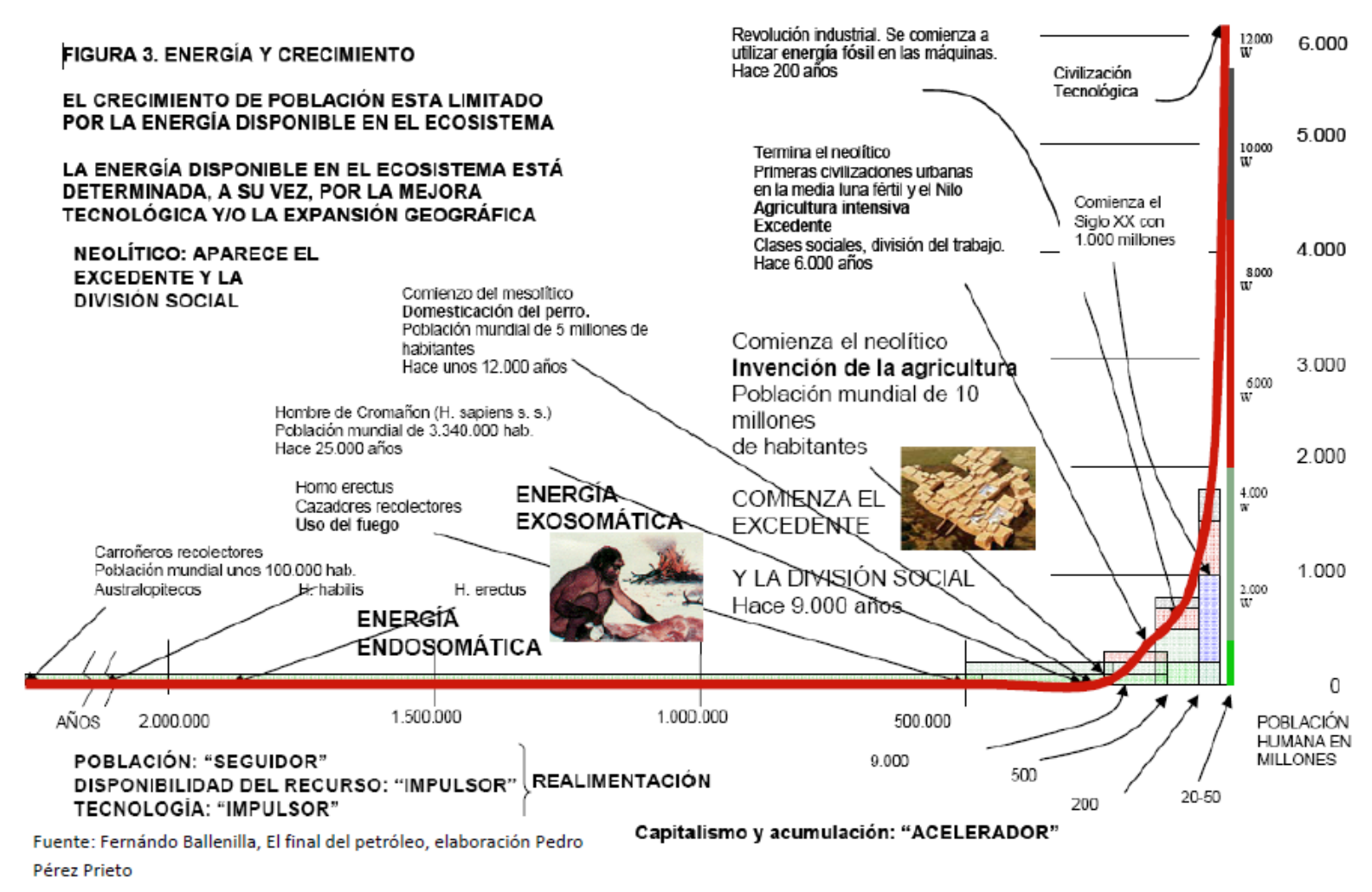

Fuente: Fernando Ballenilla

Este escenario no es más que un simple preámbulo a la inminente crisis energética que afrontara nuestro planeta si no reducimos el ritmo con el cual estamos consumiendo nuestros recursos. Si el ritmo de extracción de un recurso es mayor que el de su regeneración natural estamos poniendo en peligro su continuidad (estamos vaciando el stock). La única manera de llegar a ser una sociedad sostenible es, sencillamente, teniendo una gestión acorde con esos ritmos naturales de reposición, que permita que el stock se mantenga y se siga produciendo en el futuro sin necesidad de sobreexplotar nuestras fuentes no renovables de energía.

Ahora mismo, el consumo de energía mundial es de 13 Teravatios, mientras que la superficie terrestre, cubierta toda de unos hipotéticos paneles fotovoltaicos con un rendimiento del $100 \%$, podría suministrar once mil veces esa energía. Esto parece una cantidad enorme, que podría servirnos para siglos y siglos de consumo, pero si el consumo actual crece a "sólo" un 2,5\% anual (que no es un escenario que escape de la realidad), en 380 años ya habríamos superado toda la radiación que incide sobre la superficie terrestre (suponiendo que pudiéramos vivir sin comer) (Mediavilla, M., 2010). 
Según la estimación de UPPSALA (Mediavilla, M., 2012), si la demanda máxima de petróleo y la cantidad total equivalente de petróleo que podría ponerse en el mercado le sumamos los biocombustibles, y el petróleo que se ha dejado de consumir con los vehículos eléctricos e híbridos. Podemos ver que la demanda es mucho mayor que la oferta total del petróleo más sus sustitutos (de hecho, lo está siendo ya, puesto que el consumo es mayor del esperado según las tendencias de décadas pasadas).

\section{Gráfica $N^{\circ}$ 3: Petróleo Escenario Business as usual}

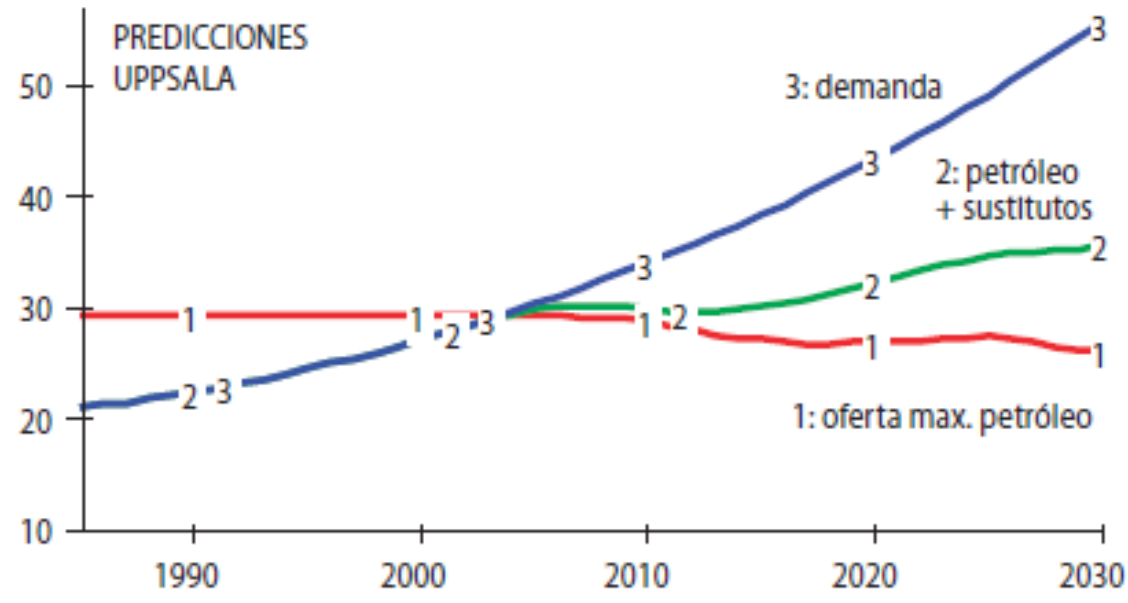

Fuente: UPPSALA

El pico del petróleo marca un claro punto de ruptura en la economía mundial que, o bien debe independizarse del petróleo de forma abrupta y aumentar su eficiencia mucho más de lo que ha hecho en décadas pasadas, o bien debe resignarse al decrecimiento; y lo marca ya, esta misma década (o lo está marcando desde 2005).

En el panorama eléctrico, se puede ver que la demanda se puede cubrir hasta el año 2020, pero a partir de ese momento alcanza el techo máximo de extracción de energía eléctrica no renovable (debido a los picos de gas, carbón y uranio). 


\section{Gráfica $N^{\circ}$ 4: Electricidad. Escenario Business as usual}

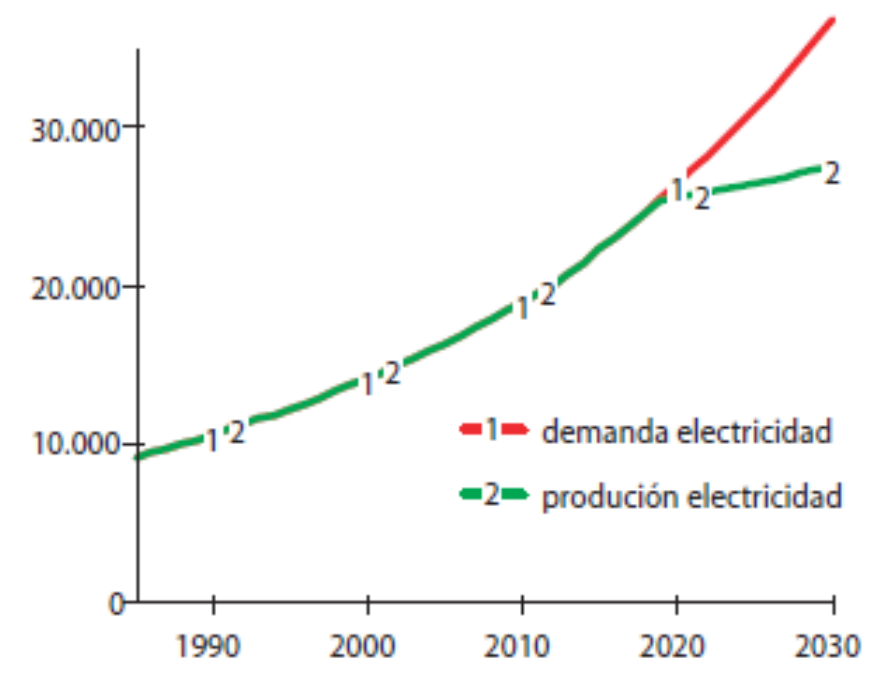

Fuente: UPPSALA

Todo indica que estamos encaminados a una crisis de escases energética a causa de nuestro alto nivel de consumo de recursos no renovables como nuestra principal fuente de energía y al parecer ya es tarde para cambiar la estructura bajo la cual está formada nuestra sociedad. Una acción de contingencia ante esto es establecer políticas ambientalistas y anti-consumistas que amortigüen el efecto que la crisis pueda causar en el mundo, aunque esto no es suficiente. Es por ello que es necesario encontrar diferentes fuentes alternativas de generación de energía no convencional, que si bien no puedan remplazar en su totalidad a las fuentes actuales, puedan dar soporte y así ayudar a reducir el impacto de la crisis convirtiéndonos en una sociedad más sostenible.

\subsubsection{Situación Energética Peruana}

En la última década, el Sector Energético peruano ha registrado un importante crecimiento y desarrollo debido al incremento de la demanda interna ligada al fuerte desarrollo económico. En el periodo del 2003 al 2013, el Producto Bruto Interno (PBI) se incrementó en 86\% y la producción de electricidad aumentó en $92 \%$, en tanto que la producción de hidrocarburos lo hizo en 2.6 veces. En el mismo período, el consumo final nacional de estos recursos energéticos se incrementó en 92\% para la electricidad mientras que en 100\% para los hidrocarburos líquidos y el gas natural agregados. (MINEM, 2014). Esto demuestra el mayor crecimiento de la actividad económica y de la demanda energética de las últimas décadas. Es así como la producción y el consumo final de la energía eléctrica aumentó en la misma proporción. 
Al tercer trimestre del 2014, la energía consumida fue 31,888 GWh mayor en 5.38\% respecto al mismo periodo del 2013; en ese mismo periodo, el PBI creció 2.80\% (Pacific Credit Rating). Es así como el consumo de energía se encuentra muy ligado al desarrollo de la economía. En el caso peruano, esto se da en mayor medida en las empresas mineras e industriales como se puede evidenciar en la siguiente gráfica:

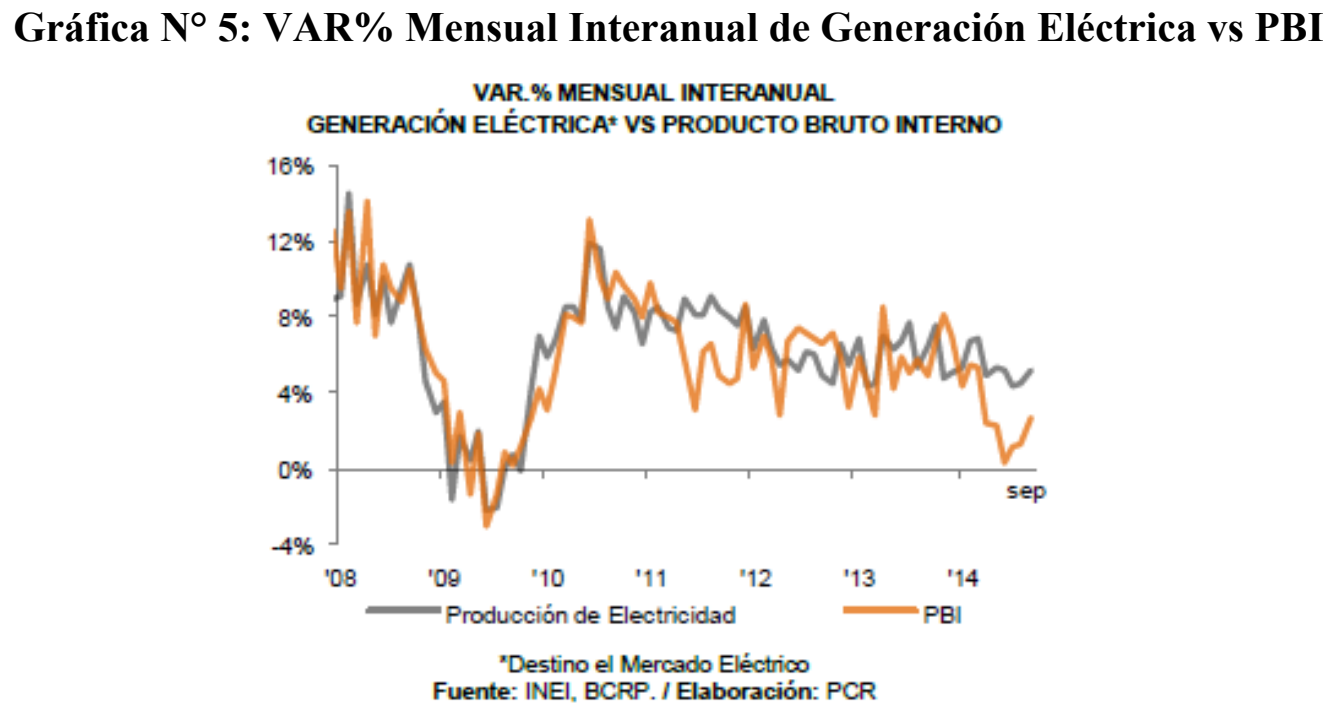

Fuente: INEI, BCRP

En el próximo periodo, se espera que el consumo final de energía continúe creciendo en función del desarrollo de la economía interna, del aumento de la población urbana y de la ampliación de la cobertura energética del país. Es por ello que se estima que el consumo final de energía siga orientado por su tendencia creciente y pase de 800 miles de Tera Joule (TJ) a la fecha, a un rango entre 1321 miles de TJ y 1612 miles de TJ en el 2025.

Gráfica N$^{\circ}$ 6: Proyección del Consumo Final de Energía (TJ) 


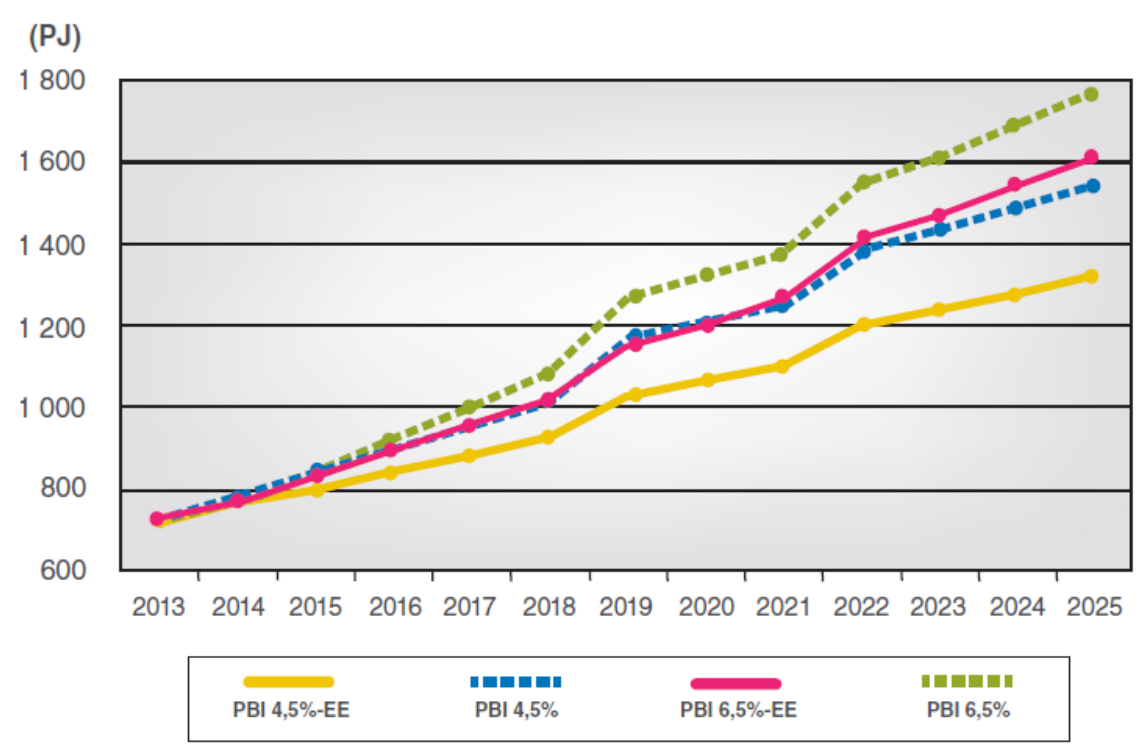

EE: proyección del consumo final de energía con medidas de eficiencia energética.

Fuente: MINEM

Fuente: MINEM

En el periodo 2014 - 2025 se espera que el consumo de combustibles líquidos pase de 209 Miles de Barriles Diarios (MBD) a 285 MBD o, en otro escenario, de 212 a 339 MBD.

\section{Gráfica $N^{\circ}$ 7: Crecimiento del consumo final de Hidrocarburos Líquidos}

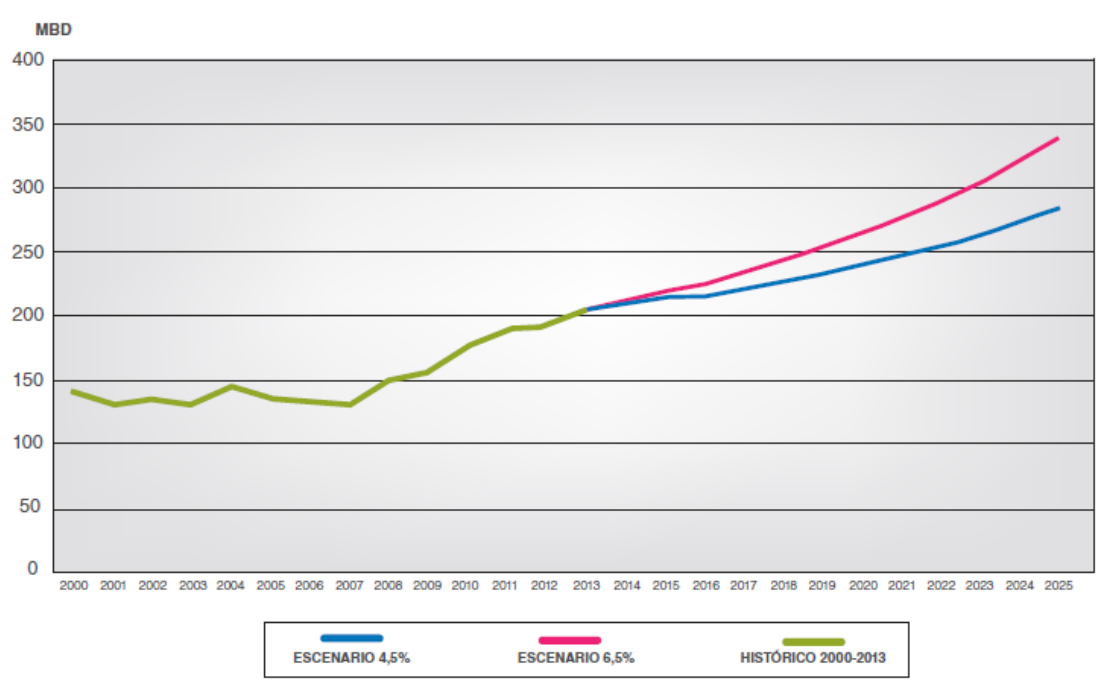

Fuente: MINEM 
Se prevé que en el año 2025 la demanda de gas natural, que incluye el consumo final más lo requerido para la generación de electricidad y el desarrollo de la petroquímica a nivel nacional ascenderá entre 1,900 millones de pies cúbicos día (MMPCD) a 2,400 MMPCD al 2025.

\section{Gráfica $N^{\circ}$ 8: Crecimiento de la demanda de Gas Natural}

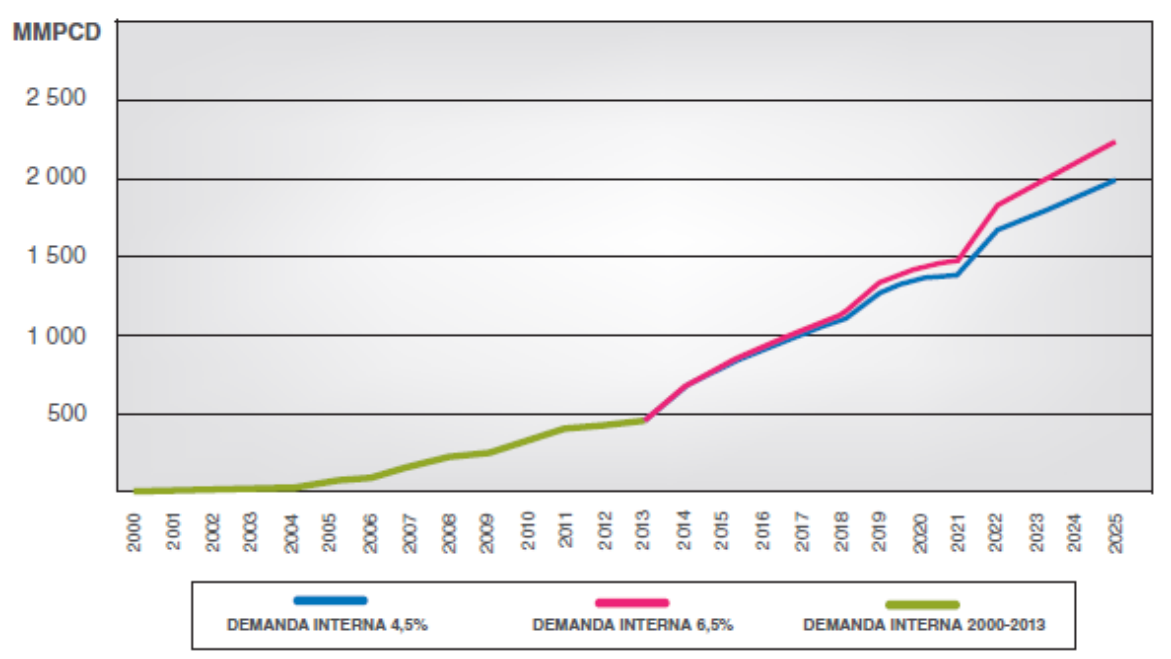

Fuente: MINEM

Se estima que la demanda eléctrica continuará con su tendencia creciente de los últimos veinte años y pase de los actuales 5800 megavatios (MW) a un rango entre 9,500 MW y $12300 \mathrm{MW}$ al 2025 según los escenarios de crecimiento del PBI de $4.5 \%$ y $6.5 \%$ respectivamente. 


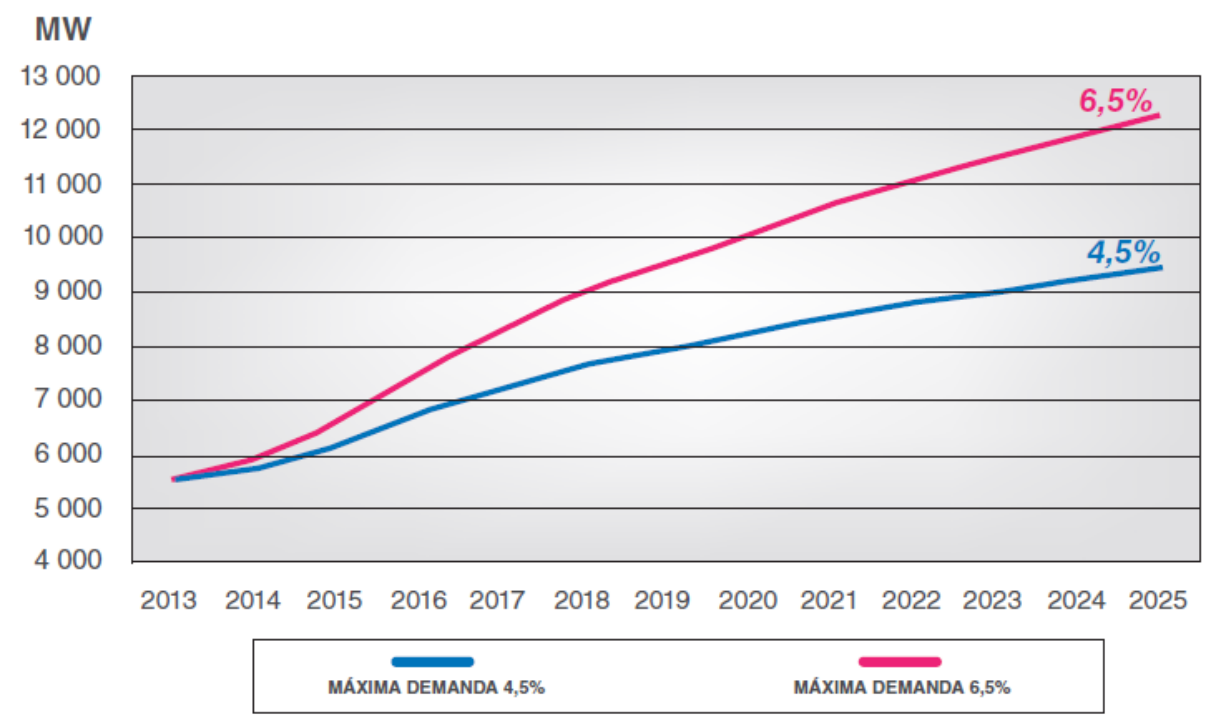

Fuente: MINEM

La producción de energía eléctrica en el país proviene en mayor proporción de la hidroelectricidad, seguida de la generación térmica a base de tecnologías de suministro de alimentación a gas natural. Mientras que los otros tipos de generación de energía eléctrica como solar, eólica, biomasa, entre otras, mantienen una participación mínima con respecto a las anteriormente mencionadas. A continuación, se presenta su distribución y el pronóstico al año 2025 .

Gráfica N 10: Producción de electricidad por fuente (2013-2025)-1

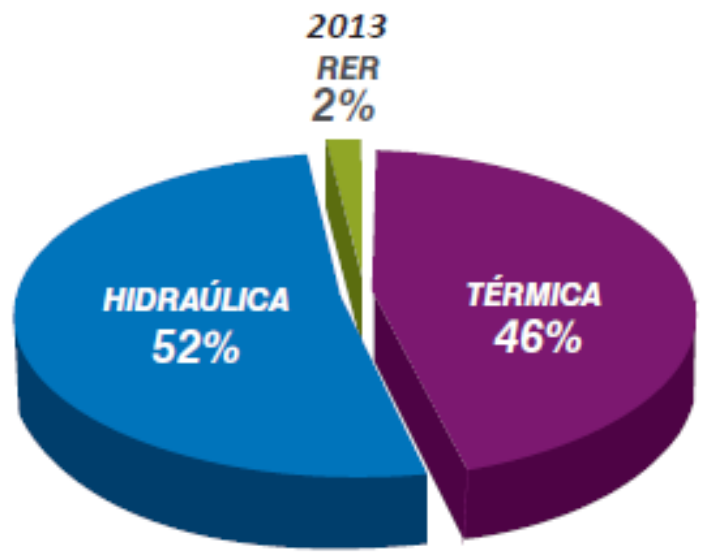

Fuente: MINEM 
Gráfica No 11: Producción de electricidad por fuente (2013-2025) - Escenario PBI 4,5\%

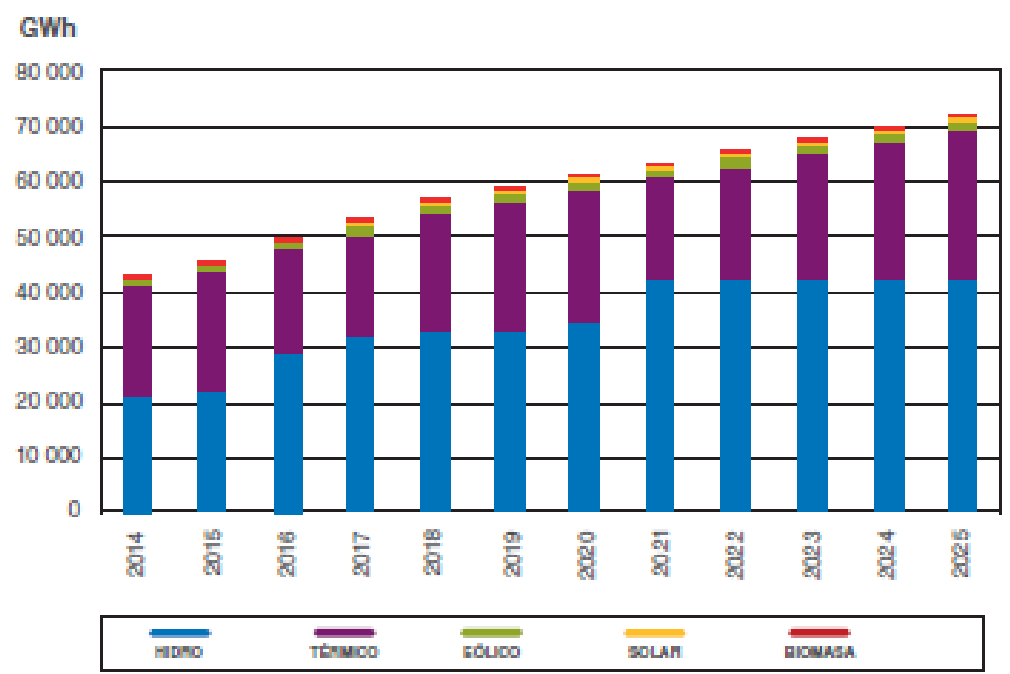

Fuente: MINEM

Gráfica $N^{\circ}$ 12: Producción de electricidad por fuente (2013-2025) - Escenario PBI 6,5\%

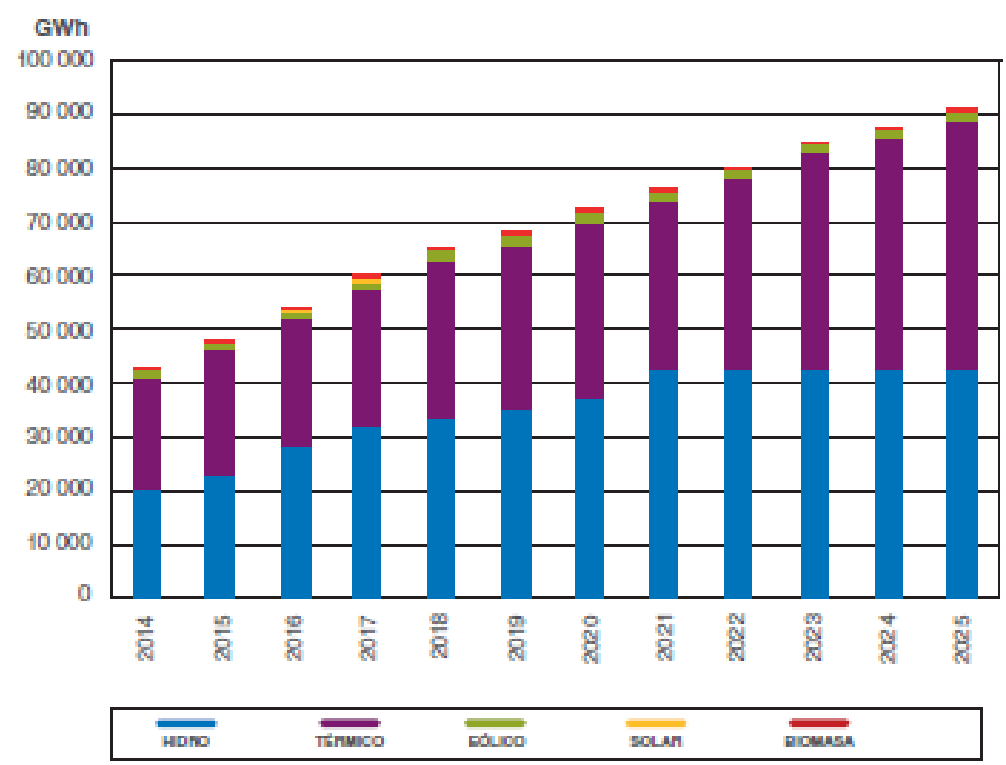

Fuente: MINEM 
Por otro lado, las tarifas eléctricas presentan una tendencia creciente ininterrumpida desde el año 2008, el cual se sustenta en el incremento tanto de los precios libres como en el de los regulados. El precio medio de energía muestra un incremento de $20.8 \%$ desde el 2008, creciendo en promedio 3.9\% anual. A partir del año 2015, las tarifas eléctricas se incrementarán en $1 \%$ de forma anual hasta el año 2020.

Es de mencionar que Lima concentra el $41.6 \%$ del consumo total de energía eléctrica nacional, resaltando que solo el $31.3 \%$ de la población se ubica en la capital. El consumo promedio de energía per cápita fue de $1,352.7 \mathrm{KWh} / \mathrm{hab}$.

Puesto que los pronósticos de demanda, de consumos de la energía eléctrica y las tarifas eléctricas muestran una tendencia creciente, será un reto para nuestro país enfrentarse a esta realidad sin caer en una posible crisis energética. Adicionalmente a esto, la ciudad de Lima tiene la mayor participación en el consumo de energía del país. Siendo determinante para su sostenibilidad, la búsqueda de alternativas no convencionales que ayuden a disminuir los riesgos de sucumbir ante esta crisis. Por este motivo, este Proyecto de Tesis busca aplicar una nueva tecnología para la generación de energía renovable como soporte ante una inminente crisis futura y a su vez catalogar al Perú como pionero en la utilización de energías renovables frente a los países Latinoamericanos.

\subsubsection{Simulación Montecarlo en Software Arena}

\subsubsection{Definición}

La simulación Montecarlo es una herramienta muy poderosa para poder modelar, simular y analizar sistemas complejos. En la actualidad, muchos de los sistemas de negocios de producción o servicios, suelen ser muy complejos o de una duración muy larga para analizarlos personalmente y obtener resultados de las muestras obtenidas. Por este motivo, es que se acude a las simulaciones para poder ingresar los datos abstractos de los problemas a analizar y poder obtener resultados o historias que puedan dar a conocer cómo es que resultaría un modelo planteado teóricamente. Mediante los resultados obtenidos, gracias a la simulación, se puede entender mejor el rendimiento o el éxito de un sistema bajo las restricciones establecidas. Estas pueden ser de cantidad de personas, operarios, máquinas, espacio, materiales, etc. Las restricciones que se le puede dar a cada uno de los modelos dependen de cada uno de ellos, para así lograr que estos sean los más parecidos a la realidad y brinden las respuestas más exactas y veraces para tomar decisiones correctas. (Altiok y Melamed, 2007) 


\subsubsection{Beneficios y Usos}

Uno de los beneficios más grandes que provee la simulación es dar la respuesta a la pregunta que mucha gente se realiza a sí misma “¿Qué pasaría si se realiza algo?”.

Hoy en día, las simulaciones son utilizadas en muchos diversos escenarios, los cuales pueden abarcar producción, distribución, inventariado, comunicación, abastecimiento, consideraciones económicas, estándares de calidad o tiempo, etc. Dependiendo del objetivo de cada una de las simulaciones, se pueden predecir diversos escenarios, los cuales te indiquen que opción se debe tomar, cuál es la más rentable, la más riesgosa, la más rápida, la más lenta, etc. De este modo, la simulación te ayuda a prevenir los posibles escenarios futuros y los resultados que un modelo planteado puede traer consigo sin tener que esperar a que suceda en la realidad, ya que estos resultados pueden ser tanto positivos como negativos y ninguna empresa quiere que sean negativos. Por tal motivo, es que se suele utilizar la simulación para reducir los riesgos de los proyectos o soluciones a implementar en los diversos negocios. (Altiok y Melamed, 2007, p.13)

\subsubsection{Pilares de la Sostenibilidad}

Los 3 pilares de la sostenibilidad se aplicaron por primera vez en el documento conocido como "Informe Brundtland" de 1987 fruto de la Comisión Mundial de Medio Ambiente y Desarrollo de las Naciones Unidas en 1983. A partir de la década de 1970, los científicos se comenzaron a dar cuenta que muchas de las acciones del ser humano estaban contaminando el medio ambiente y causando un impacto negativo sobre la naturaleza, lo cual generaba una pérdida de la biodiversidad terrestre.

Debido a estas reflexiones, se comenzó a tratar los tres pilares de la sostenibilidad "Ambiental, Económico y Social", para que así todas las empresas aspiren a integrar estos pilares en su cultura organizacional, para que todos sus proyectos y actividades se vean influenciados por esta metodología y así lograr los objetivos de una manera correcta con respecto a la sociedad, al medio ambiente y a la rentabilidad que toda empresa busca para crecer y ser exitosos.

Muchas compañías, actualmente, se enfocan principalmente en mejorar la rentabilidad de la compañía sin importar el medio de lograrlo. Debido a esto, los factores ambientales y sociales son olvidados, lo cual conlleva que estos sean contaminados y perjudicados negativamente por distintas acciones y residuos. 
Figura $N^{\circ}$ 35: Tres Pilares de la Sostenibilidad

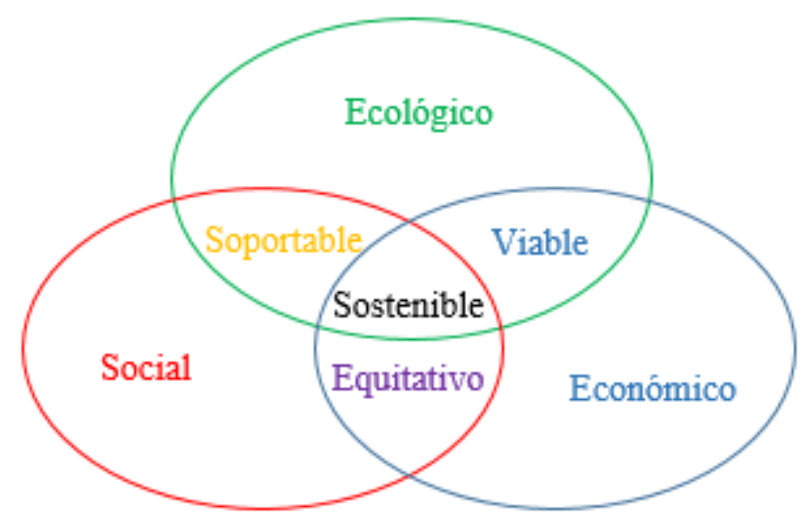

Fuente: Elaboración propia

\subsubsection{Pilar Económico}

El pilar económico es al que más importancia le prestan la mayoría de las empresas en la actualidad, ya que este pilar busca mejorar la rentabilidad y las utilidades de las compañías para que así estas puedan subsistir y crecer en el futuro.

Día a día, todos buscamos generar mayores ingresos y crecer profesionalmente para poder obtener una mejor calidad de vida y así poder superarnos personalmente. Sin embargo, muchos no son conscientes de que muchas de nuestras actividades pueden estar perjudicando directa o indirectamente a nuestro entorno, el cual está constituido por la sociedad y el ambiente que nos rodea.

\subsubsection{Pilar Ambiental}

El pilar ambiental busca la preservación de los recursos naturales y la biodiversidad del planeta tierra, algo que ha sido muy descuidado desde los inicios de la Revolución Industrial.

Esto es posible, siempre y cuando las empresas comiencen a tomar conciencia de sus efectos ante el medio ambiente. Después de haber reflexionado sobre sus contribuciones con el medio ambiente, las empresas deben analizar cada uno de sus procesos para revisar los insumos utilizados, la eficiencia y efectividad de sus procesos o maquinarias y principalmente analizar sus puntos de emisión hacia el medio ambiente. Las emisiones suelen ser gaseosas, líquidas o sólidas. 
Las gaseosas son producidas principalmente por la quema de combustible, evaporación de productos químicos, uso de aerosoles, fragmentación micrométrica de partículas que luego quedan suspendidas en el aire, etc.

La contaminación realizada en cuanto a los recursos hídricos, provienen de sus desagües y mal tratamiento de químicos utilizados en sus procesos productivos.

Los residuos sólidos emitidos por las empresas vienen a ser principalmente la basura que desechan día a día sin haber tenido la iniciativa de reciclarla y poder reducir su contaminación. Además, muchos de estos residuos son incinerados y esto contamina posteriormente al ambiente.

\subsubsection{Pilar Social}

El pilar social de la sostenibilidad se basa principalmente en el mantenimiento de la cohesión social con las personas de su entorno y la habilidad para poder conseguir objetivos comunes para contar con el apoyo de la sociedad.

Como fue mencionado anteriormente, estos pilares son de suma importancia para el correcto funcionamiento de una empresa, ya que sin ellos la empresa puede que no esté caminando a su máximo rendimiento. Por ejemplo, si no se cumpliera con el pilar social de la sostenibilidad, la población en algún momento podría revelarse contra la empresa por diversas actividades que la empresa haya realizado y estas no hayan sido aceptadas correctamente o posiblemente hayan causado daños colaterales a la población.

\subsubsection{Distribución de Planta}

\subsubsection{Definición}

La distribución de planta, es la ordenación física de los elementos tanto industriales como no industriales. Incluye tanto los espacios necesarios para el movimiento de materiales, almacenamiento, trabajadores y todas las otras actividades o servicios asociados a los procesos productivos o de servicio de una empresa. 
Es clave saber localizar estratégicamente cada una de las diversas áreas de la empresa para poder aprovechar al máximo los espacios disponibles, saber aprovechar la afluencia de personas, brindar comodidad a los trabajadores y a los clientes para que así todos se encuentren satisfechos con el servicio o trabajo y puedan rendir más eficientemente.

Una correcta distribución de un establecimiento puede determinar la eficiencia del servicio o proceso de la empresa, hasta determinar, a veces, la supervivencia de la misma.

Para este proyecto de Tesis, se evaluará la distribución de planta para encontrar las mejores zonas en donde se pueda instalar las baldosas PAVEGEN con la tecnología piezoeléctrica para poder conseguir el mejor aprovechamiento de la energía cinética generada por los clientes del servicio del tren eléctrico brindado por la institución AATE.

\subsubsection{Beneficios}

En este proyecto, el principal beneficio será la correcta distribución de las baldosas para aprovechar al máximo la energía cinética generada por los pasajeros y buscar el lugar óptimo para instalar la batería que almacenará toda la energía recaudada y generada por las baldosas. De esta manera, se garantizará la seguridad de los empleados con respecto al condensador que almacenará una gran cantidad de energía eléctrica y se podrá explotar al máximo las características de las baldosas para generar la mayor cantidad de energía renovable con un cierto número de pasajeros.

Además de estos beneficios mencionados, una correcta distribución de planta puede conllevar a:

- Reducción de riesgos de salud y aumento de la seguridad de los empleados y clientes.

- Simplificación de los servicios brindados.

- Incremento de la productividad de los operarios y del mismo servicio.

- Utilización eficiente del espacio.

- Reducción de la manipulación de los materiales.

- Flexibilidad de ajuste ante los cambios de condiciones. 
Como se puede ver, la distribución de planta es una herramienta sumamente útil para asegurar la máxima efectividad de las baldosas y la correcta distribución del establecimiento para mejorar el servicio brindado a los clientes.

\subsubsection{Gestión del Riesgo}

\subsubsection{Definición}

La gestión de los riesgos está destinada a poder identificar los riesgos, analizarlos y planificar una respuesta contra estos mismos. De esta manera, su objetivo principal es aumentar la probabilidad de los impactos positivos en los proyectos, y disminuir la probabilidad y el impacto de los eventos negativos en los proyectos. (PMBOOK)

Un riesgo es un evento o condición incierta que, de producirse, tiene un efecto positivo o negativo en uno o más objetivos de los proyectos. Por este motivo, la correcta gestión de los riesgos disminuye la probabilidad de falla del mismo. (PMBOOK)

Esta gestión se consigue mediante los siguientes pasos:

- Planificar la Gestión de los Riesgos.

- Identificar los Riesgos.

- Realizar un análisis cualitativo de los Riesgos.

- Realizar un Análisis cuantitativo.

- Planificar la Respuesta a los Riesgos.

- Controlar los Riesgos.

\subsubsection{Beneficios}

Aplicar una buena gestión de los riesgos en cualquier trabajo, proyecto o sector es de suma importancia, ya que este permitirá estar alerta a cualquier imprevisto que pueda ocurrir. De esta manera, la empresa ya contará con planes estratégicos definidos para combatir estos imprevistos que pueden perjudicar el bienestar del proyecto, de la misma empresa o de sus trabajadores. 


\subsubsection{Investigación de Operaciones}

\subsubsection{Definición}

Desde el advenimiento de la Revolución industrial, el mundo ha sido testigo de un crecimiento importante del tamaño y la complejidad de las organizaciones. Una parte esencial de este cambio revolucionario fue el gran aumento de la división del trabajo y la separación de las responsabilidades administrativas en las organizaciones, lo cual conllevo a que el aumento del grado de especialización traiga consigo problemas nuevos para las organizaciones. Con frecuencia, no siempre lo que es beneficioso para un área es beneficioso para las otras áreas de la empresa, ya que sus acciones pueden caminar hacia objetivos opuestos. Un problema relacionado es que, a medida que aumenta la complejidad y la especialización, se vuelve más difícil asignar los recursos disponibles a las diferentes actividades de la manera más eficaz para la organización como un todo. Debido a este tipo de problemas y la necesidad de encontrar la mejor solución para las empresas, se creó un ambiente propicio para el surgimiento de la INVESTIGACIÓN DE OPERACIONES. (Hillier y Lieberman, 2010, p1-2)

\subsubsection{Beneficios}

La Investigación de Operaciones (IO) se aplica a la problemática relacionada con la conducción y la coordinación de actividades en una organización. En esencia, la naturaleza de la organización es irrelevante, por lo cual la IO ha sido aplicada de manera extensa en áreas tan diversas como manufactura, transporte, construcción, telecomunicaciones, planeación financiera, cuidado de la salud, fuerzas armadas, servicios públicos, etc. Por tal motivo, la IO se puede aplicar para solucionar casi cualquier problemática que se pueda hallar en una empresa.

La IO incluye el término investigación, ya que utiliza un enfoque similar al que se aplica en las áreas científicas. Este método científico se utiliza para explorar los diversos problemas que deben ser enfrentados comenzando por la observación cuidadosa y la formulación del problema, lo cual incluye la recolección de datos pertinentes. En segundo lugar, se procede a construir un modelo científico, el cual generalmente se realiza matemáticamente, con el que se trata de abstraer la esencia del problema real. En esta etapa se propone una hipótesis de que el modelo será una representación tan precisa de las características esenciales de la situación, que permitirá que las conclusiones obtenidas en su solución, serán válidas también para resolver el 
problema de la manera más adecuada. Posteriormente, se llevan a cabo experimentos, los cuales permitirán probar la hipótesis planteada y modificarla si es necesario. (Hillier y Lieberman, 2010, p. 2-3)

En conclusión, la Investigación de Operaciones permitirá encontrar soluciones óptimas para los diversos problemas que se puedan presentar, para así poder corroborar que las decisiones tomadas sean las más adecuadas para garantizar el éxito del proyecto.

\subsubsection{Software Lingo}

Lingo es una herramienta completa diseñada para llevar a cabo la construcción y la solución lineal, no lineal (convexo y no convexo / Global), cuadrática, cuadrática restringida, segundo orden cónico, estocástico y modelos de optimización de enteros de manera más rápida, más fácil y más eficiente. LINGO ofrece un paquete completamente integrado que incluye un potente lenguaje para expresar los modelos de optimización, un ambiente con todas las funciones para los problemas de construcción y edición, y un conjunto de solucionadores rápidos incorporados.

Figura $N^{\circ}$ 36: Software Lingo 


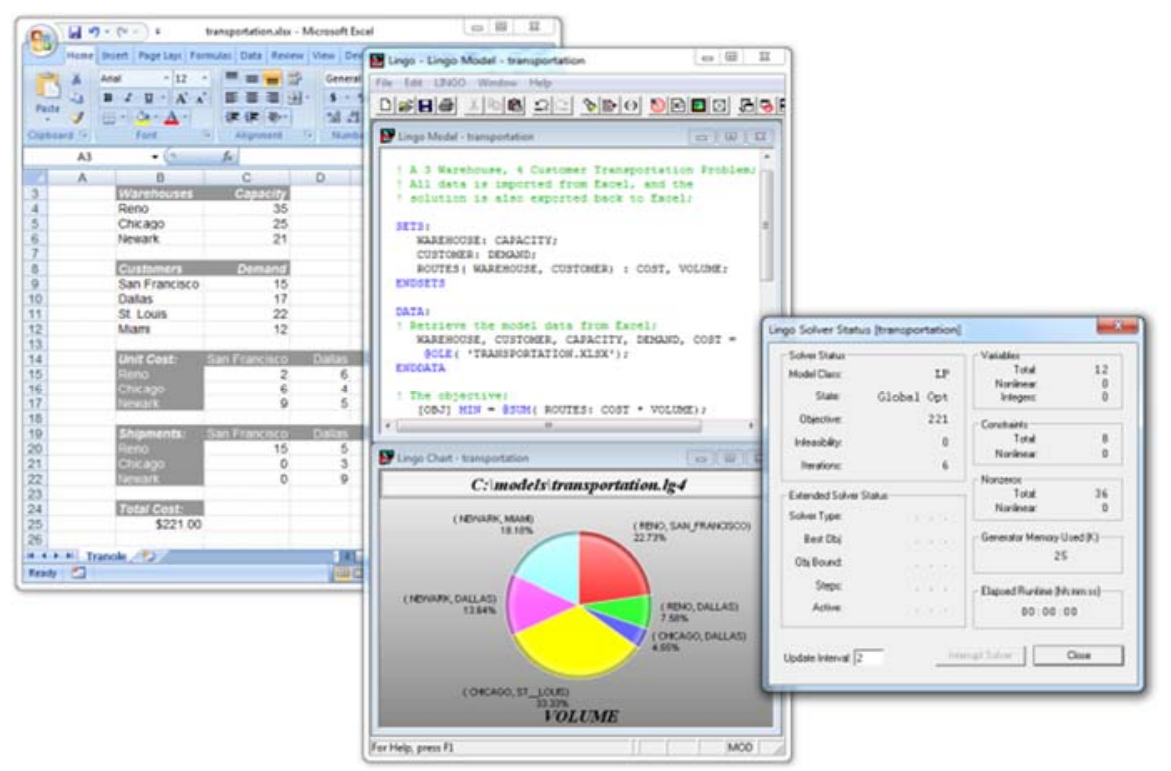

Fuente: Lingo

\subsubsection{Beneficios}

- Modelación de fácil expresión:

- LINGO ayuda a reducir el tiempo de desarrollo del modelo, ya que le permite formular sus problemas lineales, no lineales y enteros rápidamente en una forma muy fácil de leer. El lenguaje de modelado del LINGO le permite expresar los modelos de una manera intuitiva directa utilizando sumas y variables con subíndices al igual que lo haría con lápiz y papel. Los modelos son más fáciles de construir, más fácil de entender, y, por lo tanto, más fácil de mantener.

- Convenientes opciones de datos:

- LINGO se toma el tiempo y la molestia de gestionar sus datos. Le permite construir modelos que importan información directamente de una base de datos y hojas de cálculo. Del mismo modo, LINGO puede exportar información de una solución hacia una base de datos u hoja de cálculo haciendo que se puedan generar informes más rápido en la aplicación de su elección. (Lindo Systems Inc., 2016).

- Solucionadores de gran alcance: 
- LINGO está disponible con un amplio conjunto de solucionadores rápidos incorporados para resolver programación lineal, no lineal (convexo y no convexo / Global), cuadrática, cuadrática restringida, segundo orden, estocástico y optimización entera. El usuario no tiene que especificar o cargar un programa de solución por separado, debido a que LINGO lee su formulación y selecciona automáticamente el más apropiado.

\subsubsection{Conclusiones}

A lo largo del desarrollo del primer Capítulo, se han tratado temas referentes a la situación energética del país y del mundo, la empresa AATE, la tecnología piezoeléctrica, entre otros. Se ha podido concluir que la situación energética tanto global como peruana viene siendo abastecida principalmente por combustibles fósiles, los cuales son recursos no renovables y se agotarán en el futuro, lo que conllevará a una inminente crisis energética, perjudicando seriamente a la sociedad. Teniendo conocimiento de este problema, es recomendable aprovechar las diferentes fuentes de energía que hay en nuestro entorno y mediante Energy Harvester (Recolectores de energía) transformarlas en energías renovables que puedan remplazar las convencionales, ya que este tipo de energía mitigará una futura escasez y contribuirá a la reducción de la contaminación ambiental.

Como se mencionó anteriormente y como se desarrollará en los siguientes capítulos, los costos operativos del tren eléctrico no son cubiertos en su totalidad por los pasajes pagador por los usuarios; por lo tanto, es necesario que el Estado peruano tenga que asumir la diferencia para cumplir con los pagos de concesión.

Por lo tanto, este proyecto de investigación se basará en analizar la factibilidad de instalar un sistema de generación de energía renovable, basado en la tecnología piezoeléctrica, en las estaciones del Tren Eléctrico de la Línea 1 de la ciudad de Lima, las cuales pertenecen a la institución Autoridad Autónoma del Sistema Eléctrico de Transporte Masivo de Lima y Callao; mediante la implementación de dicho proyecto, se busca reducir los costos energéticos de las estaciones y por ende sus costos operativos.

En el Capítulo 2 se desarrollará el diagnóstico del problema de manera específica, utilizando tanto datos recolectados por nosotros mismos, como información brindada por la empresa AATE. Además, se realizarán los cálculos necesarios para saber cuánto es que representan los 
costos energéticos de la estación del tren y qué impacto tendrá nuestra solución ante la empresa y la sociedad. 


\section{CAPÍTULO 2: DIAGNÓSTICO E IDENTIFICACIÓN DEL PROBLEMA}

\subsection{Diagnóstico General}

\subsubsection{Tendencias del Consumo Energético en Lima}

Como se mencionó en el capítulo anterior, en los últimos 10 años el país ha atravesado un importante crecimiento y desarrollo económico, lo cual está muy ligado al crecimiento de la demanda energética interna. Tanto así que en el periodo del 2003 al 2013 el producto bruto interno (PBI), la producción de electricidad y el consumo final nacional aumentaron en $86 \%$, 92\% y 92\% respectivamente. Para el año 2014 la energía consumida ya había aumentado un $5.38 \%$ con respecto al año 2013, mientras que el PBI siguió la misma tendencia con un $2.8 \%$ en el mismo periodo. Es así como se ve evidenciada la relación directamente proporcional que existe entre el crecimiento económico y el energético, tanto en producción como en consumo. Está proyectado que este crecimiento siga encaminado por su tendencia creciente, de manera que el consumo final de energía aumente entre un 65\% y el doble para el 2025 y la demanda eléctrica entre un $63 \%$ y 2.12 veces en escenarios de crecimiento del PBI de un $4.5 \%$ y $6.5 \%$ respectivamente.

La gráfica $\mathrm{N}^{\circ} 13$ presenta un resumen del crecimiento energético desde el 2003 hasta el 2025 donde se puede observar de manera más clara y objetiva la tendencia del consumo energético del país.

Es por este motivo que es necesario incursionar en diferentes alternativas de generación no convencional, para poder enfrentar el inminente creciente de la demanda energética del país e incluso una muy probable crisis energética. 
Gráfica $N^{\circ}$ 13: Tendencia del crecimiento energético 2003-2025

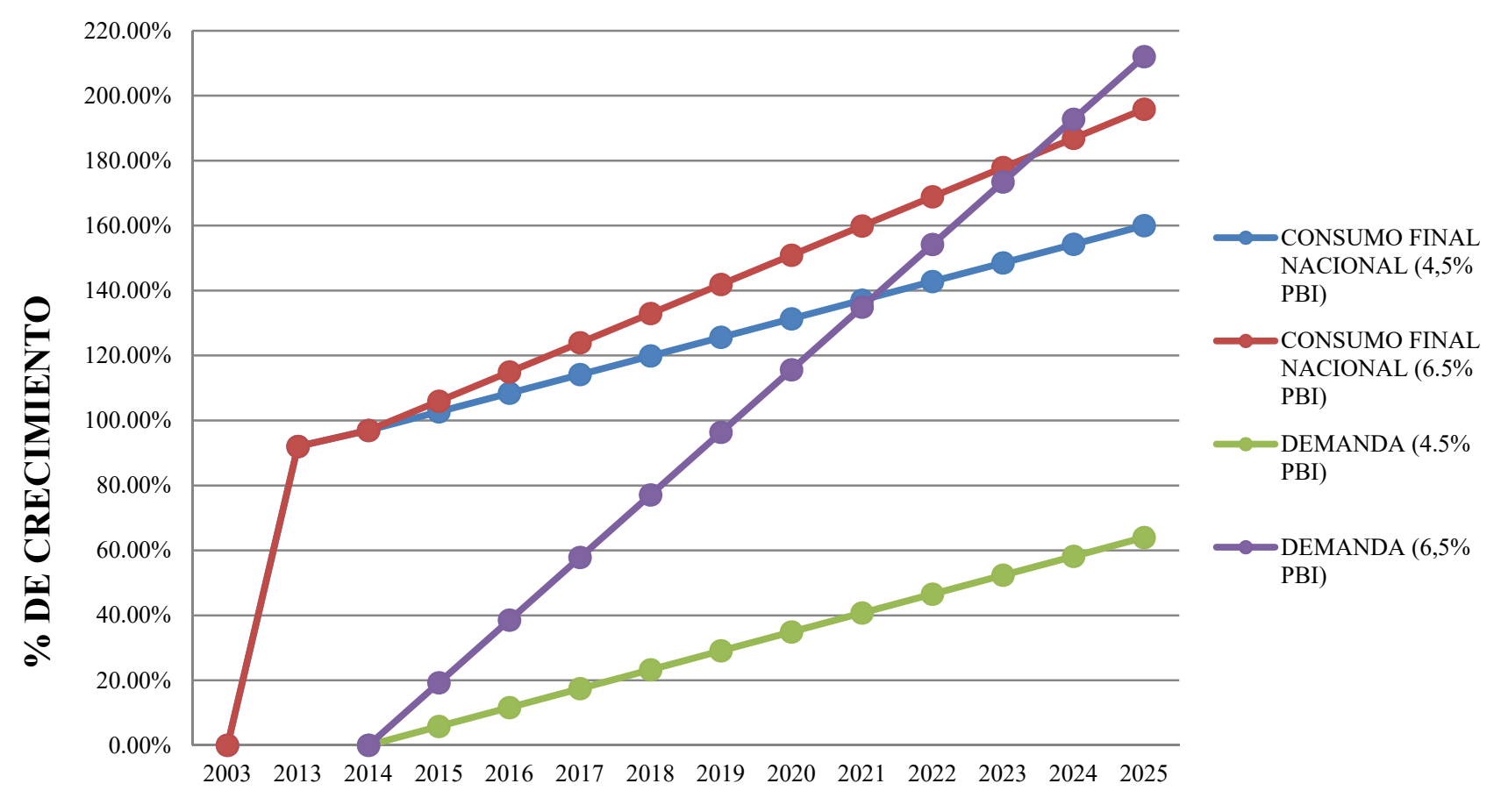

Fuente: Elaboración propia

\subsubsection{El Estado Peruano frente a las Energías Renovables}

El Estado peruano promueve la inversión de las empresas en generación de electricidad con el uso de energías renovables, con el objetivo de promover el aprovechamiento de los Recursos Energéticos Renovables (RER) y poder así proteger el medio ambiente.

Para poder promover la generación de esta energía, anualmente generan subastas para el Suministro de Energía al Sistema Eléctrico Interconectado (SEIN) y así contar con diversas empresas que presenten proyectos que utilicen los RER (OSINERGMIN, 2013). De esta manera, se podrá cumplir con el objetivo establecido por el Ministerio de Energía y Minas que busca que el 5\% del consumo nacional de electricidad sea cubierto por energías renovables que no sean hidroeléctricas (MINEM, 2010).

\subsubsection{Marco Legal}

Para la realización y el desarrollo del proyecto, es necesario respaldarse con el marco legislativo correspondiente al rubro de generación de recursos energéticos renovables (RER) y 
cuál es la postura del Estado frente a las mismas. Por tal motivo, se ha utilizado el respaldo del siguiente marco legal:

\begin{tabular}{|c|c|}
\hline Marco Legislativo & Descripción \\
\hline $\begin{array}{l}\text { Decreto Legislativo } \\
\qquad \mathrm{N}^{\circ} 1002\end{array}$ & $\begin{array}{l}\text { Promoción de la inversión para la generación de } \\
\text { electricidad con el uso de energías renovables. }\end{array}$ \\
\hline $\begin{array}{l}\text { Decreto Ley } \\
\mathrm{N}^{\circ} 25844\end{array}$ & Ley de concesiones eléctricas. \\
\hline $\begin{array}{l}\text { Decreto Legislativo } \\
\qquad \mathrm{N}^{\circ} 757\end{array}$ & $\begin{array}{l}\text { Aprueban ley Marco para el crecimiento de la } \\
\text { inversión Privada. }\end{array}$ \\
\hline
\end{tabular}

Para esto, han sido evaluados cada uno de los decretos con el fin de dar a conocer el panorama actual y plantear el escenario futuro del proyecto consecuente con el marco legal del Perú.

\section{$\underline{\text { Decreto Legislativo } N^{\circ} 1002 / D e c r e t o}$ Ley $N^{\circ} 25844:$}

El decreto expone como es que la economía peruana viene experimentando un incremento sostenido, que a su vez genera una mayor demanda de energía eléctrica, cuyas tasas han sido de $9,3 \%$ en 2006 y $10,8 \%$ en 2007 . Se estima que hasta el 2015 la tasa promedio anual de crecimiento será de 7,3\%. Los requerimientos de nueva oferta de generación para dicho año serán aproximadamente más de $3600 \mathrm{MW}$ (Decreto Legislativo $\mathrm{N}^{\circ} 1002$ ), para ello, la opción más limpia y beneficiosa es promover que una parte importante de dicha oferta sea con energías renovables, en lugar de la generación de electricidad con derivados del petróleo y gas natural, por ser estas fuentes no renovables y contaminantes.

Según el Artículo $1^{\circ}$ objeto del presente decreto, es promover el aprovechamiento de los Recursos Energéticos Renovables (RER) para mejorar la calidad de vida de la población y proteger el medio ambiente, mediante la promoción de la inversión en la producción de electricidad.

El Artículo $2^{\circ}$ resalta la importancia de las RER, siendo su uso de interés nacional y necesidad pública. Tanto así, que el ministerio de Energía y Minas establecerá cada 5 años un porcentaje objetivo en el que el consumo nacional de electricidad, debe ser proveniente de generación a 
base de RER (Sin considerarse en este porcentaje a las centrales hidroeléctricas, y siendo hasta un $5 \%$ en cada uno de los años del primer quinquenio).

Con respecto a la fijación de tarifas y la prima fijada por OSINERGMIN, según el Artículo $5^{\circ}$, la entidad efectuara los cálculos correspondientes considerando la clasificación de las instalaciones por categorías y grupos según las características de las distintas RER. La tarifa y la prima se determinarán de tal manera que garanticen una rentabilidad no menor a la establecida en el Artículo $7^{\circ}$ del Decreto Ley $\mathbf{N}^{\circ} \mathbf{2 5 8 4 4}$ (La tasa de actualización a utilizar en la presente Ley será de 12\% real anual, la cual solo podrá ser modificada por el Ministerio de Energía y Minas, y no podrá diferir en más de dos puntos porcentuales de la tasa vigente). (Artículo $79^{\circ}$ del Decreto Ley $N^{\circ} 25844$ )

La implementación de mecanismos y acciones correspondientes para el desarrollo de proyectos de investigación sobre energías renovables, según el Artículo 10² estará a cargo de El Consejo Nacional de Ciencia, Tecnología e Innovación Tecnológica (CONCYTEC), en coordinación con el Ministerio de Energía y Minas y los Gobiernos Regionales, promoviendo la participación de universidades, instituciones técnicas y organizaciones de desarrollo especializadas en la materia.

\section{Decreto Legislativo $N^{\circ} 757$ :}

En el Capítulo Tercero, Titulo VI: De la Seguridad Jurídica en la conservación del Medio Ambiente, el Estado promueve la participación de empresas o instituciones privadas en las actividades a la protección del medio ambiente y la reducción de la contaminación ambiental.

Según el Artículo 49 ${ }^{\circ}$, El Estado estimula el equilibrio racional entre el desarrollo socioeconómico, la conservación del ambiente y el uso sostenido de los recursos naturales, garantizando la debida seguridad jurídica a los inversionistas mediante el establecimiento de normas claras de protección del medio ambiente. Siendo las autoridades sectoriales competentes para conocer sobre los asuntos relacionados con la aplicación de las disposiciones del Código del Medio Ambiente y los Recursos naturales, según el Artículo 50, son los Ministerios o los organismos fiscalizadores de los sectores correspondientes a las actividades que desarrollan las empresas. 


\subsubsection{Situación del Transporte Público Limeño}

Actualmente, el sistema de transporte limeño tiende a mejorar y actualizarse, debido a la falta de transporte organizado en la sociedad limeña, ya que el parque automotor es sumamente grande, el tráfico es desorganizado, los servicios públicos de transporte no respetan las leyes, y las distancias recorridas tienden a ser cada vez mayores.

La mayoría de los peruanos utiliza los servicios de transporte público para ir a trabajar o estudiar. El 65\% de la población se transporta mediante el uso de combis o buses, mientras que solo el 13\% utiliza el metropolitano. Por otro lado, el 13\% utiliza carro, 5\% se moviliza caminando, 3\% lo realiza en taxi y solo el 1\% utiliza su bicicleta (GESTIÓN, 2013).

Las principales razones por las que la población limeña utiliza el transporte público responden al factor económico, la escasez de servicios de transporte de calidad como el tren eléctrico o el metropolitano y las largas distancias entre los centros de trabajo y las viviendas de los pobladores.

Durante el año 2015, el servicio de la Línea 1 del Tren Eléctrico ha tenido una demanda constante de 320,000.00 personas diarias aproximadamente, lo cual equivale al $3.31 \%$ de toda la población limeña.

\subsection{Diagnóstico Específico}

\subsubsection{Términos de la concesión del Tren Eléctrico}

La concesión de la Línea 1 del tren eléctrico la obtuvo Graña y Montero al culminar el segundo tramo, ya que ellos fueron también los que llevaron a cabo la construcción del segundo y tercer tramo de la Línea 1 del Tren para que este pudiera funcionar adecuadamente y se pudieran cumplir los objetivos de transportar a la población limeña. Estos habían sido trancados en el pasado por diversos problemas políticos en el Perú.

Cuando AATE le brinda la concesión a la Empresa G\&M, AATE pierde el control total que tenía sobre las estaciones, por lo que ahora solo se dedican a supervisar su correcto funcionamiento para garantizar un servicio de transporte óptimo y eficaz para la población limeña. 
Las condiciones bajo las que trabaja la empresa G\&M se rigen bajo el cumplimiento del contrato que estipula un kilometraje mínimo establecido por la institución AATE para que la población limeña pueda desplazarse de un distrito a otro. Es decir, se aplicará una penalización cuando no cumpla con el kilometraje pactado.

Los pagos realizados a G\&M por AATE son realizados trimestralmente para así asegurar el cumplimiento del kilometraje y fidelizar a G\&M para que mantenga la concesión, ya que los pasajes, actualmente, no cubren los costos operativos de este servicio de transporte.

Es necesario especificar que cada año se reevalúa el contrato con Graña y Montero para regular los precios y así salvaguardar los intereses de ambas empresas.

Durante el 2013 se tenían las siguientes metas con respeto a los kilómetros garantizados:

Tabla N 2: Condiciones de la Concesión con Graña y Montero 2013

\section{Condiciones de la Concesión con Graña y Montero 2013}

\begin{tabular}{|l|r|}
\hline Kilómetros anuales garantizados (cinco trenes). & 812,539 \\
\hline Kilómetros anuales garantizados (doce trenes). & $1,626,905$ \\
\hline Precio por kilómetro garantizado. & 73.53 \\
\hline Precio por Kilómetro adicional. & 27.38 \\
\hline
\end{tabular}

\section{Fuente: AATE}

Sin embargo, durante el 2015, el kilometraje garantizado con los doce trenes no era solo de $1,626,905.00 \mathrm{~km}$, más bien estos se convirtieron en 2, 603,453.00 km.

Actualmente, la institución AATE, debe reembolsar G\&M un monto de "S/.26,870,506.00 anualmente", pues los pasajes de los usuarios no llegan a cubrir los costos de operación que asume G\&M. 
Tabla $N^{\circ}$ 3: Balance económico del contrato de la Concesión con G\&M

\begin{tabular}{|c|c|c|c|}
\hline \multicolumn{3}{|c|}{ Balance económico del contrato de la Concesión (ANUAL) } \\
\hline \multicolumn{2}{|c|}{ Pago a GM } & 71.97 & Ingresos Recaudados \\
\hline $\begin{array}{c}\text { Pago por kilómetro } \\
\text { (S/./km) }\end{array}$ & $2,603,453$ & $\begin{array}{c}\text { Cantidad de pasajeros } \\
\text { promedio al mes }\end{array}$ & $8,916,667$ \\
\hline $\begin{array}{c}\text { Cantidad de pasajeros } \\
\text { promedio al año } \\
\text { garantizados }\end{array}$ & $107,000,004$ \\
\hline Pago Total (S/.) & $187,370,51.41$ & $\begin{array}{c}\text { Ingreso Total (S/.) } \\
\text { Faltante asumido por AATE (S/.) }\end{array}$ & $160,500,006$ \\
\hline Faltan & $\mathbf{2 6 . 8 7 0 . 5 0 6 , 4 1}$ \\
\hline
\end{tabular}

\section{FUENTE: AATE}

A continuación, se presenta un diagrama de flujo, el cual facilitará la visualización de los procesos que se deben llevar a cabo para que Graña y Montero reciba su paga por administrar el tren eléctrico.

\section{Gráfica $N^{\circ}$ 14: Flujograma del Proceso de Concesión}

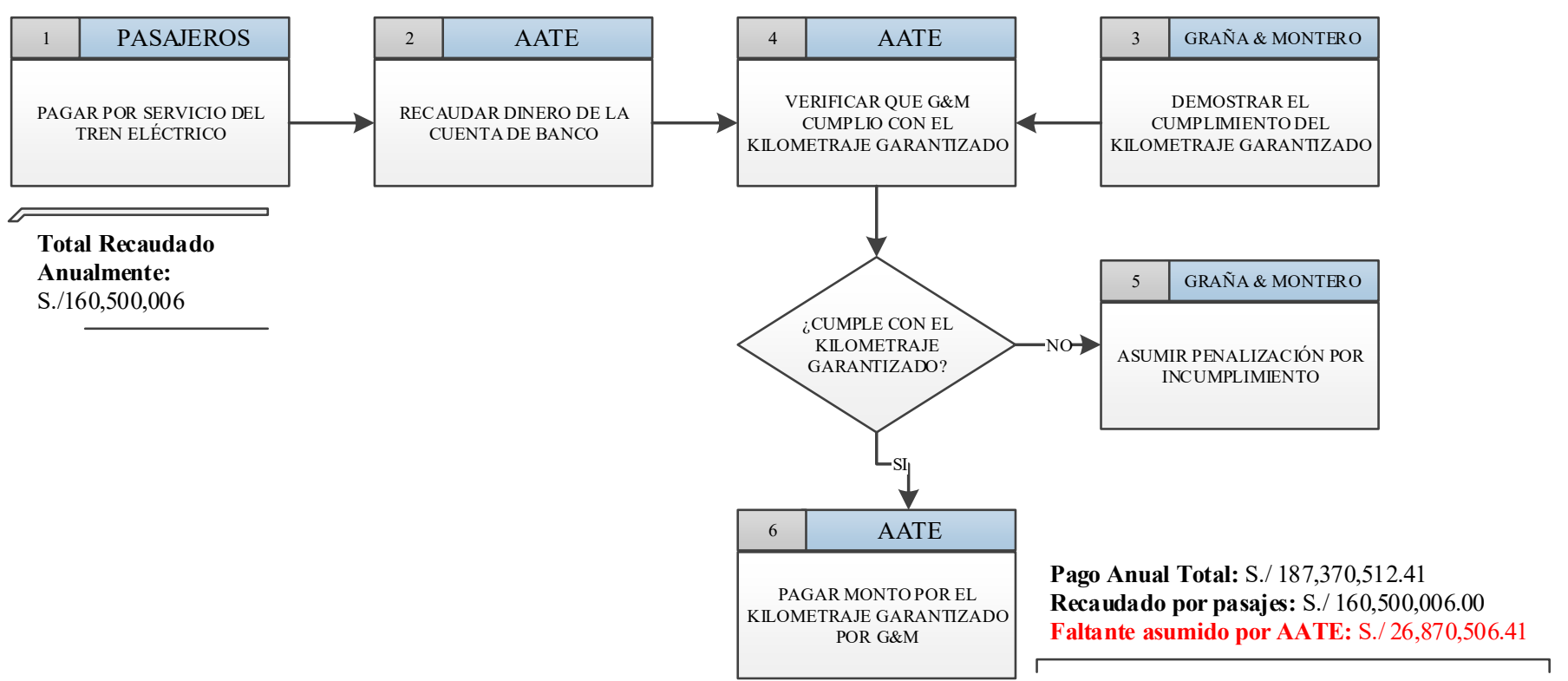




\subsubsection{Afluencia de personas en las estaciones del tren eléctrico}

En esta sección, se analizará la afluencia de personas en todas las estaciones del tren eléctrico, para así determinar cuál es el promedio diario de personas que transitan cada una de estas e identificar las más concurrentes.

Este análisis ha sido elaborado mediante la utilización de información brindada por la empresa AATE, como se podrá observar a continuación.

\section{Gráfica $N^{\circ}$ 15: Afluencia de Gente en las Estaciones del Tren Eléctrico}

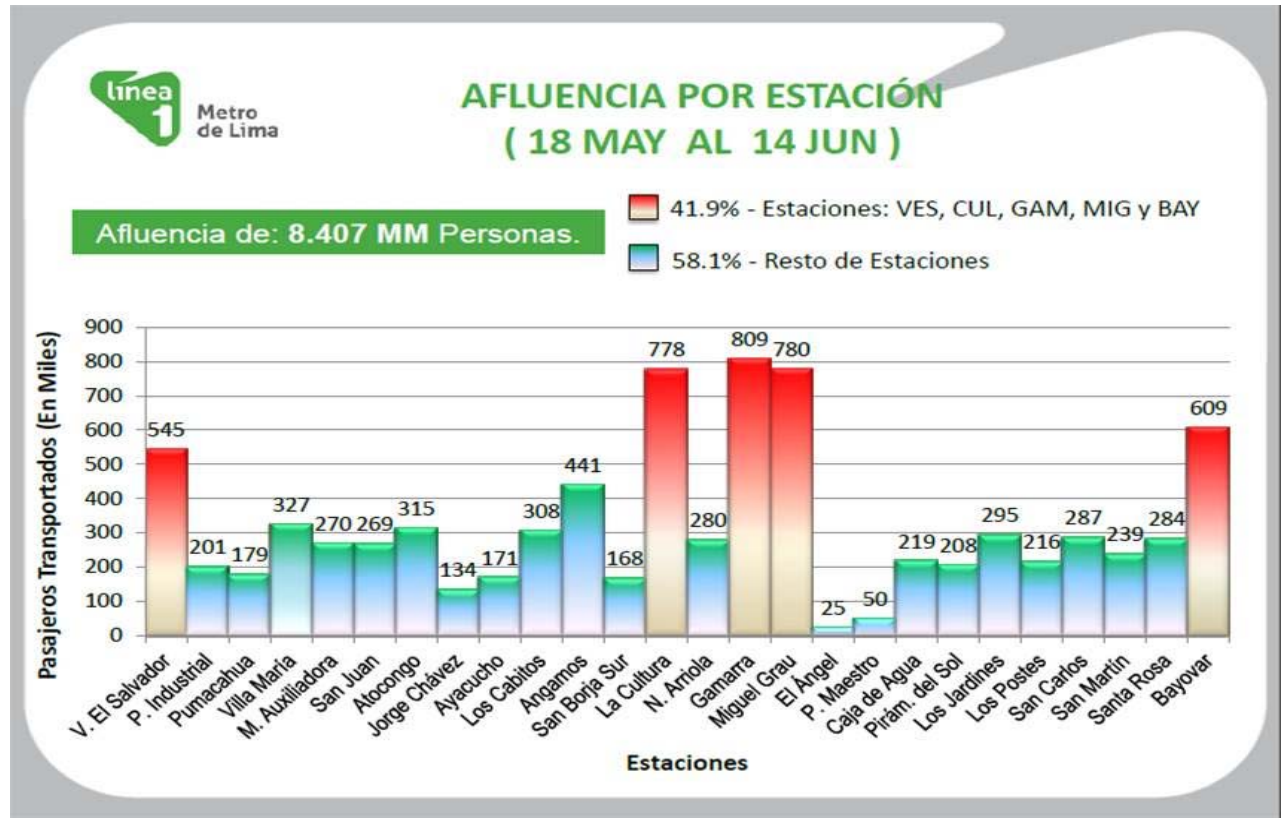

Fuente: AATE 
Tabla $N^{\circ}$ 4: Distribución de personas por Estación

\begin{tabular}{|r|c|c|c|c|}
\hline Afluencia por Estación & \multicolumn{3}{|c|}{ (18-May al 14Jun del 2015) en MM } \\
\hline & Estación & $\begin{array}{c}\text { Personas } \\
\text { en Miles }\end{array}$ & Porcentaje & $\begin{array}{c}\text { Prom. } \\
\text { Diario }\end{array}$ \\
\hline $\mathbf{1}$ & Gamarra & 809 & $9.623 \%$ & 31,115 \\
\hline $\mathbf{2}$ & Miguel Grau & 780 & $9.278 \%$ & 30,000 \\
\hline $\mathbf{3}$ & La Cultura & 778 & $9.254 \%$ & 29,923 \\
\hline $\mathbf{4}$ & Bayovar & 609 & $7.244 \%$ & 23,423 \\
\hline $\mathbf{5}$ & Villa El Salvador & 545 & $6.483 \%$ & 20,962 \\
\hline $\mathbf{6}$ & Angamos & 441 & $5.246 \%$ & 16,962 \\
\hline $\mathbf{7}$ & Villa María & 327 & $3.890 \%$ & 12,577 \\
\hline $\mathbf{8}$ & Atocongo & 315 & $3.747 \%$ & 12,115 \\
\hline $\mathbf{9}$ & Los cabitos & 308 & $3.664 \%$ & 11,846 \\
\hline $\mathbf{1 0}$ & Los Jardines & 295 & $3.509 \%$ & 11,346 \\
\hline $\mathbf{1 1}$ & San Carlos & 287 & $3.414 \%$ & 11,038 \\
\hline $\mathbf{1 2}$ & Santa Rosa & 284 & $3.378 \%$ & 10,923 \\
\hline $\mathbf{1 3}$ & Nicolás Arriola & 280 & $3.331 \%$ & 10,769 \\
\hline $\mathbf{1 4}$ & María Auxiliadora & 270 & $3.212 \%$ & 10,385 \\
\hline $\mathbf{1 5}$ & San Juan & 269 & $3.200 \%$ & 10,346 \\
\hline $\mathbf{1 6}$ & San Martin & 239 & $2.843 \%$ & 9,192 \\
\hline $\mathbf{1 7}$ & Caja de Agua & 219 & $2.605 \%$ & 8,423 \\
\hline $\mathbf{1 8}$ & Los postes & 216 & $2.569 \%$ & 8,308 \\
\hline $\mathbf{1 9}$ & Pirámide del Sol & 208 & $2.474 \%$ & 8,000 \\
\hline $\mathbf{2 0}$ & P. Industrial & 201 & $2.391 \%$ & 7,731 \\
\hline $\mathbf{2 1}$ & Pumacahua & 179 & $2.129 \%$ & 6,885 \\
\hline $\mathbf{2 2}$ & Ayacucho & 171 & $2.034 \%$ & 6,577 \\
\hline $\mathbf{2 3}$ & San Borja Sur & 168 & $1.998 \%$ & 6,462 \\
\hline $\mathbf{2 4}$ & Jorge Chávez & 134 & $1.594 \%$ & 5,154 \\
\hline $\mathbf{2 5}$ & Parque Maestro & 50 & $0.595 \%$ & 1,923 \\
\hline $\mathbf{2 6}$ & El Ángel & 25 & $0.297 \%$ & 962 \\
\hline & & $\mathbf{8 , 4 0 7}$ & & $\mathbf{3 2 3 , 3 4 6}$ \\
\hline
\end{tabular}

Fuente: Elaboración Propia 
Como se puede observar en la gráfica $\mathrm{N}^{\circ} 15$ y en la tabla $\mathrm{N}^{\circ} 4$, las estaciones con mayor afluencia de personas son Gamarra, Miguel Grau y La Cultura, con 31,115, 30,000 y 29,923 personas respectivamente. Para este proyecto, se tomará como piloto la estación La Cultura, por lo cual se analizará a detalle el comportamiento de su afluencia de entrada a lo largo de todo el año 2015 con información del promedio diario por mes, para así poder trabajar con datos más reales y precisos sobre la cantidad de pasajeros con la que cuenta dicha estación. 
Tabla N 5: Afluencia Promedio diaria de pasajeros en la Estación La Cultura durante el año 2015

\begin{tabular}{|c|c|c|c|c|c|c|c|c|c|c|c|c|}
\hline \multirow[b]{2}{*}{ Hora } & \multicolumn{12}{|c|}{ Afluencia promedio diaria de Pasajeros en la Estación La Cultura durante el año 2015} \\
\hline & Enero & Febrero & Marzo & Abril & Mayo & Junio & Julio & Agosto & Septiembre & Octubre & Noviembre & Diciembre \\
\hline 06 a.m. & 281 & 259 & 302 & 332 & 338 & 330 & 323 & 310 & 341 & 233 & 322 & 294 \\
\hline 07 a.m. & 774 & 789 & 867 & 913 & 914 & 903 & 865 & 875 & 955 & 615 & 819 & 769 \\
\hline 08 a.m. & 656 & 665 & 652 & 691 & 672 & 694 & 683 & 663 & 697 & 470 & 647 & 638 \\
\hline 09 a.m. & 683 & 665 & 680 & 663 & 660 & 666 & 641 & 663 & 653 & 444 & 649 & 651 \\
\hline 10 a.m. & 822 & 791 & 770 & 759 & 743 & 735 & 730 & 724 & 717 & 497 & 726 & 752 \\
\hline 11 a.m. & 903 & 899 & 867 & 880 & 868 & 854 & 848 & 854 & 858 & 566 & 834 & 847 \\
\hline 12 p.m. & 1,039 & 1,065 & 1,064 & 1,115 & 1,101 & 1,067 & 1,057 & 1,037 & 1,047 & 715 & 1,026 & 1,078 \\
\hline 01 p.m. & 1,135 & 1,168 & 1,340 & 1,479 & 1,421 & 1,390 & 1,154 & 1,224 & 1,337 & 873 & 1,258 & 1,303 \\
\hline 02 p.m. & 1,192 & 1,178 & 1,223 & 1,315 & 1,278 & 1,266 & 1,161 & 1,149 & 1,218 & 809 & 1,205 & 1,368 \\
\hline 03 p.m. & 1,250 & 1,280 & 1,276 & 1,334 & 1,330 & 1,368 & 1,249 & 1,252 & 1,299 & 880 & 1,256 & 1,424 \\
\hline 04 p.m. & 1,623 & 1,663 & 1,690 & 1,764 & 1,807 & 1,821 & 1,749 & 1,706 & 1,726 & 1,170 & 1,730 & 1,805 \\
\hline 05 p.m. & 2,781 & 2,788 & 3,042 & 3,140 & 3,340 & 3,402 & 3,198 & 3,077 & 3,065 & 2,084 & 2,957 & 2,900 \\
\hline 06 p.m. & 3,913 & 3,787 & 4,243 & 4,374 & 4,409 & 4,694 & 4,580 & 4,281 & 4,404 & 2,955 & 4,150 & 4,071 \\
\hline 07 p.m. & 4,232 & 4,250 & 4,393 & 4,445 & 4,369 & 4,544 & 4,647 & 4,648 & 4,680 & 3,169 & 4,506 & 4,212 \\
\hline 08 p.m. & 3,714 & 3,547 & 3,639 & 3,834 & 3,784 & 3,740 & 3,657 & 4,031 & 3,759 & 2,654 & 3,647 & 3,564 \\
\hline 09 p.m. & 3,538 & 3,536 & 3,781 & 4,114 & 4,065 & 4,024 & 4,031 & 4,268 & 4,124 & 2,718 & 4,020 & 4,096 \\
\hline $\begin{array}{c}\text { Prom. } \\
\text { Diario } \\
\text { mensual }\end{array}$ & 28,536 & 28,330 & 29,829 & 31,153 & 31,099 & 31,497 & 30,573 & 30,763 & 30,881 & 20,853 & 29,753 & 29,771 \\
\hline
\end{tabular}

Fuente: AATE 
Como se puede observar en la tabla de afluencia promedio diario de personas mostrada anteriormente, la afluencia promedio mensual varía un poco dependiendo de cada mes según la cantidad de días que tiene cada uno. Por tal motivo, se hallará el promedio exacto diario para así poder trabajar con el número más preciso posible en lo que ha de venir en este trabajo de investigación.

Tabla No 6: Afluencia Mensual y Anual de la Estación La Cultura
\begin{tabular}{|c|c|c|c|}
\hline Mes & $\begin{array}{c}\text { Promedio } \\
\text { Diario }\end{array}$ & $\begin{array}{c}\text { Número de } \\
\text { Días al mes }\end{array}$ & $\begin{array}{c}\text { Afluencia } \\
\text { Mensual }\end{array}$ \\
\hline Enero & 28,536 & 31 & 884,608 \\
\hline Febrero & 28,330 & 28 & 793,229 \\
\hline Marzo & 29,829 & 31 & 924,692 \\
\hline Abril & 31,153 & 30 & 934,575 \\
\hline Mayo & 31,099 & 31 & 964,075 \\
\hline Junio & 31,497 & 30 & 944,896 \\
\hline Julio & 30,573 & 31 & 947,748 \\
\hline Agosto & 30,763 & 31 & 953,660 \\
\hline Septiembre & 30,881 & 30 & 926,415 \\
\hline Octubre & 20,853 & 31 & 646,449 \\
\hline Noviembre & 29,753 & 30 & 892,597 \\
\hline Diciembre & 29,771 & 31 & 922,886 \\
\hline \multicolumn{2}{|c|}{ TOTAL } & 365 & $\mathbf{1 0 , 7 3 5 , 8 3 0}$ \\
\hline
\end{tabular}

\section{Fuente: Elaboración propia}

A continuación, se procederá a hallar el promedio diario anual de la estación con los datos hallados en la tabla anterior.

$$
x=\frac{10,735,830}{365}=29,413
$$


La estación del tren eléctrico La Cultura tiene una afluencia de ingreso promedio diaria de 29,413 personas, dato con el que se trabajará de aquí en adelante para los siguientes capítulos y subcapítulos.

\subsubsection{Selección de la Estación}

En este subcapítulo, para poder corroborar y sustentar la decisión tomada en el subcapítulo anterior, se señalarán las principales razones por las cuales se ha optado por elaborar el plan piloto en la Estación La Cultura localizada en el cruce de las avenidas Javier Prado y Aviación en la ciudad de Lima. No está de más decir que estas dos avenidas son sumamente importantes y transcurridas por la población limeña.

Esta estación ha sido seleccionada estratégicamente por las siguientes razones.

En primer lugar, cuenta con una afluencia promedio de 29,413 personas diarias, lo cual es una de las principales variables a considerar para obtener una mayor generación de energía mediante el aprovechamiento de su energía cinética.

En segundo lugar, esta estación cuenta con un solo punto de acceso, lo cual obliga a sus usuarios a movilizarse por un mismo lugar al momento de ingresar y al momento de salir. Esta distribución permite un mejor aprovechamiento de las baldosas PAVEGEN a instalar, ya que una misma baldosa aprovechará la energía cinética de las pisadas, tanto de las personas que entran como de las que salen, lo cual permite que la eficiencia y la utilización de las baldosas sea mayor de lo que sería si es que hubieran sido instaladas en una estación que cuente con dos o más accesos.

Por último, la estación La Cultura también fue seleccionada por motivos estratégicos en cuanto al marketing de la empresa y al de la misma energía renovable, estando ubicada adyacente al nuevo y remodelado Museo de la Nación, y frente al nuevo gran centro comercial La Rambla. Mediante su instalación en esta estación, se busca promover la utilización de energías renovables en la población limeña, para así poder mitigar la crisis energética del país.

Figura No 37: Vista exterior de la Estación La Cultura 


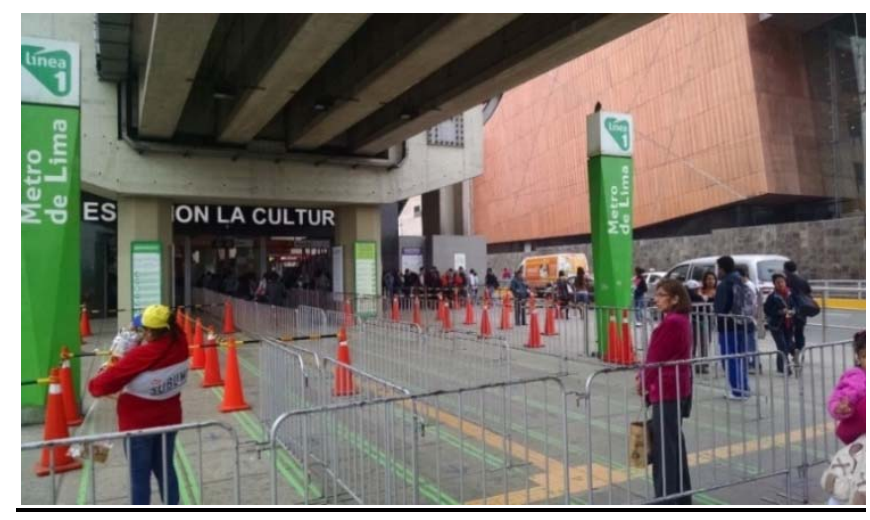

Fuente: Elaboración Propia

Figura $N^{\circ}$ 38: Entrada de la Estación La Cultura

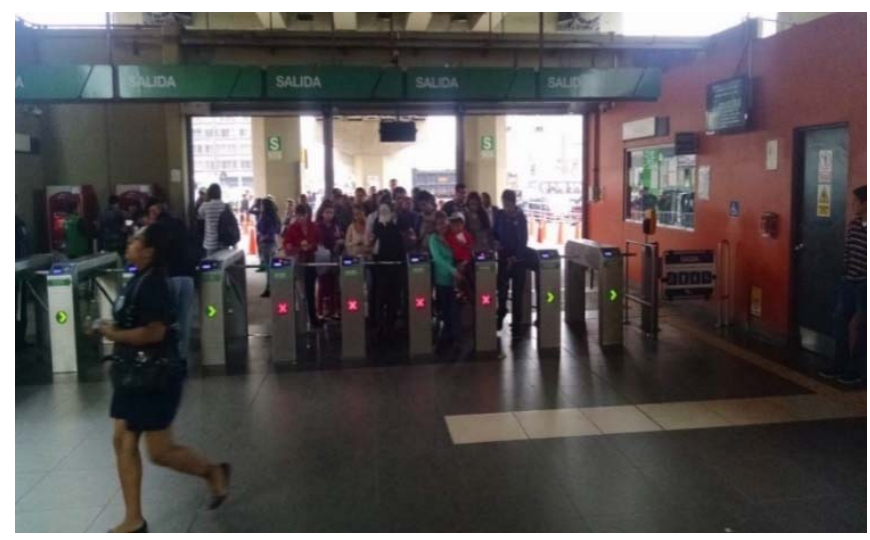

Fuente: Elaboración Propia

\subsubsection{Consumo eléctrico de la Estación La Cultura}

Inicialmente, la empresa AATE ha brindado información acerca de cómo está distribuida su estructura de costos. Para el costo energético anual, de todas las estaciones, tenemos un monto equivalente a S/. 3, 000,000, tal como se muestra en la Figura $\mathrm{N}^{\circ} 39$.

Figura N 39: Distribución de Costos Operativos G\&M 


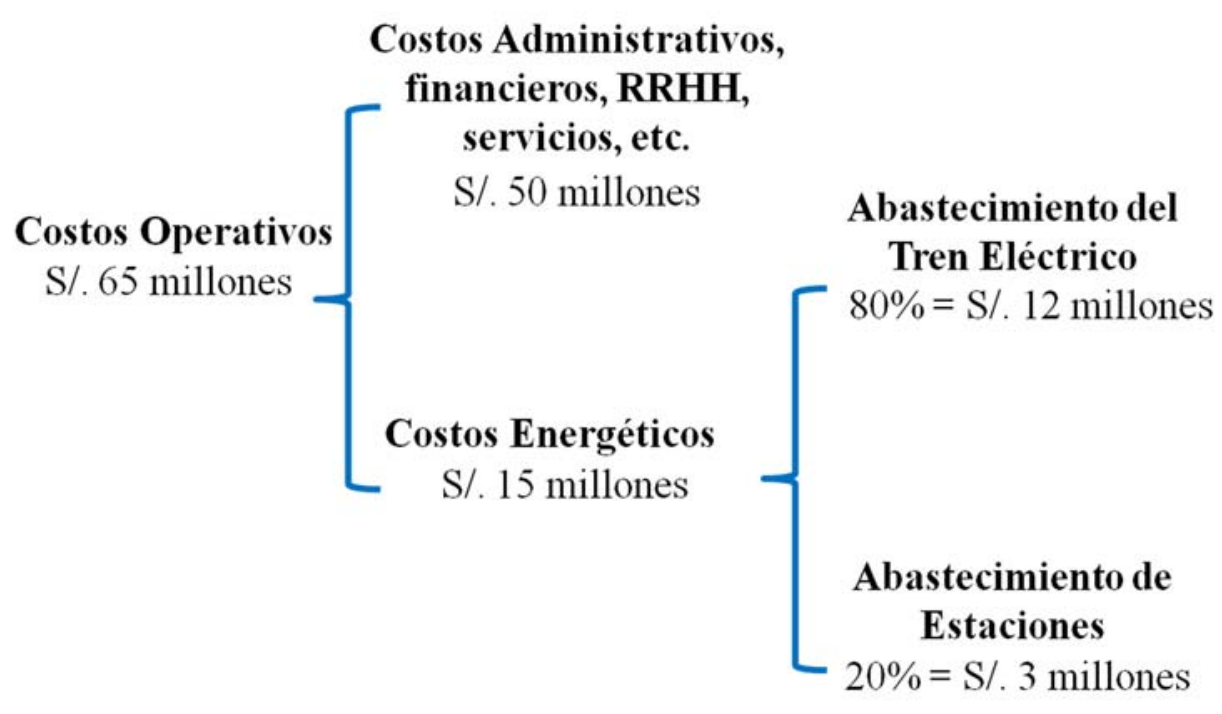

Fuente: AATE

Con fines académicos se tomará como piloto la implementación del proyecto en la Estación La Cultura ubicada en la Avenida Javier Prado con Aviación. Por tal motivo, se ha recopilado información sobre esta estación.

En primera instancia, la empresa AATE nos ha proporcionado información referida al consumo eléctrico que requiere la estación mencionada. Tal como se aprecia en la Tabla $\mathrm{N}^{\circ} 8$.

Para los siguientes cálculos de costos energéticos, se tomó en cuenta como tarifa base el costo de S/.0.4174 por kWh, según la tarifa ofrecida por EDELNOR para las empresas que cuentan con un consumo no mayor a 100kWh. 
Tabla $N^{\circ}$ 7: Tarifa para la venta de Energía Eléctrica

\begin{tabular}{|c|c|c|c|}
\hline \multirow[t]{10}{*}{ TARIFA BT5D : } & $\begin{array}{l}\text { TARIFA CON SIMPLE MEDICION DE ENERGIA .- } 1 E \\
\text { a) Para clientes con consumos menores o iguales a } 100 \mathrm{~kW} . \mathrm{h} \text { por mes } \\
0-30 \mathrm{~kW} . \mathrm{h}\end{array}$ & & \\
\hline & Cargo Fijo Mensual & S/Jcliente & 2.83 \\
\hline & Cargo por Energia & Cent.SIJJkW.h & 31.31 \\
\hline & 31 - 100 kW.h & & \\
\hline & Cargo Fijo Mensual & S/Jcliente & 2.83 \\
\hline & Cargo por Energia - Primeros $30 \mathrm{~kW} . \mathrm{h}$ & S/Jcliente & 9.39 \\
\hline & Cargo por Energia - Exceso de $30 \mathrm{~kW} . \mathrm{h}$ & Cent.SIJ/kW.h & 41.74 \\
\hline & b) Para clientes con consumos mayores a $100 \mathrm{~kW} . \mathrm{h}$ por mes & & \\
\hline & Cargo Fijo Mensual & S/Jcliente & 2.91 \\
\hline & Cargo por Energia Activa & Cent.SI/JkW.h & 42.95 \\
\hline
\end{tabular}

Fuente: Empresa de Distribución Eléctrica Lima Norte, EDELNOR

Tabla Nº 8: Consumo Eléctrico Estación La Cultura

\begin{tabular}{|l|r|}
\hline \multicolumn{2}{|c|}{ Estación La Cultura } \\
\hline Demanda promedio diaria de kW & 2,400 \\
\hline Demanda promedio Anual & 876,000 \\
\hline Costo Anual (S/.0.4174 por kWh) & $365,642.40$ \\
\hline
\end{tabular}

\section{Fuente: AATE}

Debido a que se desea verificar que la información brindada por la empresa ATEE sea correcta, se desarrolló una matriz energética que evalúa todos los puntos de consumo en la estación tanto en el área técnica como en área pública. Tal y como se muestra a continuación: 
Tabla No 9: Matriz Energética

\begin{tabular}{|c|c|c|c|c|c|c|c|c|c|c|c|c|c|c|c|c|c|c|c|c|c|c|c|c|c|c|c|c|c|c|c|c|c|c|c|}
\hline \multicolumn{36}{|c|}{ Análisis del consumo energético de la Estación La Cultura } \\
\hline & \multirow[b]{2}{*}{ Zona } & \multirow[b]{2}{*}{ Artefacto } & \multirow[b]{2}{*}{ Cantidad } & \multicolumn{2}{|c|}{ Potencia } & \multicolumn{24}{|c|}{ Hora } & \multicolumn{4}{|c|}{ Consumo } & \multirow{2}{*}{\begin{tabular}{|c|} 
Precio \\
kW-h \\
(C/ $)$
\end{tabular}} & \multirow{2}{*}{$\begin{array}{l}\text { Costo } \\
\text { Total }\end{array}$} \\
\hline & & & & (Watt) & $(\mathrm{kW})$ & 1 & 2 & 3 & 4 t: & 5 & 6 & 7 & 8 & 9 & 10 & 11 & 12 & 13 & 14 & 15 & 16 & 17 & 18 & 19 & 20 & 21 & 22 & 23 & 24 & Días & $\begin{array}{c}\begin{array}{c}\text { Horas } \\
\text { (diarias) }\end{array} \\
\end{array}$ & \begin{tabular}{|c|} 
Kw-h \\
(diarios)
\end{tabular} & $\begin{array}{c}\mathbf{k W}-\mathbf{h} \\
\text { (mensual) }\end{array}$ & & \\
\hline & Tablero T-AT-JPIA & Alumbrado & 173 & 25 & 0.03 & 0.0 & $0.0 \mathrm{c}$ & 0.0 & 0.00 & .011 & 1.0 & 1.0 & 1.0 & 0.0 & 0.0 & 0.0 & 0.0 & 0.0 & 0.0 & 0.0 & 0.0 & 0.5 & 1.0 & 1.0 & 1.0 & 1.0 & 1.0 & 0.5 & 0.0 & 30 & 9.0 & 38.93 & $1,167.75$ & 0.42 & 487.42 \\
\hline & Tablero T-AT-JP1B & Alumbrado & 65 & $\frac{25}{550}$ & 0.03 & 0.0 & $0.0 \mathrm{c}$ & & & $\begin{array}{ll}0.01 \\
0.016\end{array}$ & 1.0 & 1.0 & \begin{tabular}{|l|l}
1.0 \\
0.
\end{tabular} & 0.0 & \begin{tabular}{|c|c|}
0.0 \\
0.6
\end{tabular} & \begin{tabular}{|l|l|}
0.0 \\
0.
\end{tabular} & \begin{tabular}{|c|c|}
0.0 \\
\end{tabular} & \begin{tabular}{|l|l|}
0.0 \\
0.
\end{tabular} & 0.0 & 0.0 & $\begin{array}{ll}0.0 \\
0.6\end{array}$ & \begin{tabular}{|l|l|}
0.5 \\
\end{tabular} & \begin{tabular}{|l|l}
0.0 \\
\end{tabular} & 1.0 & 1.0 & 1.0 & \begin{tabular}{|l|l|}
0.0 \\
\end{tabular} & \begin{tabular}{|l|l|}
0.5 \\
\end{tabular} & 0.0 & 30 & 9.0 & 14.63 & 438.75 & 0.42 & $\frac{183.13}{27048}$ \\
\hline & & Tomacorriente & 4 & 500 & 0.50 & $0.0 \mid$ & $0.0 \mathrm{c}$ & & 0.00 & & 0.6 & 0.6 & \begin{tabular}{|l|l|}
0.6 & \\
\end{tabular} & 0.6 & \begin{tabular}{|c|c|}
0.6 & \\
\end{tabular} & \begin{tabular}{|l|l|}
0.6 & \\
\end{tabular} & \begin{tabular}{|l|l|}
0.6 & \multicolumn{1}{|c|}{} \\
\end{tabular} & \begin{tabular}{|l|l|}
0.6 & \\
\end{tabular} & 0.6 & 0.6 & \begin{tabular}{|c|c|}
0.6 \\
\end{tabular} & \begin{tabular}{|l|l|}
0.6 \\
\end{tabular} & 0.6 & 0.6 & 0.6 & \begin{tabular}{|c|}
0.6 \\
\end{tabular} & \begin{tabular}{|l|l|}
0.6 & \\
\end{tabular} & \begin{tabular}{|l|l|}
0.6 & \\
\end{tabular} & 0.0 & 30 & 10.8 & 21.60 & 648.00 & 0.42 & 270.48 \\
\hline & & Tomacorriente Industrial & 3 & 4,000 & 4.00 & 0.0 & $0.0 \mathrm{c}-2 \mathrm{c}-\mathrm{c}$ & 0.0 & 0.00 & 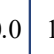 & 1.0 & 1.0 & 1.0 & 1.0 & 1.0 & 0.5 & 0.5 & 1.0 & 1.0 & 0.5 & 0.5 & 0.5 & 0.0 & 1.0 & 1.0 & 0.5 & 0.5 & 0.5 & 0.0 & 30 & 13.0 & 156.00 & $4,680.00$ & 0.42 & $1,953.43$ \\
\hline & Tablero T-AP-JP2A & \begin{tabular}{|c|c|c|} 
Tomacorriente Industrial \\
$380 \mathrm{~V}$
\end{tabular} & 3 & 10,000 & 10.00 & 0.0 & $0.0 \mathrm{c}$ & 0.0 & 0.00 & $\begin{array}{ll}0 & 1 \\
\end{array}$ & 1.0 & 1.0 & 1.0 & 1.0 & 1.0 & 0.5 & 0.5 & 1.0 & 1.0 & 0.5 & 0.5 & 0.5 & 0.0 & 1.0 & 1.0 & 0.5 & 0.5 & 0.5 & 0.0 & 30 & 13.0 & 390.00 & $11,700.00$ & 0.42 & $4,883.58$ \\
\hline & & Ventilador Eléctrico 4HP & 2 & 2,983 & 2.98 & 0.0 & 0.00 & 0.0 & 0.00 & $.0 \mathrm{c}$ & 0.0 & 1.0 & 1.0 & 1.0 & 1.0 & 1.0 & 1.0 & 1.0 & 1.0 & 1.0 & 1.0 & 1.0 & 1.0 & 1.0 & 1.0 & 0.0 & 0.0 & 0.0 & 0.0 & 30 & 14.0 & 83.52 & $2,505.55$ & 0.42 & $1,045.82$ \\
\hline & & \begin{tabular}{l|l} 
Extractor $0.25 \mathrm{hp}$ \\
Tomacorriente
\end{tabular} & $\frac{1}{4}$ & $\frac{186}{500}$ & 0.19 & \begin{tabular}{l|l}
0.0 & $(1$ \\
0.0 & $(10$
\end{tabular} & 0.00 & \begin{tabular}{l|l}
0.0 \\
0.0
\end{tabular} & $\begin{array}{l}0.00 \\
0.00\end{array}$ & $\begin{array}{ll}.0 & 0 \\
.0 & 6\end{array}$ & \begin{tabular}{l|l}
0.0 \\
0.6
\end{tabular} & \begin{tabular}{l|l}
0.0 \\
0.6
\end{tabular} & \begin{tabular}{|l|l|l|l|l|l}
1.0 & 0 \\
0.6 & \\
\end{tabular} & $\frac{1.0}{0.6}$ & \begin{tabular}{|l|l|l|l|l}
1.0 & 0 \\
0.6 & \\
\end{tabular} & \begin{tabular}{|l|l|l|l|l|l}
1.0 & 0 \\
0.6 & \\
\end{tabular} & \begin{tabular}{|l|l|l|l|l|l|}
1.0 & \\
0.6 & \\
\end{tabular} & \begin{tabular}{|l|l|}
1.0 \\
0.6
\end{tabular} & \begin{tabular}{l|l}
1.0 \\
0.6
\end{tabular} & 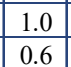 & 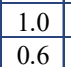 & \begin{tabular}{|l|l|}
1.0 \\
0.6
\end{tabular} & \begin{tabular}{|l|l|}
1.0 \\
0.6
\end{tabular} & $\begin{array}{ll}1.0 \\
0.6\end{array}$ & \begin{tabular}{l|l}
1.0 \\
0.6
\end{tabular} & \begin{tabular}{|l|}
0.0 \\
0.6
\end{tabular} & \begin{tabular}{|l|l|l|l|l|l}
0.0 & \\
0.6 &
\end{tabular} & \begin{tabular}{|l|l|l|l|l|l}
0.0 & \\
0.6 & \\
\end{tabular} & $\frac{0.0}{0.0}$ & $\frac{30}{30}$ & $\frac{13.0}{10.8}$ & $\begin{array}{ll}2.42 \\
21.60\end{array}$ & $\begin{array}{ll}72.70 \\
648.00\end{array}$ & $\begin{array}{ll}0.42 \\
0.42\end{array}$ & $\frac{30.35}{270.48}$ \\
\hline & & \begin{tabular}{|l}
$\begin{array}{c}\text { Tomacorriente Industrial } \\
220 \mathrm{~V}\end{array}$ \\
.
\end{tabular} & 2 & 4,000 & 4.00 & 0.0 & $0.0 \mathrm{c}$ & & 0.00 & & 1.0 & 1.0 & 1.0 & 1.0 & 1.0 & 0.5 & 0.5 & 1.0 & 1.0 & 0.5 & 0.5 & 0.5 & 0.0 & 1.0 & 1.0 & 0.5 & 0.5 & 0.5 & 0.0 & 30 & 13.0 & 104.00 & $3,120.00$ & 0.42 & $1,302.29$ \\
\hline & Tablero T-AP-JP2B & \begin{tabular}{|l} 
Tomacorriente Industrial \\
senV
\end{tabular} & 2 & 10,000 & 10.00 & \begin{tabular}{|c|c|c|c|c|}
0.0 & $c$
\end{tabular} & $0.0 \mathrm{c}-2 \mathrm{c}-\mathrm{c}$ & & 0.00 & 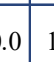 & 1.0 & 1.0 & 1.0 & 1.0 & 1.0 & 0.5 & 0.5 & 1.0 & 1.0 & 0.5 & 0.5 & 0.5 & 0.0 & 1.0 & 1.0 & 0.5 & 0.5 & 0.5 & 0.0 & 30 & 13.0 & 260.00 & $7,800.00$ & 0.42 & $3,255.72$ \\
\hline & & \begin{tabular}{|l} 
Ventilador Eléctrico $4 \mathrm{HP}$ \\
\end{tabular} & 2 & 2,983 & 2.98 & 0.0 & 0.00 & & 0.00 & & 0.0 & 1.0 & 1.0 & 1.0 & 1.0 & 1.0 & 1.0 & 1.0 & 1.0 & 1.0 & 1.0 & 1.0 & 1.0 & 1.0 & 1.0 & 0.0 & 0.0 & 0.0 & 0.0 & 30 & 14.0 & 83.52 & $2,505.55$ & 0.42 & $1,045.82$ \\
\hline & & Extractor $0.25 \mathrm{hp}$ & 1 & 186 & 0.19 & 0.0 & 0.00 & 0.0 & 0.00 & .00 & 0.0 & 0.0 & 1.0 & 1.0 & 1.0 & 1.0 & 1.0 & 1.0 & 1.0 & 1.0 & 1.0 & 1.0 & 1.0 & 1.0 & 1.0 & 0.0 & 0.0 & 0.0 & 0.0 & 30 & 130 & 2.42 & 72.70 & 0.012 & $\frac{10.002}{30.35}$ \\
\hline & & Alumbrado & 104 & 25 & 0.03 & $0.0 \mathrm{C}$ & $0.0 \mathrm{C}$ & \begin{tabular}{l|l}
0.0 \\
\end{tabular} & 0.00 & $\begin{array}{ll}01 & 1 \\
\end{array}$ & 1.0 & 1.0 & 1.0 & 0.0 & 0.0 & \begin{tabular}{|l|}
0.0 \\
\end{tabular} & \begin{tabular}{|l|}
0.0 \\
\end{tabular} & \begin{tabular}{|l|}
0.0 \\
\end{tabular} & 0.0 & \begin{tabular}{|l|}
0.0 \\
\end{tabular} & 0.0 & 0.5 & 1.0 & 1.0 & 1.0 & 1.0 & 1.0 & 0.5 & 0.0 & 30 & 9.0 & 23.40 & 702.00 & 0.42 & 293.01 \\
\hline & Tablero TE-AT-JPA & $\begin{array}{l}\text { Luminarias de } \\
\text { Evycuaciono }\end{array}$ & 3 & 30 & 0.03 & 0.0 & $0.0 \mathrm{c}$ & 0.0 & 0.00 & .00 & 0.0 & 0.0 & 0.0 & 0.0 & 0.0 & 0.0 & 0.0 & $\mid 0.0$ & 0.0 & 0.0 & 0.0 & 0.0 & 0.0 & 0.0 & 0.0 & $\mid 0.0$ & 0.0 & $\mid 0.0$ & 0.0 & 30 & 0.0 & 0.00 & 0.00 & 0.42 & 0.00 \\
\hline & & Alumbrado & 43 & 25 & 0.03 & 0.0 & $0.0 \mathrm{c}$ & 0.0 & 0.00 & .011 & 1.0 & 1.0 & 1.0 & 0.0 & 0.0 & 0.0 & 0.0 & 0.0 & 0.0 & 0.0 & 0.0 & 0.5 & 1.0 & 1.0 & 1.0 & 1.0 & 1.0 & 0.5 & 0.0 & 30 & 9.0 & 9.68 & 290.25 & 0.42 & 121.15 \\
\hline & Tablero TE-AT-JP IB & Aire Acondicionado & 2 & 6,150 & 6.15 & $0.0 \mathrm{C}$ & $\overline{0.0 C}$ & \begin{tabular}{l|l}
0.0 \\
\end{tabular} & 0.00 & $10 \mathrm{C}$ & \begin{tabular}{l|l}
0.0 \\
\end{tabular} & \begin{tabular}{l|}
0.0 \\
\end{tabular} & \begin{tabular}{|l|l|}
0.5 \\
\end{tabular} & 1.0 & \begin{tabular}{|l|l|}
0.0 \\
\end{tabular} & \begin{tabular}{|l|l|}
0.0 \\
\end{tabular} & \begin{tabular}{|l|l|}
1.0 \\
\end{tabular} & \begin{tabular}{|l|l|}
1.0 \\
\end{tabular} & 1.0 & \begin{tabular}{|l|l|}
1.0 \\
\end{tabular} & 0.0 & \begin{tabular}{|l|}
0.0 \\
\end{tabular} & \begin{tabular}{|l|}
1.0 \\
\end{tabular} & 1.0 & 1.0 & \begin{tabular}{|l|}
0.0 \\
\end{tabular} & \begin{tabular}{|l|l|}
0.0 \\
\end{tabular} & \begin{tabular}{|l|l|}
0.0 \\
\end{tabular} & 0.0 & 30 & 8.5 & 104.55 & $3,136.50$ & 0.42 & $1,309.18$ \\
\hline & & Luminarias de & 3 & 30 & 0.03 & $0.0 \mathrm{C}$ & $0.0 \mathrm{C}$ & 0.0 & 0.00 & 100 & 0.0 & 0.0 & \begin{tabular}{|l|l|}
0.0 \\
\end{tabular} & 0.0 & \begin{tabular}{|l|l|}
0.0 \\
\end{tabular} & \begin{tabular}{|l|l|}
0.0 \\
\end{tabular} & \begin{tabular}{|l|l|}
0.0 \\
\end{tabular} & \begin{tabular}{|l|l|} 
& 0.0 \\
\end{tabular} & 0.0 & 0.0 & 0.0 & 0.0 & 0.0 & 0.0 & 0.0 & 0.0 & \begin{tabular}{|l|l|}
0.0 \\
\end{tabular} & \begin{tabular}{|l|l|} 
& 0.0 \\
\end{tabular} & 0.0 & 30 & & 0.00 & 0.00 & 0.42 & 0.00 \\
\hline & & Alumb & 43 & 25 & 0.03 & 0.0 & $0.0 \mathrm{C}$ & 0.0 & 0.00 & $\begin{array}{ll}0 & 1 \\
\end{array}$ & 1.0 & 1.0 & \begin{tabular}{|l|l|}
1.0 \\
\end{tabular} & 0.0 & \begin{tabular}{|l|l|}
0.0 \\
\end{tabular} & \begin{tabular}{|l|l|}
0.0 \\
\end{tabular} & \begin{tabular}{|l|l|}
0.0 \\
\end{tabular} & \begin{tabular}{|l|l|}
0.0 \\
\end{tabular} & 0.0 & 0.0 & \begin{tabular}{|l|l|}
0.0 \\
\end{tabular} & \begin{tabular}{|l|l|}
0.5 \\
\end{tabular} & 1.0 & 1.0 & 1.0 & 1.0 & \begin{tabular}{|l|l|}
1.0 \\
\end{tabular} & \begin{tabular}{|l|l|}
0.5 \\
\end{tabular} & 0.0 & 30 & & & & 042 & 121.15 \\
\hline & Tablero TE-AT-JPB & Aire Acondicionado & 2 & 6,150 & 6.15 & 0.0 & $0.0 \mathrm{C}$ & 0.0 & 0.00 & 100 & 0.0 & 0.0 & 0.5 & 1.0 & \begin{tabular}{|l|l|}
0.0 \\
\end{tabular} & \begin{tabular}{|l|l|}
0.0 \\
\end{tabular} & \begin{tabular}{|l|l|}
1.0 \\
\end{tabular} & \begin{tabular}{|l|l|} 
& \\
\end{tabular} & 1.0 & 1.0 & \begin{tabular}{|l|l|}
0.0 \\
\end{tabular} & \begin{tabular}{|l|l|}
0.0 \\
\end{tabular} & 1.0 & 1.0 & 1.0 & \begin{tabular}{|c|} 
\\
0.0 \\
\end{tabular} & \begin{tabular}{|l|l|}
0.0 \\
\end{tabular} & \begin{tabular}{|l|l|}
0.0 \\
\end{tabular} & 0.0 & 30 & 8.5 & 104.55 & $3,136.50$ & 0.42 & $1,309.18$ \\
\hline & & $\begin{array}{l}\text { Luminarias de } \\
\text { Evacuación }\end{array}$ & 3 & 30 & 0.03 & 0.0 & $0.0 \mathrm{c}$ & 0.0 & 0.00 & .00 & 0.0 & 0.0 & 0.0 & 0.0 & 0.0 & 0.0 & 0.0 & 0.0 & 0.0 & 0.0 & 0.0 & 0.0 & 0.0 & 0.0 & 0.0 & \begin{tabular}{|l|} 
\\
\end{tabular} & 0.0 & 0.0 & 0.0 & 30 & 0.0 & 0.00 & 0.00 & 0.42 & 0.00 \\
\hline & to de & Alumbrado y & 33 & 25 & 0.03 & $0.0 \mid$ & $0.0 \mathrm{c}$ & 0.0 & 0.00 & . 0.01 & 1.0 & 1.0 & 1.0 & 0.0 & 0.0 & $\mid 0.0$ & $\mid 0.0$ & $\mid 0.0$ & 0.0 & $\mid 0.0$ & 0.0 & $\mid 0.5$ & 1.0 & 1.0 & 1.0 & 1.0 & $\mid 1.0$ & 0.5 & 0.0 & 30 & 9.0 & 7.43 & 222.75 & 0.42 & 92.98 \\
\hline & Bomba & $\begin{array}{r}\text { Tom } \\
\text { Bomb }\end{array}$ & 2 & 1,119 & 1.12 & 0.0 & 0.00 & & & & 1.0 & 1.0 & \begin{tabular}{l|}
1.0 \\
1.0
\end{tabular} & $\begin{array}{l}0.0 \\
1.0\end{array}$ & $\begin{array}{l}0.0 \\
1.0\end{array}$ & \begin{tabular}{|c|}
0.0 \\
1.0
\end{tabular} & \begin{tabular}{|c|}
0.0 \\
1.0
\end{tabular} & \begin{tabular}{|l|}
0.0 \\
1.0
\end{tabular} & \begin{tabular}{|l|}
0.0 \\
1.0
\end{tabular} & $\begin{array}{l}0.0 \\
1.0\end{array}$ & $\begin{array}{l}0.0 \\
1.0\end{array}$ & 1.0 & $\begin{array}{l}1.0 \\
1.0\end{array}$ & 1.0 & \begin{tabular}{|l|}
1.0 \\
1.0
\end{tabular} & $\begin{array}{l}1.0 \\
1.0\end{array}$ & \begin{tabular}{|c|}
1.0 \\
1.0
\end{tabular} & 0.0 & 0.0 & 30 & 9.0 & 1.43 & 1.140.91 & $\begin{array}{l}0.42 \\
0.42 \\
\end{array}$ & $\frac{92.98}{476.21}$ \\
\hline & ablero T-BA Bombas & Bombas de Agua & 2 & 1,119 & 1.12 & 0.0 & 0.00 & & 0.00 & $\begin{array}{ll}0 & 1 \\
\end{array}$ & 1.0 & 1.0 & \begin{tabular}{|l|}
1.0 \\
\end{tabular} & 1.0 & 1.0 & 1.0 & 1.0 & \begin{tabular}{|l|l|} 
\\
\end{tabular} & \begin{tabular}{ll|} 
& 0 \\
\end{tabular} & 1.0 & 1.0 & 1.0 & 1.0 & 1.0 & \begin{tabular}{|c|}
1.0 \\
\end{tabular} & 1.0 & 1.0 & \begin{tabular}{|l|}
0.0 \\
\end{tabular} & 0.0 & 30 & 17.0 & 38.03 & $1,140.91$ & 0.42 & 476.21 \\
\hline & Total del Á & Área Técnica & - & 127,173 & \begin{tabular}{|l|l|}
127.17 \\
\end{tabular} & & & & & & & & & & & & & - & & & & & & & & & & & & 30 & 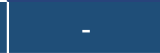 & $1,513.97$ & $45,419.07$ & 0.42 & $18,957.92$ \\
\hline & & Alumbrado & 450 & 10 & 0.01 & 0.0 & 0.00 & & 0.00 & $\begin{array}{ll}.0 & 1 \\
\end{array}$ & 1.0 & 1.0 & 1.0 & 0.0 & 0.0 & 0.0 & \begin{tabular}{|l|}
0.0 \\
\end{tabular} & \begin{tabular}{|l|} 
\\
0.0 \\
\end{tabular} & $\mid 0.0$ & 0.0 & 0.0 & 0.5 & 1.0 & 1.0 & 1.0 & 1.0 & 1.0 & \begin{tabular}{|l|}
0.5 \\
\end{tabular} & 0.0 & 30 & 9.0 & 40.50 & $1,215.00$ & 0.42 & 507.14 \\
\hline & & & 24 & 56 & 0.06 & 0.0 & 0.00 & 0.0 & 0.00 & .01 & 1.0 & 1.0 & 1.0 & 0.0 & 0.0 & 0.0 & \begin{tabular}{|l|}
0.0 \\
\end{tabular} & \begin{tabular}{|l|} 
\\
\end{tabular} & \begin{tabular}{|l|}
0.0 \\
\end{tabular} & 0.0 & 0.0 & 0.5 & 1.0 & 1.0 & 1.0 & 1.0 & 1.0 & 0.5 & & & & & & & \\
\hline & Tablero TE-AP-JP & Alum & 24 & 56 & 0.06 & 0.0 ( & $0.00 \mathrm{c}$ & (0.0 & 0.00 & $\frac{1.0] 1}{1}-3$ & 1.0 & 1.0 & 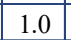 & 0.0 & 0.0 & 0.0 & 0.0 & 0.0 & 0.0 & 0.0 & 0.0 & 0.5 & 1.0 & 1.0 & 1.0 & 1.0 & 1.0 & 0.5 & & & & & & & 47 \\
\hline & & Alumb & 24 & 56 & 0.06 & 0.0 & 0.00 & 0.0 & 0.00 & .01 & 1.0 & 1.0 & 1.0 & 0.0 & \begin{tabular}{|l|}
0.0 \\
\end{tabular} & \begin{tabular}{|l|}
0.0 \\
\end{tabular} & \begin{tabular}{|l|}
0.0 \\
\end{tabular} & \begin{tabular}{|l|}
0.0 \\
\end{tabular} & 0.0 & 0.0 & \begin{tabular}{|l|}
0.0 \\
\end{tabular} & 0.5 & 1.0 & 1.0 & 1.0 & 1.0 & 1.0 & 0.5 & 0 & & & 12. $2>3$ & & & 47 \\
\hline & & Alumbr & 24 & 56 & 0.06 & 0.0 & 0.00 & 0.0 & $\overline{0.0} 0$ & 101 & 1.0 & 1.0 & 1.0 & 0.0 & 0.0 & \begin{tabular}{|l|}
0.0 \\
\end{tabular} & 0.0 & \begin{tabular}{|l|}
0.0 \\
\end{tabular} & 0.0 & 0.0 & 0.0 & 0.5 & 1.0 & 1.0 & 1.0 & 1.0 & 1.0 & 0.5 & 0 & 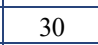 & 9 & 12 & 362 & & 151.47 \\
\hline & & Ascensor 1 & 1 & 10,000 & 10.00 & 0.0 & 0.00 & 0.0 & 0.00 & .00 & 0.0 & 0.1 & \begin{tabular}{|l|}
0.1 \\
\end{tabular} & 0.1 & \begin{tabular}{|l|}
0.1 \\
\end{tabular} & \begin{tabular}{|l|}
0.1 \\
\end{tabular} & \begin{tabular}{|l|}
0.1 \\
\end{tabular} & \begin{tabular}{|l|}
0.1 \\
\end{tabular} & \begin{tabular}{|l|}
0.1 \\
\end{tabular} & 0.1 & \begin{tabular}{|l|}
0.1 \\
\end{tabular} & 0.1 & 0.1 & 0.1 & \begin{tabular}{|l|}
0.1 \\
\end{tabular} & \begin{tabular}{|l|}
0.1 \\
\end{tabular} & \begin{tabular}{|l|}
0.1 \\
\end{tabular} & \begin{tabular}{|l|}
0.0 \\
\end{tabular} & 0 & 30 & 1.6 & 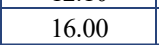 & & 0.4 & 200.35 \\
\hline & Tablero T-AP-ASC-JP & Ascensor 2 & 1 & 10,000 & 10.00 & 0.0 & 0.00 & & 0.00 & .00 & 0.0 & 0.1 & \begin{tabular}{|l|}
0.1 \\
\end{tabular} & 0.1 & \begin{tabular}{|l|}
0.1 \\
\end{tabular} & \begin{tabular}{|l|}
0.1 \\
\end{tabular} & \begin{tabular}{|l|}
0.1 \\
\end{tabular} & \begin{tabular}{|l|l|}
0.1 \\
\end{tabular} & \begin{tabular}{|l|}
0.1 \\
\end{tabular} & 0.1 & \begin{tabular}{|l|}
0.1 \\
\end{tabular} & \begin{tabular}{|l|}
0.1 \\
\end{tabular} & \begin{tabular}{|l|}
0.1 \\
\end{tabular} & 0.1 & \begin{tabular}{|l|}
0.1 \\
\end{tabular} & 0.1 & \begin{tabular}{|l|}
0.1 \\
\end{tabular} & \begin{tabular}{|l|}
0.0 \\
\end{tabular} & 0 & 30 & 1.6 & 16.0 & 48 & & 00.35 \\
\hline & & Alumbrado & 675 & 10 & 0.01 & $0.0 \mathrm{C}$ & 0.00 & \begin{tabular}{l|l}
0.0 \\
\end{tabular} & 0.00 & & 1.0 & 1.0 & \begin{tabular}{|l|l|}
1.0 \\
\end{tabular} & 0.0 & \begin{tabular}{|l|}
0.0 \\
\end{tabular} & \begin{tabular}{|l|l|}
0.0 \\
\end{tabular} & \begin{tabular}{|l|l|}
0.0 \\
\end{tabular} & \begin{tabular}{|l|}
0.0 \\
\end{tabular} & \begin{tabular}{|l|}
0.0 \\
\end{tabular} & \begin{tabular}{|l|l|}
0.0 \\
\end{tabular} & 0.0 & \begin{tabular}{|l|}
0.5 \\
\end{tabular} & 1.0 & 1.0 & \begin{tabular}{|l|}
1.0 \\
\end{tabular} & \begin{tabular}{|l|}
1.0 \\
\end{tabular} & \begin{tabular}{|l|}
1.0 \\
\end{tabular} & \begin{tabular}{|l|}
0.5 \\
\end{tabular} & 0.0 & 30 & 9.0 & 60.75 & $1,822.50$ & 0.42 & 760.71 \\
\hline & & \begin{tabular}{|c|} 
Alumbrado y \\
Tomacorreinte Anden 1
\end{tabular} & 24 & 56 & 0.06 & 0.0 ( & 0.00 & & 0.00 & & 1.0 & 1.0 & 1.0 & 0.0 & 0.0 & 0.0 & 0.0 & 0.0 & 0.0 & 0.0 & 0.0 & 0.5 & 1.0 & 1.0 & 1.0 & 1.0 & 1.0 & 0.5 & 0.0 & 30 & 9.0 & 12.10 & 362.88 & 0.42 & 151.47 \\
\hline & Tablero T-AP-IP1 & $\begin{array}{c}\text { Alumbrado y } \\
\text { Acrreinte }\end{array}$ & 24 & 56 & 0.06 & $0.0 \mid$ & $0.0 \mathrm{c}$ & 0.0 & 0.00 & & 1.0 & 1.0 & 1.0 & 0.0 & $\mid 0.0$ & 0.0 & $\mid 0.0$ & $\mid 0.0$ & 0.0 & $\mid 0.0$ & 0.0 & 0.5 & 1.0 & 1.0 & 1.0 & 1.0 & $\mid 1.0$ & 0.5 & 0.0 & 30 & 9.0 & 12.10 & 362.88 & 0.42 & 151.47 \\
\hline & 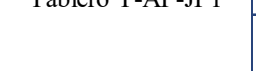 & Alumbrado y & 24 & 56 & 0.06 & $0.0 \mid$ & $0.0 \mathrm{c}$ & 0.0 & 0.00 & .0. 1 & 1.0 & 1.0 & 1.0 & 0.0 & $\mid 0.0$ & 0.0 & $\mid 0.0$ & $\mid 0.0$ & 0.0 & $\mid 0.0$ & 0.0 & 0.5 & 1.0 & 1.0 & 1.0 & 1.0 & $\mid 1.0$ & 0.5 & 0.0 & 30 & 9.0 & 12.10 & 362.88 & 0.42 & 151.47 \\
\hline & & A & 24 & 56 & 0.06 & 0.0 & $0.0 \mathrm{c}$ & 0.0 & $0.0 \mid 0$ & $\begin{array}{ll}1.0 & 1 \\
1 & \end{array}$ & 1.0 & 1.0 & 1.0 & 0.0 & 0.0 & $\mid 0.0$ & \begin{tabular}{|l|} 
\\
\end{tabular} & \begin{tabular}{|l|} 
\\
\end{tabular} & \begin{tabular}{|l|} 
\\
0.0
\end{tabular} & 0.0 & 0.0 & 0.5 & 1.0 & 1.0 & \begin{tabular}{|l|}
1.0 \\
\end{tabular} & 1.0 & 1.0 & 0.5 & 0.0 & 30 & 9.0 & 12.10 & 362.88 & 0.42 & 151.47 \\
\hline & & & 24 & 180 & 0.18 & 0.0 & 0.00 & 0.0 & 0.00 & .00 & 0.6 & 0.6 & 0.6 & 0.6 & 0.6 & 0.6 & 0.6 & 0.6 & 0.6 & 0.6 & 0.6 & 0.6 & 0.6 & 0.6 & \begin{tabular}{|l|}
0.6 \\
\end{tabular} & 0.6 & 0.6 & 0.6 & 0.0 & 30 & 10.8 & 46.66 & $1,399.68$ & 0.42 & 584.23 \\
\hline & Tablero T-AP-JP2 & \begin{tabular}{|l} 
Tomacorriente Industrial \\
$220 \mathrm{~V}$
\end{tabular} & 4 & 4,000 & 4.00 & 0.0 & 0.0 & & $0.0 \mid 0$ & & 0.5 & 0.5 & 0.5 & 0.5 & 0.5 & 0.5 & 0.5 & 0.5 & 0.5 & 0.5 & 0.5 & 0.5 & 0.5 & 0.5 & 0.5 & 0.5 & 0.5 & 0.5 & 0.0 & 30 & 9.0 & 144.00 & $4,320.00$ & 0.42 & $1,803.17$ \\
\hline & & Tomacorriente Industrial & 4 & 10,000 & 10.00 & 0.0 & 0.0 & 0.0 & 0.00 & $\begin{array}{ll}.0 & 1 \\
\end{array}$ & 1.0 & 1.0 & 1.0 & 1.0 & 0.5 & 0.5 & $\mid 0.5$ & 0.5 & 0.5 & 0.5 & 0.5 & 0.5 & $\mid 0.0$ & 1.0 & 1.0 & \begin{tabular}{|l|} 
\\
\end{tabular} & 0.5 & 0.5 & 0.0 & 30 & 11.5 & 460.00 & $13,800.00$ & 0.42 & $5,760.12$ \\
\hline & T $A \mathrm{P} F \mathrm{JP}$ & Escaler & 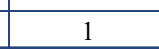 & 15,000 & 15.00 & 0.0 & 0.0 & 0.0 & - & .0 & 0.0 & 0.0 & \begin{tabular}{|l|}
0.0 \\
\end{tabular} & 0.0 & 1.0 & 1.0 & 1.0 & 1.0 & 1.0 & 1.0 & 1.0 & 1.0 & 0.0 & 0.0 & 0.0 & 0.0 & \begin{tabular}{|l|}
0.0 \\
\end{tabular} & \begin{tabular}{|l|}
0.0 \\
\end{tabular} & 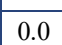 & 30 & 8.0 & 120.00 & $3,600.00$ & 0.42 & $1,502.64$ \\
\hline & I-AR-EVIVIT & Escalera Mecánica & 1 & 15,000 & 15.00 & 0.0 & 0.0 & 0.0 & 0.000 & $\begin{array}{l}1.0[1 \\
0\end{array}$ & 0.0 & 0.0 & \begin{tabular}{|c|c|} 
& 0.0 \\
\end{tabular} & 0.0 & 1.0 & \begin{tabular}{|l|l|l|l|l|l|l|l|l|} 
& 1.0 \\
\end{tabular} & 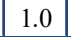 & \begin{tabular}{|l|l|} 
& \\
\end{tabular} & \begin{tabular}{|l|l|l|l|l|} 
& \\
\end{tabular} & 1.0 & 1.0 & \begin{tabular}{|l|l|l|l|l|l|l|} 
& \\
\end{tabular} & 0.0 & 0.0 & 0.0 & 0.0 & \begin{tabular}{|c|c|} 
& 0.0 \\
\end{tabular} & \begin{tabular}{|c|c|} 
\\
\end{tabular} & 0.0 & 30 & 8.0 & 120.00 & $3,600.00$ & 0.42 & 1,502.64 \\
\hline & Total del Á & Área Pública & & 132,322 & 132.32 & & & & & & & & & & & & & & & & & & & & & & & & & 30 & & $1,120.67$ & $33,620.22$ & 0.42 & $4,033.08$ \\
\hline & & XIMA POTENCIA & & & & 0 & 0 & 0 & 0 & 0 & 161 & 175 & 188 & 166 & 15? & 117 & 1 & 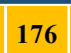 & 176 & 141 & 117 & 134 & 90 & 200 & 200 & 108 & 88 & 85 & 0 & - & & $2,634.64$ & - & - & $32,991.00$ \\
\hline
\end{tabular}


Según los resultados energéticos obtenidos de la matriz energética, se verifica que AATE ha entregado datos reales; pues la máxima potencia consumida es de $200 \mathrm{kWh}$ y el promedio es de $109,78 \mathrm{kWh}$.

Debido a esta pequeña diferencia de $9,78 \mathrm{kWh}$ entre los datos brindados por la empresa AATE y la data obtenida en la matriz energética, se procederá a utilizar los 109,78 kWh para los cálculos respectivos que se vayan a dar en este proyecto de investigación.

Tabla N 10: Consumo Eléctrico Estación La Cultura

\begin{tabular}{|l|r|}
\hline \multicolumn{2}{|c|}{ Estación La Cultura } \\
\hline Demanda promedio diaria de kW & $2,634.64$ \\
\hline Demanda promedio Anual & $961,643.60$ \\
\hline Costo Anual (S/.0.4174 por kWh) & $401,390.04$ \\
\hline
\end{tabular}

\section{Fuente: Elaboración Propia}

A continuación, se podrá observar la distribución diaria del consumo energético de la estación, lo cual permitirá visualizar cuales son las horas pico de consumo y cuáles son los consumos máximos del día. 
Gráfica $N^{\circ}$ 16: Consumo energético por horario Situación Actual

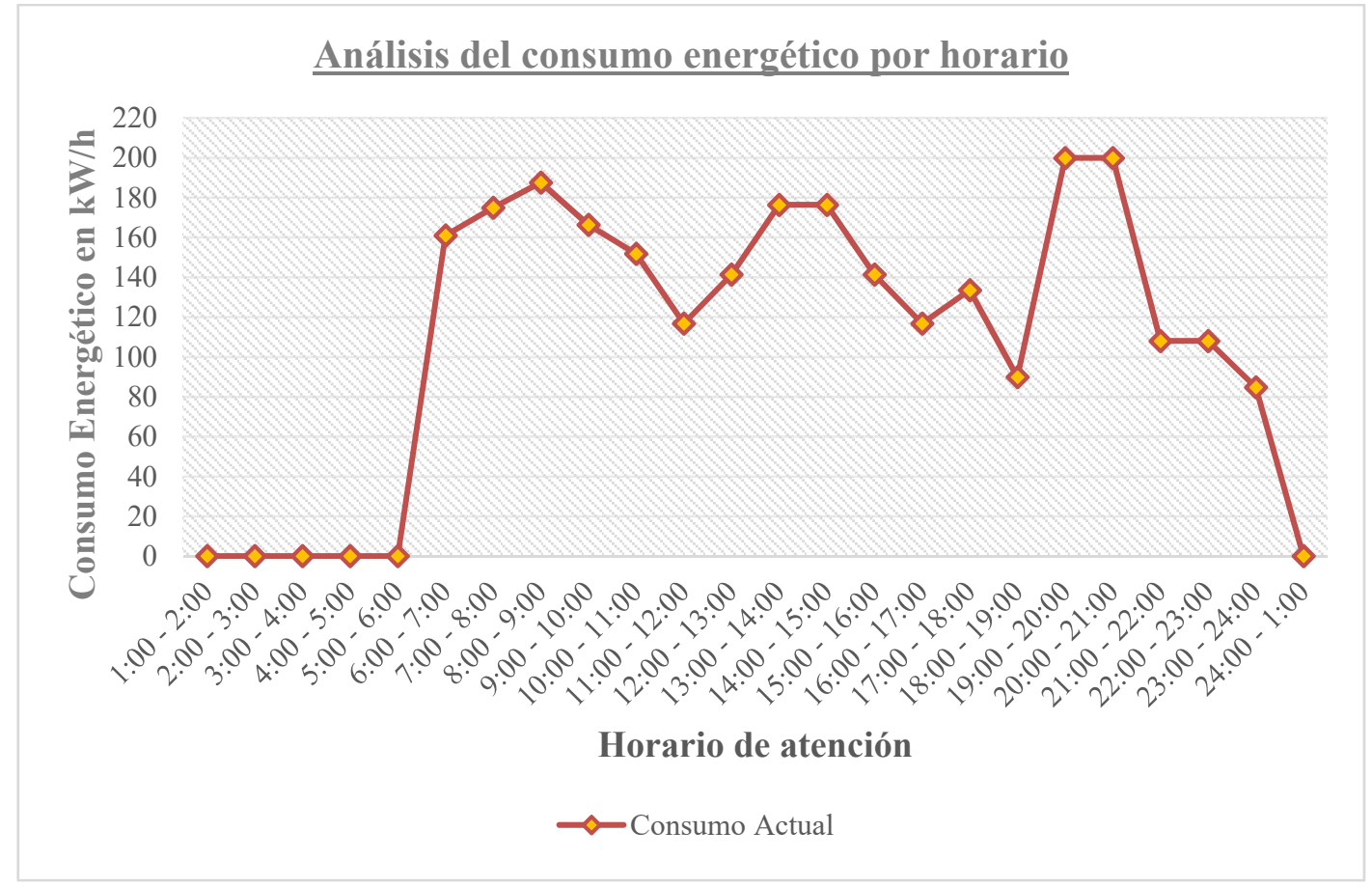

Fuente: Elaboración Propia

Como se puede observar en la gráfica anterior, la Estación La Cultura tiene un consumo promedio diario superior a los $110 \mathrm{kWh}$ cuando sus instalaciones están operativas. Durante las noches, el consumo de estas es mínimo.

Mediante la matriz energética elaborada, se puede validar el problema energético de la estación y su elevado consumo, lo cual se traduce en grandes costos energéticos.

\subsubsection{Recopilación de Datos}

Para poder validar adecuadamente los problemas que enfrenta la institución AATE, se realizaron dos tipos de encuesta, las cuales estuvieron dirigidas a las entidades representativas de AATE y al público general limeño que utiliza o tiene conocimiento del servicio del tren eléctrico. 


\subsubsection{Datos cualitativos}

\subsection{Análisis FODA de AATE}

\section{Fortalezas}

- Gran poder adquisitivo.

- Gran participación del mercado (alta afluencia de personas).

- Buena imagen al público.

- Priorización en la evaluación de riesgos.

- No existe competencia explicitamente directa.

- Establecimientos seguros.

\section{Oportunidades}

- Aprovechamiento de la alta afluencia de personas.

- Aprovechamiento de la tecnología piezoeléctrica.

- Reducir los costos energéticos de las estaciones.

- Reducir el monto asumido por la empresa AATE por el pago de la conseción.

\section{Análisis}

\section{FODA}

\section{Debilidades}

- Exceso de burocracia.

- Falta de un departamento de Investigación + Desarrollo (I+D).

- Sobrecostos debido al pago de conseción.

- Imposibilidad de subir los precios (limitación del mercado).

\section{Amenazas}

- Malas prácticas y mal manejo del negocio.

- Incumplir con los pagos de la conseción.

- Perder la conseción por incumplimiento del contrato.

En función del Análisis FODA previamente presentado, se definieron ciertas estrategias en las cuales estará basado el desarrollo del trabajo: 
Tabla $N^{\circ}$ 11: Estrategias FODA

\begin{tabular}{|c|c|c|}
\hline & Oportunidades & Amenazas \\
\hline Fortalezas & $\begin{array}{l}\text { Estrategias FO: APROVECHAR } \\
\text { La gran afluencia de personas permite } \\
\text { que se pueda sacar el máximo provecho } \\
\text { de la tecnología piezoeléctrica. } \\
\text { Mientras la imagen que muestran al } \\
\text { público sea buena y llamativa, irá } \\
\text { aumentando la afluencia de las personas. }\end{array}$ & $\begin{array}{l}\text { Estrategias FA: DEFENDER } \\
\text { - Evaluar constantemente los } \\
\text { riesgos de la implementación del } \\
\text { proyecto. }\end{array}$ \\
\hline Debilidades & $\begin{array}{l}\text { Estrategias DO: MOVILIZAR } \\
\text { El ahorro en los costos energéticos de las } \\
\text { estaciones, se puede destinar al pago de la } \\
\text { concesión. }\end{array}$ & $\begin{array}{l}\text { Estrategias DA: REFORZAR } \\
\text { - Se debe de reducir el exceso de } \\
\text { burocracia, ya que esto } \\
\text { desencadena malas prácticas y por } \\
\text { ende mal manejo del negocio } \\
\text { - Eliminar o reducir los sobrecostos } \\
\text { del pago de la concesión, ya que } \\
\text { generan que en ocasiones no se } \\
\text { pueda cumplir con ellos y se } \\
\text { podría perder la concesión por } \\
\text { incumplir el contrato. }\end{array}$ \\
\hline
\end{tabular}

\section{Fuente: Elaboración Propia}

\subsection{Entrevista personal a miembros de AATE}

En primer lugar, se realizó una entrevista personal a miembros de AATE, la cual brindó datos de alta importancia para poder identificar el problema del servicio del tren eléctrico y la posible validación de la propuesta de solución propuesta "Implementación de un Sistema de Energía Renovable mediante la utilización de la Tecnología Piezoeléctrica”.

La entrevista fue realizada a dos representantes de la institución AATE que serán mencionados a continuación: 
- Alejandro Ballesta: "Gerente de Operaciones".

- Humberto Covarrubias: "Especialista en Mantenimiento de Sistemas Eléctricos de la Unidad Gerencial de Operaciones y Mantenimiento".

Mediante la encuesta realizada a estos funcionarios, se pudo conocer que el principal problema de la institución eran los sobrecostos de sus operaciones y este tenía que ser subvencionado por el Estado Peruano para que este servicio de transporte pueda seguir funcionando. De lo contrario, el costo sería muy elevado y los pasajeros, la población limeña, no podrían pagarlo.

Además de ello, indicaron que la institución cuenta con un grupo especializado en la evaluación de proyectos de mejora, pero todas las propuestas que han surgido, en los últimos tiempos, han sido un tanto descabelladas y poco factibles.

Se les consultó si estaban a favor de la energía renovable y ambos representantes afirmaron su postura a favor acerca de ella. Consecutivamente, fueron consultados si tenían conocimientos acerca de la piezoelectricidad y ambos negaron haber escuchado sobre su existencia y su forma de generación de energía.

Al finalizar la encuesta, ambos representantes se encontraban a favor de la implementación de energía renovable en las estaciones del tren eléctrico para reducir sus costos energéticos. Adicionalmente, recomendaron que el proyecto fuera realizado en la Estación la Cultura por motivos estratégicos.

Esta encuesta, con sus respectivas preguntas y respuestas, se encuentra en la sección de anexos al final de este documento de investigación. (ANEXO 1).

\subsection{Identificación de STAKEHOLDERS}

Es importante conocer a las personas y entidades que se verán afectadas, beneficiadas o tienen un punto de relación con el desarrollo del proyecto y la tecnología que se pretende emplear.

1. Estado Peruano.

2. Sociedad Limeña.

3. Usuarios del servicio.

4. Trabajadores del tren eléctrico.

5. Luz del Sur (empresa que brinda de energía eléctrica a los alimentadores). 

6. Directivos de AATE.
7. Graña y Montero (G\&M).
8. Gestores del proyecto.

Tabla N 12: Gestión de Comunicaciones

\begin{tabular}{|c|c|c|}
\hline 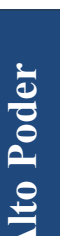 & $\begin{array}{l}\text { Mantener satisfechos } \\
\\
\text { - Estado Peruano. } \\
\text { - G\&M. }\end{array}$ & $\begin{array}{l}\text { Administrar de cerca } \\
\text { - Gestores del proyecto. } \\
\text { - Directivos de AATE. }\end{array}$ \\
\hline 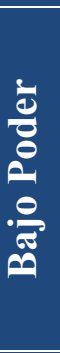 & Observar o Monitorear & \begin{tabular}{ll} 
& \multicolumn{1}{c}{ Informar } \\
- & Edelnor. \\
- & Sociedad limeña. \\
- & Usuarios del Servicio. \\
- & Trabajadores del tren \\
& eléctrico.
\end{tabular} \\
\hline & Bajo Interés & Alto Interés \\
\hline
\end{tabular}

\section{Fuente: Elaboración Propia}

\subsubsection{Datos Cuantitativos}

Para tener un mejor panorama al realizar el diagnóstico del problema, es necesario entender cuál es la percepción de la sociedad (usuarios) con respecto a los temas que competen a esta investigación. Para ello, se diseñó una encuesta con el fin de obtener información cuantificable, la cual permitiría darle un enfoque más certero al desarrollo del proyecto.

\subsection{Objetivos de la Investigación}

Los objetivos de este estudio giran en torno al entendimiento de la perspectiva y percepción de la sociedad con respecto a temas de interés para el proyecto, como:

o El servicio de transporte del Tren Eléctrico de Lima.

o Energías Renovables.

o La crisis energética en Lima.

Los objetivos específicos son: 
- Identificar el nivel de sensibilidad de la sociedad ante un cambio de precio del servicio del Tren Eléctrico de Lima.

- Cuantificar las opiniones de la sociedad con respecto a la situación energética de la ciudad de Lima.

- Identificar el nivel de aceptación de las energías renovables y su utilización en la ciudad.

- Segmentar los resultados por género y edad para diferenciarlos.

- Discernir los resultados del estudio y utilizarlos para evaluar, analizar y validar nuestro diagnóstico.

\subsection{Preguntas de Investigación}

Paralelamente a la encuesta realizada a los representantes de AATE, se realizó una encuesta utilizando la aplicación Formularios de Google, la cual fue publicada en diversas redes sociales para poder obtener información lo más verás posible. Esta encuesta no fue realizada solo a personas pertenecientes al nivel socioeconómico A o B, más bien fue distribuida especialmente para poder alcanzar usuarios del tren eléctrico y personas pertenecientes a los niveles $\mathrm{C}$ y $\mathrm{D}$, ya que son los principales usuarios de este medio de transporte.

La encuesta estuvo compuesta por 15 preguntas, con el objetivo de conocer la percepción de la sociedad limeña ante las energías renovables, la situación energética actual y futura del país, y el costo del servicio del Tren Eléctrico. Esta encuesta también busca segmentar las respuestas mediante edades, lo cual brinda información relevante a conocimientos y tendencias de las distintas generaciones de la población peruana. (ANEXO 2). El análisis de los resultados de esta encuesta se encuentra en los siguientes puntos de investigación de este proyecto.

Ambas encuestas fueron validadas por el profesor Alejandro Barbachan Callirgos y la profesora Claudia León Chavarri, quienes dictan, actualmente, el curso de "Ingeniería y Gestión Ambiental" en la Universidad Peruana de Ciencias Aplicadas. El profesor se encuentra cursando un MBA en CENTRUM CATÓLICA y la profesora cuenta con una Maestría de Ingeniería Civil y Ambiental del MIT con especialización en la calidad del agua. 
El profesor Alejandro comento que la encuesta estaba correctamente elaborada y la información recabada era útil para la evaluación del proyecto. Adicionalmente, sugirió que, para la próxima encuesta a realizar, se parafraseen algunas de las preguntas generando que estas sean más directas.

La profesora Claudia analizo ambas encuestas e indico que habían sido correctamente elaboradas para poder contrastarlas y obtener información de calidad para la elaboración y el respaldo del proyecto de factibilidad de la instalación de energía renovable mediante la utilización de energía piezoeléctrica.

\subsection{Justificación de la Investigación}

Como se mencionó anteriormente, las principales razones por las cuales se realizó este estudio, se enfocan en conocer la opinión de la sociedad con respecto a temas relacionados al proyecto de investigación y así esbozar un panorama más claro de este. A su vez, esto brindará un enfoque más real para el desarrollo del proyecto. También, se podrá evaluar, analizar y validar la información para dar soporte al sustento de posturas mencionadas en los puntos anteriores.

\subsection{Tamaño de Muestra a considerar}

Para poder determinar el número adecuado y necesario de personas que deben de responder la encuesta para este caso, se aplicara el método de Distribución Gaussiana. Este método se basa en la aplicación de la siguiente fórmula:

$$
n=\frac{N \times Z^{2} \times p \times(1-p)}{(N-1) \times e^{2}+Z^{2} \times p \times(1-p)}
$$

Donde:

$$
\begin{aligned}
& \mathrm{n}=\text { Tamaño de muestra } \\
& \mathrm{N}=\text { Tamaño del universo } \\
& \mathrm{Z}=\text { Desviación del valor medio aceptado (depende del nivel de confianza deseado) } \\
& \mathrm{e}=\text { Margen de error máximo admitido } \\
& \mathrm{p}=\text { Proporción deseada }
\end{aligned}
$$


Para nuestra investigación se considerará un universo de 29,413 personas, ya que, es la cantidad de personas que transcurren día a día por la estación La Cultura. Además, se admitirá como máximo un error del $5 \%$ con un intervalo de confianza del $90 \%$, por lo cual el valor de $\mathrm{Z}$ es de 1.645. Como se desconoce la proporción deseada para este caso, se utilizará una proporción deseada del $50 \%$.

A continuación, se realizarán los cálculos:

\begin{tabular}{|l|l|}
\hline \multicolumn{2}{|c|}{ Datos } \\
\hline N & 29,413 \\
\hline Z & 1.645 \\
\hline e & $5 \%$ \\
\hline$P$ & $50 \%$ \\
\hline
\end{tabular}

$$
n=\frac{29,413 \times 1.645^{2} \times 50 \% \times(1-50 \%)}{(29,413-1) \times 5 \%^{2}+1.645^{2} \times 50 \% \times(1-50 \%)}
$$

$$
\begin{gathered}
n=268,144 \\
n=269
\end{gathered}
$$

Según la aplicación del método Gaussiano, se obtuvo como resultado un tamaño de muestra de 269 personas para la investigación. Por lo tanto, se aplicará la encuesta a un mínimo de 269 personas y se evaluarán los resultados del análisis cualitativo.

\subsection{Reporte de resultados del análisis cuantitativo}

El estudio fue aplicado a 275 personas de la ciudad de Lima entre hombres y mujeres, segmentadas por edades. Donde se obtuvieron los siguientes resultados.

\section{Gráfica $N^{\circ}$ 17: Muestra evaluada para la Encuesta}




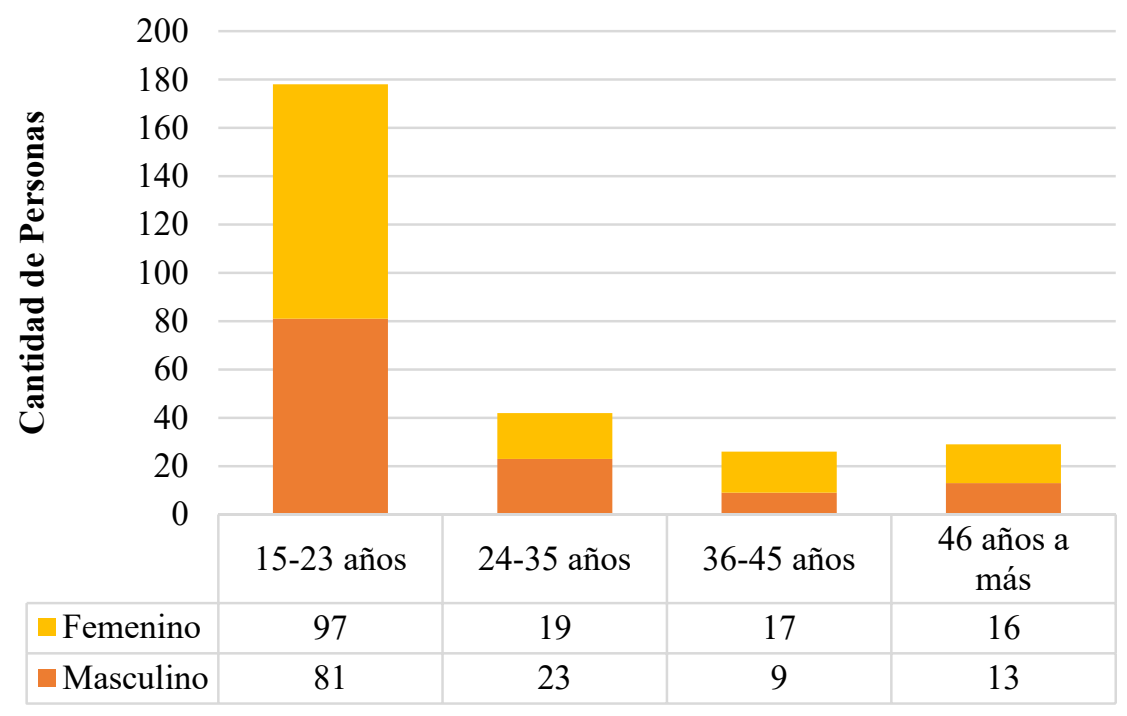

Fuente: Elaboración Propia

Como se puede observar, el universo de las 275 personas encuestadas se ve distribuido en 178 jóvenes de entre 15-23 años, 42 de entre 24-35 años, 26 adultos de entre 36-45 años y 29 adultos mayores de 46 años a más.

Gráfica N’ 18: ¿Tiene conocimiento del servicio de transporte público del Tren Eléctrico de Lima? 


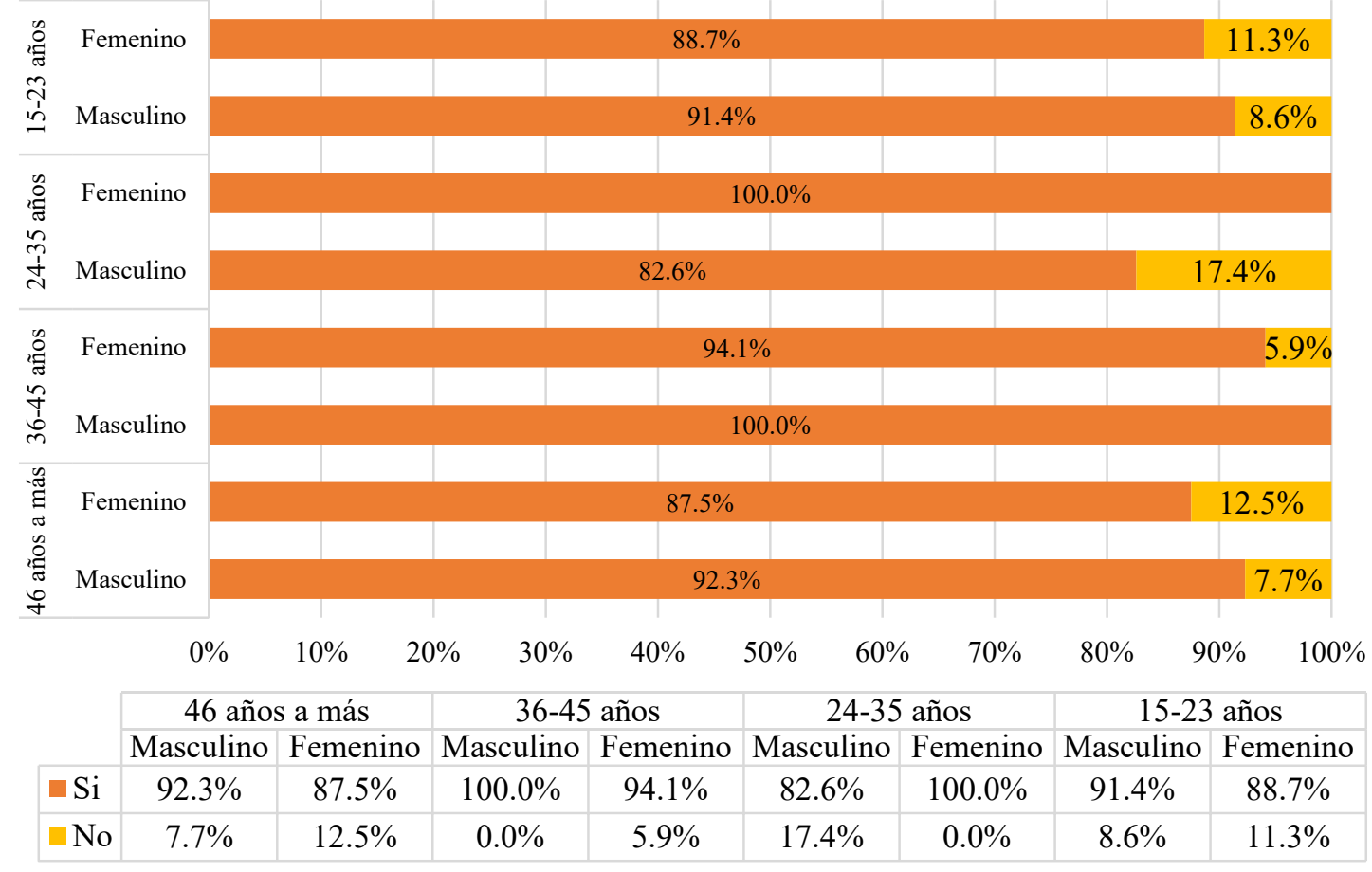

\section{Fuente: Elaboración Propia}

En la gráfica anterior se puede apreciar cómo es que la gran mayoría de los encuestados tienen conocimiento del servicio de transporte público del Tren eléctrico de Lima. Esta proporción representa un $90,5 \%$ de respuestas afirmativas sobre el total.

Gráfica N 19: ¿Alguna vez ha utilizado el Tren Eléctrico en Lima Perú? 


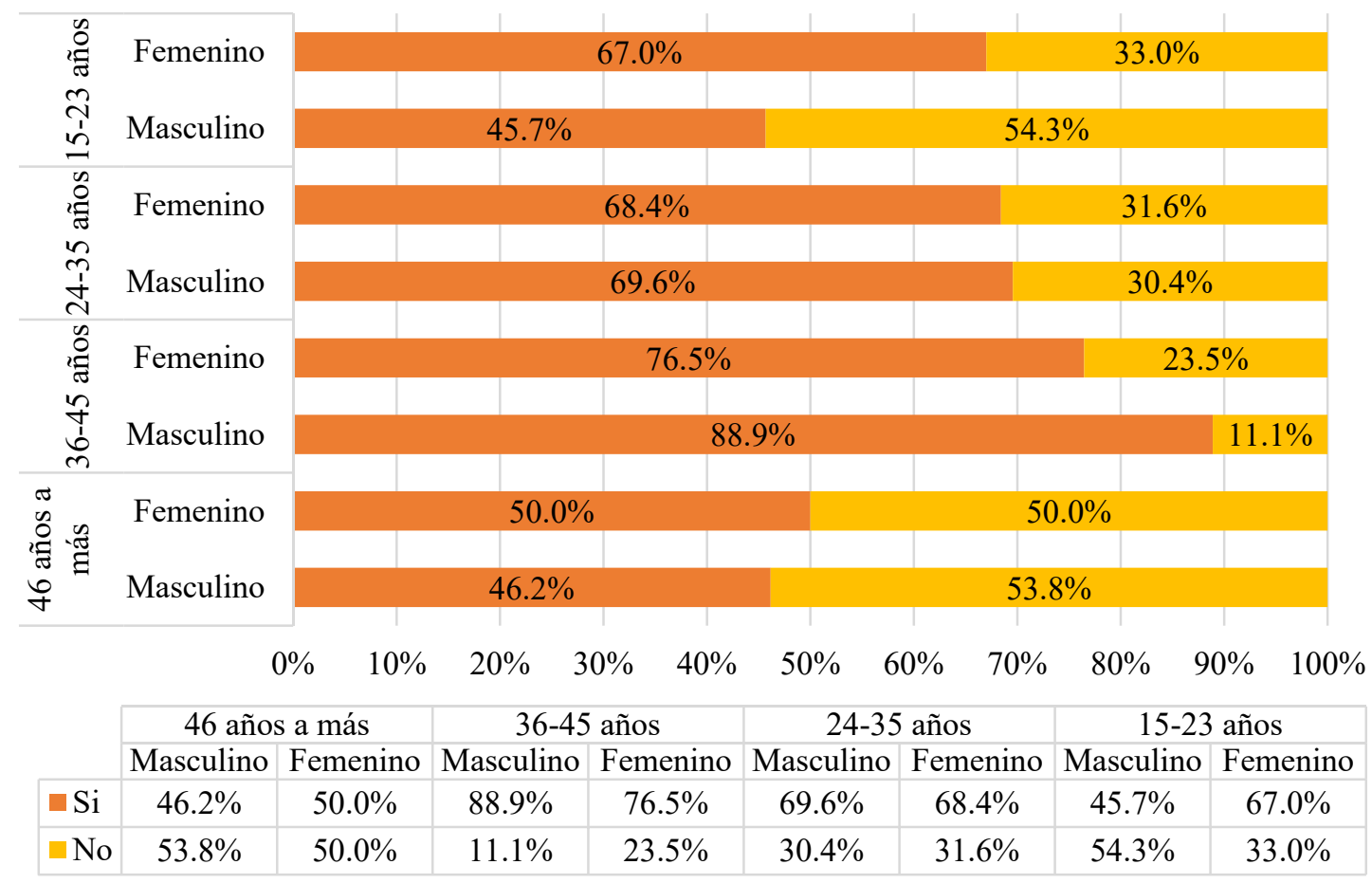

Fuente: Elaboración Propia

Se puede apreciar cómo es que más del 50\% de las personas encuestadas han utilizado alguna vez el Tren Eléctrico en Lima, siendo los adultos de entre 36-45 años los que más han utilizado el servicio. En síntesis, un 60,4\% de los entrevistados han utilizado el Tren Eléctrico.

Gráfica $N^{\circ}$ 20: ¿Con qué frecuencia lo utiliza? 


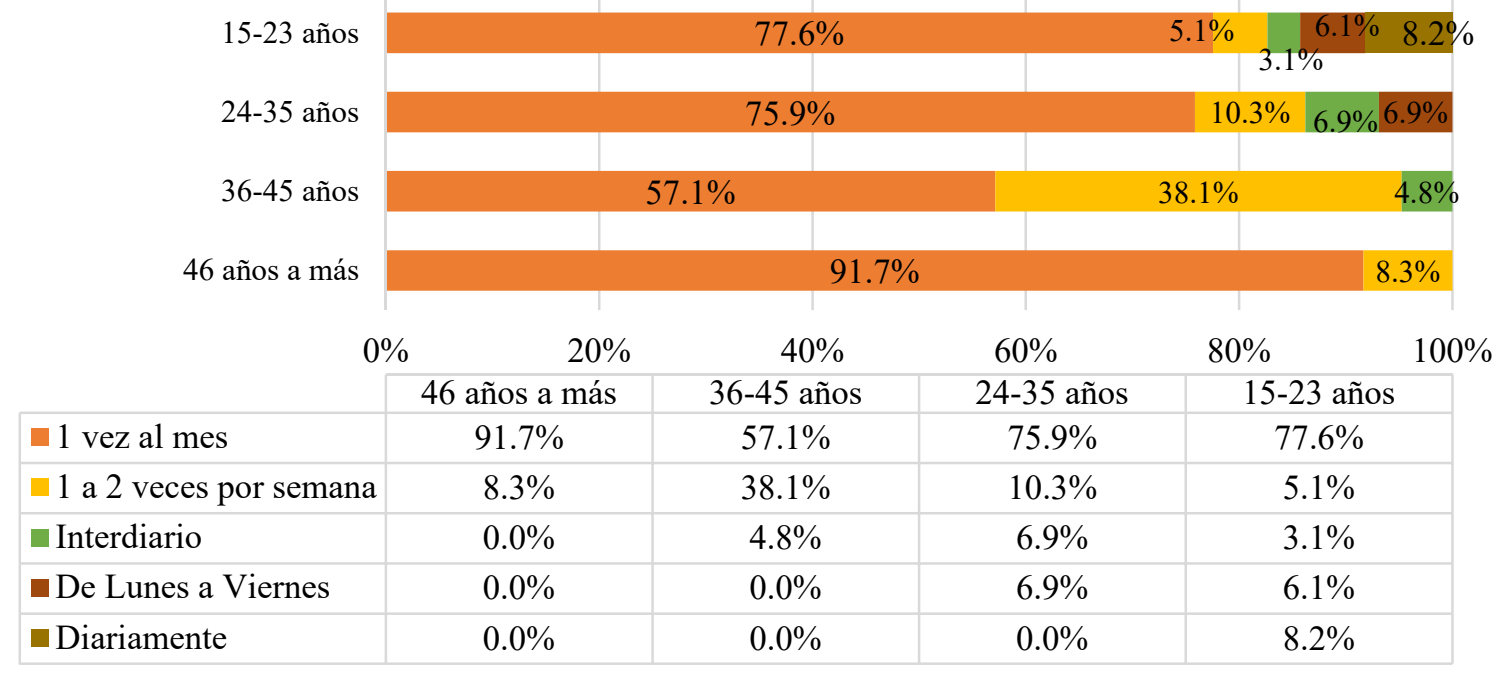

\section{Fuente: Elaboración Propia}

De las personas encuestadas que respondieron que "SI" utilizaron el servicio del Tren Eléctrico, se ve evidenciado que en su mayoría han usado el servicio con una frecuencia de 1 vez al mes, lo cual representa un $76 \%$. Del resto de personas, un 10,2\% lo han utilizado entre 1 y 2 veces por semana.

Con el fin de identificar el impacto del precio del servicio del Tren eléctrico y la sensibilidad de la sociedad ante el alza o baja de este, se han elaborado las siguientes gráficas:

Gráfica $N^{\circ} 21:$ ¿Qué opina usted del actual costo del pasaje del Tren Eléctrico de Lima (S/.1.50), considerando el servicio que brinda? 


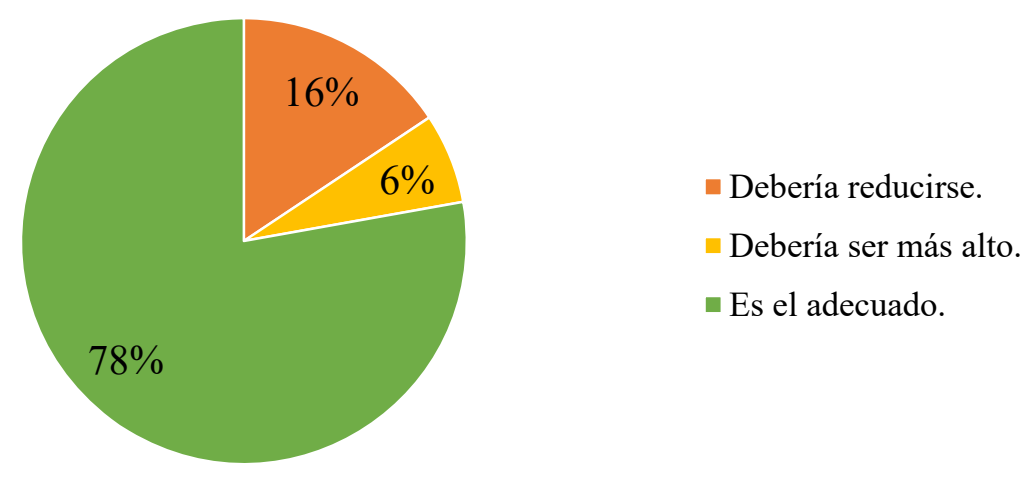

Fuente: Elaboración Propia

Gráfica $N^{\circ} 22:$ ¿Qué opina usted del actual costo del pasaje del Tren Eléctrico de Lima (S/.1.50), considerando el servicio que brinda? - 15-23 años

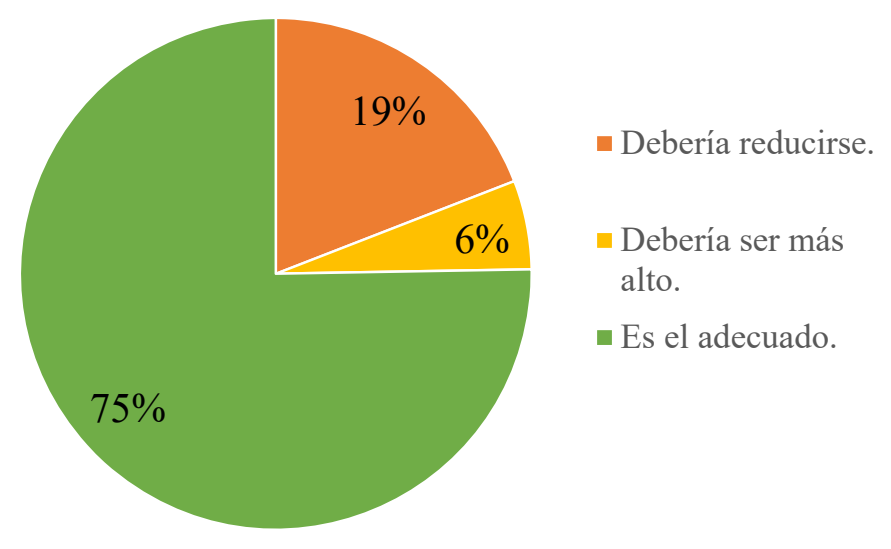

Fuente: Elaboración Propia

Gráfica $N^{\circ}$ 23: ¿Qué opina usted del actual costo del pasaje del Tren Eléctrico de Lima (S/.1.50), considerando el servicio que brinda? - 24-35 años 


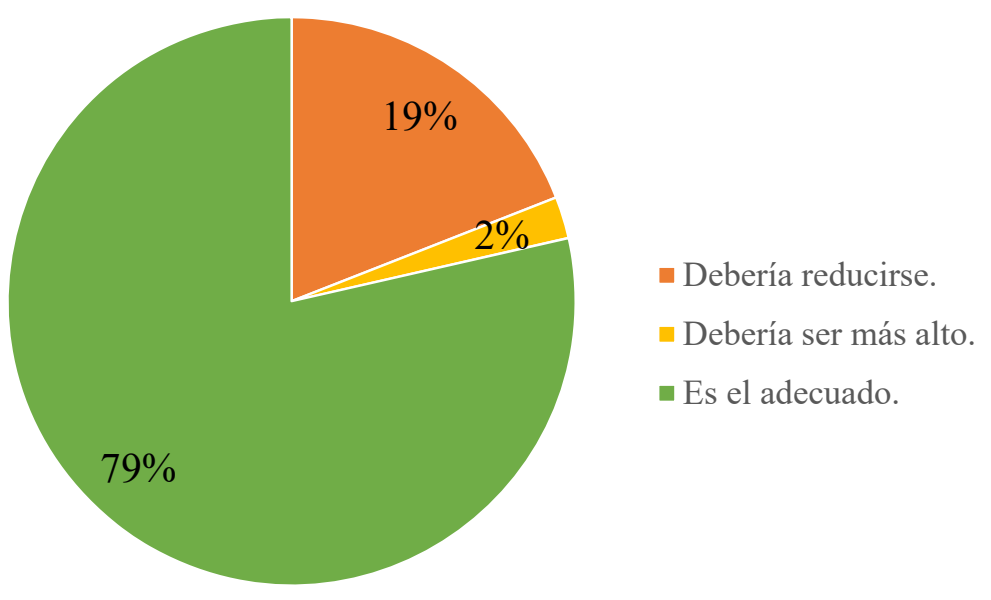

Fuente: Elaboración Propia

Gráfica $N^{\circ}$ 24: ¿Qué opina usted del actual costo del pasaje del Tren Eléctrico de Lima (S/.1.50), considerando el servicio que brinda? - 36-45 años

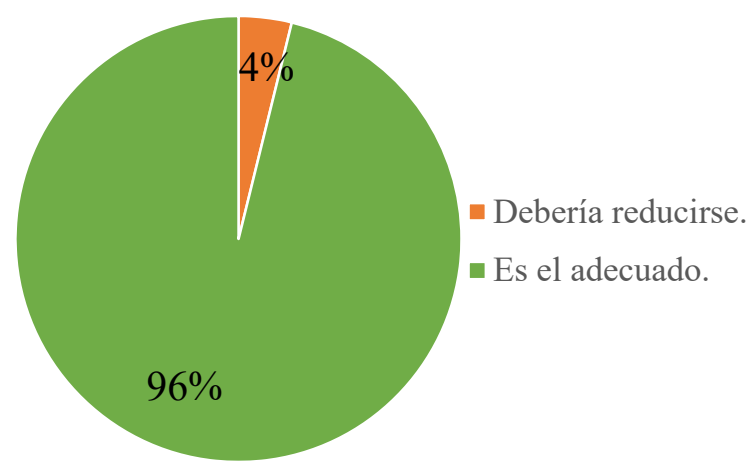

Fuente: Elaboración Propia

Gráfica $N^{\circ}$ 25: ¿Qué opina usted del actual costo del pasaje del Tren Eléctrico de Lima (S/.1.50), considerando el servicio que brinda? - 46 años a más 


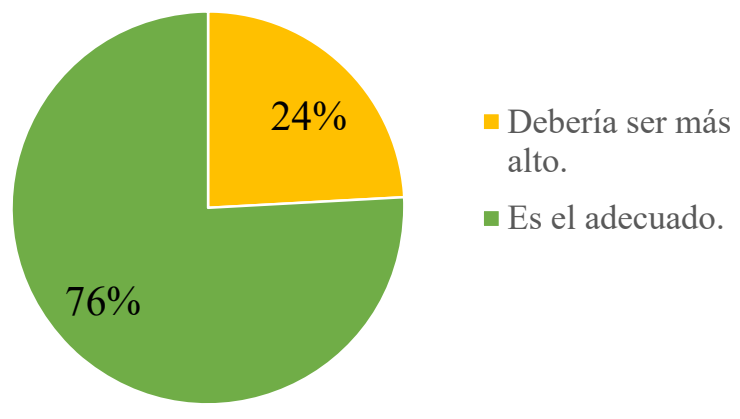

Fuente: Elaboración Propia

Como síntesis de las gráficas anteriores, se puede decir que los encuestados son sensibles a el precio del servicio de transporte del tren eléctrico y se sienten cómodos con la tarifa actual, ya que creen que es la justa y adecuada. Aunque si tornamos nuestro análisis por comparar si se debería subir o bajar el precio, detectamos que solo el $6 \%$ del total cree bajo sus criterios que el precio debería ser más alto; mientras que el 19\% cree que incluso debería ser más bajo.

\section{Gráfica $N^{\circ}$ 26: ¿Ha escuchado sobre las energías Renovables?}

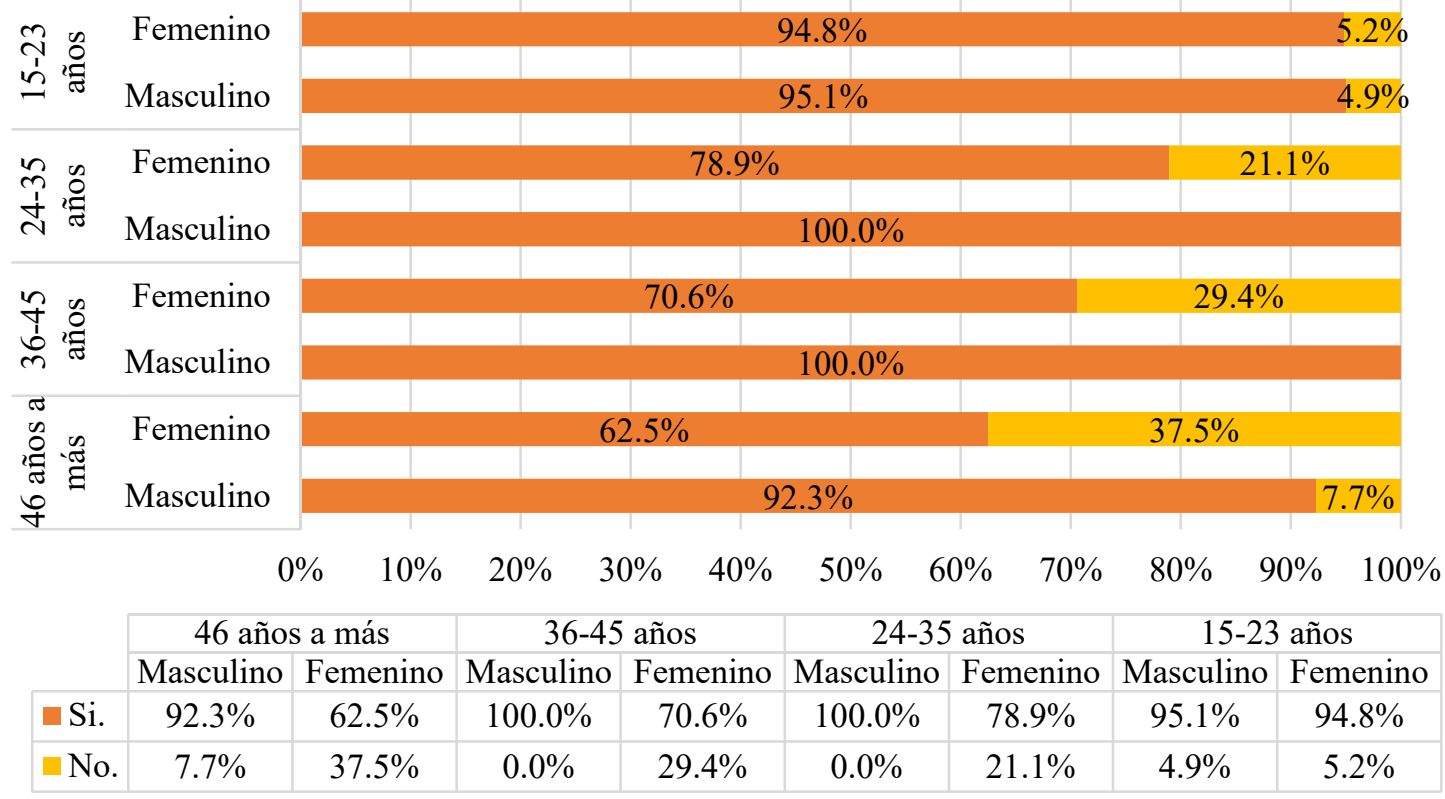

\section{Fuente: Elaboración Propia}


Según este resultado, de todos los encuestados el 90,9\% tiene conocimiento de lo que son las energías renovables. Lo cual es positivo para nuestro estudio, ya que los entrevistados tendrán un mejor criterio para responder las siguientes preguntas. Además, esta grafica nos dice que los temas de generación de energía renovable han cobrado mayor relevancia en la sociedad.

\section{Gráfica $N^{\circ}$ 27: ¿Está a favor del uso de Energías Renovables?}

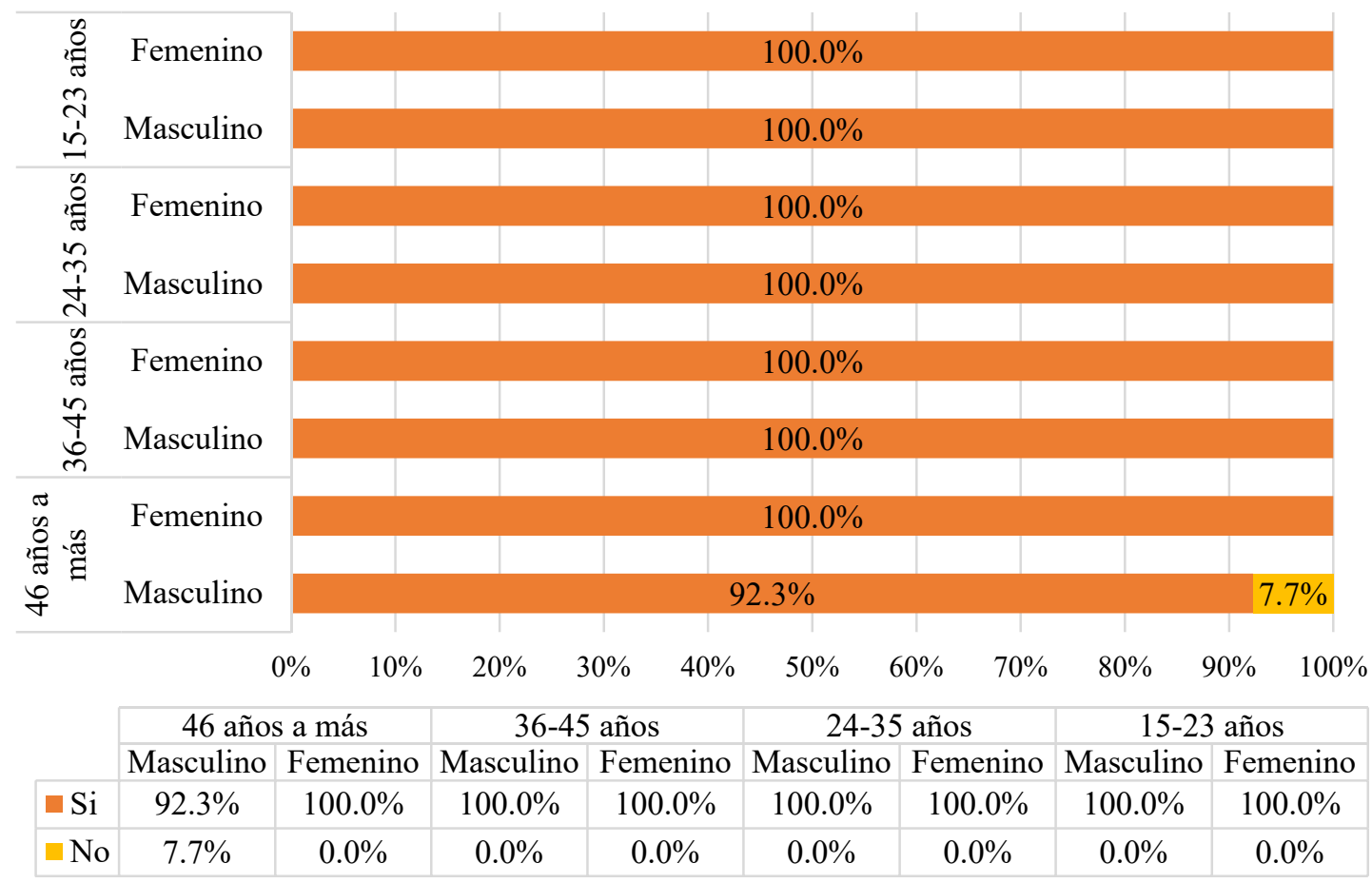

\section{Fuente: Elaboración Propia}

En esta grafica se refleja la casi unánime aceptación por el uso de energías renovables con un $99,6 \%$ de resultados afirmativos y reafirma lo mencionado en la gráfica anterior con respecto a la relevancia de las energías renovables en la sociedad.

Gráfica $N^{\circ}$ 28: ¿Estaría de acuerdo en el uso de Energías Renovables en la ciudad? 


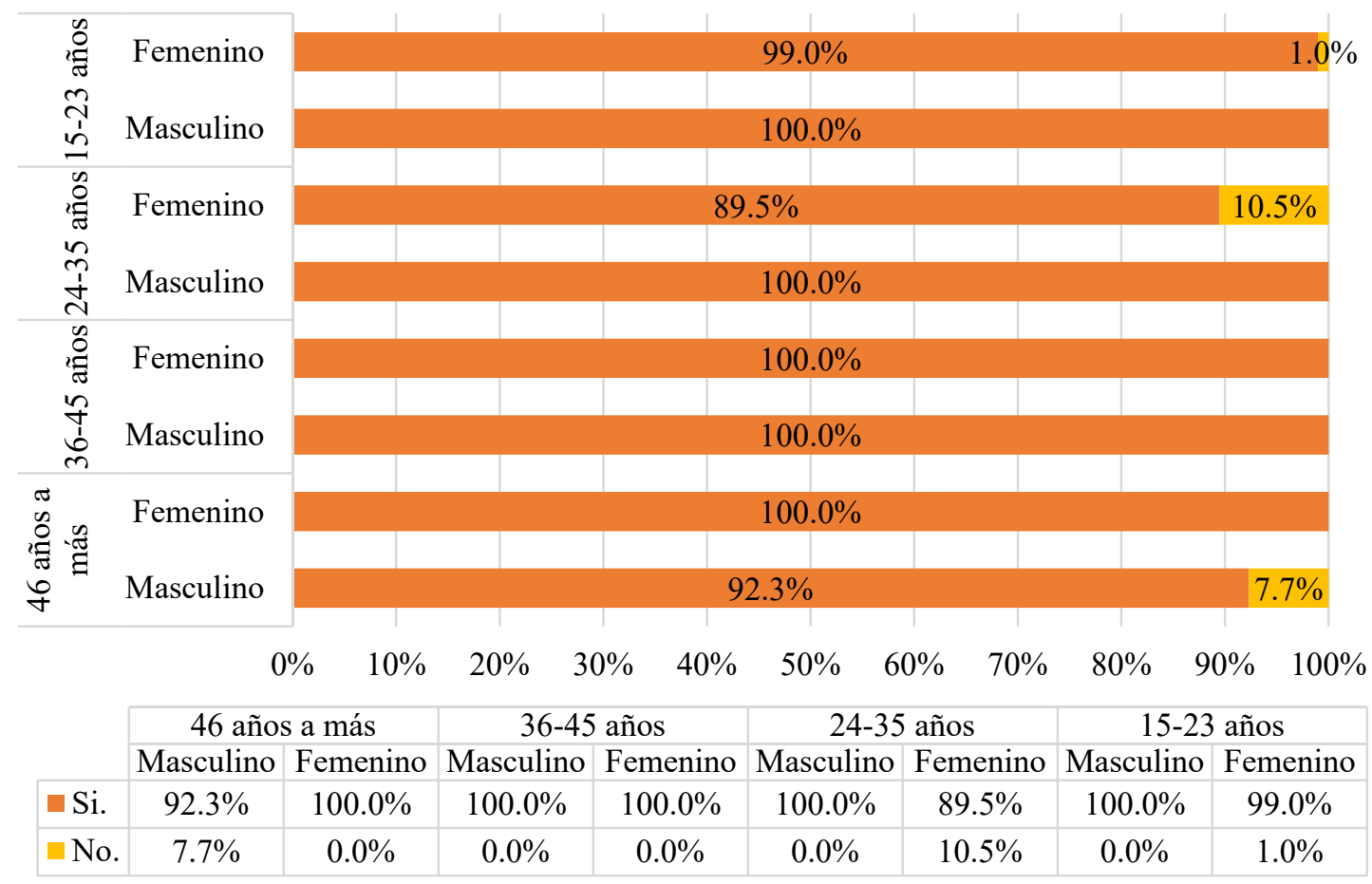

\section{Fuente: Elaboración Propia}

Al igual que gráficas anteriores es casi unánime, con un 98,5\% de resultados afirmativos, la aceptación de los encuestados por el uso de energías renovables en la ciudad de Lima. Esto nos da sustento para continuar con el proyecto de implementación de un sistema de generación de energía renovable en base a la tecnología piezoeléctrica.

Gráfica $N^{\circ}$ 29: ¿Cree usted que los ciudadanos de Lima tienen una cultura de ahorro de energía? 


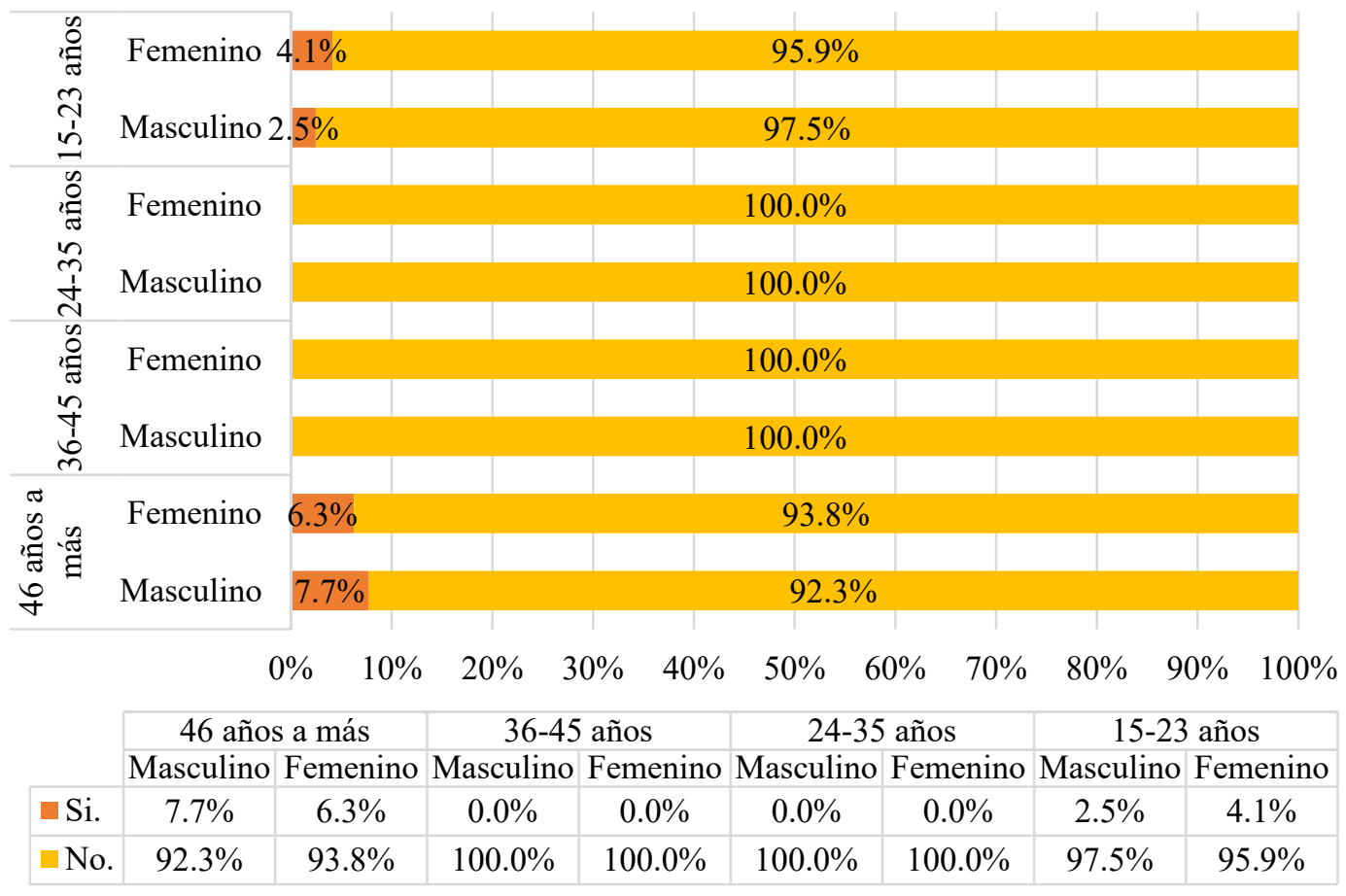

\section{Fuente: Elaboración Propia}

Es muy notorio en esta gráfica que los ciudadanos de Lima no cuentan con una cultura de ahorro de energía, con un $97,1 \%$ de resultados negativos. Esto nos dice que somos una sociedad consumista, lo cual, sumado al exponencial crecimiento económico del país y su estrecha relación con el crecimiento de la demanda energética, nos llevaría a una inminente crisis energética como bien se menciona en páginas anteriores. Pero dejemos que los encuestados den su opinión con respecto a este tema en las siguientes gráficas.

Gráfica $N^{\circ} 30:$ ¿Considera que la ciudad de Lima esta propensa a una crisis energética en los próximos 10 años? 


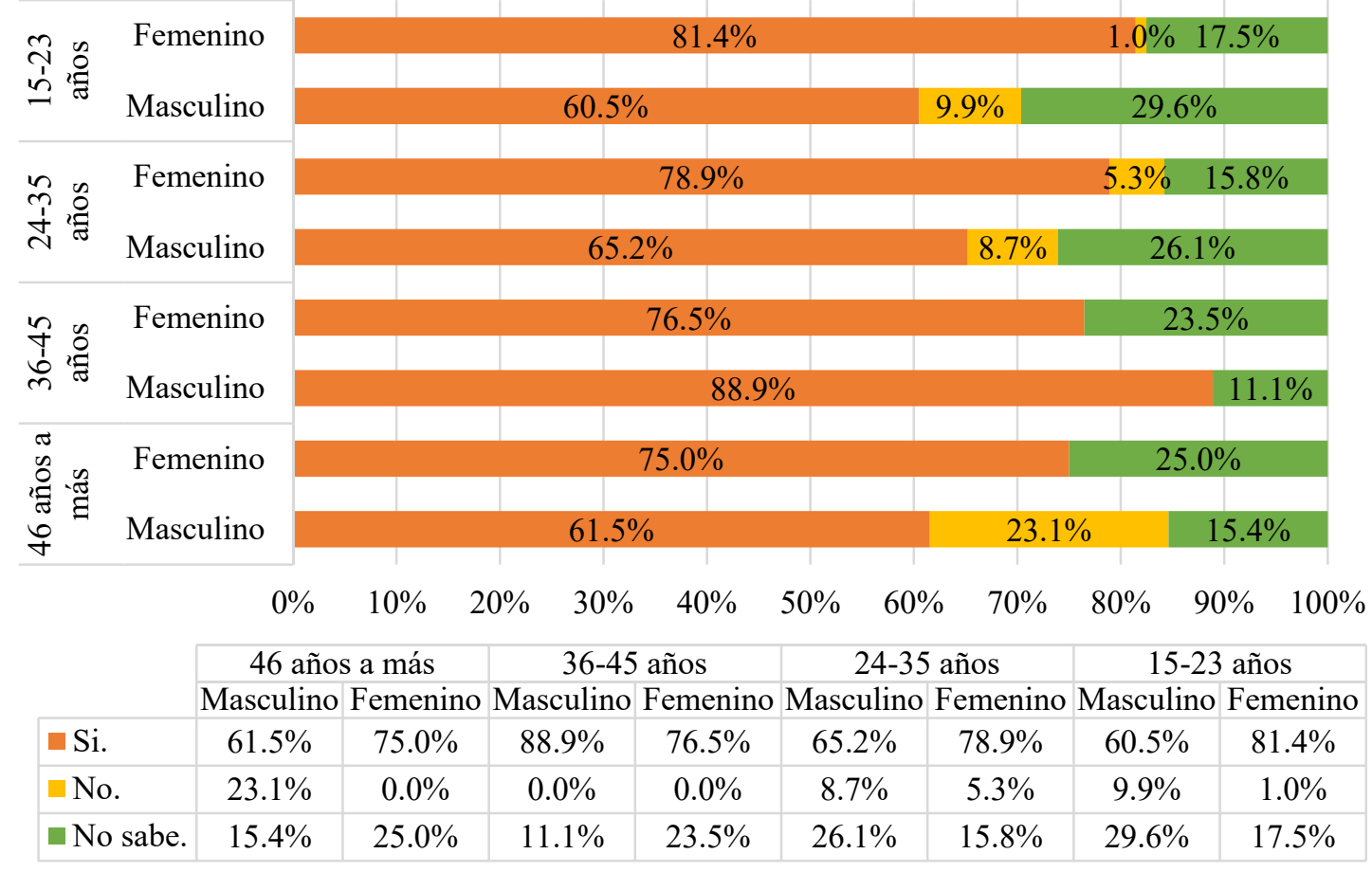

Fuente: Elaboración Propia 
Gráfica $N^{\circ}$ 31: ¿Considera que la ciudad de Lima está atravesando una crisis energética actualmente?

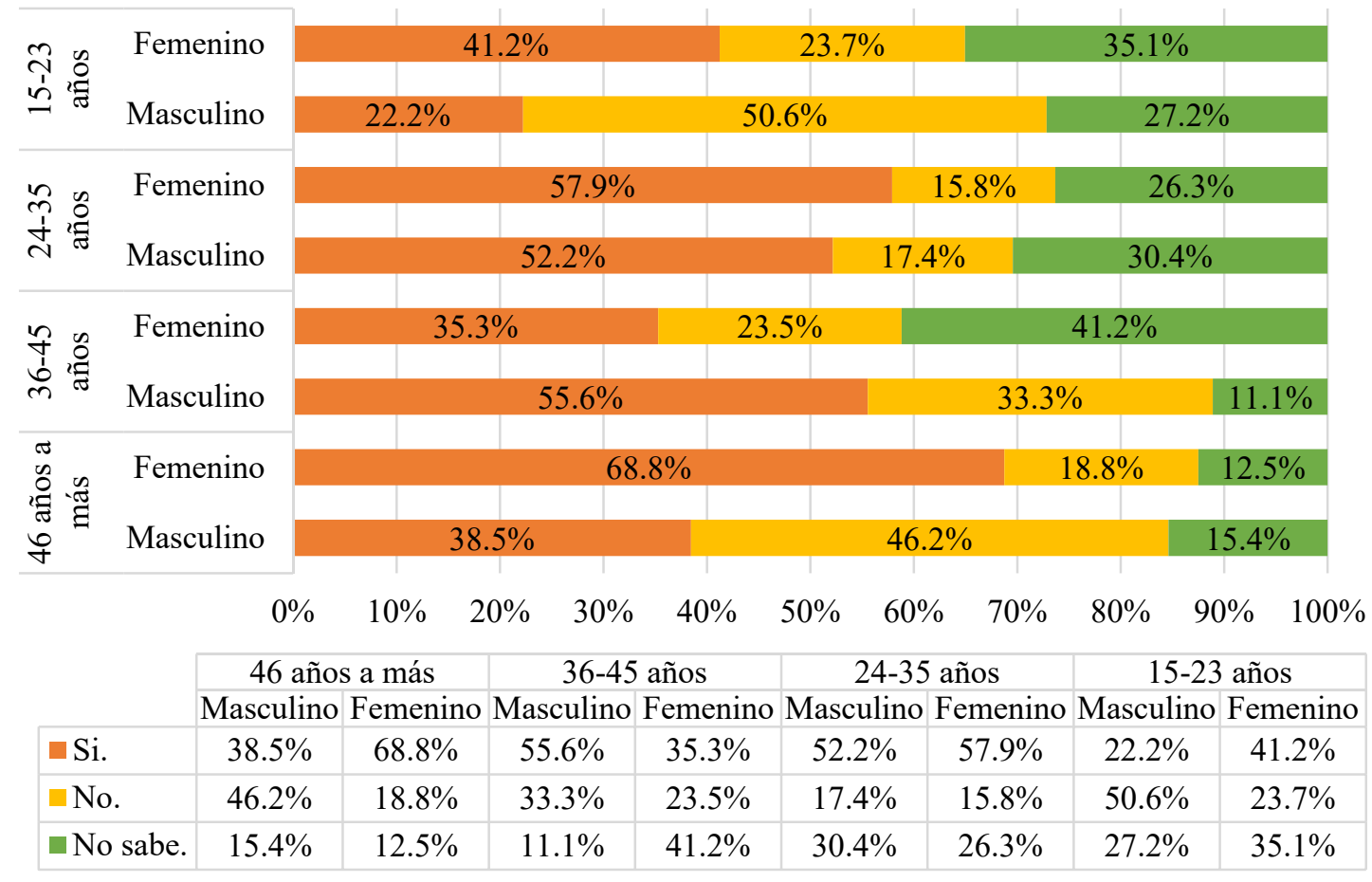

\section{Fuente: Elaboración Propia}

Los resultados de la opinión de los encuestados con respecto a la crisis energética eran de esperarse. Un $72,4 \%$ opina que estamos propenso a una crisis energética en los próximos 10 años, mientras que un 39,3\% opina que estamos atravesando por una crisis energética actualmente. Entonces, la percepción de la sociedad en resumen es la siguiente, ellos consideran que somos una sociedad consumista y que esto nos va a llevar a una próxima crisis energética, por no decir que ya estamos atravesando por una actualmente. Es por estos motivos que debemos empezar a prepararnos y a buscar alternativas no convencionales de generación y suministro de energía en nuestro país. 


\section{Gráfica $N^{\circ}$ 32: ¿Considera que la ciudad de Lima tiene problemas de contaminación}

ambiental?

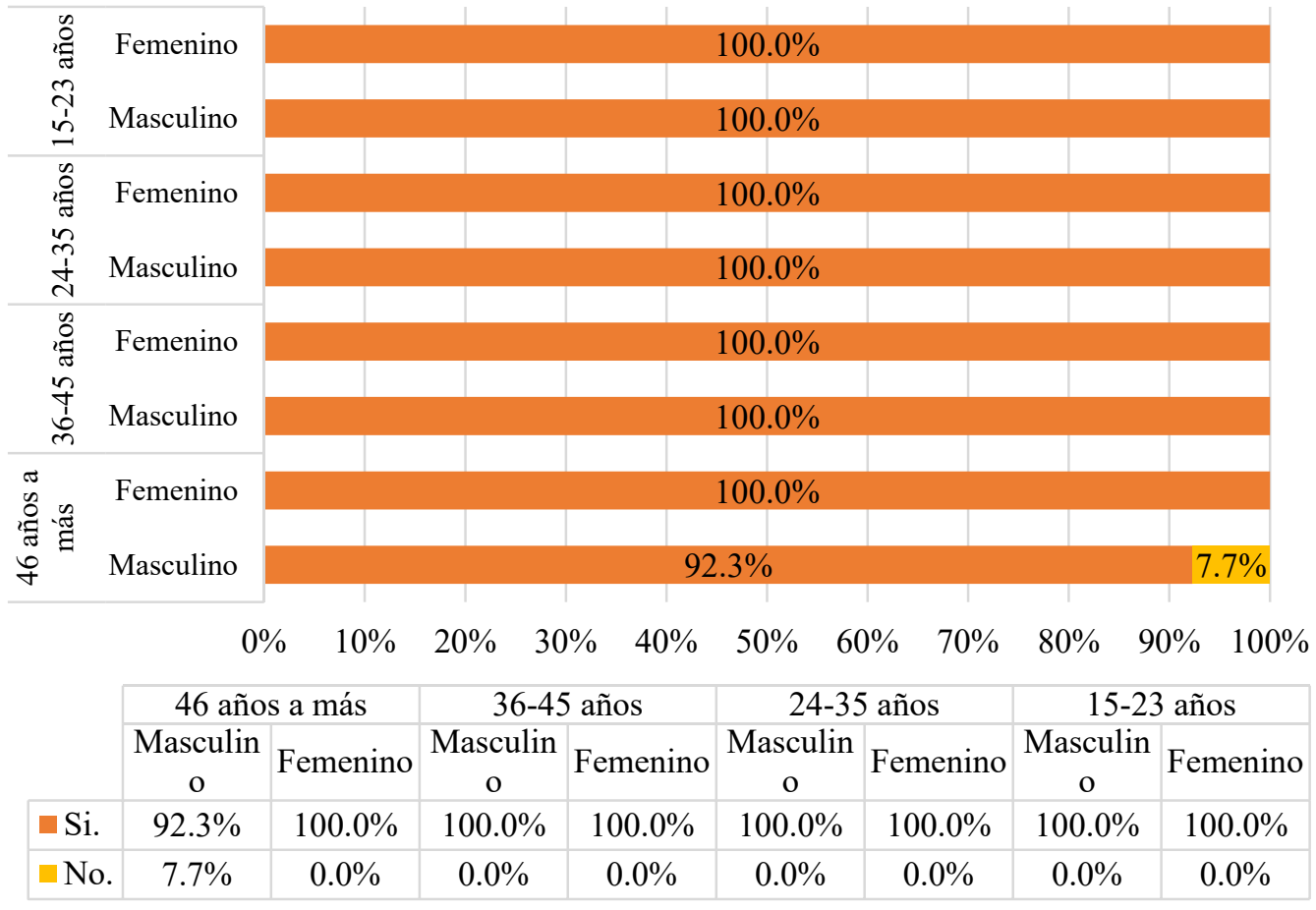

\section{Fuente: Elaboración Propia}

Al igual que en gráficas anteriores y por obvias razones, los encuestados opinan que la ciudad de Lima tiene problemas de contaminación ambiental. Si a la crisis energética le agregamos un caso critico de contaminación, estamos hablando de una sociedad con un futuro caótico que, si no busca un plan de contingencia, simplemente estaría encaminada a la autodestrucción.

\subsubsection{Confrontación de la encuesta Cualitativa con la Cuantitativa}

Según la información recabada en ambas encuestas, podemos identificar que la institución AATE tiene un problema en cuanto a la administración y a la prestación del servicio del Tren Eléctrico, ya que este servicio de transporte no es auto-sostenible y tiene que ser financiado por el Estado peruano.

El 78\% de la población limeña considera que el pasaje cobrado por este servicio es el adecuado y el $16 \%$ opina que debería ser reducido. En cambio, costo real del pasaje debería ser mayor, pero este no puede ser incrementado por las consecuencias negativas que traería consigo ante 
la población limeña, ya que este servicio es principalmente utilizado por los niveles socioeconómicos $\mathrm{B}, \mathrm{C}$ y D.

Paralelamente, los representantes de la institución AATE están de acuerdo en cuanto al uso de energía renovable al igual que la mayoría de la población limeña y ninguno de estos dos stakeholders tenían conocimientos acerca de la tecnología piezoeléctrica; esto indica que el proyecto será sumamente innovador.

\subsection{Identificación del Problema}

Como se ha podido observar tanto en el diagnóstico general como en el específico, se han podido identificar dos problemas, para los cuales se realizarán propuestas de solución para mitigarlos. El primero de ellos afecta directamente a la población peruana y el segundo particularmente a la institución AATE.

En Primer lugar, el Perú se encuentra atravesando una crisis energética la cual traerá consigo consecuencias negativas para la sociedad peruana.

En segundo Lugar, se pudo evidenciar que la institución AATE cuenta con sobrecostos de operación, los cuales deben ser subvencionados por el Estado peruano para que el servicio del tren eléctrico pueda seguir en funcionamiento. Siendo más específicos, AATE debe reembolsar a la empresa Graña y Montero (G\&M) el monto S/ 26' 870,560.4 anuales, ya que los pasajes de los usuarios no llegan a cubrir los costos de operación que asume G\&M para mantener el Tren Eléctrico en funcionamiento.

En el siguiente capítulo, se presentarán dos propuestas de solución, las cuales buscarán mitigar los problemas hallados en el diagnóstico.

\subsection{Conclusión}

Luego de haber realizado un diagnóstico sobre el ambiente exterior e interior de la Institución AATE, se ha podido identificar que cuentan con sobrecostos y estos están siendo asumidos por el Estado peruano para que el servicio del Tren Eléctrico, el cual es sumamente necesario para la sociedad limeña, pueda seguir funcionando adecuadamente. Estos sobrecostos equivalen a 
S/ 26'870,506.40 anuales. Además de estos sobrecostos, el Perú se encuentra atravesando una crisis energética, la cual debe ser mitigada lo antes posible para así reducir los posibles efectos negativos que traerá consigo en el futuro. 


\section{CAPÍTULO 3: PROPUESTAS DE SOLUCIÓN}

\subsection{Objetivos del Proyecto}

Los objetivos del proyecto se basarán en los tres pilares de la sostenibilidad, para así lograr un proyecto auto-sostenible, el cual beneficie económicamente a la empresa, colabore con el medio ambiente y sea socialmente viable para poder estar acorde a la población peruana.

A continuación, se especificarán los objetivos específicos en cada uno de los pilares:

\section{- Económico:}

Reducir los costos energéticos de las estaciones del Tren Eléctrico de Lima remplazando gradualmente su consumo de energía eléctrica convencional con la energía almacenada por las baldosas instaladas en sus establecimientos.

\section{- Ambiental:}

Disminuir la contaminación ambiental al utilizar energía renovable proveniente de tecnología piezoeléctrica, que tenga un menor impacto negativo frente al medio ambiente, tanto en su generación, almacenamiento y transmisión.

\section{- Social:}

Brindarles un mejor servicio a los pasajeros y mejorar la imagen de la empresa ante la sociedad. A su vez, difundir la utilización de energía renovable por la población limeña, fomentar la cultura del ahorro energético y así tratar de mitigar una posible crisis energética futura.

\subsection{Variables a considerar}

Las principales variables a tomar en cuenta en este proyecto de pre factibilidad, para asegurar su éxito, son las siguientes: 


\section{- Número de personas diarias por estación:}

La afluencia de gente es la principal variable que se debe tomar en cuenta, ya que sin una correcta afluencia no se podrá generar energía y el proyecto no será rentable a corto ni a largo plazo.

\section{- Número de Baldosas a instalar:}

Este número podrá asegurar que se aprovechen un número mayor de pasos de los usuarios del tren eléctrico y así se pueda generar la mayor energía posible. Un número inadecuado de baldosas puede generar pérdidas de energía cinética no aprovechada o si se instalarán demasiadas sería un desperdicio de capital que no sería aprovechado adecuadamente.

\section{- Distribución de las baldosas:}

Las baldosas deben localizarse en puntos críticos, dentro de las estaciones, los cuales cuenten con mayor afluencia de gente para así no desaprovechar los espacios más transcurridos por los clientes. Además, también debe asegurarse que se encuentren dentro del establecimiento para así asegurar su resguardo ante delincuentes.

\section{- Distribución física de las estaciones:}

La distribución física de las instalaciones debe ser analizada cuidadosamente, ya que hay lugares que cuentan con instalaciones eléctricas y estos no pueden ser perforados sin haber estudiado los planos. También se debe encontrar un espacio en donde se pueda colocar el UPS, para así asegurar el resguardo de los trabajadores y la clientela contra posibles accidentes eléctricos que se pudieran generar por algún error.

\section{- Comportamiento de los usuarios durante el uso de las instalaciones:}

Se debe analizar el comportamiento de los usuarios en las instalaciones del Tren Eléctrico, ya que no todos ellos se comportan de la misma manera. Es decir, ciertas personas utilizan las escaleras, otras los ascensores y, en sí, cada una de ellas tiene rutas distintas para subir a los andenes del segundo piso para utilizar el servicio de transporte. 


\subsection{Propuestas de Solución}

\subsubsection{Propuesta 1: Implementación de un sistema de generación de Energía}

\section{Renovable}

La primera propuesta de solución para reducir los costos energéticos de la Estación La Cultura del servicio del tren eléctrico en la Línea 1 corresponde a la implementación de un sistema de generación de energía renovable mediante la utilización de tecnología piezoeléctrica.

\subsubsection{Evaluación de Proveedores}

Para poder adquirir las baldosas, se han evaluado diferentes compañías que aplican esta tecnología en sus productos para la generación de energía eléctrica mediante el aprovechamiento de la energía cinética de las personas (mediante sus pisadas). A continuación, se desarrollará un comparativo entre dichos productos, para determinar cuál de estos se adapta de mejor manera al proyecto y garantizan una mejor eficiencia.

Las compañías a evaluar son las siguientes:

Tabla $N^{\circ}$ 13: Descripción de Compañías proveedoras

\begin{tabular}{|c|c|}
\hline $\begin{array}{c}\text { NOMBRE DE LA } \\
\text { COMPAÑ́́A }\end{array}$ & DESCRIPCIÓN \\
\hline INNOWATTECH & $\begin{array}{l}\text { - En el 2007, en Israel, ingenieros del centro } \\
\text { tecnológico Innowattech crearon un nuevo tipo de } \\
\text { material para carreteras basado en cristales } \\
\text { piezoeléctricos, los cuales permitieron aprovechar la } \\
\text { energía cinética del paso de los vehículos. } \\
\text { - Innowatech también creo dispositivos peatonales, los } \\
\text { cuales tienen el mismo principio de generación que } \\
\text { sus dispositivos vehiculares mencionados } \\
\text { anteriormente, pero con una mayor sensibilidad para } \\
\text { poder generar energía eléctrica a partir del caminar de } \\
\text { los peatones. }\end{array}$ \\
\hline
\end{tabular}




\begin{tabular}{|c|c|}
\hline & $\begin{array}{l}\text { - Su dispositivo destinado a los peatones tiene la } \\
\text { capacidad de generar } 1 \mathrm{kWh} \text { mediante el caminar de } \\
3000 \text { personas durante una hora por un tramo de } \\
100 \mathrm{~m} \text {. } \\
\text { - Las dimensiones de sus baldosas (dispositivos) es de } \\
40,0 \times 50,0 \mathrm{~cm} \text {. }\end{array}$ \\
\hline PIEZO POWER & $\begin{array}{l}\text { - Esta empresa creo un producto piezoeléctrico, el cual } \\
\text { podría generar un total de } 17 \mathrm{~W} \text { de energía eléctrica } \\
\text { mediante el tránsito de cada persona en un recorrido } \\
\text { de } 153,00 \mathrm{~cm} \text { aproximadamente. } \\
\text { - Sus productos miden } 92 \mathrm{~cm} \text { de ancho y } 153 \mathrm{~cm} \mathrm{de} \\
\text { largo. }\end{array}$ \\
\hline SOUND POWER & $\begin{array}{l}\text { - La empresa japonesa Soundpower, ha elaborado un } \\
\text { panel, el cual puede generar } 0,5 \mathrm{~W} \text { mediante el } \\
\text { aprovechamiento de la energía cinética generada por } \\
\text { dos pasos de una persona de } 60 \mathrm{~kg} \text {. }\end{array}$ \\
\hline POWER LEAP & $\begin{array}{l}\text { - La compañía Powerleap muestra que la POWER floor } \\
\text { es capaz de generar } 1 \mathrm{kWh} \text { de energía procedente de } \\
\text { un área de } 50 \mathrm{~m}^{2} \text { con al menos } 5000 \text { peatones que la } \\
\text { transiten por una hora. }\end{array}$ \\
\hline PAVEGEN & $\begin{array}{l}\text { - La compañía PAVEGEN bajo la dirección del inglés } \\
\text { Laurence Kemball-Cook ha logrado desarrollar un } \\
\text { dispositivo de generación de energía eléctrica en base } \\
\text { a las pisadas de las personas. } \\
\text { - Este dispositivo, al ser creado podía generar } 7 \mathrm{~W} \text { por } \\
\text { pisada, pero con el pasar de los años PAVEGEN ha } \\
\text { ido mejorando constantemente su producto y anuncia } \\
\text { que será más eficiente aún. } \\
\text { Otras características de las baldosas son: } \\
\text { - Baldosas Plug and Play. Su producto cuenta con } \\
\text { diversas certificaciones, está hecho de } \\
\text { materiales reciclados, es impermeable, tiene alta }\end{array}$ \\
\hline
\end{tabular}




\begin{tabular}{|c|c|}
\hline & $\begin{array}{c}\text { durabilidad, incluye un sistema de control de las } \\
\text { baldosas, entre otros. }\end{array}$ \\
- & Estas baldosas ya han sido implementadas en varios \\
proyectos alrededor del mundo y en la actualidad son \\
las más eficientes del mercado. \\
- Las dimensiones de las baldosas son de $60 \times 45 \mathrm{~cm}$. \\
\hline
\end{tabular}

\section{Fuente: Elaboración propia}

Para evaluar objetivamente a las compañías mencionadas anteriormente, se les asignara una calificación en base a variables que nos permitan seleccionar el mejor producto para la implementación del proyecto. La calificación se hará con una puntuación desde 0 hasta el 5 , siento 5 la mejor calificación y 0 la mínima. A cada variable se le asignó una ponderación dependiendo de la importancia que esta tenga para el proyecto.

Las variables a considerar son:

- Cantidad de energía generada por el producto.

- Adaptabilidad de las dimensiones del producto con el espacio disponible.

- Información disponible sobre el producto.

- Antecedentes de implementación.

- Durabilidad y Funcionabilidad.

A continuación, se mostrará una tabla con los resultados de calificación de las 5 variables para las compañías seleccionadas: 
Tabla $N^{\circ}$ 14: Calificación de las Compañías

\begin{tabular}{|c|c|c|c|c|c|c|}
\hline & & $\begin{array}{c}\text { INNOWA } \\
\text { TTECH }\end{array}$ & $\begin{array}{c}\text { PIEZO } \\
\text { POWER }\end{array}$ & $\begin{array}{l}\text { SOUND } \\
\text { POWER }\end{array}$ & $\begin{array}{l}\text { POWER } \\
\text { LEAP }\end{array}$ & PAVEGEN \\
\hline VARIABLE & PESO & \multicolumn{5}{|c|}{ PUNTUACIÓN } \\
\hline $\begin{array}{l}\text { Cantidad de energía } \\
\text { generada por el } \\
\text { producto }\end{array}$ & $30 \%$ & 3 & 4 & 2 & 4 & 5 \\
\hline $\begin{array}{l}\text { Adaptabilidad de las } \\
\text { dimensiones del } \\
\text { producto con el espacio } \\
\text { disponible }\end{array}$ & $20 \%$ & 5 & 2 & 5 & 0 & 5 \\
\hline $\begin{array}{l}\text { Antecedentes de } \\
\text { implementación }\end{array}$ & $20 \%$ & 2 & 2 & 3 & 2 & 5 \\
\hline $\begin{array}{ll}\text { Durabilidad } & \mathrm{y} \\
\text { Funcionabilidad } & \end{array}$ & $15 \%$ & 3 & 3 & 3 & 2 & 5 \\
\hline $\begin{array}{l}\text { Información disponible } \\
\text { sobre el producto }\end{array}$ & $15 \%$ & 2 & 1 & 1 & 2 & 4 \\
\hline & $100 \%$ & 3,05 & 2,6 & 2,8 & 2,2 & 4,85 \\
\hline
\end{tabular}

\section{Fuente: Elaboración propia}


Gráfica $N^{\circ}$ 33: Calificación de proveedores

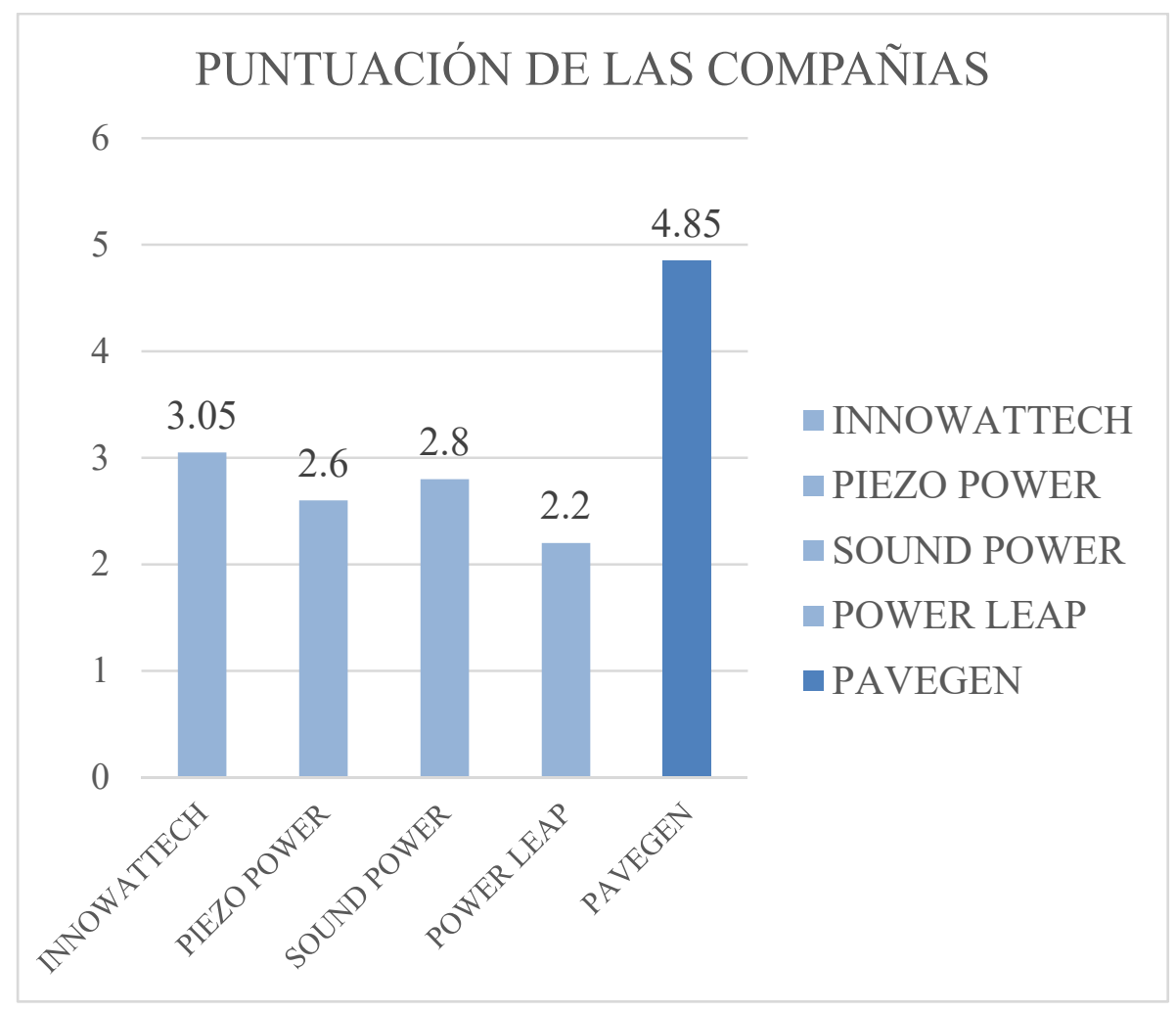

Fuente: Elaboración propia

Según los resultados de la evaluación de las compañías en base a las variables y su ponderación, se evidencia que las baldosas PAVEGEN son las mejores del mercado en la actualidad y notoriamente las más adecuadas para este proyecto. Esta compañía ofrece un producto de mejor calidad y eficiencia, están en constante mejora y han tenido antecedentes con resultados exitosos.

\subsubsection{Localización de las baldosas}

Además de haber seleccionado las baldosas adecuadas para el proyecto, se deberá tener clara cuál será la ubicación donde se instalarán las baldosas para así maximizar su utilización. Para poder definir esta ubicación, se deberá comprender la distribución física de la estación, el comportamiento de los usuarios e identificar las actividades críticas del servicio.

Para ello, a continuación, se presentará el plano de la Estación La Cultura, un diagrama de recorrido en el cual se podrá visualizar las diversas rutas que suelen frecuentar los usuarios y un flujograma explicativo de las actividades del servicio. 
Figura $N^{\circ}$ 40: Distribución física de la Estación La Cultura

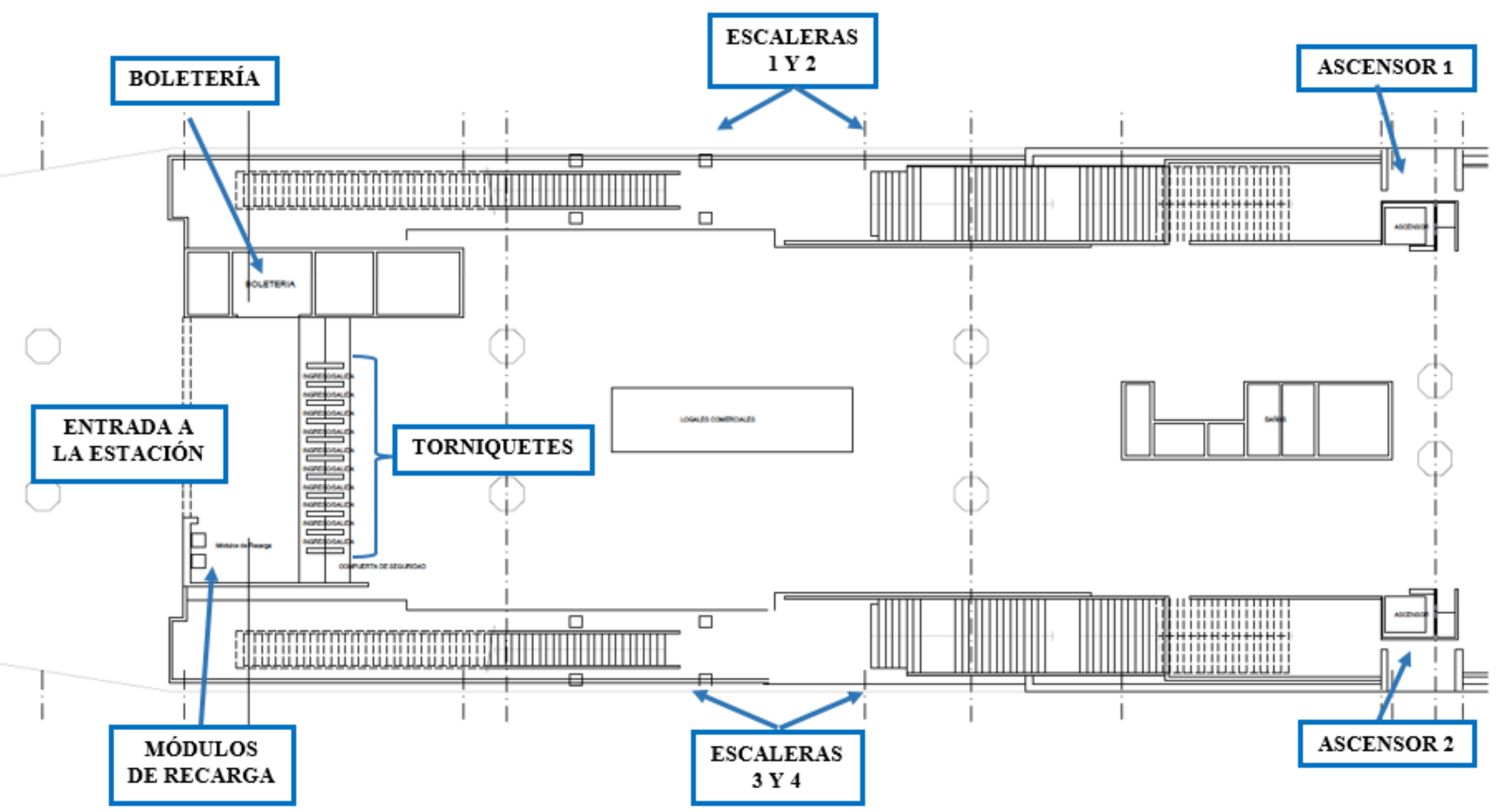

Fuente: Elaboración Propia 
Figura $N^{\circ}$ 41: Rutas disponibles en la Estación La Cultura para la utilización del Tren Eléctrico

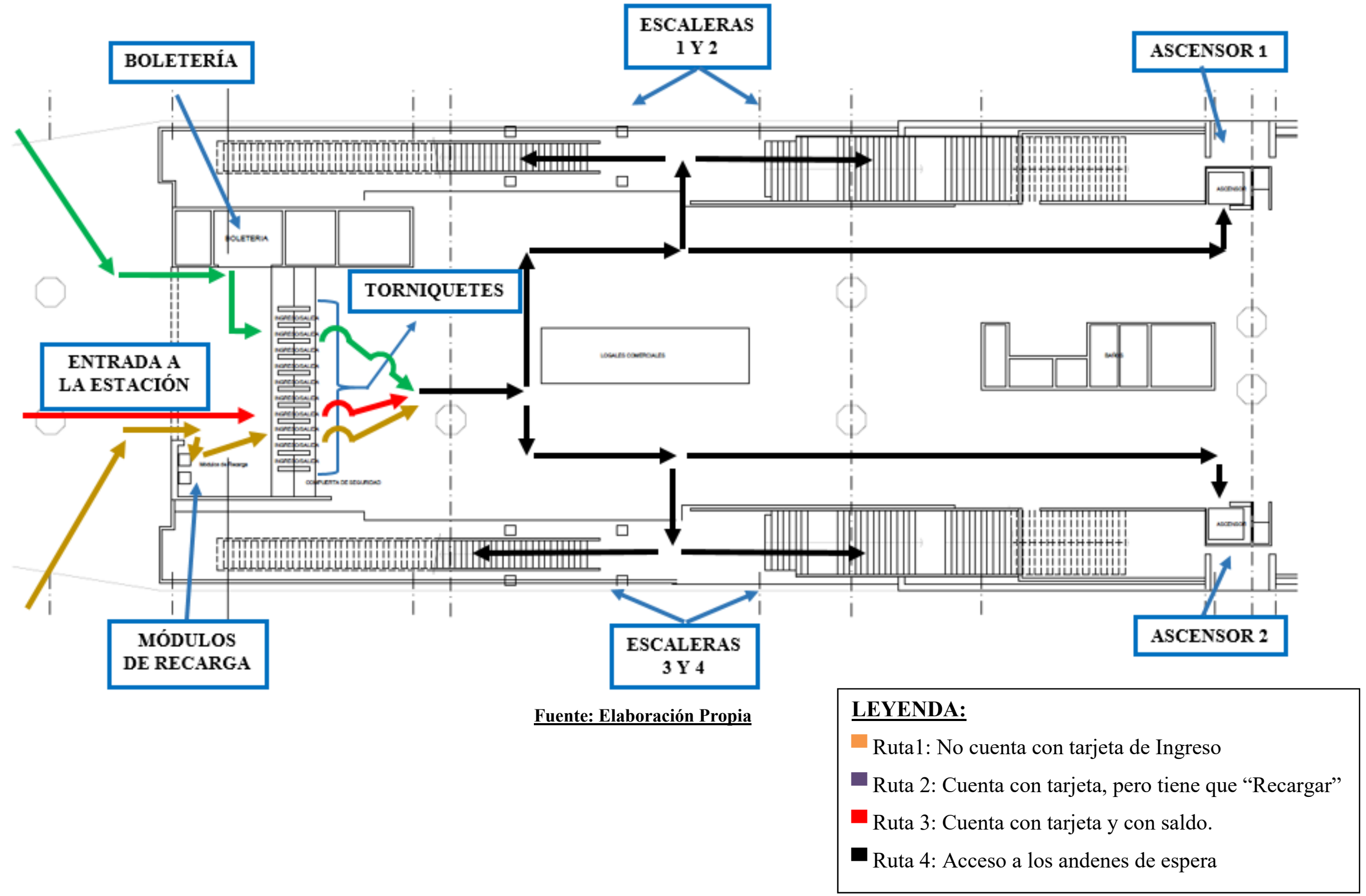




\section{Rutas posibles de los Usuarios:}

\section{- Ruta 1: No cuenta con tarjeta de ingreso}

En esta ruta el usuario no cuenta con tarjeta de ingreso a la estación, por lo cual antes de pasar por los torniquetes de ingreso, deberá acercarse a la boletería para adquirir su tarjeta vinculada a su DNI. Una vez obtenida la tarjeta, el usurario puede ingresar a la estación y luego tiene la opción de acceder a los andenes de espera, ya sea por las escaleras o por algún ascensor.

\section{- Ruta 2: Cuenta con tarjeta, pero tiene que "Recargarla"}

En esta ruta el usuario cuenta con una tarjeta de ingreso a la estación, pero esta no tiene saldo disponible para pasar por los torniquetes de ingreso. Es por esto el usuario debe acercarse a los módulos de recarga y una vez cuente con saldo disponible para ingresar a la estación, podrá pasar por los torniquetes y luego tiene la opción de acceder a los andenes de espera, ya sea por las escaleras o por algún ascensor.

\section{- Ruta 3: Cuenta con tarjeta y con saldo}

En esta ruta el usuario cuenta con una tarjeta de ingreso a la estación y esta cuenta con saldo disponible para pasar por los torniquetes de ingreso. Es por esto que su recorrido de ingreso es directo por los torniquetes y luego tiene la opción de acceder a los andenes de espera, ya sea por las escaleras o por algún ascensor.

\section{- Ruta 4: Acceso a los andenes de espera}

En esta ruta el usuario ya se encuentra dentro de la estación y se aplica para todas las otras rutas. El usuario tiene la opción de acceder a los andenes de espera, ya sea por cualquiera de las 4 escaleras o por alguno de los dos ascensores.

Figura $N^{\circ}$ 42: Flujo de atención al cliente en las estaciones 


\section{FLUJO DE ATENCIÓN AL CLIENTE EN LAS ESTACIONES}

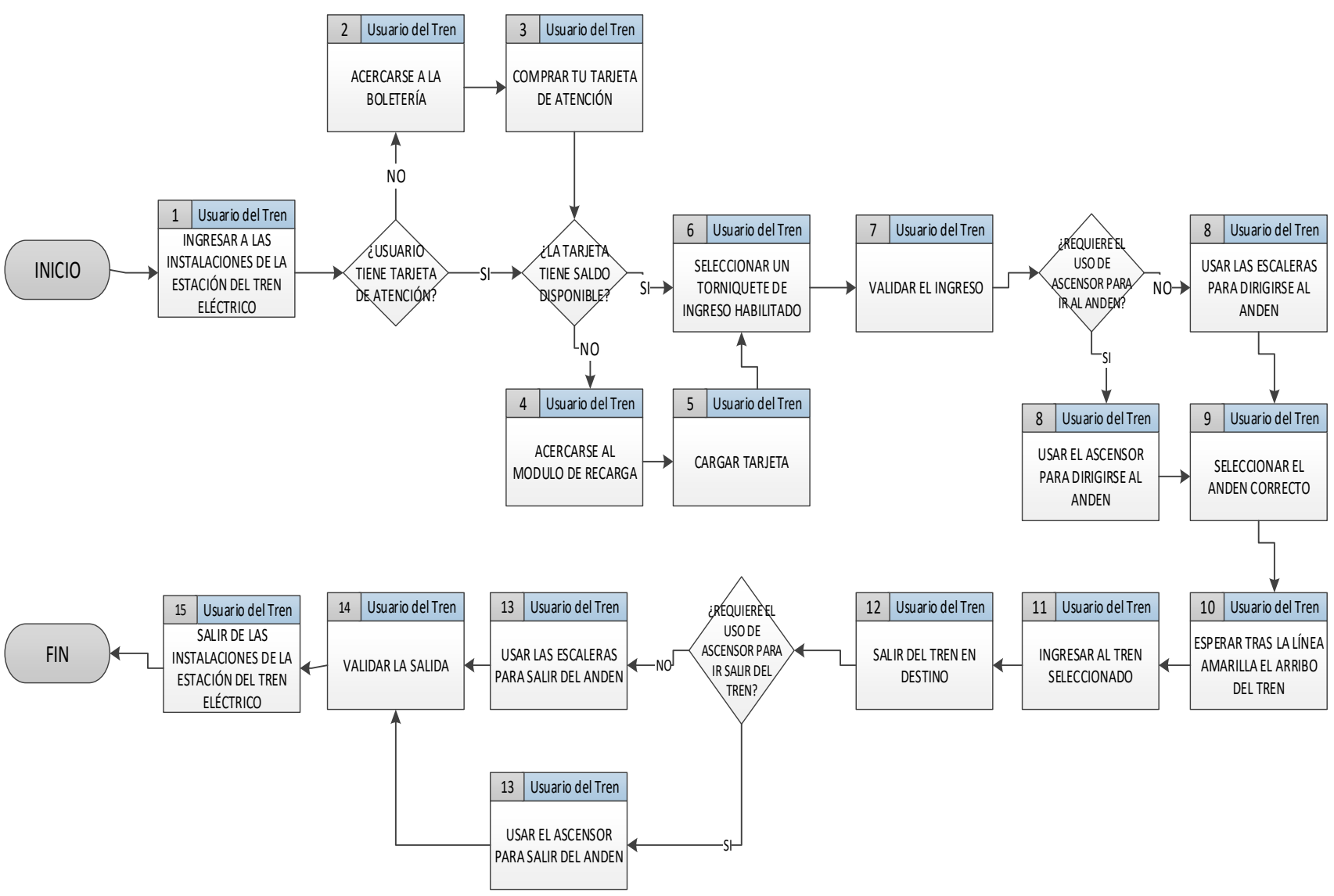

Fuente: Línea 1 del Tren Eléctrico

Elaboración: Propia

Fuente: Elaboración Propia 
Tabla $N^{\circ}$ 15: Descripción de Actividades

\begin{tabular}{|c|c|c|}
\hline $\mathrm{N}^{0}$ & Actividad(es) & Descripción \\
\hline 1 & $\begin{array}{l}\text { - Ingresar a las instalaciones } \\
\text { de la Estación del Tren } \\
\text { eléctrico. }\end{array}$ & $\begin{array}{l}\text { El ingreso a las estaciones del Tren } \\
\text { eléctrico es por la(s) puerta(s) principales, } \\
\text { ya que, algunas estaciones cuentan con } \\
\text { más de una entrada (En el caso de la } \\
\text { estación La Cultura, solo hay una entrada). } \\
\text { Los horarios de mayor afluencia en la } \\
\text { LÍNEA1 son: De } 6 \text { a 10am y de } 5 \text { a } 9 \mathrm{pm} \\
\text { en los cuales los trenes operan a su } \\
\text { máxima capacidad. }\end{array}$ \\
\hline 2,3 & $\begin{array}{l}\text { - Acercarse a la boletería. } \\
\text { - Comprar tu tarjeta de } \\
\text { atención. }\end{array}$ & $\begin{array}{l}\text { En caso que el usuario sea nuevo o no } \\
\text { cuente con una tarjeta de atención, será } \\
\text { necesario que se traslade a la boletería y } \\
\text { pueda comprar una "nueva tarjeta de } \\
\text { atención" vinculada a su DNI. Esta tarjeta } \\
\text { puede ser: } \\
\text { - Tarjeta medio pasaje. } \\
\text { - Tarjeta pasaje adulto. }\end{array}$ \\
\hline 4,5 & $\begin{array}{l}\text { - Acercarse al módulo de } \\
\text { Recarga. } \\
\text { - Cargar tarjeta. }\end{array}$ & $\begin{array}{l}\text { En caso la tarjeta que tenga el usuario se } \\
\text { encuentre sin saldo disponible para pagar } \\
\text { por el servicio, es necesario que el usuario } \\
\text { se traslade al "módulo de recarga" y siga } \\
\text { los siguientes pasos: } \\
\text { 1. Colocar la tarjeta. } \\
\text { 2. Seleccionar cargar la tarjeta } \\
\text { indicando el monto que desee } \\
\text { recargar y siga las instrucciones. } \\
\text { 3. Cuando se active la luz verde, } \\
\text { deberá ingresar sus monedas o } \\
\text { billetes, dependiendo del modo } \\
\text { que desee realizar el pago. } \\
\text { 4. Finalizado el paso anterior, deberá } \\
\text { recoger su comprobante. } \\
\text { 5. Al recoger su comprobante, podrá } \\
\text { guardarlo o depositarlo en los } \\
\text { tachos de basura. }\end{array}$ \\
\hline 6,7 & $\begin{array}{l}\text { - } \begin{array}{l}\text { Seleccionar un torniquete } \\
\text { de ingreso habilitado. }\end{array} \\
\end{array}$ & $\begin{array}{l}\text { - Una vez se tenga la tarjeta } \\
\text { recargada, se debe ubicar los }\end{array}$ \\
\hline
\end{tabular}




\begin{tabular}{|c|c|c|}
\hline & - Validar el ingreso. & $\begin{array}{l}\text { torniquetes de ingreso que estén } \\
\text { habilitados y colocar la tarjeta en } \\
\text { la lectora ubicada a mano derecha } \\
\text { para validar nuestro ingreso. } \\
\text { - Cuando la luz verde se encienda, } \\
\text { ya se puede ingresar por la barra } \\
\text { ubicada al lado izquierdo. (Este } \\
\text { procedimiento es obligatorio para } \\
\text { todos los usuarios) }\end{array}$ \\
\hline 8,13 & $\begin{array}{l}\text { - Usar las escaleras/ascensor } \\
\text { para dirigirse al andén. } \\
\text { - Usar las escaleras/ascensor } \\
\text { para salir del andén. }\end{array}$ & $\begin{array}{l}\text { - Una vez pasado el torniquete de } \\
\text { ingreso, el usuario tiene dos } \\
\text { opciones para continuar con el } \\
\text { flujo del servicio; pueden usar las } \\
\text { escaleras o usar el ascensor para } \\
\text { llegar a los andenes del tren } \\
\text { localizados en la planta del } \\
\text { segundo nivel de las instalaciones. } \\
\text { - El ascensor es de uso exclusivo } \\
\text { para quienes los necesiten } \\
\text { (Embarazadas, madres con hijos } \\
\text { pequeños, ancianos, } \\
\text { discapacitados, etc). } \\
\text { En el momento que se llega al } \\
\text { destino deseado, el procedimiento } \\
\text { es el mismo para la salida. }\end{array}$ \\
\hline $9,10,11$ & $\begin{array}{l}\text { - Seleccionar el andén } \\
\text { correcto. } \\
\text { - Esperar tras la línea } \\
\text { amarilla el arribo del tren. } \\
\text { - } \begin{array}{l}\text { Ingresar al Tren } \\
\text { seleccionado. }\end{array}\end{array}$ & $\begin{array}{l}\text { - Cuando se pasen los torniquetes, el } \\
\text { usuario debe dirigirse hacia el } \\
\text { andén correcto guiándose con los } \\
\text { letreros y señales de orientación. } \\
\text { Una vez en el andén, deben } \\
\text { distribuirse a lo largo de esta y } \\
\text { mantenerse siempre detrás de la } \\
\text { línea amarilla hasta que el tren se } \\
\text { haya detenido por completo. }\end{array}$ \\
\hline $\begin{array}{c}12,14 \\
15\end{array}$ & $\begin{array}{l}\text { - } \quad \text { Salir del tren destino. } \\
\text { - } \quad \text { Validar la salida. } \\
\text { Salir de las instalaciones } \\
\text { de la Estación del Tren } \\
\text { eléctrico. }\end{array}$ & $\begin{array}{l}\text { - Cuando el usuario llega a su } \\
\text { destino debe seleccionar y } \\
\text { acercarse a un torniquete de salida } \\
\text { para retirarse de la estación. } \\
\text { - Primero debe colocar su tarjeta en } \\
\text { la lectora ubicada a su mano } \\
\text { izquierda y salir por la barra } \\
\text { ubicada a su lado derecho cuando } \\
\text { la luz verde se encienda. (Este } \\
\text { procedimiento es obligatorio para } \\
\text { todos los usuarios) }\end{array}$ \\
\hline
\end{tabular}

Fuente: Elaboración Propia 
Después de haber analizado el flujograma y el mapa de rutas sugeridas, se ha podido identificar que el lugar con mayor afluencia de usuarios durante el uso del servicio son los torniquetes, en los cuales se llevan a cabo las actividades $(1,6,7,12,14,15)$. Durante estas actividades, todos los usuarios son canalizados por un mismo sendero, ya que no pueden ingresar o salir de la estación si no atraviesan estos torniquetes. Por este motivo, se optará por instalar las baldosas PAVEGEN pasando los torniquetes de ingreso a la estación, para así lograr un mejor aprovechamiento de las pisadas o energía cinética de los usuarios; esto conllevará a una mayor generación de energía por parte de las baldosas.

En las otras actividades, el flujo de las personas es desordenado e impredecible, ya que depende de muchas variables personales de cada usuario; debido a ello, no han sido seleccionadas para la instalación de las baldosas a primera instancia.

Después de haber seleccionado los puntos en donde se instalarán las baldosas, se ha realizado un nuevo diagrama de flujo para poder visualizar si es que la implementación de esta tecnología perjudicará o incomodará a los usuarios del tren eléctrico. 


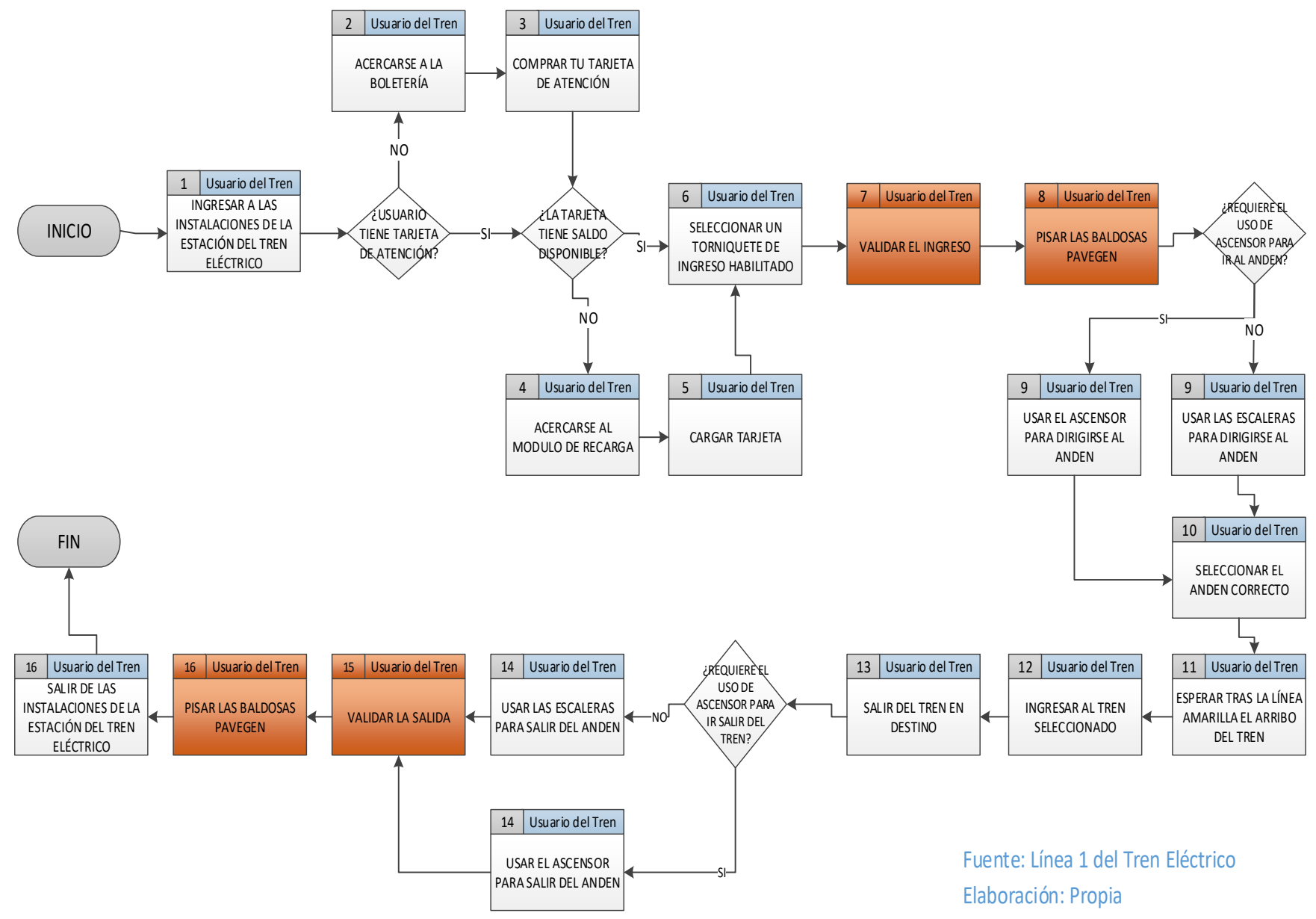

Fuente: Elaboración Propia

Como se puede observar en el nuevo diagrama de flujo, la implementación de las baldosas no afecta en lo más mínimo ninguna de las otras actividades realizadas por los usuarios, ya que estas remplazarán solamente unas zonas del piso por el cual suelen transitar los mismos.

En el siguiente subcapítulo, se podrá visualizar la distribución y el diseño arquitectónico para la instalación de las baldosas PAVEGEN en los puntos críticos de la Estación La Cultura del tren eléctrico. 


\subsubsection{Cálculo del Lote óptimo de Baldosas a instalar en la Estación}

Una de las principales variables para el desarrollo de este proyecto es el número de baldosas a instalar, por lo cual se utilizará la Programación Lineal para el cálculo del lote óptimo de baldosas a instalar en la estación La Cultura. Una vez planteado el caso con la función objetivo y las ecuaciones de restricción, se introducirán las mismas al software LINGO para poder interpretar los resultados.

A continuación, se modelará el caso:

\section{PLANTEAMIENTO DEL PROBLEMA}

\section{Función objetivo:}

Se planteará como función objetivo a la Utilidad que se obtendrá con la energía generada por las baldosas instaladas, valorizadas a una tarifa de energía regular (S/ $0.417 \mathrm{x} \mathrm{kW}), \mathrm{y}$ considerando los costos implicados en su adquisición. Vale decir que nuestro objetivo será maximizar las utilidades obtenidas, buscando un lote óptimo de baldosas a instalar considerando ciertas variables y restricciones que se definirán a continuación:

\section{Variables:}

- Afluencia:

o La estación tiene una afluencia de personas promedio de 29,413 personas diarias.

- Costo:

o El costo total de la inversión para las baldosas no debe exceder los $\mathrm{S} / 401,390.04$ que son los costos energéticos que incurre la estación.

- Adquisición:

o La adquisición de las baldosas tiene un costo unitario de S/. 1,265 por baldosa.

- Espacio: 
o Se sabe que cada baldosa tiene una dimensión de 0,45 x 0,60 m y además se considerara un espacio adicional alrededor de cada una de 0,025 m. Es por esto que las dimensiones finales a considerar serán de $0,5 \times 0,65 \mathrm{~m}$, lo cual nos da como resultado que cada baldosa ocupa un espacio de $0,325 \mathrm{~m}^{2}$.

o El espacio disponible para la implementación de las baldosas es de 0,5 $\mathrm{m}$ de ancho y 3,9 m de largo, lo cual nos da como resultado un espacio de aproximadamente $2 \mathrm{~m}^{2}$ por carril.

- La cantidad de pasos por persona, dependerá del número de baldosas que se instalen por carril. Según la universidad del estado de Colorado, se estima que la longitud de los pasos de un hombre es de 0,415 con respecto a su estatura, mientras que en el caso de las mujeres es de 0,413 respectivamente. (INEN, 2006). Para esto se ha investigado cual es la altura promedio de los peruanos y se ha encontrado que el promedio de estatura de los hombres es de $164 \mathrm{~cm}$ y el de las mujeres es de $151 \mathrm{~cm}$, con una media de 158,5 cm. (INEN, 2006). Con esta información se ha calculado la distancia de cada pisada por persona como se ve a continuación:

Tabla $\mathrm{N}^{\circ}$ 16: Distancia promedio de las pisadas de los peruanos

\begin{tabular}{|c|c|c|c|}
\hline \multicolumn{4}{|c|}{ Cálculo de distancia de pisadas según estatura (Perú) } \\
Genero & Estatura (cm) & $\begin{array}{c}\text { Factor de } \\
\text { conversión }\end{array}$ & $\begin{array}{c}\text { Distancia por pisada } \\
\text { (cm) }\end{array}$ \\
\hline Hombres & 164,0 & 0,415 & 68,06 \\
\hline Mujeres & 151,0 & 0,413 & 62,363 \\
\hline Media & 158,5 & 0,414 & 65,619 \\
\hline
\end{tabular}

\section{Fuente: Propia}

o Como se puede observar las pisadas de cada persona oscilan entre $62,363 \mathrm{~cm}$ y $68,06 \mathrm{~cm}$, con un promedio de $65,619 \mathrm{~cm}$. Estas distancias son muy similares al largo de las baldosas $(65 \mathrm{~cm})$, por lo cual se estima que cada baldosa representara una pisada. 
o La estación cuenta con 10 torniquetes.

- Energía:

o Cada baldosa puede almacenar 7W por pisada.

o Se busca que el ahorro sea mayor a un $30 \%$ de los costos energéticos de la estación (S/ 401,390.04).

o Se considerará una eficiencia energética del $70 \%$ con respecto a la energía generada por las pérdidas en la derivación de la energía.

\section{MODELO MATEMÁTICO}

Luego de analizar el caso con la información presentada previamente, se planteó un modelo matemático que lo resuelva dando el resultado óptimo.

Para el siguiente modelo se presentarán las siguientes variables con su respectiva representación en las ecuaciones:

$\mathrm{X}=$ Número óptimo de baldosas

$\mathrm{Y}=$ Costos de las baldosas

$\mathrm{Z}=$ Cantidad de energía obtenida valorizada

$\mathrm{W}=$ Espacio utilizado

Según estas variables y la información definida para el caso, se plantearon las siguientes ecuaciones:

$\operatorname{Max}$.

$$
\begin{gathered}
\left(\frac{7 \text { Watts } \times 29413 \text { personas } \times 365 \text { días } \times 70 \% \times S / .0 .4172 k W \times \frac{X}{10}}{1000 \frac{\text { Watts }}{k W}}\right) \\
-S / .1265 \times X
\end{gathered}
$$

s. a:

\section{RESTRICCIONES DE COSTO:}




$$
\begin{aligned}
& Y=S / 1265 \times X \\
& Y \leq S / 401,390.04
\end{aligned}
$$

\section{RESTRICCIONES DE ENERGÍA:}

$$
Z=\left(\frac{7 \text { Watts } \times 29413 \text { personas } \times 365 \text { días } \times 70 \% \times \frac{S}{.} 0.4172 \mathrm{~kW} \times \frac{X}{10}}{1000 \frac{W a t t s}{k W}}\right)
$$

$Z \geq 30 \% \times S / 401,390.04$

\section{RESTRICCIONES DE ESPACIO:}

$$
\begin{aligned}
& W=0.325 m^{2} \times X \\
& W \leq 2 m^{2} \times 10 \text { torniquetes }
\end{aligned}
$$

$$
X, Y, Z, W \geq 0
$$

\section{INTRODUCCIÓN DE EL MODELO MATEMÁTICO AL SOFTWARE LINGO}

Una vez planteado el modelo matemático, se introducirá las ecuaciones al software LINGO, el cual calculará los valores óptimos para la resolución del caso:

Figura $N^{\circ}$ 44: Modelo de Programación Lineal en LINGO 


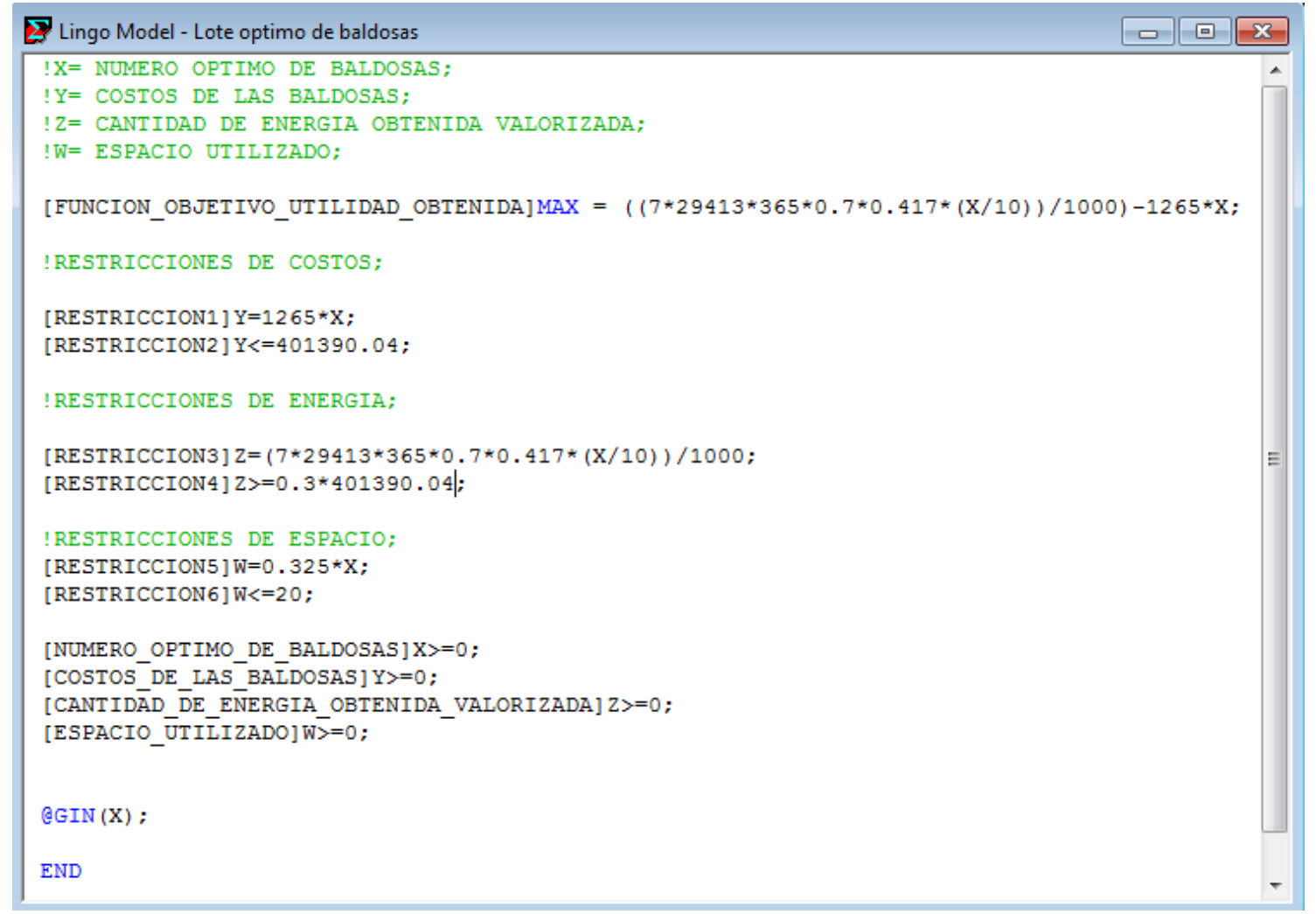

Fuente: Elaboración Propia

Una vez introducidas las ecuaciones en el software, se procede a resolver el modelo obteniendo los siguientes resultados:

Figura $N^{\circ}$ 45: Resultados del Modelo en LINGO 

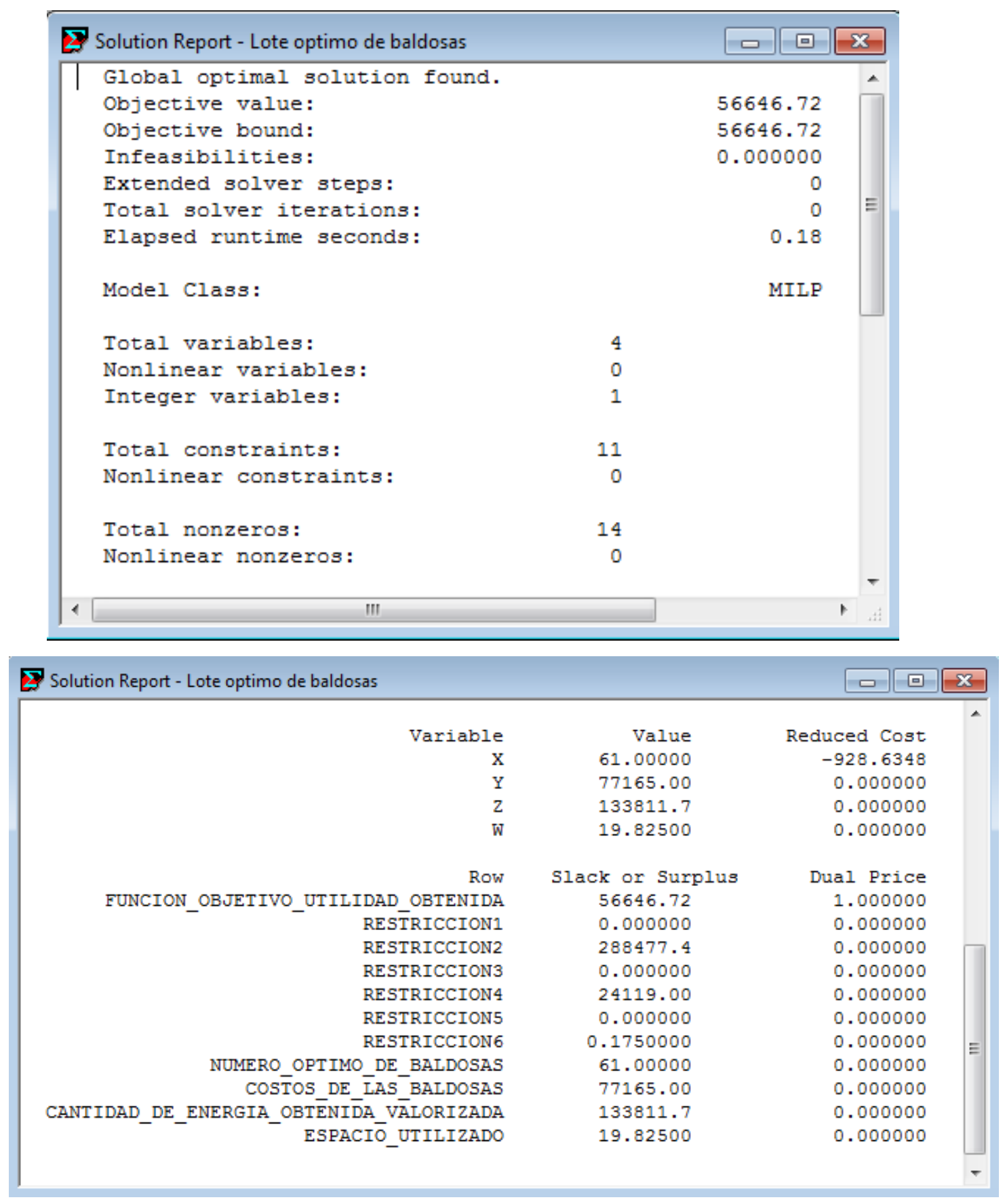

Fuente: Elaboración Propia

\section{INTERPRETACIÓN DE RESULTADOS}


Ya con el modelo resuelto, se pueden interpretar los resultados obtenidos con la corrida en el software LINGO.

1. Como resultado óptimo, se concluyó que la variable "X" es igual a "60". Esto quiere decir que la cantidad óptima de baldosas a instalar según el resultado del software, es de 61 baldosas. Como se mencionó en el planteamiento del caso, existen 10 torniquetes, por lo cual es recomendable instalar la misma cantidad de baldosas en cada carril de torniquete. Vale decir que la cantidad de baldosas consideradas para el desarrollo del proyecto será de 60, con una distribución de 6 por cada hilera de torniquete.

2. Con la instalación de las 61 baldosas se obtuvo como resultado un costo de adquisición (Variable Y) de S/ 77,165.00.

3. Con la instalación de las 61 baldosas se obtuvo como resultado una cantidad de energía obtenida valorizada (Variable Z) de S/ 133,811.7.

4. Esto nos da como resultado que la utilidad obtenida (Función Objetivo) por la instalación de 61 baldosas es de S/ 56,646.72.

5. Con la instalación de 61 baldosas se obtuvo como resultado un espacio utilizado (Variable W) de $19.825 \mathrm{~m}^{2}$.

6. Finalmente, en la columna Reduced Cost se puede apreciar que por cada baldosa adicional instalada se incrementan las utilidades en S/. 928.63.

7. Se puede concluir según los resultados obtenidos y la interpretación de los mismos, que la cantidad de baldosas a instalar para que el desarrollo del proyecto sea el óptimo debe ser de 60 baldosas. Para los cálculos posteriores se utilizará como dato dicha cantidad. 


\subsubsection{Cálculo de beneficios de la Implementación}

A continuación, se podrán observar diversas tablas de cálculo con los posibles ahorros con tres escenarios cada una, ya que el primero se basará principalmente en la información brindada por la institución AATE que confirma el ingreso de 29,413 personas al día, pero este escenario no considera las personas que salen de la estación. Por este motivo, se realizó una encuesta tanto a los usuarios que entraban como a los que salían de la estación consultándoles si es que ellos entraban y salían por la misma estación el mismo día, obteniendo como resultado que el $85,6 \%$ de los usuarios transitaban por la estación 2 veces al día, lo cual brinda una afluencia de salida equivalente al 85,6\% de la afluencia de entrada. En el escenario número dos, se considerará tanto la afluencia de entrada como la afluencia de salida. El tercer escenario contemplará la implementación de las baldosas en todas las estaciones del tren eléctrico, lo cual permitirá aprovechar tanto la afluencia de entrada como de salida de todas las personas que utilizan este servicio durante todo el año. La encuesta realizada donde se pudo hallar que el 85,6\% de las personas que entran por la estación La Cultura también salen por ella, podrá ser visualizada en el (Anexo 4).

Tabla N 17: Cálculo de Ahorros en los tres escenarios con 6 Pasos aprovechados por Usuario 


\begin{tabular}{|l|r|r|r|}
\hline \multicolumn{4}{|c|}{ 6 PASOS POR PERSONA } \\
\hline \multicolumn{1}{|c|}{ ESCENARIOS } & \multicolumn{2}{c|}{ Estación La Cultura } & $\begin{array}{c}\text { Todas las } \\
\text { Estaciones }\end{array}$ \\
\hline $\begin{array}{l}\text { Afluencia Anual de la Estación La } \\
\text { Cultura }\end{array}$ & Escenario 1 & Escenario 2 & Escenario 3 \\
\hline Días al año & $\mathbf{1 0 , 7 3 5 , 8 3 0}$ & $\mathbf{1 9 , 9 6 8 , 6 4 3 . 8 0}$ & $\mathbf{2 3 6 , 0 4 2 , 5 8 0}$ \\
\hline Flujo de personas diario & 365 & 365 & 365 \\
\hline Numero de pasos (6 pasos/persona) & 29,413 & 54,709 & 646,692 \\
\hline Watt por paso = W W & 176,479 & 328,252 & $3,880,152$ \\
\hline kW generados por día & 1,235 & $2,297,762$ & $27,161,064$ \\
\hline kWh generados al día. & 73 & 2,298 & 27,161 \\
\hline Porcentaje de Eficiencia Estimado & $70 \%$ & 135 & 1,598 \\
\hline Costo kW & 0.42 & 0.70 & 0.70 \\
\hline Ahorro Diario S/. & 360.95 & 0.42 & 0.42 \\
\hline Ahorro Mensual S/. & $10,828.39$ & $20,140.80$ & $238,077.59$ \\
\hline Ahorro Anual S/. & $\mathbf{1 3 1 , 7 4 5 . 3 9}$ & $\mathbf{2 4 1 , 6 8 9 . 6 1}$ & $\mathbf{2 , 8 5 6 , 9 3 1 . 0 8}$ \\
\hline
\end{tabular}

Fuente: Elaboración Propia

Tabla N 18: Cálculo de Ahorros en los tres escenarios con 7 Pasos aprovechados por Usuario

\begin{tabular}{|l|r|r|r|}
\hline \multicolumn{1}{|c|}{ 7 PASOS POR PERSONA } \\
\hline \multicolumn{1}{|c|}{ ESCENARIOS } & \multicolumn{2}{c|}{ Estación La Cultura } & $\begin{array}{c}\text { Todas las } \\
\text { Estaciones }\end{array}$ \\
\hline $\begin{array}{l}\text { Afluencia Anual de la Estación La } \\
\text { Cultura }\end{array}$ & \multicolumn{1}{|c|}{ Escenario 1 } & Escenario 2 & Escenario 3 \\
\hline Días al año & $10,735,830$ & $19,968,643$ & $236,042,580$ \\
\hline Flujo de personas diario & 365 & 365 & 365 \\
\hline Numero de pasos (7 pasos/persona) & 29,413 & 54,709 & 646,692 \\
\hline Watt por paso = W & 205,893 & 382,960 & $4,526,844$ \\
\hline kW generados por día & $1,441,248.46$ & $2,680,722$ & $31,687,908$ \\
\hline kWh generados al día. & $1,441.25$ & $2,680.72$ & 31,688 \\
\hline Porcentaje de Eficiencia Estimado & 84.78 & 158 & 1,864 \\
\hline Costo kW & $70 \%$ & $70 \%$ & 0.70 \\
\hline Ahorro Diario S/. & 0.4174 & 0.4174 & 0.42 \\
\hline Ahorro Mensual S/. & 421.10 & 783.25 & $9,258.57$ \\
\hline Ahorro Anual S/. & $\mathbf{1 5 3 , 7 0 2 . 9 5}$ & $\mathbf{2 8 1 , 9 7 1 . 2 1}$ & $\mathbf{3 , 3 3 3 , 0 8 6 . 2 7}$ \\
\hline
\end{tabular}

Fuente: Elaboración Propia

Tabla N 19: Cálculo de Ahorros en los tres escenarios con 8 Pasos aprovechados por Usuario 


\begin{tabular}{|l|r|r|r|}
\hline \multicolumn{4}{|c|}{ 8 PASOS POR PERSONA } \\
\hline \multicolumn{1}{|c|}{ ESTACIONES } & \multicolumn{2}{|c|}{ Estación La Cultura } & $\begin{array}{c}\text { Todas las } \\
\text { Estaciones }\end{array}$ \\
\hline $\begin{array}{l}\text { ESCNARIOS } \\
\text { Cultura }\end{array}$ & $\begin{array}{r}\text { Escenario } \\
\mathbf{1}\end{array}$ & \multicolumn{1}{c|}{$\begin{array}{c}\mathbf{2} \\
\text { Escenario }\end{array}$} & Escenario 3 \\
\hline Días al año & $\mathbf{1 0 , 7 3 5 , 8 3 0}$ & $\mathbf{1 9 , 9 6 8 , 6 4 3}$ & $\mathbf{2 3 6 , 0 4 2 , 5 8 0}$ \\
\hline Flujo de personas diario & 365 & 365 & 365 \\
\hline Numero de pasos (8 pasos/persona) & 29,413 & 54,709 & 646,692 \\
\hline Watt por paso = 7 W & 235,306 & 437,672 & $5,173,536$ \\
\hline kW generados por día & $1,647,141$ & $3,063,704$ & $36,214,752$ \\
\hline kWh generados al día. & $1,647.14$ & 3,064 & 36,215 \\
\hline Porcentaje de Eficiencia Estimado & 96.89 & 180.22 & 2,130 \\
\hline Costo kW & $70 \%$ & $70 \%$ & 0.70 \\
\hline Ahorro Diario S/. & 0.4174 & 0.42 & 0.42 \\
\hline Ahorro Mensual S/. & 481.26 & 895.15 & $10,581.23$ \\
\hline Ahorro Anual S/. & 14437.85 & $26,854.59$ & $317,436.79$ \\
\hline
\end{tabular}

Fuente: Elaboración Propia

El consumo actual energético de la Estación de La Cultura es de 961,643.60kW anuales aproximadamente, los cuales representan un costo de S/. 401,390.04, de cuales se estima reducir como mínimo el $32.82 \%$ y como máximo el $80.28 \%$. Por otro lado, si es que se lleva a cabo la implementación de este sistema de generación de energía renovable en todas las estaciones del tren eléctrico, se podría ahorrar como mínimo un 95,23\% del costo total energético de las estaciones, el cual equivale a 3 millones de soles y como máximo un 127\%, lo cual permitiría reducir el déficit total de 27 millones de soles anuales que asume el Estado peruano entre un $10,6 \%$ y un $14,2 \%$. 
Tabla $N^{\circ}$ 20: Costos y ahorros Energéticos Estación la Cultura

\begin{tabular}{|c|c|c|c|}
\hline \multicolumn{2}{|c|}{ COSTOS } & \multicolumn{2}{c|}{ AHORROS } \\
\hline COSTOS TOTALES & $\begin{array}{c}\text { COSTOS ESTACIÓN } \\
\text { LA CULTURA }\end{array}$ & MÍNIMO & MÁXIMO \\
\hline S/.3.000.000,00 & S/ $401,390.04$ & S/ $131,745.39$ & S/ 322,255.09 \\
\hline \multicolumn{2}{|c|}{ PROPORCIÓN } & $\mathbf{3 2 . 8 2 \%}$ & $\mathbf{8 0 . 2 8 \%}$ \\
\hline
\end{tabular}

$\underline{\text { Fuente: Elaboración propia }}$

Tabla $N^{\circ} 21$ : Costos y ahorros Energéticos del tren eléctrico

\begin{tabular}{|c|c|c|c|}
\hline \multicolumn{2}{|c|}{ COSTOS } & \multicolumn{2}{c|}{ AHORROS } \\
\hline COSTOS TOTALES & $\begin{array}{c}\text { COSTOS } \\
\text { ENERGÉTICOS }\end{array}$ & UNA ESTACIÓN & $\begin{array}{c}\text { TODAS LAS } \\
\text { ESTACIONES }\end{array}$ \\
\cline { 1 - 2 } S/. $3.000 .000,00$ & S/ $3,000,000$ & $\mathbf{4 , 4 \%}$ & $\mathbf{9 5 , 2 3 \%}$ \\
\hline \multicolumn{2}{|c|}{ AHORRO MINIMO } & $\mathbf{1 0 , 7 4 \%}$ & $\mathbf{1 2 7 \%}$ \\
\hline \multicolumn{2}{|c|}{ AHORRO MAXIMO }
\end{tabular}

Fuente: Elaboración propia

Tabla N 22: Porcentaje de Ahorro del Déficit del Estado

\begin{tabular}{|c|c|c|}
\hline COSTOS & \multicolumn{2}{|c|}{ AHORROS } \\
\cline { 1 - 1 } Déficit Actual & \multirow{2}{*}{ UNA ESTACIÓN } & TODAS LAS ESTACIONES \\
\hline S/ $\mathbf{2 6 , 8 7 0 , 5 0 6}$ & $\mathbf{0 , 5} \%$ & $\mathbf{1 0 , 6 \%}$ \\
\hline AHORRO MINIMO & $\mathbf{1 , 2} \%$ & $\mathbf{1 4 , 2} \%$ \\
\hline AHORRO MAXIMO & & \\
\hline
\end{tabular}

Fuente: Elaboración Propia

\subsubsection{Análisis de Riesgos}

Para poder estar a la vanguardia de cualquier percance y ocurrencia inesperada, se ha elaborado una matriz de evaluación de riesgos, la cual permitirá tener un plan de contingencia como respuesta a cualquier riesgo que pueda sufrir el proyecto. 
Tabla No 23: Matriz de Riesgos

\begin{tabular}{|c|c|c|c|c|c|c|}
\hline Nro & $\begin{array}{c}\text { RIESGO / } \\
\text { CONSECUENCIA }\end{array}$ & IMPACTO & PROB & SEVERIDAD & SEVERIDAD & MITIGACIÓN \\
\hline 1 & $\begin{array}{l}\text { Probabilidad que AATE no } \\
\text { acepte el proyecto }\end{array}$ & 0.8 & 0.5 & 0.4 & Alta & $\begin{array}{l}\text { - Preparar un análisis sobre la sostenibilidad del proyecto y presentarlo a la } \\
\text { empresa AATE con el fin de captar su interés mediante visitas, } \\
\text { presentaciones, antecedentes de proyectos similares, etc. } \\
\text { - Se podría tener en cuenta otras empresas públicas o privadas interesadas en } \\
\text { este tipo de producto. } \\
\text { - Estudio de mercado para expandir alcance. } \\
\text { - Asistir a ferias tecnológicas en el Perú para captar la atención de empresas } \\
\text { privadas y generar futuros proyectos con ellas. } \\
\text { - Promover el proyecto y la tecnología Pavegen mediante Marketing, planes } \\
\text { piloto, publicidad, etc. }\end{array}$ \\
\hline 2 & $\begin{array}{l}\text { Problemas de } \\
\text { almacenamiento de energía } \\
\text { del condensador }\end{array}$ & 0.8 & 0.1 & 0.08 & Media & $\begin{array}{l}\text { - Estudio de pre-factibilidad y pruebas respectivas al condensador antes de } \\
\text { adquirirlo. } \\
\text { - Evaluar la posibilidad de tener repuestos para la disponibilidad inmediata. } \\
\text { - Mantener contacto permanentemente con los proveedores, para así asegurar } \\
\text { un mantenimiento inmediato. } \\
\text { - Incluir en el contrato cláusulas de mantenimiento anual por un lapso de } 2 \\
\text { años. }\end{array}$ \\
\hline 3 & $\begin{array}{l}\text { Daño de las baldosas } \\
\text { durante la importación } \\
\text { (función y apariencia) }\end{array}$ & 0.4 & 0.2 & 0.08 & Media & $\begin{array}{l}\text { - Contratar un buen transportista y un buen seguro de importación para la } \\
\text { mercancía, el cual pueda cubrir los costos totales del producto dañado. }\end{array}$ \\
\hline 4 & $\begin{array}{l}\text { Incumplimiento de } \\
\text { expectativas ofrecidas al } \\
\text { cliente }\end{array}$ & 0.8 & 0.1 & 0.08 & Media & $\begin{array}{l}\text { - Obtener un cierto número de baldosas extras para generar una holgura de } \\
\text { ahorro mayor a la ofrecida. }\end{array}$ \\
\hline 5 & $\begin{array}{l}\text { Caída de los usuarios al } \\
\text { caminar sobre las baldosas } \\
\text { PAVEGEN }\end{array}$ & 0.8 & 0.1 & 0.06 & Alta & $\begin{array}{l}\text { - Obtener Información sobre la deformación de las baldosas al caminar de las } \\
\text { personas. } \\
\text { - Analizar la posible implementación de barandas, mediante un diseño } \\
\text { antropométrico. } \\
\text { - Garantizar a la institución AATE que los usuarios no se caerán. }\end{array}$ \\
\hline 6 & $\begin{array}{l}\text { Incumplimiento de obreros } \\
\text { "Retrasos del proyecto" }\end{array}$ & 0.2 & 0.1 & 0.02 & Baja & $\begin{array}{l}\text { - Ofrecer bonificaciones a nuestros obreros contratados para el correcto } \\
\text { cumplimiento de sus labores. } \\
\text { - Cláusulas de contrato. }\end{array}$ \\
\hline 7 & $\begin{array}{l}\text { Falta de apoyo de AATE } \\
\text { "Recorte del presupuesto } \\
\text { y/o Alargamiento de los } \\
\text { plazos de pagos" }\end{array}$ & 0.4 & 0.1 & 0.04 & Baja & $\begin{array}{l}\text { - Establecer términos y condiciones específicas en contrato con AATE. } \\
\text { - Generarles interés y compromiso para el cumplimiento del proyecto. }\end{array}$ \\
\hline 8 & $\begin{array}{l}\text { Quejas por parte de los } \\
\text { usuarios del "Tren } \\
\text { eléctrico" }\end{array}$ & 0.05 & 0.1 & 0.005 & Baja & $\begin{array}{l}\text { - Informar los beneficios que traerá consigo el proyecto a los clientes un mes } \\
\text { antes de su implementación, para que así estos se encuentren interesados en } \\
\text { ver en funcionamiento esta nueva tecnología. } \\
\text { - Esta información se entregará mediante el uso de volantes o grandes paneles } \\
\text { publicitarios pegados por las paredes de la estación del tren eléctrico. }\end{array}$ \\
\hline 9 & $\begin{array}{l}\text { Problemas de } \\
\text { incumplimiento por parte } \\
\text { de PAVEGEN }\end{array}$ & 0.8 & 0.1 & 0.08 & Media & $\begin{array}{l}\text { - Generar contratos de abastecimiento y exclusividad con Pavegen, con } \\
\text { cláusulas de penalización por incumplimiento. }\end{array}$ \\
\hline
\end{tabular}

- Ofrecer el proyecto al Metropolitano y posteriormente a establecimientos como supermercados, centros comerciales, etc.

- Visita a empresas privadas frecuentadas por personas.

- Participacín constante en ferias tecnológicas y Participación constante en ferias tecia
conferencias para salir al mercado.

- Contactar al proveedor del condensador y exigirles un cambio de generador por motivos de garantía.

- Por otro lado, se podría adaptar o reparar el condensador para su correcto funcionamiento.

- Apelación a la garantía contratada para recuperar el dinero perdido.

- Cobrar los sobrecostos al transportista.

- Instalación de las baldosas extras para poder cumplir con el ahorro propuesto.

- Implementación de barandas antropométricas segun la estatura promedio de los usuarios.

- Exigir al contratista la contratación de mano de obra extra para poder recuperar los retrasos.

- Buscar el financiamiento por parte de otra entidad financiera para poder cumplir con los plazos del proyecto ext timpo establecido y asi generar una buena imagen de la empresa.

- Clausurar el área donde se llevará a cabo la instalación de las baldosas por partes, para así no impedir el tránsito total de las personas.

- Apelar al contrato establecido, obligándolos así a cumplir y asumir los costos extras generados por el incumplimiento en el plazo establecido. 


\begin{tabular}{|c|c|c|c|c|c|c|c|}
\hline Nro & $\begin{array}{l}\text { RIESGO } / \\
\text { CONSECUENCIA }\end{array}$ & IMPACTO & PROB & SEVERIDAD & SEVERIDAD & MITIGACIÓN & CONTINGENCIA \\
\hline 10 & $\begin{array}{l}\text { Documentación legal mal } \\
\text { elaborada y con retrasos: a } \\
\text { nivel interno y documentos } \\
\text { de importación }\end{array}$ & 0.4 & 0.5 & 0.2 & Alta & $\begin{array}{l}\text { - Contratar un buen asesor legal especializado en importaciones y contratos } \\
\text { con clientes internacionales. }\end{array}$ & $\begin{array}{l}\text { - Priorizar el arreglo de estos documentos } \\
\text { mediante el apoyo del asesor legal y } \\
\text { posiblemente un par de asesores extras para } \\
\text { acelerar el proceso. }\end{array}$ \\
\hline 11 & $\begin{array}{l}\text { Calidad de los equipos no } \\
\text { cumplen las exigencias y } \\
\text { requerimientos }\end{array}$ & 0.8 & 0.1 & 0.08 & Media & - Establecer en el contrato la calidad de las baldosas. & $\begin{array}{l}\text { - Contactar a PAVEGEN y la solución de este } \\
\text { problema. } \\
\text { - PAVEGEN deberá de enviar un técnico a reparar } \\
\text { sus baldosas o el remplazo de las mismas. }\end{array}$ \\
\hline 12 & $\begin{array}{l}\text { Desabastecimiento de } \\
\text { productos e incumplimiento } \\
\text { de plazos "productos } \\
\text { nacionales referidos a la } \\
\text { obra civil que se realizará" }\end{array}$ & 0.4 & 0.3 & 0.12 & Media & $\begin{array}{l}\text { - Homologar buenos proveedores y establecer contratos rigurosos en cuanto } \\
\text { a tiempos, cantidad y calidad. En estos contratos, también se especificarán } \\
\text { las cláusulas de penalización. }\end{array}$ & $\begin{array}{l}\text { - Buscar un proveedor local para satisfacer las } \\
\text { necesidades correspondientes al momento. } \\
\text { - Posteriormente, se aplicará la penalización al } \\
\text { proveedor que incumplió con lo establecido en el } \\
\text { contrato. }\end{array}$ \\
\hline 13 & $\begin{array}{l}\text { Fenómenos que impidan } \\
\text { que el buque, que } \\
\text { transporta las baldosas de } \\
\text { Inglaterra a Perú, llegue a } \\
\text { tiempo. }\end{array}$ & 0.2 & 0.1 & 0.02 & Baja & $\begin{array}{l}\text { - Planificar que el arribo del buque al Perú tenga una holgura de } 3 \text { semanas } \\
\text { antes del periodo de instalación. } \\
\text { - Gestionar los documentos de aduanas antes de su llegada para agilizar los } \\
\text { trámites. }\end{array}$ & $\begin{array}{l}\text { - Aplicar el "Crashing" al proyecto, par a poder } \\
\text { finalizarlo en el tiempo establecido. }\end{array}$ \\
\hline 14 & $\begin{array}{l}\text { Fenómenos climatológicos } \\
\text { que afecten la instalación } \\
\text { de las baldosas (lluvia y } \\
\text { exceso de humedad) }\end{array}$ & 0.4 & 0.1 & 0.04 & Baja & $\begin{array}{l}\text { - Instalar un recubrimiento en la zona de trabajo, para proteger el perímetro } \\
\text { del mismo. }\end{array}$ & $\begin{array}{l}\text { - Tomar mayores precauciones los siguientes días, } \\
\text { ya que si sucedió una vez podría suceder } \\
\text { nuevamente. } \\
\text { - Reparar los daños ocasionados por estos } \\
\text { fenómenos. }\end{array}$ \\
\hline 15 & $\begin{array}{l}\text { Fenómenos externos que } \\
\text { afecten la integridad del } \\
\text { proyecto "robo, daños" }\end{array}$ & 0.4 & 0.7 & 0.28 & Alta & $\begin{array}{l}\text { - Exigir a AATE la vigilancia } 24 \text { horas al día mediante al menos un guardia. } \\
\text { - Verificar el funcionamiento correcto de las cámaras de seguridad. }\end{array}$ & $\begin{array}{l}\text { - Usar las baldosas extras que se adquirieron en la } \\
\text { importación. } \\
\text { - Exigir a AATE un reembolso por los daños } \\
\text { ocasionados por los clientes, ya que no } \\
\text { cumplieron bien con su rol de vigilancia. }\end{array}$ \\
\hline
\end{tabular}

\section{Fuente: Elaboración Propia}


Como resultado de la matriz de impactos, identificamos 4 principales riesgos con severidad alta, los cuales son:

- Probabilidad que AATE no acepte el proyecto.

- Posibles caídas de los usuarios al caminar sobre las baldosas PAVEGEN.

- Documentación legal mal elaborada y con retrasos: a nivel interno y documentos de importación.

- Fenómenos externos que afecten la integridad del proyecto "robo, daños".

Para cada uno de los riesgos, se presentan en la matriz un plan de mitigación y de contingencia, lo cual nos permitirá estar preparados para cualquier tipo de percance y/o accidente de ocurrencia inoportuna en el transcurso del proyecto. A continuación, se presentará la asignación de riesgos con sus respectivos responsables. 
Tabla N²4: Asignación de Riesgos

\begin{tabular}{|c|c|c|c|c|}
\hline Nro. & $\begin{array}{c}\text { RIESGO / } \\
\text { CONSECUENCIA }\end{array}$ & CATEGORIA & $\begin{array}{c}\text { FECHA DE } \\
\text { IDENTIFICACION }\end{array}$ & ASIGNADO A \\
\hline 1 & $\begin{array}{l}\text { Probabilidad que AATE no } \\
\text { acepte el proyecto }\end{array}$ & $\begin{array}{l}\text { Gestión del } \\
\text { Proyecto }\end{array}$ & $12 / 8 / 2015$ & Renato Concha \\
\hline 2 & $\begin{array}{l}\text { Problemas de } \\
\text { almacenamiento de energía } \\
\text { del condensador }\end{array}$ & Implementación & $12 / 8 / 2015$ & $\begin{array}{l}\text { Rodrigo } \\
\text { Zamalloa }\end{array}$ \\
\hline 3 & $\begin{array}{l}\text { Daño de las baldosas } \\
\text { durante la importación } \\
\text { "tanto en funcionamiento } \\
\text { como en apariencia" }\end{array}$ & Abastecimiento & $12 / 8 / 2015$ & $\begin{array}{l}\text { Rodrigo } \\
\text { Zamalloa }\end{array}$ \\
\hline 4 & $\begin{array}{l}\text { Incumplimiento de las } \\
\text { expectativas ofrecidas al } \\
\text { cliente "el ahorro obtenido } \\
\text { es menor al propuesto" }\end{array}$ & Cierre & $12 / 8 / 2015$ & $\begin{array}{l}\text { Rodrigo } \\
\text { Zamalloa }\end{array}$ \\
\hline 5 & $\begin{array}{l}\text { Posibles caídas de los } \\
\text { usuarios al caminar sobre } \\
\text { las baldosas PAVEGEN }\end{array}$ & Implementación & $18 / 08 / 2015$ & $\begin{array}{l}\text { Rodrigo } \\
\text { Zamalloa }\end{array}$ \\
\hline 6 & $\begin{array}{l}\text { Incumplimiento de obreros } \\
\text { "Retrasos del proyecto" }\end{array}$ & Implementación & $20 / 8 / 2015$ & Renato Concha \\
\hline 7 & $\begin{array}{c}\text { Falta de apoyo de AATE } \\
\text { "Recorte del presupuesto- } \\
\text { Alargamiento de plazo de } \\
\text { pagos" }\end{array}$ & Implementación & $28 / 8 / 2015$ & Renato Concha \\
\hline 8 & $\begin{array}{l}\text { Quejas por parte de los } \\
\text { usuarios del Tren eléctrico " }\end{array}$ & Implementación & $28 / 8 / 2015$ & Renato Concha \\
\hline 9 & $\begin{array}{l}\text { Problemas de } \\
\text { incumplimiento por parte } \\
\text { de PAVEGEN }\end{array}$ & Abastecimiento & $28 / 8 / 2015$ & Renato Concha \\
\hline 10 & $\begin{array}{l}\text { Documentación legal mal } \\
\text { elaborada y con retrasos: a } \\
\text { nivel interno y también } \\
\text { documentos de importación }\end{array}$ & Abastecimiento & $28 / 8 / 2015$ & Renato Concha \\
\hline 11 & $\begin{array}{l}\text { Calidad de los equipos no } \\
\text { cumplen las exigencias y } \\
\text { requerimientos }\end{array}$ & Implementación & $28 / 8 / 2015$ & $\begin{array}{l}\text { Rodrigo } \\
\text { Zamalloa }\end{array}$ \\
\hline 12 & $\begin{array}{l}\text { Falta de cumplimiento del } \\
\text { abastecimiento de los } \\
\text { productos y fechas de } \\
\text { entrega "productos } \\
\text { nacionales referidos a la } \\
\text { obra civil que se realizará" }\end{array}$ & Abastecimiento & $28 / 8 / 2015$ & $\begin{array}{l}\text { Rodrigo } \\
\text { Zamalloa }\end{array}$ \\
\hline 13 & $\begin{array}{c}\text { Fenómenos que impidan } \\
\text { que el buque que transporta } \\
\text { las baldosas de Inglaterra a } \\
\text { Perú llegue a tiempo. }\end{array}$ & Abastecimiento & $28 / 8 / 2015$ & $\begin{array}{l}\text { Rodrigo } \\
\text { Zamalloa }\end{array}$ \\
\hline 14 & $\begin{array}{l}\text { Fenómenos climatológicos } \\
\text { que afecten la instalación de } \\
\text { las baldosas (lluvia y } \\
\text { exceso de humedad) }\end{array}$ & Implementación & $28 / 8 / 2015$ & $\begin{array}{l}\text { Rodrigo } \\
\text { Zamalloa }\end{array}$ \\
\hline
\end{tabular}




\section{Fuente: Elaboración Propia}

\subsubsection{Propuesta 2: Cambio de luminaria en la estación}

Según el levantamiento de información que se realizó en la estación La Cultura y la matriz energética elaborada, actualmente la estación cuenta con luminaria Fluorescente CFL, las cuales tienen un consumo promedio diario de $301,4 \mathrm{~kW}$ en total.

Mediante la instalación de Luminarias LED, se podría reducir este consumo en un total de $150.87 \mathrm{~kW}$ al día, lo cual equivale a S/. 62.97 diarios y a un total de S/ 22,985.20 soles anualmente. Este ahorro representa aproximadamente un 5,7\% de los costos energéticos actuales de la estación.

A continuación, se presentará la nueva matriz energética elaborada con la nueva luminaria: 
Tabla No 25: Matriz Energética propuesta

\begin{tabular}{|c|c|c|c|c|c|c|c|c|c|c|c|c|c|c|c|c|c|c|c|c|c|c|c|c|c|c|c|c|c|c|c|c|c|c|c|}
\hline \multicolumn{36}{|c|}{ Análisis del consumo energético de la Estación La Cultura } \\
\hline & \multirow[b]{2}{*}{ Zona } & \multirow[b]{2}{*}{ Artefacto } & \multirow[b]{2}{*}{ Cantidad } & \multicolumn{2}{|c|}{ Potencia } & \multicolumn{24}{|c|}{ Hora } & \multicolumn{4}{|c|}{ Consumo } & \multirow{2}{*}{\begin{tabular}{|c|} 
Precio \\
kW-h \\
(S/.)
\end{tabular}} & \multirow{2}{*}{$\begin{array}{l}\text { Costo } \\
\text { Total }\end{array}$} \\
\hline & & & & (Watt) & $(\mathrm{kW})$ & 1 & 2 & 3 & 4 & 5 & 6 & 7 & 8 & 9 & 10 & 11 & 12 & 13 & 14 & 15 & 16 & $17 \mid$ & 18 & 19 & 20 & 21 & 22 & 23 & 24 & Días & \begin{tabular}{|c|} 
Horas \\
(diarias)
\end{tabular} & \begin{tabular}{|c|} 
Kw-h \\
(diarios)
\end{tabular} & $\begin{array}{c}\mathbf{k W}-\mathbf{h} \\
\text { (mensual) }\end{array}$ & & \\
\hline & Tablero T-AT-JP1A & Alumbrado LED & 173 & 13 & 0.01 & 0.0 & 0.0 & 0.0 & 0.0 & 0.0 & 1.0 & 1.0 & 1.0 & 0.0 & 0.0 & 0.0 & 0.0 & 0.0 & 0.0 & 0.0 & 0.0 & 0.5 & 1.0 & 1.0 & 1.0 & 1.0 & 1.0 & \begin{tabular}{|l|l}
0.5 \\
0.5
\end{tabular} & 0.0 & 30 & $\begin{array}{l}9.0 \\
90\end{array}$ & 19.46 & 583.88 & 0.42 & $\frac{243.71}{0.15}$ \\
\hline & Tablero T-AT-JPIB & $\begin{array}{l}\text { Alumbrado LED } \\
\text { Tomacorriente }\end{array}$ & $\frac{65}{4}$ & $\begin{array}{r}13 \\
500\end{array}$ & 0.50 & $\mid \begin{array}{l}0.0 \\
0.0\end{array}$ & $\begin{array}{l}0.0 \\
0.0 \\
\end{array}$ & $\begin{array}{l}0.0 \\
0.0\end{array}$ & 0.0 & 0.0 & 0.6 & $\begin{array}{l}1.0 \\
0.6\end{array}$ & $\begin{array}{l}1.0 \\
0.6\end{array}$ & $\begin{array}{l}0.0 \\
0.6 \\
\end{array}$ & $\begin{array}{l}0.0 \\
0.6 \\
\end{array}$ & 0.0 & 0.6 & 0.0 & 0.0 & 0.0 & $\begin{array}{l}0.0 \\
0.6\end{array}$ & 0.6 & $\begin{array}{l}1.0 \\
0.6 \\
\end{array}$ & $\begin{array}{l}1.0 \\
0.6 \\
\end{array}$ & $\begin{array}{l}1.0 \\
0.6 \\
\end{array}$ & $\begin{array}{l}1.0 \\
0.6\end{array}$ & $\begin{array}{l}1.0 \\
0.6\end{array}$ & $\begin{array}{l}0.5 \\
0.6 \\
\end{array}$ & $\begin{array}{l}0.0 \\
0.0\end{array}$ & 30 & $\begin{array}{l}9.0 \\
10.8 \\
\end{array}$ & $\begin{array}{r}7.31 \\
21.60\end{array}$ & $\begin{array}{l}219.38 \\
648.00\end{array}$ & 0.42 & $\begin{array}{c}91.57 \\
270.48\end{array}$ \\
\hline & & \begin{tabular}{|l} 
Tomacorriente Industrial \\
$220 \mathrm{~V}$
\end{tabular} & 3 & 4,000 & 4.00 & 0.0 & 0.0 & 0.0 & 0.0 & 0.0 & 1.0 & 1.0 & 1.0 & 1.0 & 1.0 & 0.5 & 0.5 & 1.0 & 1.0 & 0.5 & 0.5 & 0.5 & 0.0 & 1.0 & 1.0 & 0.5 & 0.5 & 0.5 & 0.0 & 30 & 13.0 & 156.00 & $4,680.00$ & 0.42 & $1,953.43$ \\
\hline & Tablero T-AP-JP2A & \begin{tabular}{|c} 
Tomacorriente Industrial \\
$380 \mathrm{~V}$ \\
\end{tabular} & 3 & 10,000 & 10.00 & 0.0 & 0.0 & 0.0 & 0.0 & 0.0 & 1.0 & 1.0 & 1.0 & 1.0 & \begin{tabular}{|l|l|}
1.0 \\
\end{tabular} & 0.5 & 0.5 & 1.0 & 1.0 & 0.5 & \begin{tabular}{|c|c|c|}
0.5 & \\
\end{tabular} & 0.5 & 0.0 & 1.0 & 1.0 & 0.5 & 0.5 & 0.5 & 0.0 & 30 & 13.0 & 390.00 & $11,700.00$ & 0.42 & $4,883.58$ \\
\hline & & 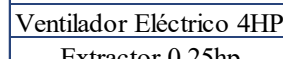 & 2 & 2,983 & 2.98 & 0.0 & 0.0 & 0.0 & 0.0 & 0.0 & 0.0 & 1.0 & 1.0 & 1.0 & 1.0 & 1.0 & 1.0 & 1.0 & 1.0 & 1.0 & 1.0 & 1.0 & 1.0 & 1.0 & 1.0 & 0.0 & 0.0 & 0.0 & 0.0 & 30 & 14.0 & 83.52 & $2,505.55$ & 0.42 & $1,045.82$ \\
\hline & & $\begin{array}{l}\text { Extractor } 0.25 \text { Shp } \\
\text { Tomacorriente }\end{array}$ & $\frac{1}{4}$ & $\frac{186}{500}$ & 0.19 & \begin{tabular}{|l|}
0.0 \\
0.0
\end{tabular} & \begin{tabular}{|l|}
0.0 \\
0.0
\end{tabular} & 0.0 & $\begin{array}{l}0.0 \\
0.0\end{array}$ & \begin{tabular}{l|l}
0.0 & $(1$ \\
0.0 & $(1$
\end{tabular} & $\begin{array}{l}0.0 \\
0.6\end{array}$ & $\begin{array}{l}0.0 \\
0.6\end{array}$ & 1.0 & $\begin{array}{l}1.0 \\
0.6\end{array}$ & \begin{tabular}{|l|l|}
1.0 & 0.6 \\
0.6 & \\
\end{tabular} & 1.0 & $\frac{1.0}{0.6}$ & 1.0 & $1.0 \mid$ & \begin{tabular}{l|l}
1.0 & \\
0.6 &
\end{tabular} & \begin{tabular}{l|l}
1.0 & 0 \\
0.6 & \\
\end{tabular} & \begin{tabular}{l|l}
1.0 & 0.6 \\
0.6 &
\end{tabular} & \begin{tabular}{l|l}
1.0 \\
0.6
\end{tabular} & $\begin{array}{l}1.0 \\
0.6\end{array}$ & \begin{tabular}{|l|}
1.0 \\
0.6
\end{tabular} & 0.0 & $\begin{array}{l}0.0 \\
0.6\end{array}$ & \begin{tabular}{|l|l|}
0.0 & 0.6 \\
0.6 & \\
\end{tabular} & 0.0 & $\begin{array}{l}30 \\
30\end{array}$ & $\begin{array}{l}\frac{13.0}{10.8} \\
10.8\end{array}$ & $\begin{array}{r}2.42 \\
21.60\end{array}$ & $\frac{72.70}{648.00}$ & 0.42 & $\begin{array}{c}30.35 \\
270.48\end{array}$ \\
\hline & & \begin{tabular}{|l} 
Tomacorriente Industrial \\
$220 \mathrm{~V}$
\end{tabular} & 2 & 4,000 & 4.00 & 0.0 & 0.0 & 0.0 & 0.0 & 0.0 & 1.0 & 1.0 & 1.0 & 1.0 & 1.0 & 0.5 & 0.5 & 1.0 & 1.0 & 0.5 & 0.5 & 0.5 & 0.0 & 1.0 & 1.0 & 0.5 & 0.5 & 0.5 & 0.0 & 30 & 13.0 & 104.00 & $3,120.00$ & 0.42 & $1,302.29$ \\
\hline & Tablero T-AP-JP2B & \begin{tabular}{|c|} 
Tomacoorriente Industrial \\
$380 \mathrm{~V}$ \\
\end{tabular} & 2 & 10,000 & 10.00 & 0.0 & 0.0 & 0.0 & 0.0 & 0.0 & 1.0 & 1.0 & 1.0 & 1.0 & 1.0 & 0.5 & 0.5 & 1.0 & 1.0 & 0.5 & \begin{tabular}{|c|c|c|c|}
0.5 & 6 \\
\end{tabular} & 0.5 & 0.0 & 1.0 & 1.0 & 0.5 & 0.5 & 0.5 & 0.0 & 30 & 13.0 & 260.00 & $7,800.00$ & 0.42 & $3,255.72$ \\
\hline & & Ventilador Eléctrico 4HP & 2 & 2,983 & 2.98 & \begin{tabular}{l|l|}
0.0 \\
\end{tabular} & 0.0 & 0.0 & 0.0 & 0.0 & 0.0 & 1.0 & 1.0 & 1.0 & \begin{tabular}{l|l}
1.0 \\
\end{tabular} & 1.0 & 1.0 & 1.0 & 1.0 & 1.0 & \begin{tabular}{l|l}
1.0 \\
10
\end{tabular} & 1.0 & 1.0 & 1.0 & 1.0 & 0.0 & 0.0 & \begin{tabular}{l|l}
0.0 \\
\end{tabular} & 0.0 & 30 & 14.0 & 83.52 & $2,505.55$ & 0.42 & $1,045.82$ \\
\hline & & $\begin{array}{l}\text { Extractor } 0.25 \mathrm{hp} \\
\text { Alumbrado OED }\end{array}$ & $\frac{1}{104}$ & $\frac{186}{13}$ & $\begin{array}{l}0.19 \\
0.01\end{array}$ & \begin{tabular}{|l|}
0.0 \\
0.0
\end{tabular} & \begin{tabular}{|l|}
0.0 \\
0.0
\end{tabular} & 0.0 .0 & 0.0 & 0.0 & $\frac{0.0}{1.0}$ & $\begin{array}{l}0.0 \\
1.0\end{array}$ & $\frac{1.0}{1.0}$ & $\frac{1.0}{0.0}$ & \begin{tabular}{l|l}
1.0 & \\
0.0 &
\end{tabular} & $\frac{1.0}{0.0}$ & $\frac{1.0}{0.0}$ & $\frac{1.0}{0.0}$ & $\frac{1.0}{0.0}$ & 1.0 & \begin{tabular}{l|l}
1.0 & 0.0 \\
0.0 & 0
\end{tabular} & \begin{tabular}{l|l}
1.0 \\
0.5
\end{tabular} & \begin{tabular}{l|l}
$\frac{1.0}{1.0}$ \\
1
\end{tabular} & $\frac{1.0}{1.0}$ & \begin{tabular}{|l|l|}
1.0 \\
1.0
\end{tabular} & $\frac{0.0}{1.0}$ & $\frac{0.0}{1.0}$ & \begin{tabular}{|l|l}
0.0 & 0.5 \\
\end{tabular} & 0.0 & $\frac{30}{30}$ & $\frac{13.0}{9.0}$ & 2.42 & $\frac{72.70}{3510}$ & 0.42 & $\begin{array}{l}30.35 \\
14651\end{array}$ \\
\hline & Tablero TE-AT-JPA & Luminarias de & 3 & 30 & 0.03 & 0.0 & 0.0 & 0.0 & 0.0 & 0.0 & 0.0 & 0.0 & 0.0 & 0.0 & \begin{tabular}{|l|}
0.0 \\
\end{tabular} & 0.0 & 0.0 & 0.0 & 0.0 & 0.0 & 0.0 & 0.0 & 0.0 & 0.0 & 0.0 & 0.0 & 0.0 & \begin{tabular}{|l|}
0.0 \\
\end{tabular} & 0.0 & 30 & 0.0 & 0.00 & 0.00 & 0.42 & 0.00 \\
\hline & & $\begin{array}{l}\text { Ev } \\
\text { Alum }\end{array}$ & 43 & 13 & 0.01 & 0.0 & 00 & 00 & 00 & 0.0 & 10 & 10 & 10 & 00 & \begin{tabular}{|l|}
0.0 \\
\end{tabular} & 00 & 00 & 0.0 & 00 & 00 & $\mid \begin{array}{l}0.0 \\
0.0\end{array}$ & 05 & 10 & 10 & 10 & 10 & 10 & 05 & 00 & 30 & 90 & & & 0.42 & 60.58 \\
\hline & Tablero TE-AT-JP1B & Aire A & 2 & 6,150 & 6.15 & 0.0 & 0.0 & 0.0 & 0.0 & 0.0 & 0.0 & 0.0 & 0.5 & 1.0 & \begin{tabular}{|l|}
0.0 \\
\end{tabular} & 0.0 & 1.0 & 1.0 & 1.0 & 1.0 & 0.0 & 0.0 & 1.0 & 1.0 & 1.0 & 0.0 & 0.0 & $\mid \begin{array}{l}0.0 \\
\end{array}$ & 0.0 & 30 & 8.5 & 10 & $\frac{3,136.50}{3,50}, 0$ & $\frac{12}{12}$ & $1,309.18$ \\
\hline & & & 3 & 30 & & 0.0 & 0.0 & 0.0 & 0.0 & 0.0 & 0.0 & 0.0 & 0.0 & 0.0 & 0.0 & 0.0 & 0.0 & 0.0 & 0.0 & 0.0 & \begin{tabular}{l|l|l|l|}
0.0 \\
\end{tabular} & 0.0 & 0.0 & 0.0 & 0.0 & 0.0 & 0.0 & \begin{tabular}{|l|}
0.0 \\
\end{tabular} & 0.0 & 30 & 0. & & & & 0.00 \\
\hline & & & 43 & 13 & 0.01 & 0.0 & 0.0 & 0.0 & 0.0 & 0.0 & 1.0 & 1.0 & 1.0 & 0.0 & 0.0 & 0.0 & 0.0 & 0.0 & 0.0 & 0.0 & 0.0 & 0.5 & 1.0 & 1.0 & 1.0 & 1.0 & 1.0 & 0.5 & 0.0 & 30 & 9.1 & & 145.13 & 1. & 60.58 \\
\hline & Tablero TE-AT-JPB & Aire $A$ & 2 & 6,150 & 6.15 & 0.0 & 0.0 & 0.0 & 0.0 & 0.0 & 0.0 & 0.0 & 0.5 & 1.0 & \begin{tabular}{l|l}
0.0 \\
\end{tabular} & 0.0 & 1.0 & 1.0 & 1.0 & 1.0 & \begin{tabular}{l|l}
0.0 & 1 \\
\end{tabular} & 0.0 & 1.0 & 1.0 & 1.0 & 0.0 & 0.0 & \begin{tabular}{|l|l|}
0.0 \\
\end{tabular} & 0.0 & 30 & 8.5 & 104.55 & $3,136.50$ & 0.42 & $1,309.18$ \\
\hline & & $\begin{array}{l}\text { Luminarias de } \\
\text { Evacuación }\end{array}$ & 3 & 30 & 0.03 & 0.0 & 0.0 & 0.0 & 0.0 & 0.0 & 0.0 & 0.0 & 0.0 & 0.0 & 0.0 & 0.0 & 0.0 & 0.0 & 0.0 & 0.0 & 0.0 & 0.0 & 0.0 & 0.0 & 0.0 & 0.0 & 0.0 & 0.0 & 0.0 & 30 & 0.0 & 0.00 & 0.00 & 0.42 & 0.00 \\
\hline & Tablero T-B Cuarto de & $\begin{array}{l}\text { Alumbrado LED y } \\
\text { Tomacorreinte }\end{array}$ & 33 & 13 & 0.01 & 0.0 & 0.0 & 0.0 & 0.0 & 0.0 & 1.0 & 1.0 & 1.0 & 0.0 & 0.0 & 0.0 & 0.0 & 0.0 & 0.0 & 0.0 & \begin{tabular}{|l|l|l|l|}
0.0 & 1 \\
\end{tabular} & 0.5 & 1.0 & 1.0 & 1.0 & 1.0 & 1.0 & 0.5 & 0.0 & 30 & 9.0 & 3.71 & 111.38 & 0.42 & 46.49 \\
\hline & Bomba & Bombas de Agua & 2 & 1,119 & 1.12 & 0.0 & \begin{tabular}{|l|}
0.0 \\
\end{tabular} & 0.0 & 0.0 & 0.0 & 1.0 & 1.0 & 1.0 & 1.0 & 1.0 & 1.0 & 1.0 & 1.0 & 1.0 & 1.0 & 1.0 & 1.0 & 1.0 & 1.0 & 1.0 & 1.0 & 1.0 & 0.0 & 0.0 & 30 & 17.0 & 38.03 & $1,140.91$ & 0.42 & 476.21 \\
\hline & Tablero T-BA Bombas & Bombas de Agua & 2 & 1,119 & 1.12 & 0.0 & 0.0 & 0.0 & 0.0 & 0.0 & 1.0 & 1.0 & 1.0 & 1.0 & \begin{tabular}{l|l}
1.0 & \\
\end{tabular} & 1.0 & 1.0 & 1.0 & 1.0 & 1.0 & 1.0 & \begin{tabular}{l|l}
1.0 \\
\end{tabular} & \begin{tabular}{|c|c|}
1.0 & \\
\end{tabular} & 1.0 & 1.0 & 1.0 & 1.0 & \begin{tabular}{|l|l|}
0.0 & \\
\end{tabular} & 0.0 & 30 & 17.0 & 38.03 & $1,140.91$ & 0.42 & 476.21 \\
\hline & Total del $F$ & Área Técnica & - & $\mid 121,411$ & 121.41 & & & & & & & & & & & & & & & & & & & & & & & & & 30 & - & $1,462.11$ & $43,863.19$ & 0.42 & $18,308.50$ \\
\hline & & \begin{tabular}{|c} 
Alumbrado LED \\
Alumlurdar LCD Antuem
\end{tabular} & 450.00 & 5 & 0.01 & 0.0 & 0.0 & 0.0 & 0.0 & 0.0 & 1.0 & 1.0 & 1.0 & 0.0 & \begin{tabular}{|l|l|l|}
0.0 \\
\end{tabular} & 0.0 & 0.0 & 0.0 & 0.0 & 0.0 & 0.0 & 0.5 & 1.0 & 1.0 & 1.0 & 1.0 & 1.0 & 0.5 & 0.0 & 30 & 9.0 & 20.25 & 607.50 & 0.42 & 253.57 \\
\hline & & 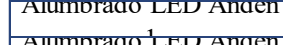 & 24.00 & 28 & 0.03 & 0.0 & \begin{tabular}{|l|}
0.0 \\
\end{tabular} & 0.0 & 0.0 & 0.0 & 1.0 & 1.0 & 1.0 & 0.0 & \begin{tabular}{l|l}
0.0 \\
\end{tabular} & 0.0 & 0.0 & 0.0 & 0.0 & 0.0 & \begin{tabular}{|l|l|}
0.0 & \\
\end{tabular} & 0.5 & 1.0 & 1.0 & 1.0 & 1.0 & 1.0 & \begin{tabular}{l|l}
0.5 \\
\end{tabular} & 0.0 & 30 & 9.0 & 6.05 & 181.44 & 0.42 & 75.73 \\
\hline & Tablero TE-AP-JP & Alumbraco LCD Antuen & 24.00 & 28 & 0.03 & \begin{tabular}{|l|}
0.0 \\
\end{tabular} & 0.0 & 0.0 & 0.0 & 0.0 & 1.0 & 1.0 & 1.0 & 0.0 & 0.0 & 0.0 & 0.0 & 0.0 & 0.0 & 0.0 & 0.0 & 0.5 & 1.0 & 1.0 & 1.0 & 1.0 & 1.0 & 0.5 & 0.0 & 30 & 9.0 & 6.05 & 181.44 & 0.42 & 75.73 \\
\hline & & 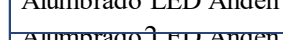 & 24.00 & 28 & 0.03 & 0.0 & 0.0 & 0.0 & 0.0 & 0.0 & 1.0 & 1.0 & 1.0 & 0.0 & 0.0 & 0.0 & 0.0 & 0.0 & 0.0 & 0.0 & 0.0 & 0.5 . & 1.0 & 1.0 & 1.0 & 1.0 & 1.0 & 0.5 & 0.0 & 30 & 9.0 & 6.05 & 181.44 & 0.42 & 75.73 \\
\hline & & Allmoracou LED Alluer & 24.00 & 28 & 0.03 & 0.0 & 0.0 & 0.0 & 0.0 & 0.0 & 1.0 & 1.0 & 1.0 & 0.0 & 0.0 & 0.0 & 0.0 & 0.0 & 0.0 & 0.0 & \begin{tabular}{|l|}
0.0 \\
\end{tabular} & 0.5 & 1.0 & 1.0 & 1.0 & 1.0 & 1.0 & 0.5 & 0.0 & 30 & 9.0 & 6.05 & 181.44 & 0.42 & 75.73 \\
\hline & & Ascensor 1 & 1.00 & 10,000 & 10.00 & 0.0 & 0.0 & 0.0 & 0.0 & 0.0 & 0.0 & 0.1 & 0.1 & 0.1 & \begin{tabular}{l|l}
0.1 & \\
\end{tabular} & 0.1 & 0.1 & 0.1 & 0.1 & 0.1 & \begin{tabular}{|l|}
0.1 \\
\end{tabular} & 0.1 & 0.1 & 0.1 & 0.1 & 0.1 & 0.1 & 0.0 & 0.0 & 30 & 1.6 & & 480.00 & 0.42 & 200.35 \\
\hline & Tablero T-AP-ASC-JP & Ascensor 2 & 1.0 & 10,000 & 10.00 & 0.0 & 0.0 & 0.0 & 0.0 & 0.0 & 0.0 & 0.1 & 0.1 & 0.1 & \begin{tabular}{|l|l|}
0.1 & \\
\end{tabular} & 0.1 & 0.1 & 0.1 & 0.1 & 0.1 & 0.1 & 0.1 & 0.1 & 0.1 & 0.1 & 0.1 & 0.1 & \begin{tabular}{|l|}
0.0 \\
\end{tabular} & 0.0 & 30 & 1 & & 480.00 & 0.42 & 200.35 \\
\hline & & Alumbrado LED & 675.00 & 5 & 0.01 & 0.0 & 0.0 & 0.0 & 0.0 & 0.0 & 1.0 & 1.0 & 1.0 & 0.0 & \begin{tabular}{|l|}
0.0 \\
\end{tabular} & 0.0 & 0.0 & 0.0 & 0.0 & 0.0 & 0.0 & 0.5 & 1.0 & 1.0 & 1.0 & 1.0 & 1.0 & 0.5 & 0.0 & 30 & 9.0 & 30.38 & 911.25 & 0.42 & 380.36 \\
\hline & & $\begin{array}{c}\text { Alumbrado LED y } \\
\text { Tomacorreinte Anden } 1\end{array}$ & 24.00 & 28 & 0.03 & 0.0 & 0.0 & 0.0 & 0.0 & 0.0 & 1.0 & 1.0 & 1.0 & 0.0 & \begin{tabular}{l|l}
0.0 \\
\end{tabular} & 0.0 & 0.0 & 0.0 & 0.0 & 0.0 & \begin{tabular}{|l|}
0.0 \\
\end{tabular} & 0.5 & 1.0 & 1.0 & 1.0 & 1.0 & 1.0 & \begin{tabular}{|l|}
0.5 \\
\end{tabular} & 0.0 & 30 & 9.0 & 6.05 & 181.44 & 0.42 & 75.73 \\
\hline & Tablere T_AP_IP1 & \begin{tabular}{|c} 
Alumbrado LED y \\
\end{tabular} & 24.00 & 28 & 0.03 & 0.0 & 0.0 & 0.0 & 0.0 & 0.0 & 1.0 & 1.0 & 1.0 & 0.0 & $\mid 0.0$ & 0.0 & 0.0 & 0.0 & 0.0 & 0.0 & 0.0 & 0.5 & 1.0 & 1.0 & 1.0 & 1.0 & 1.0 & 0.5 & 0.0 & 30 & 9.0 & 6.05 & 181.44 & 0.42 & 75.73 \\
\hline & & Alum & 24.00 & 28 & 0.03 & 0.0 & 0.0 & 0.0 & 0.0 & 0.0 & 1.0 & 1.0 & 1.0 & 0.0 & $\mid 0.0$ & 0.0 & 0.0 & 0.0 & 0.0 & 0.0 & 0.0 & 0.5 & 1.0 & 1.0 & 1.0 & 1.0 & 1.0 & 0.5 & 0.0 & 30 & 9.0 & 6.05 & 181.44 & 0.42 & 75.73 \\
\hline & & $\begin{aligned} \text { Alur } \\
\text { Tomac }\end{aligned}$ & 24.00 & 28 & 0.03 & 0.0 & $\mid 0.0$ & 0.0 & 0.0 & 0.0 & 1.0 & 1.0 & 1.0 & 0.0 & $\mid 0.0$ & 0.0 & 0.0 & 0.0 & 0.0 & 0.0 & \begin{tabular}{|c|}
0.0 \\
\end{tabular} & 0.5 & 1.0 & 1.0 & 1.0 & 1.0 & 1.0 & 0.5 & 0.0 & 30 & 9.0 & 6.05 & 181.44 & 0.42 & 75.73 \\
\hline & & $\begin{array}{c}\text { Tomacorreinte Ande } \\
\text { Tomacorriente }\end{array}$ & 24.00 & 180 & 0.18 & 0.0 & 0.0 & 0.0 & 0.0 & 0.0 & 0.6 & 0.6 & 0.6 & 0.6 & 0.6 & 0.6 & 0.6 & 0.6 & 0.6 & 0.6 & 0.6 & 0.6 & 0.6 & 0.6 & 0.6 & 0.6 & 0.6 & 0.6 & 0.0 & 30 & 10.8 & 46.66 & $1,399.68$ & 0.42 & 584.23 \\
\hline & Tablero T-AP-JP2 & $\begin{array}{l}\text { Tomacorriente Industrial } \\
220 \mathrm{~V}\end{array}$ & 4.00 & 4,000 & 4.00 & 0.0 & \begin{tabular}{|l|}
0.0 \\
\end{tabular} & 0.0 & 0.0 & 0.0 & 0.5 & 0.5 & 0.5 & 0.5 & \begin{tabular}{|l|} 
\\
\end{tabular} & 0.5 & 0.5 & 0.5 & 0.5 & 0.5 & 0.5 & 0.5 & 0.5 & 0.5 & 0.5 & 0.5 & 0.5 & 0.5 & 0.0 & 30 & 9.0 & 144.00 & $4,320.00$ & 0.42 & $1,803.17$ \\
\hline & & \begin{tabular}{|l|} 
Tomacorriente Industrial \\
\end{tabular} & 4.00 & 10,000 & 10.00 & $|0.0|$ & 0.0 & 0.0 & 0.0 & 0.0 & 1.0 & 1.0 & 1.0 & 1.0 & 0.5 | & 0.5 & 0.5 & 0.5 & 0.5 & 0.5 & $0.5 \mid$ & 0.5 & 0.0 & 1.0 & $\mid 1.0$ & 0.5 & 0.5 & 0.5 & 0.0 & 30 & 11.5 & 460.00 & $13,800.00$ & 0.42 & $5,760.12$ \\
\hline & T-AP-EM-JP & Escalera Mecánica & 1.00 & 15,000 & 15.00 & 0.0 & 0.0 & 0.0 & 0.0 & 0.0 & 0.0 & 0.0 & 0.0 & 0.0 & 1.0 & 1.0 & 1.0 & 1.0 & 1.0 & 1.0 & 1.0 & 1.0 & 0.0 & 0.0 & 0.0 & 0.0 & 0.0 & \begin{tabular}{|l|}
0.0 \\
\end{tabular} & 0.0 & 30 & 8.0 & 120. & 3,600 & 0.42 & $1,502.64$ \\
\hline & O I-AP-EM-JP & Escalera Mecánica & 1.00 & 15,000 & 15.00 & 0.0 & \begin{tabular}{|l|}
0.0 \\
\end{tabular} & 0.0 & 0.0 & 0.0 & 0.0 & 0.0 & 0.0 & 0.0 & \begin{tabular}{|l|l|l|}
1.0 &
\end{tabular} & 1.0 & 1.0 & 1.0 & 1.0 & 1.0 & 1.0 & 1.0 & 0.0 & 0.0 & 0.0 & 0.0 & 0.0 & 0.0 & 0.0 & 30 & 8.0 & 120.00 & $3,600.00$ & 0.42 & $1,502.64$ \\
\hline & Total del & a Pública & & 121,321 & 121.32 & & & & & & & & & & & & & & & & & & & & & & & & & 30 & & $1,021.67$ & $30,649.95$ & 0.42 & 12,793.29 \\
\hline & & IÁXIMA POTENCIA E & & & & 0 & 0 & 0 & 0 & 0 & 144 & 158 & 171 & 166 & 152 & 117 & 141 & 176 & 176 & 14 & 1171 & 125 & 73 & 183 & 183 & 91 & 91 & 76 & 0 & & & 2,483.77 & - & & $31,101.79$ \\
\hline
\end{tabular}


En la nueva matriz energética encontramos que el nuevo consumo promedio es de $137,99 \mathrm{~kW} / \mathrm{h}$ y el máximo de $183,13 \mathrm{~kW} / \mathrm{h}$. Es por esto que se realizó una comparación entre los consumos de la situación actual contra la propuesta planteada de manera gráfica:

Gráfica $N^{\circ}$ 34: Consumo energético por horario Situación Actual VS Propuesta

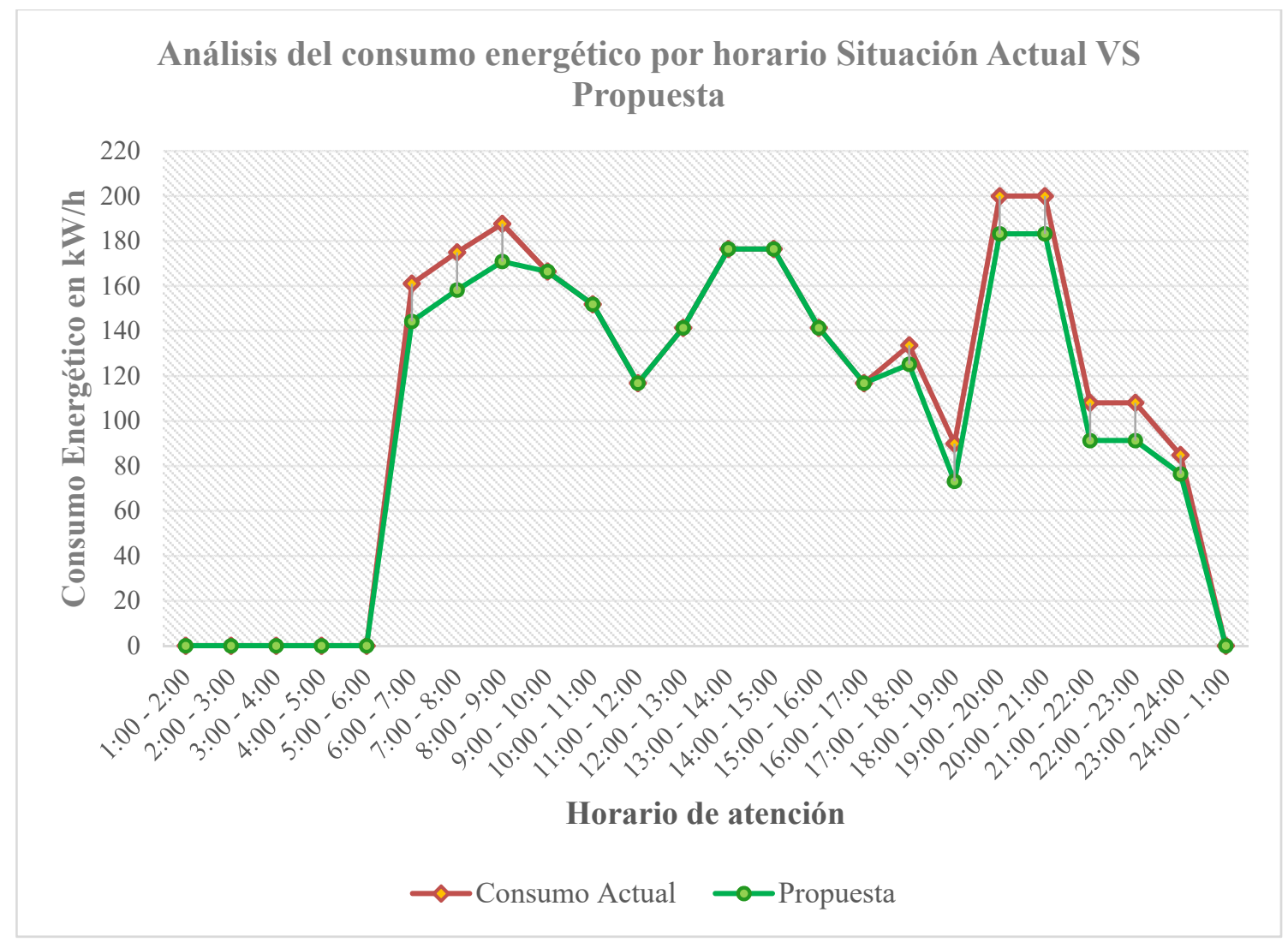

Fuente: Elaboración Propia 
Tabla N²6: Variación del consumo energético S. Actual VS Propuesta

\begin{tabular}{|c|c|c|c|c|c|c|c|c|c|}
\hline HORARIO & $6: 00$ & $7: 00$ & $8: 00$ & $9: 00$ & $10: 00$ & $11: 00$ & $12: 00$ & $13: 00$ & $14: 00$ \\
$7: 00$ & $8: 00$ & $9: 00$ & $10: 00$ & $11: 00$ & $12: 00$ & $13: 00$ & $14: 00$ & $15: 00$ \\
\hline $\begin{array}{c}\text { Situación Actual } \\
(\mathrm{kW} / \mathrm{h})\end{array}$ & 161 & 175 & 188 & 166 & 152 & 117 & 141 & 176 & 176 \\
\hline Propuesta $(\mathrm{kW} / \mathrm{h})$ & 144 & 158 & 171 & 166 & 152 & 117 & 141 & 176 & 176 \\
\hline Var. \% & $10,4 \%$ & $9,6 \%$ & $8,9 \%$ & $0,0 \%$ & $0,0 \%$ & $0,0 \%$ & $0,0 \%$ & $0,0 \%$ & $0,0 \%$ \\
\hline
\end{tabular}

Fuente: Elaboración Propia

Tabla N²7: Variación del consumo energético S. Actual VS Propuesta

\begin{tabular}{|c|c|c|c|c|c|c|c|c|c|}
\hline HORARIO & $15: 00$ & $16: 00$ & $17: 00$ & $18: 00$ & $19: 00$ & $20: 00$ & $21: 00$ & $22: 00$ & $23: 00$ \\
$16: 00$ & $17: 00$ & $18: 00$ & $19: 00$ & $20: 00$ & $21: 00$ & $22: 00$ & $23: 00$ & $24: 00$ \\
\hline $\begin{array}{c}\text { Situación Actual } \\
\text { (kW/h) }\end{array}$ & 141 & 117 & 134 & 90 & 200 & 200 & 108 & 108 & 85 \\
\hline Propuesta (kW/h) & 141 & 117 & 125 & 73 & 183 & 183 & 91 & 91 & 76 \\
\hline Var. $\%$ & $0,0 \%$ & $0,0 \%$ & $6,3 \%$ & $18,6 \%$ & $8,4 \%$ & $8,4 \%$ & $15,5 \%$ & $15,5 \%$ & $9,9 \%$ \\
\hline
\end{tabular}

\section{Fuente: Elaboración Propia}

Esta propuesta traería un ahorro promedio de $6,2 \%$ con respecto a los consumos por horario y de hasta 18,6\% en el horario de 18:00-19:00pm.

Como se puede ver, es una atractiva opción para reducir los costos energéticos de la Estación La Cultura, siempre y cuando se llegue a un acuerdo con la empresa Graña y Montero para que sea respetado y el ahorro sea reducido del monto que AATE debe pagarle trimestralmente a G\&M según lo acordado en el contrato de concesión.

La factibilidad de la realización de esta propuesta es relativamente difícil, ya que Graña y Montero recibe los recibos de luz y efectúa los pagos a EDELNOR sobre sus consumos energéticos de las estaciones. Además, según los datos obtenidos de la estación La Cultura, esta cuenta con 1778 focos los cuales podrían ser reemplazados por luminaria LED y esto generaría el ahorro de los S/. 22,985.20 soles anuales. Se calcula que realizar el cambio de todos los focos de la estación costaría alrededor de $\mathrm{S} / 80,000.00$ y el periodo de recuperación serían aproximadamente 4 años. 


\subsubsection{Selección de Propuestas de Solución}

Habiendo evaluado las 2 propuestas anteriores, se opta por elegir la Propuesta 1 que consta en la implementación de baldosas eléctricas PAVEGEN en las estaciones del Tren Eléctrico, con lo que se busca reducir los costos energéticos en una proporción mayor al $32 \%$. Esta energía renovable será generada en base al aprovechamiento de la gran afluencia de usuarios con la que cuenta este servicio público de transporte.

Es posible la implementación de esta nueva tecnología, ya que la empresa no cuenta con la capacidad de innovación tecnológica, lo cual podría traer beneficios como mejorar el servicio brindado, reducir sus costos y aumentar sus utilidades. Esta brecha tecnológica, que le impide reducir sus costos, será aprovechada mediante la implementación de un sistema completamente nuevo e innovador para la sociedad peruana.

Además, se planteará a la institución AATE aprovechar los ahorros obtenidos mediante la generación de esta energía renovable, para implementar este sistema en las estaciones que se construirán en la Línea 2 del Tren Eléctrico.

A su vez, se busca fomentar el uso de energías renovables y la cultura del ahorro energético en la población limeña, contribuyendo así con el medio ambiente.

\subsubsection{Conclusiones}

Después de haber analizado los problemas identificados en el capítulo 2 y haber propuesto dos posibles soluciones, se ha optado por considerar la instalación de un sistema de generación de energía renovable basado en la tecnología piezoeléctrica, la cual podría brindar ahorros superiores a los S/.130,000.00 anuales; esto equivale a un ahorro mayor a $32.82 \%$ y, posiblemente hasta un $80.28 \%$ del total de los costos energéticos de la Estación La Cultura, lo cual será sumamente beneficiosos para AATE.

Además de reducir los costos energéticos de la Estación la Cultura, la implementación de este sistema de energía renovable también contribuirá en reducir el impacto ambiental que trae consigo el consumo de energía no renovable, fomentar el uso de energías renovables en la población limeña e inculcar la cultura del ahorro energético en las personas. 


\subsection{Implementación de La Propuesta de Solución}

Como se ha podido evidenciar en los párrafos anteriores, la institución AATE cuenta con sobrecostos en sus operaciones, los cuales pueden ser reducidos, mediante la implementación de un sistema de generación de energía renovable, para mejorar el sistema brindado por el Tren Eléctrico, aumentar las utilidades de la institución y tratar de que las estaciones sean auto-sostenibles y no deban ser subvencionadas por el Estado peruano.

A continuación, se tratarán todos los pasos y actividades necesarias para poder implementar adecuadamente este proyecto de generación de energía renovable en la Estación la Cultura del Tren Eléctrico.

Además, se elaborará un prototipo de baldosa utilizando tecnología piezoeléctrica, con el fin de validar el aprovechamiento de la energía cinética mediante la piezoelectricidad.

\subsubsection{Diseño Arquitectónico}

Al momento de diseñar y establecer la localización de las baldosas PAVEGEN en la estación La Cultura, se localizaron puntos estratégicos mediante el análisis del comportamiento del flujo de usuarios y la metodología de distribución de planta para así maximizar la utilización de cada una de las baldosas.

Las baldosas han sido localizadas en la parte posterior de los torniquetes en 10 hileras de 6 baldosas cada una, como se podrá observar en los planos $\mathrm{N}^{\circ} 1$ y $\mathrm{N}^{\circ} 2$ elaborados en el programa AUTOCAD, lo cual implica una instalación total de 60 baldosas en toda la estación. Estas han sido instaladas solo en esta parte de la estación, ya que todos los usuarios están obligados a movilizarse por esta zona. Al inicio del proyecto se pensó en instalar las baldosas en las gradas, ya que estas aprovecharían una mayor energía cinética de las personas por la fuerza que se aplica al subir y al bajar las escaleras; sin embargo, la estación cuenta con 4 escaleras y dos ascensores, lo cual divide los 29,413 usuarios en 6 y esto minimiza la utilización de las baldosas.

Cabe resaltar que cada baldosa PAVEGEN tienen las siguientes dimensiones " $45 \mathrm{~cm}$ de ancho, $60 \mathrm{~cm}$ de largo y $6.8 \mathrm{~cm}$ de altura" como podrá ser visualizado en la siguiente 
imagen. Para el diseño se ha considerado un margen de $2.5 \mathrm{~cm}$ de ancho alrededor de cada baldosa para así poder instalar una base metálica en las cuales estarán localizadas.

Figura $N^{\circ}$ 46: Dimensiones de las baldosas PAVEGEN

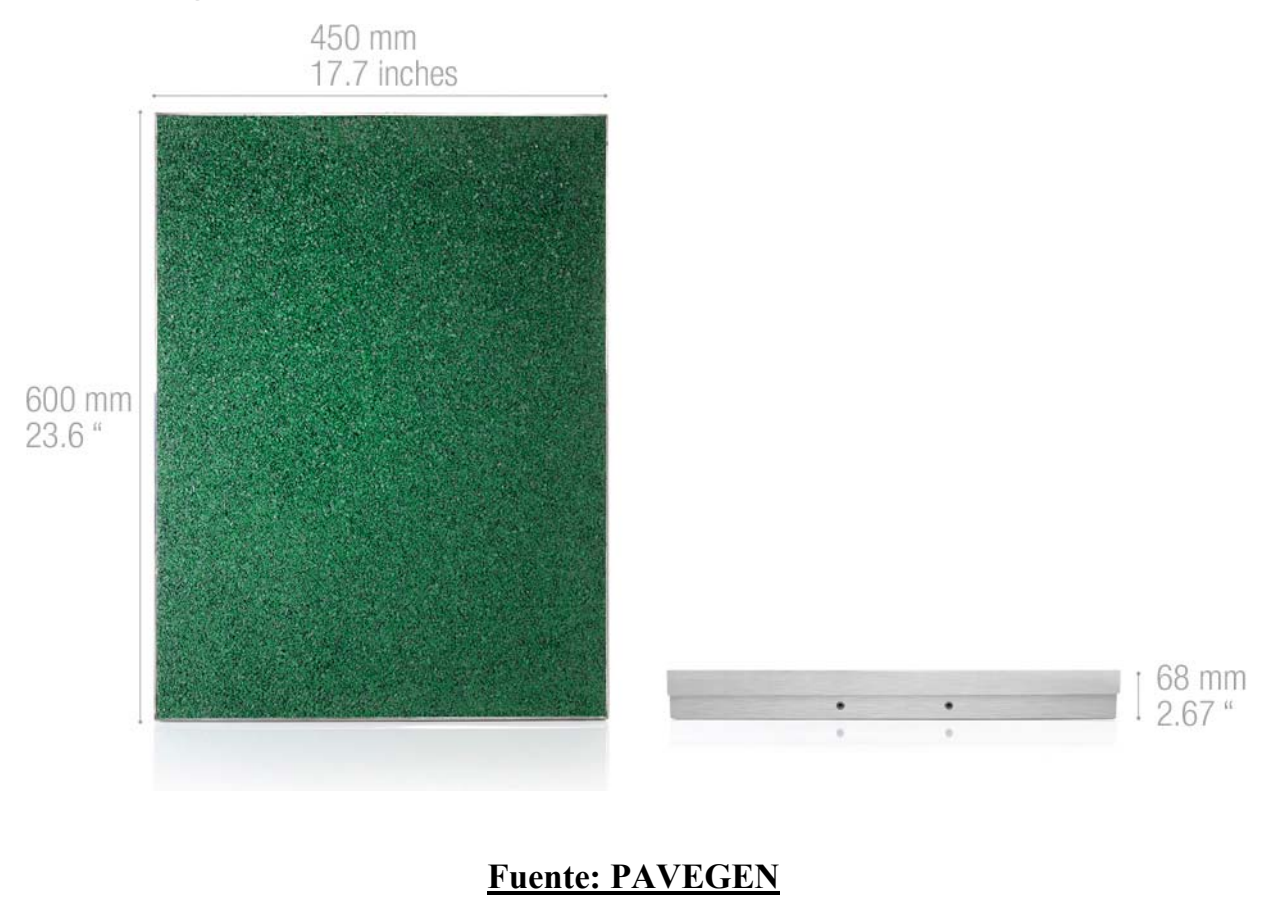

Figura $N^{\circ}$ 47: Planta Primer Nivel

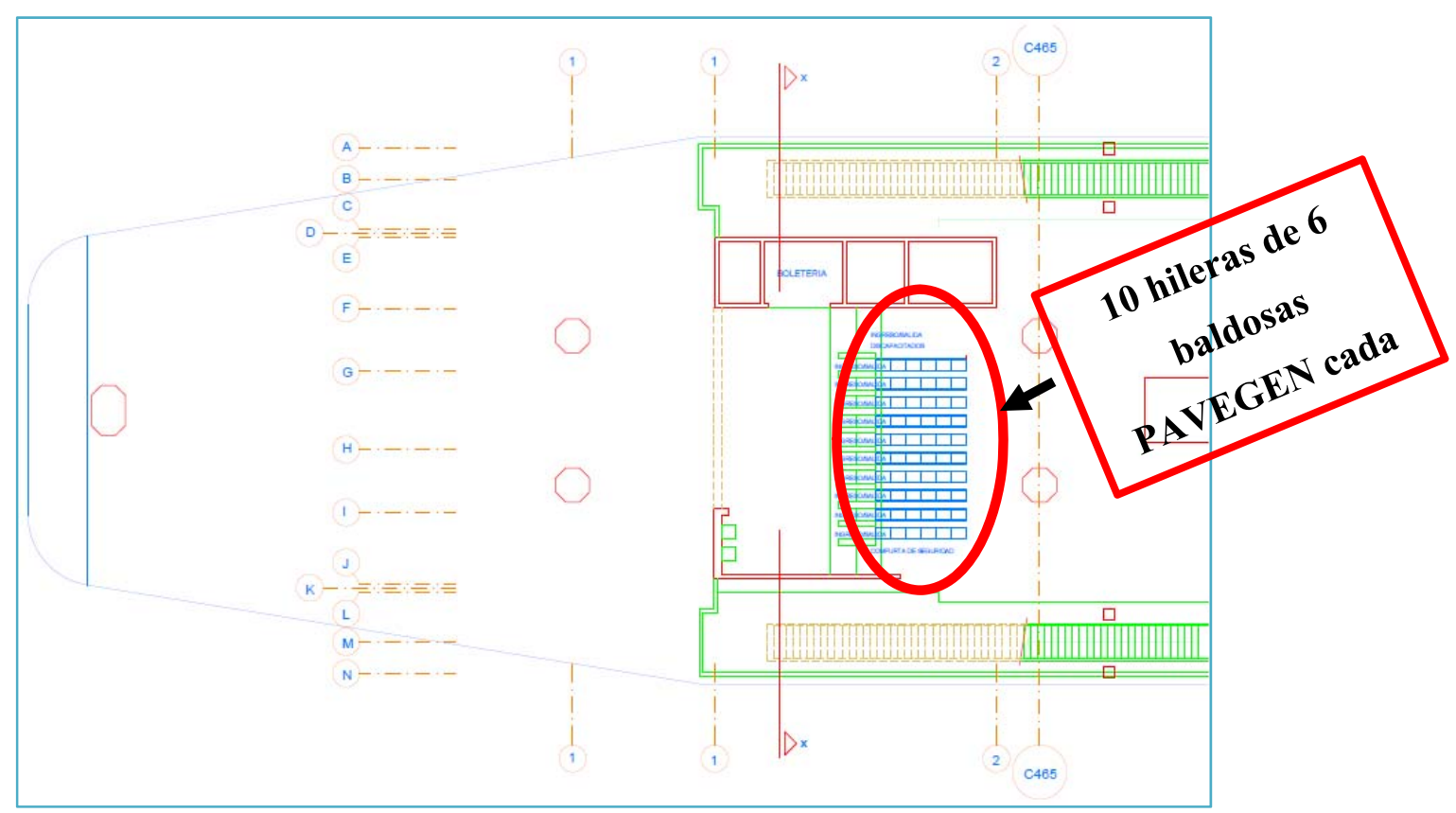

Fuente: Elaboración Propia 
Figura No 48: Fragmento Planta Primer Nivel

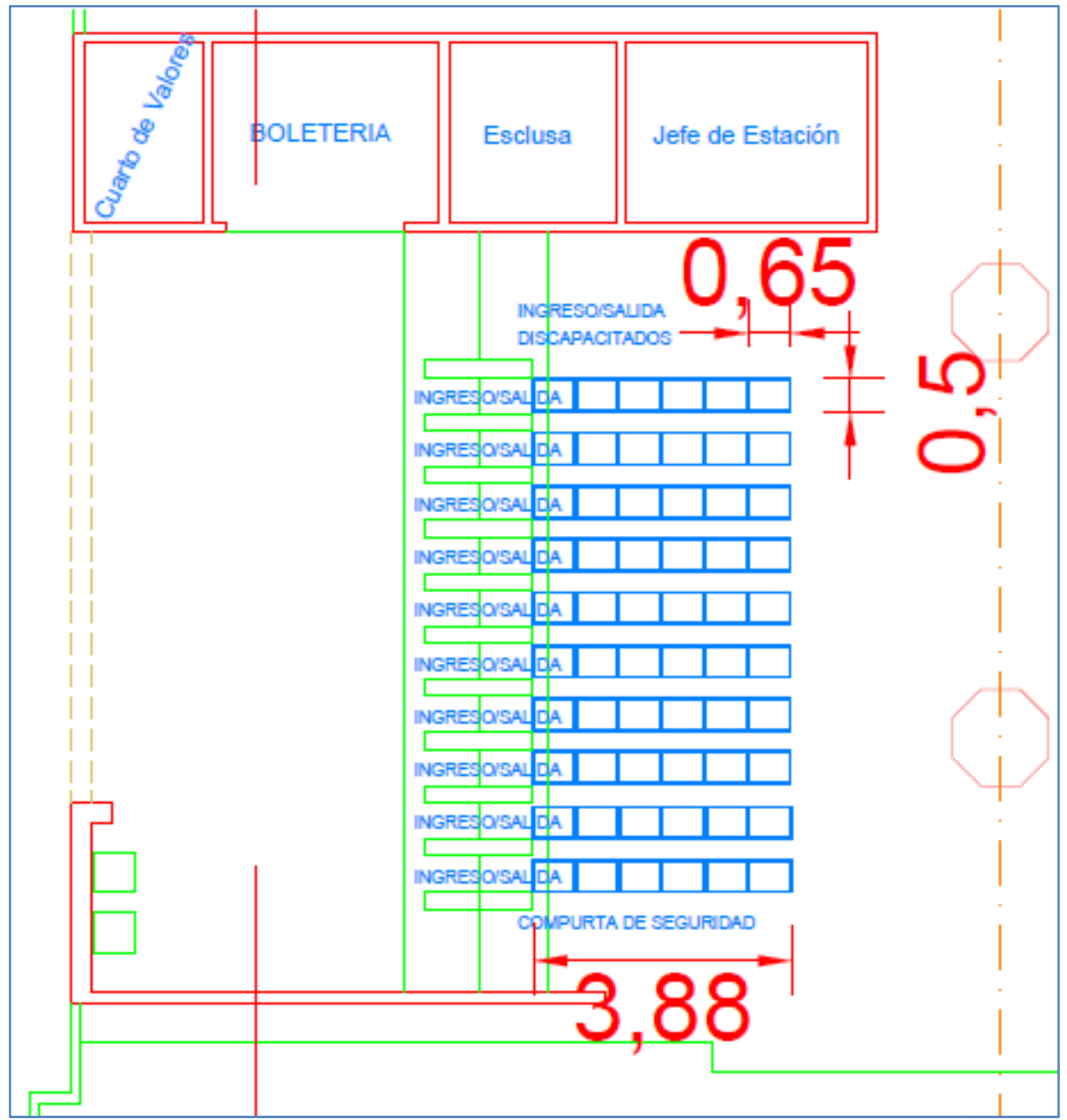

\section{Fuente: Elaboración Propia}

En el siguiente plano, se observará un corte frontal, en el cual se podrán observar las cotas necesarias para la instalación de las baldosas. Se necesita perforar una profundidad de $0.10 \mathrm{~m}$ con un ancho de $0.50 \mathrm{~m}$ para cada baldosa. Debido a que se instalarán 10 hileras de 6 baldosas cada una, la perforación debe contar con las siguientes medidas: $0.10 \mathrm{~m}$ de profundidad, $0.50 \mathrm{~m}$ de ancho y $3.88 \mathrm{~m}$ de largo. 
Figura $N^{\circ}$ 49: Corte $X-X$ "Frontal"

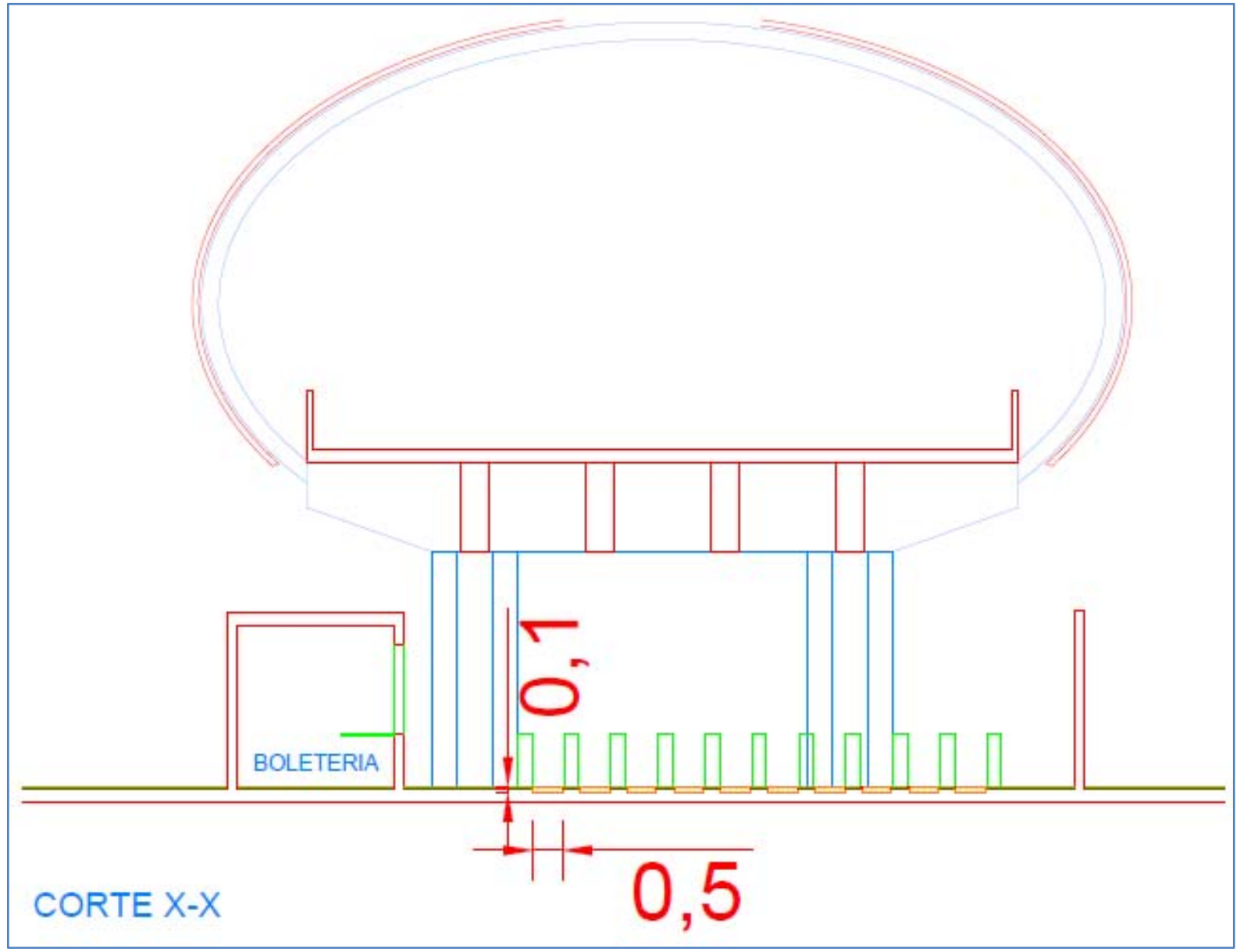

Fuente: Elaboración Propia

\subsubsection{Modelo de Implementación}

Para visualizar de manera gráfica y más clara la implementación de las baldosas, se elaboró un modelo en 3D utilizando el software SketchUp. En las siguientes vistas 3D se podrán visualizar la distribución de las baldosas y la implementación de barandas entre las diversas hileras de baldosas. 
Figura $\mathrm{N}^{\circ}$ 50: Vista frontal del ingreso de los Usuarios

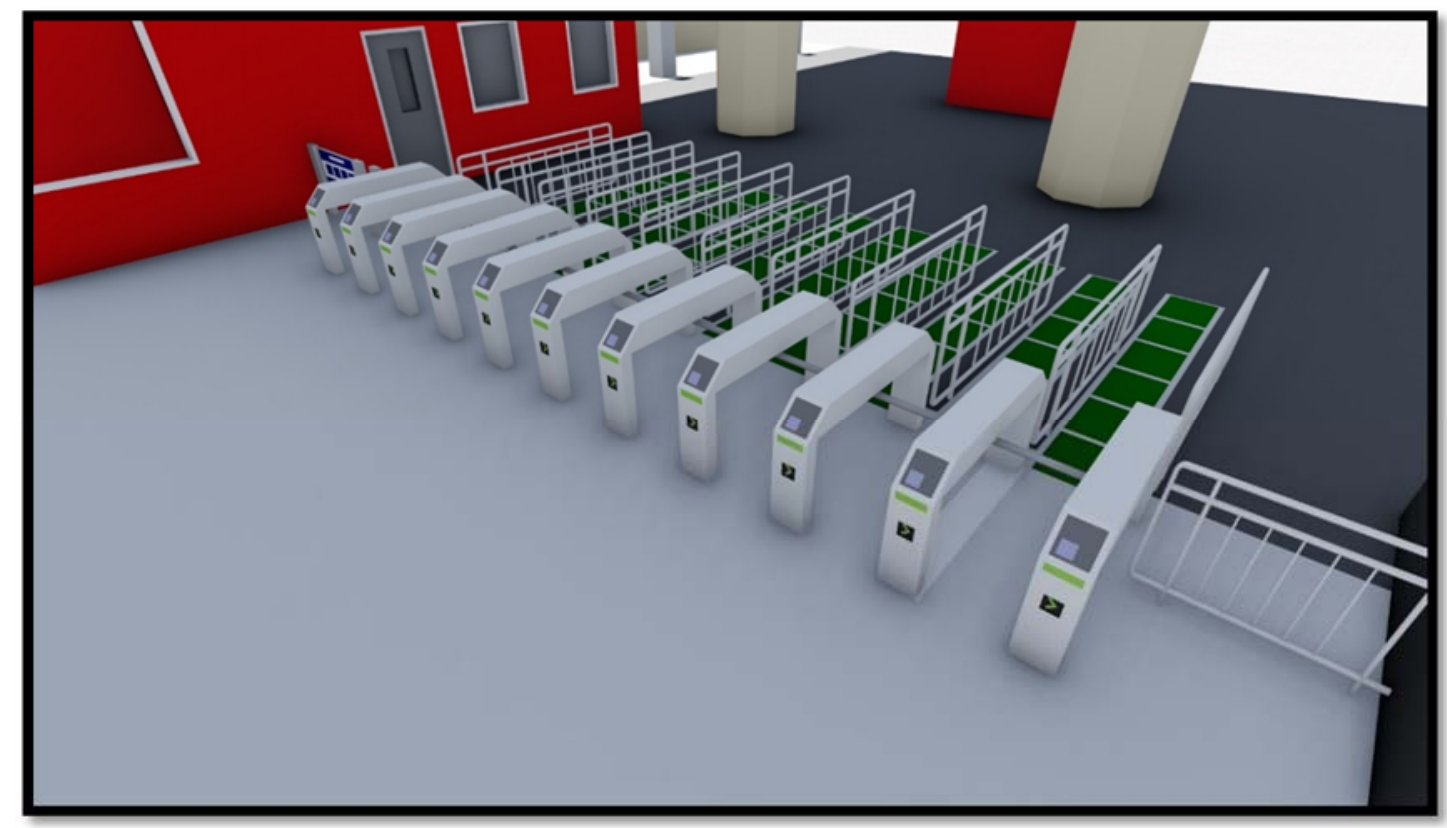

Fuente: Elaboración Propia

Figura $\mathrm{N}^{\circ}$ 51: Vista posterior del ingreso $\mathrm{N}^{\circ} 1$

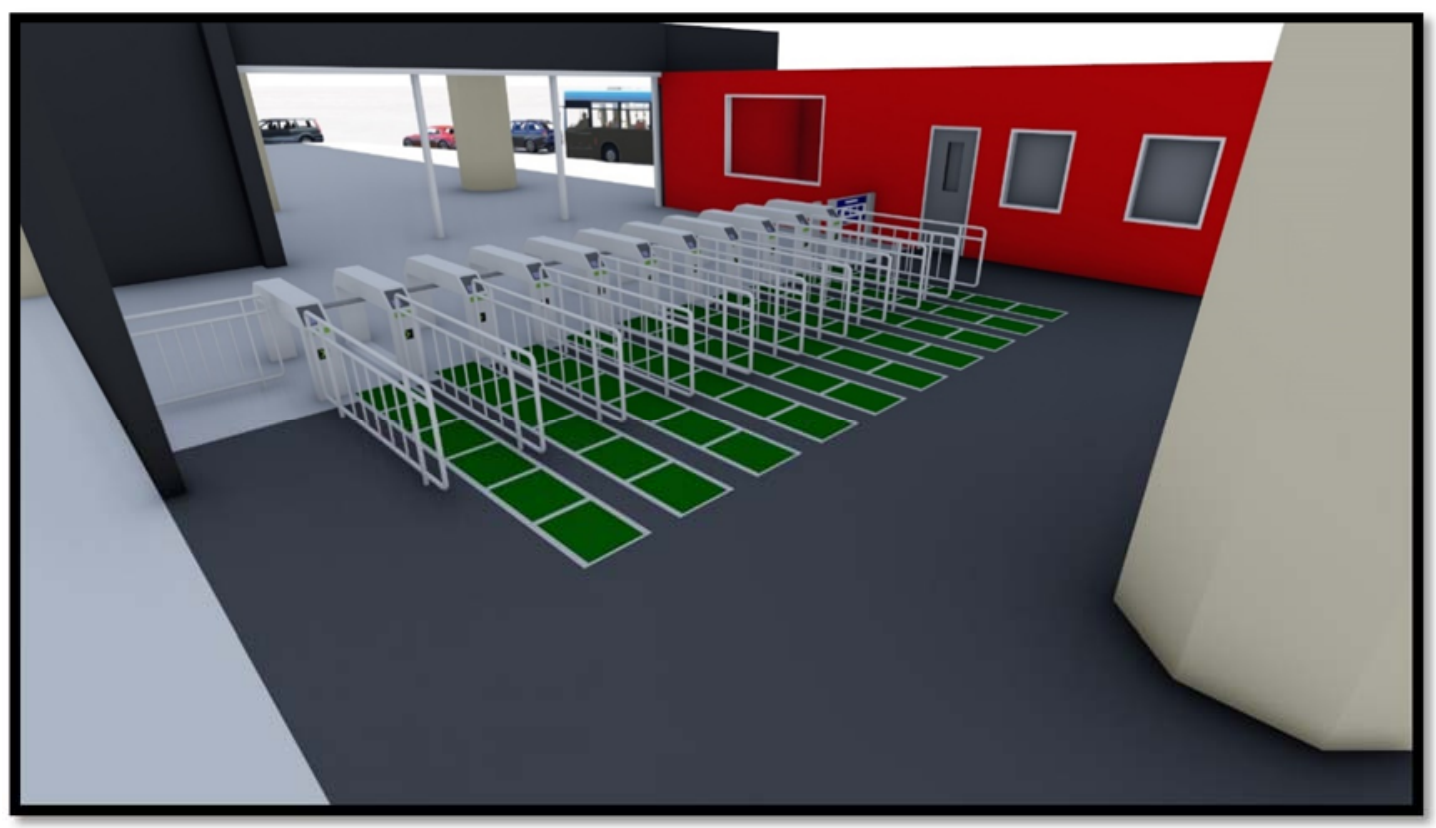

Fuente: Elaboración Propia 


\section{Figura $\mathrm{N}^{\circ}$ 52: Vista posterior del ingreso $\mathrm{N}^{\circ} 2$}

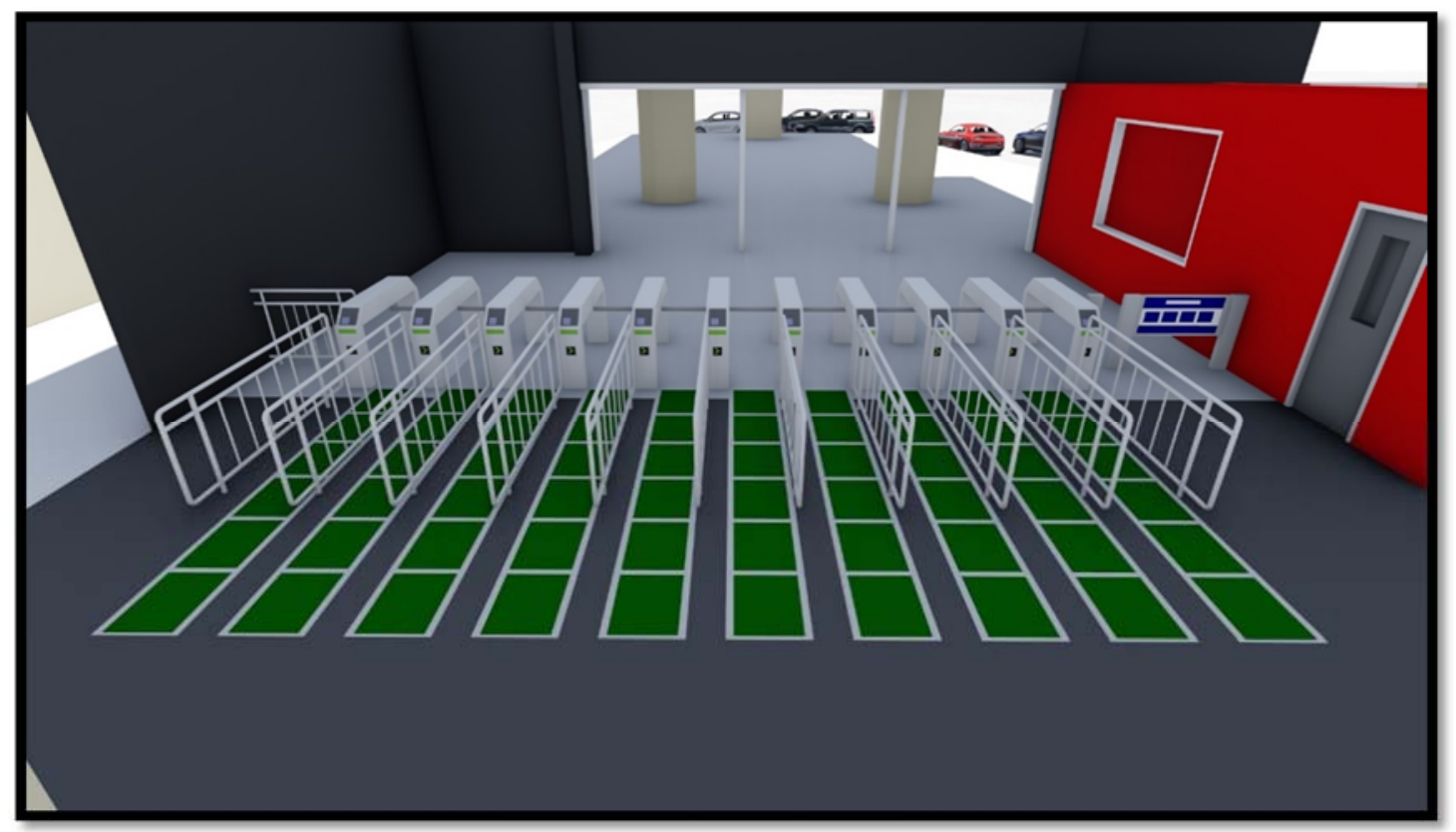

\section{Fuente: Elaboración Propia}

Las barandas han sido implementadas por los siguientes motivos:

En primer lugar, según la matriz de riesgo elaborada previamente en este informe, se identificó el riesgo "Posibles caídas de los usuarios al caminar sobre las baldosas PAVEGEN" como uno de los más críticos y con mayor severidad si es que llegara a ocurrir. Por tal motivo, se han instalado las barandas, al costado de cada hilera de baldosas, las cuales proporcionaran mayor estabilidad y seguridad a los usuarios, con el fin de reducir la probabilidad de que este accidente se produzca.

En Segundo lugar, se busca canalizar el flujo de las personas sobre las baldosas, para aumentar el aprovechamiento de su afluencia y maximizar la generación de energía mediante el sistema de generación de energía renovable, basado en la tecnología piezoeléctrica, instalado en la estación. Además, se logrará que el tránsito de los usuarios sea más ordenado y civilizado.

A continuación, se podrán apreciar algunas imágenes 3D, en las cuales se podrá ver personas transitando en la estación y utilizando las baldosas. 
Figura $\mathrm{N}^{\circ}$ 53: Usuarios utilizando las Baldosas PAVEGEN
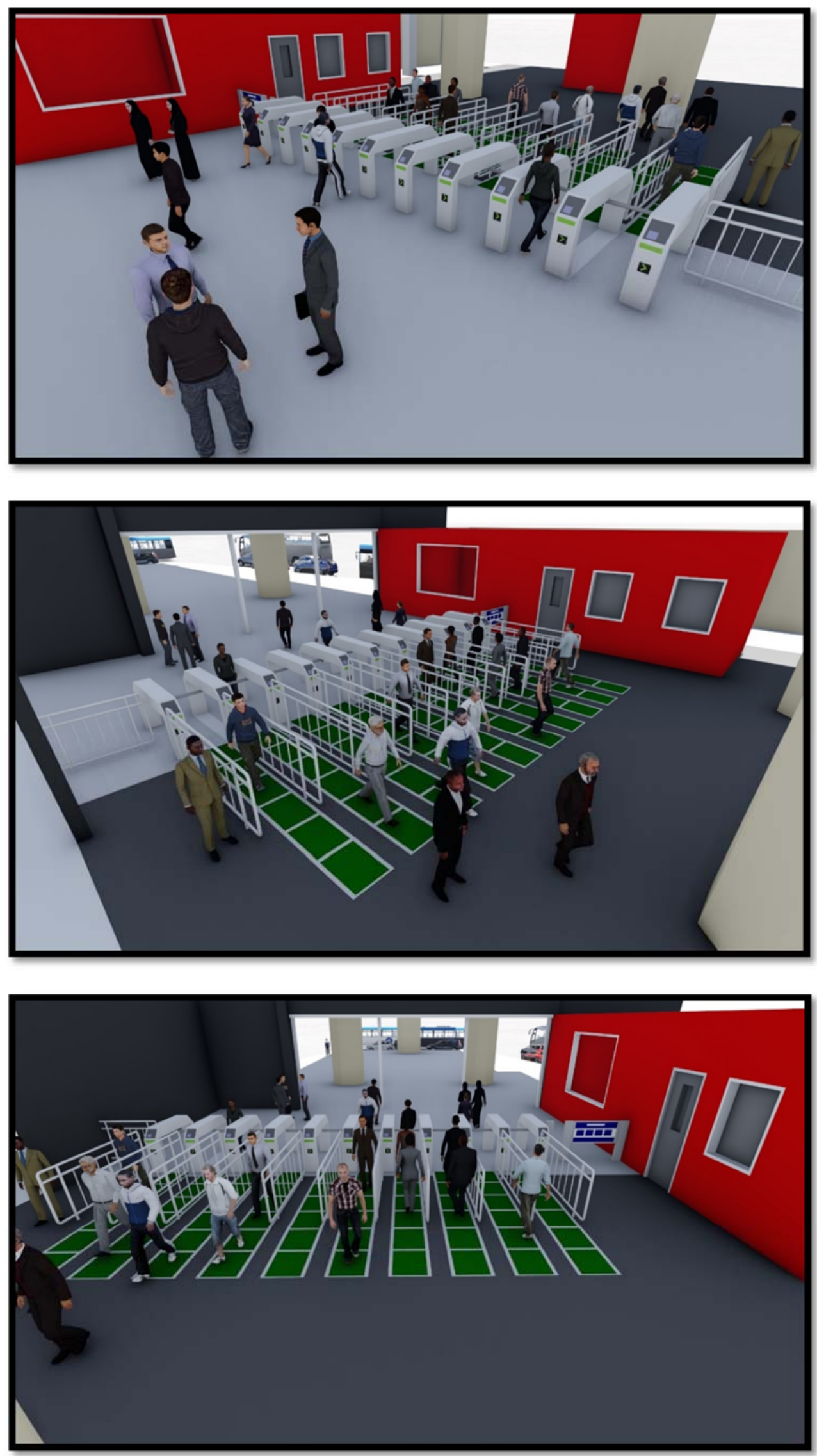


\section{Fuente: Elaboración Propia}

\subsubsection{Requerimientos y Procedimientos Civiles}

Para poder concretar los requerimientos y procedimientos civiles que serán necesarios para la ejecución del proyecto, se ha consultado la inmobiliaria RERSA INGENIEROS S.A.C. identificada con el Registro Único de Contribuyentes (RUC) 20385976802.

La ejecución de las obras civiles se realizará en el plazo de una semana trabajando nocturnamente, para así no impedir el correcto funcionamiento del servicio del tren eléctrico durante este periodo. El costo estimado es de S/ 67,400.00, los cuales incluirán el personal, maquinaria y todos los implementos requeridos para la ejecución de esta obra.

Por motivos de privacidad, la inmobiliaria brindó a grandes rasgos las actividades que se deberán realizar en la ejecución de esta obra, las cuales serán mencionadas a continuación:

- Cortado o perfilado de la losa.

- Demolición del Contrapiso "Picado".

- Nivelado.

- Instalación de rieles para el cableado.

- Vaciado de Concreto.

- Utilización de planchas metálicas para cubrir las áreas de trabajo, para que así el tren pueda seguir funcionando correctamente y los pasajeros no se vean perjudicados.

Mediante el pago de los S/ 67,400.00 la inmobiliaria asume todos los costos requeridos para la ejecución del proyecto y garantiza su ejecución en un plazo no mayor a una semana.

La información brindada por la empresa RERSA S.A.C. nos servirá como base, tanto para calcular los costos, como para el tiempo estimado de ejecución.

A continuación, se presentará la preparación del terreno sugerido por la misma empresa PAVEGEN, la cual coincide mucho con el proceso de instalación sugerido por la empresa RERSA INGENIEROS S.A.C como se podrá visualizar a continuación. 


\section{Preparación del Terreno:}

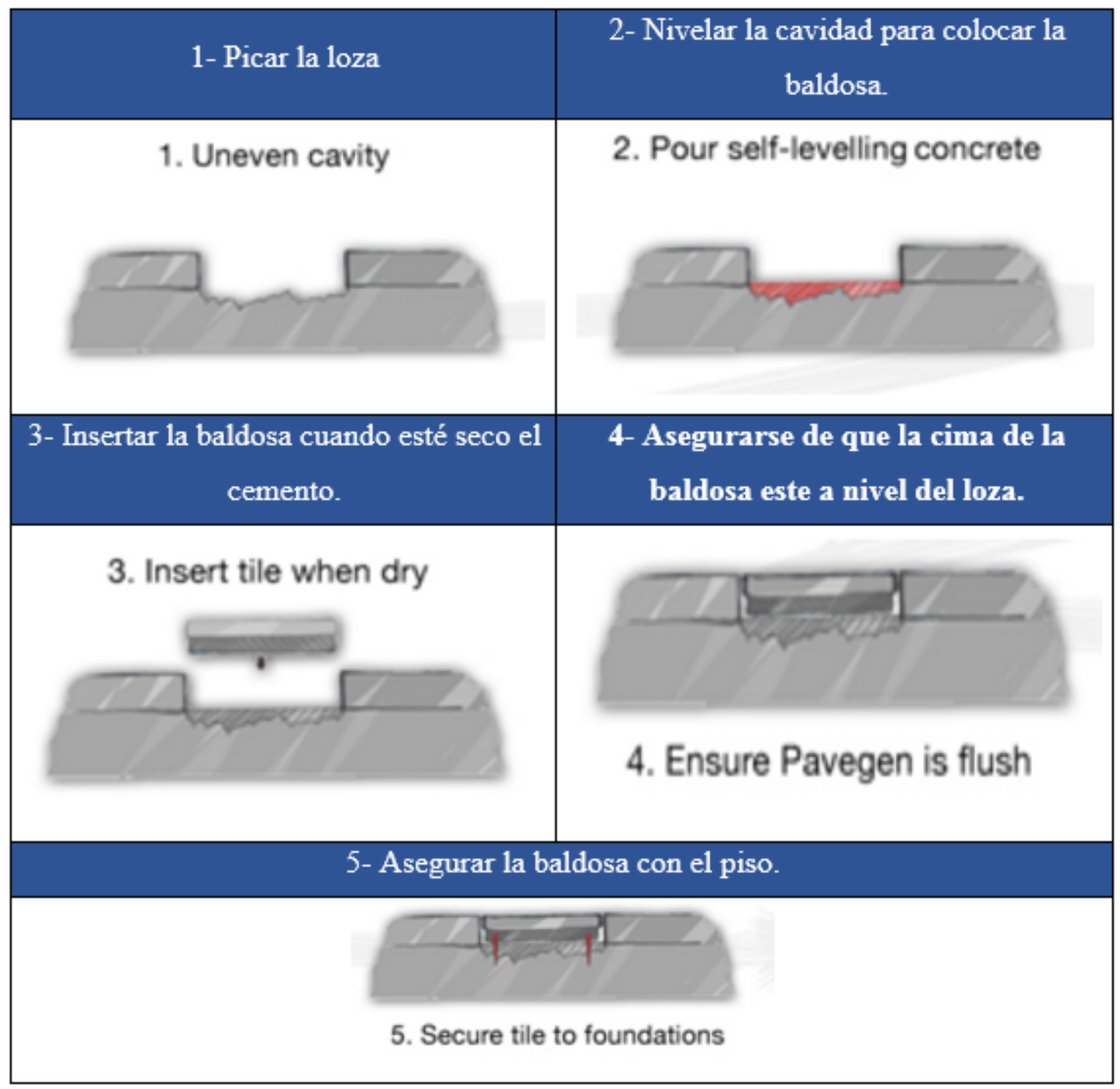


Figura $N^{\circ}$ 54: Colocación de baldosas

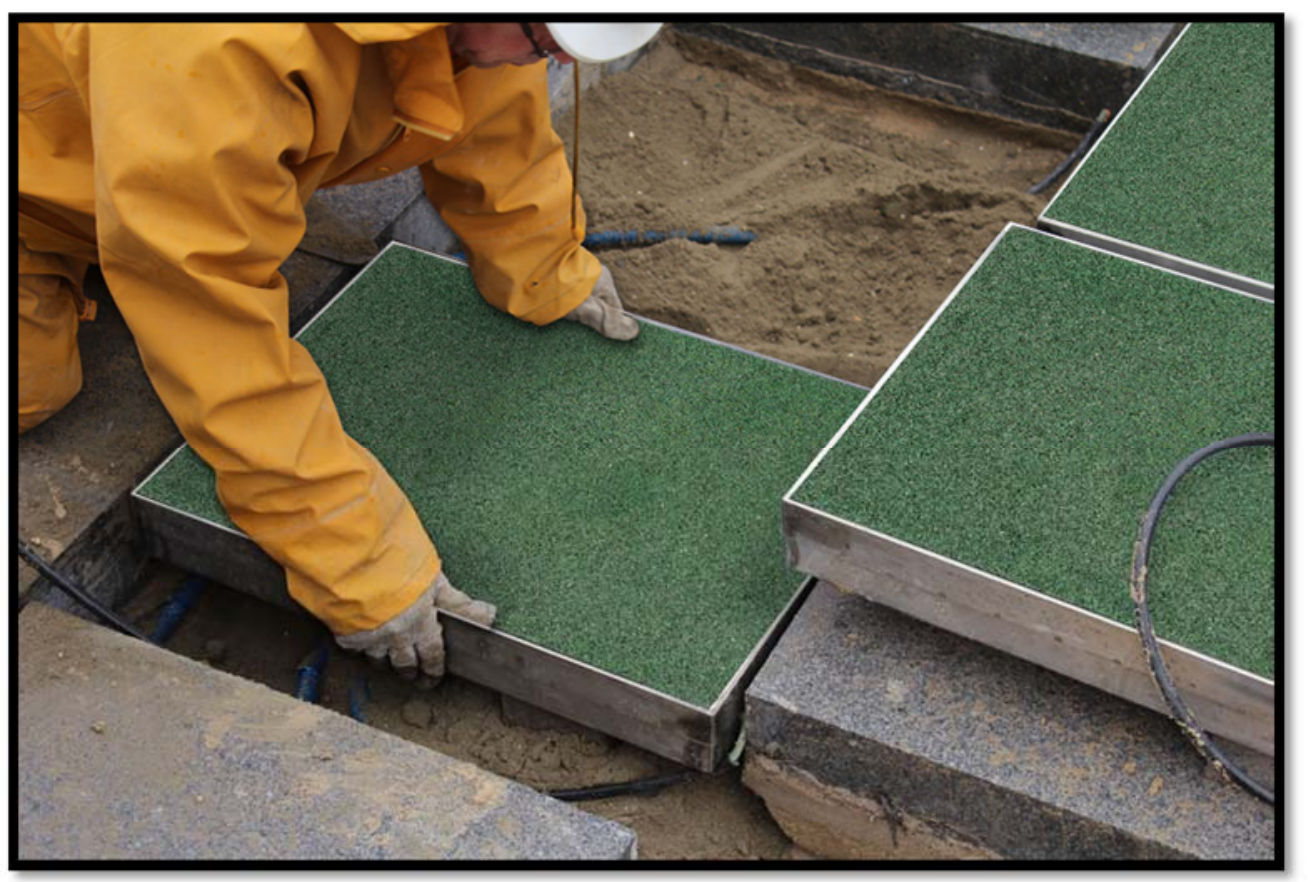

Fuente: Pavegen

De la misma manera, la empresa PAVEGEN cuenta con un procedimiento ya establecido para la instalación de las baldosas, el cual se puede ver en el cuadro adjunto junto a las baldosas ya instaladas en una imagen referencial.

\section{Instalación de las Baldosas:}

\begin{tabular}{|c|c|}
\hline 1- Coger la Baldosa & 2- Remover la capa superior de la baldosa \\
\hline & \\
\hline & \\
\hline
\end{tabular}




\begin{tabular}{|c|c|}
\hline 3- Colocarla la baldosa en la cavidad del piso & 4- Asegurar la baldosa al piso \\
\hline Place tile into level surface. & $\begin{array}{l}\text { Secure base of tile to } \\
\text { flooring. }\end{array}$ \\
\hline 5- Colocar la capa superior nuevamente & 6- Probar su funcionamiento \\
\hline Add top sheet back. & Test activating the tile. \\
\hline 7- Asegurar la capa superior & 8- Aplanar la hoja superior \\
\hline $\begin{array}{l}\text { Once working } \\
\text { secure top sheet. }\end{array}$ & Flatten top sheet flush. \\
\hline
\end{tabular}


Figura $N^{\circ}$ 55: Instalación de baldosas en proceso

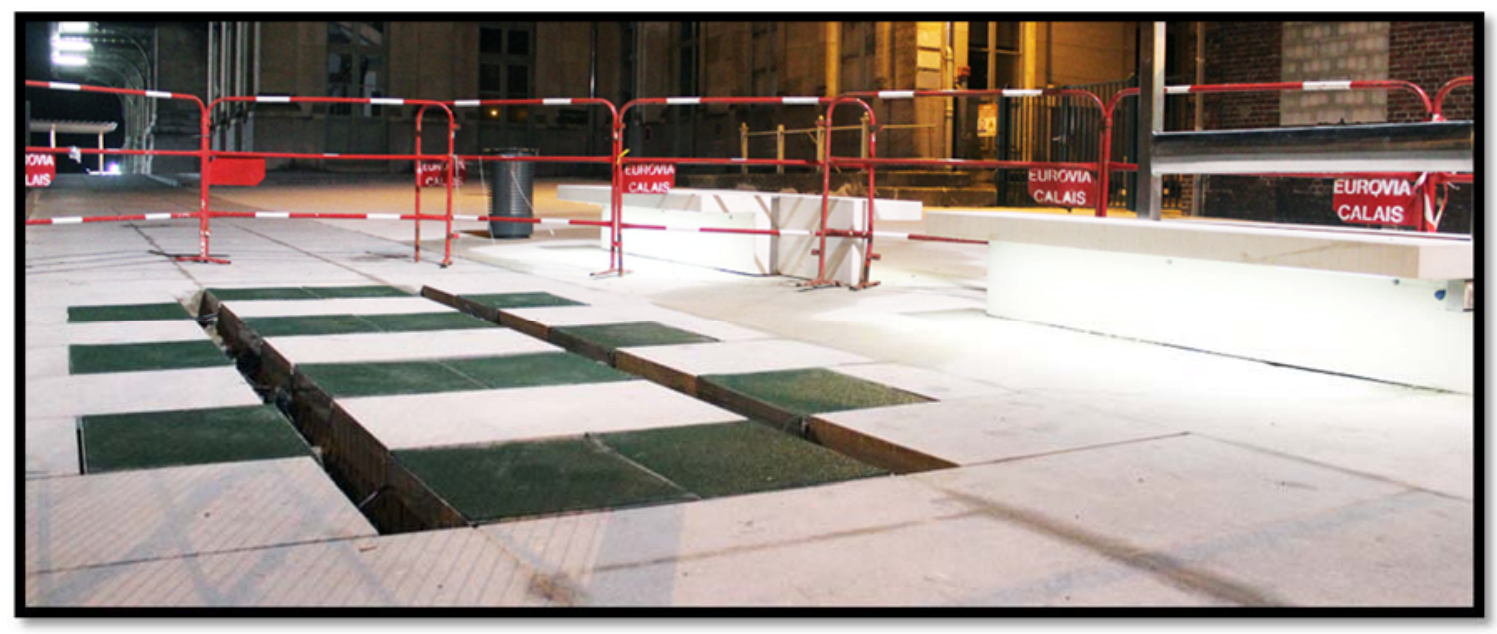

Fuente: Pavegen

\subsubsection{Almacenamiento de Energía}

La energía generada por las baldosas será almacenada en el dispositivo de Fuente de Poder Ininterruptible (UPS Uninterruptible Power Supply), con el que cuenta actualmente la institución AATE, ya que se desea reducir los costos de implementación del proyecto al no incurrir en compras innecesarias. Este UPS tiene la capacidad de $60 \mathrm{kVA}$ y cuenta con las siguientes características que serán mencionadas a continuación.

- Marca: SAFT/AEG

- Modelo: Protect C 60 kVA.

o Este UPS cuenta con tecnología On-Line de doble conversión y tensión de salida sinusoidal que garantiza una máxima protección ante perturbaciones de la tensión de red.

o Incorpora DSP (Digital Signal Processor) que dota al equipo de alta disponibilidad y un Módulo IGBT (Modulación PWM de alta frecuencia).

o Incluye By-Pass estático integrado.

o Dispone, en la cara frontal, una barra de LED's indicadores de la carga del UPS y de la capacidad de la batería. Señalización local (acústica y óptica) 
de fallo de red, sobrecarga, batería en descarga, cambio de batería y fallo común. Gestión inteligente de la batería.

- Características Técnicas:

o Tensión de Entrada 380/220 Vca trifásica, $60 \mathrm{~Hz} \pm 4$ Hz.

o Tensión de Salida $380 / 220$ Vca $\pm 1 \%$ trifásica.

o Frecuencia $60 \mathrm{~Hz} \pm 0.05 \mathrm{~Hz}$ (modo batería).

o Potencia Nominal 60 kVA $(42 \mathrm{~K} \mathrm{~W})$.

o Consumo máximo 76 A.

o Corriente de salida $64 \mathrm{~A}$.

o Tiempo de Transferencia $0 \mathrm{~ms}$.

o Forma de Onda Senoidal. THD $<4 \%$.

o Factor de Cresta 3.

o Factor de Potencia $>0.98$

o Sobrecarga Online) $125 \% 10 \mathrm{~min} / 130 \% 1 \mathrm{~s}$.

o By-Pass Estático Incluido.

o EMC EN 61000-4 Secciones 2-5 (Inmunidad), EN 61000-6-3 Clase A.

o Eficiencia Total $>88 \%$.

o $\mathrm{T}^{\mathrm{a}}$ de Operación: $0^{\circ} \mathrm{C} \mathrm{a}+40{ }^{\circ} \mathrm{C}$.

o Humedad 0 al $90 \%$ sin condensación.

o Color Negro.

o Nivel de Ruido (Online) $<55$ dBA a 1 metro. 
o Batería Plomo hermético sin mantenimiento (VRLA).

o Tiempo de recarga $<5$ horas hasta el $90 \%$ de capacidad.

o Núm. de conectores de salida, terminales para conexión permanente.

\subsubsection{Mantenimiento de las Baldosas PAVEGEN}

Actualmente, la empresa PAVEGEN no comparte públicamente información acerca del mantenimiento que deben de recibir su producto para que este siga funcionando en óptimas condiciones al pasar el tiempo. Sin embargo, sus baldosas han sido probadas mediante varias pruebas de resistencia y durabilidad, las cuales han soportado más de $1,000,000.00$ de pisadas continuas y 3,500,000.00 de pisadas, no continuos, pero manteniendo su funcionamiento óptimo.

Además de estas pruebas de calidad por las que han pasado las baldosas PAVEGEN, la empresa indica en su página web que ellos serán los encargados de instalar las baldosas $\mathrm{y}$ todo lo necesario para el funcionamiento de las mismas. Esto quiere decir a las baldosas mismas y al cableado para poder así derivar la energía a la fuente de almacenaje "UPS".

Figura $N^{\circ}$ 56: Mantenimiento cubierto por PAVEGEN

Who supplies wiring and cabling?

We will supply all wiring and cabling for all Pavegen equipment and applications supplied. We will not supply cables for any TV monitors purchased to display the data.

\section{Fuente: PAVEGEN}

Por otro lado, todos los proyectos/ instalaciones realizadas por PAVEGEN cuentan con un año de garantía garantizada contra defectos del material o de la mano de obra. Si es que se diera algún defecto en sus productos, PAVEGEN reemplazará los mismos sin costo adicional. Esto podrá ser visualizado en la siguiente imagen extraída de la misma página web de PAVEGEN. 
Figura $N^{\circ}$ 57: Mantenimiento cubierto por PAVEGEN

What maintenance cover is there?

All installations come with a 1 year guaranteed warranty against defects in material or workmanship. Pavegen will replace the Product at no extra charge. Extra warranty can be purchased

\section{Fuente: PAVEGEN}

Actualmente, la estación La Cultura cuenta con una afluencia diaria de 29,413 personas al día, las cuales son distribuidas por 10 torniquetes, dando un promedio de 2,941 personas diarias por torniquete.

Cada baldosa será comprimida "pisada" diariamente un total de 2,941 veces, dando un total anual de 1,029,350 veces, lo cual asegura el funcionamiento óptimo de las baldosas por un periodo mayor a tres años.

Por último, para asegurar el funcionamiento y el mantenimiento adecuado de las baldosas en el futuro, la empresa PAVEGEN ofrece la posibilidad de extender la garantía. El costo de esta extensión no es brindado públicamente, pero al momento de adquirir las baldosas se deberá de evaluar la factibilidad y el costo beneficio de su adquisición.

\subsubsection{Importación de las Baldosas PAVEGEN}

Debido a que las baldosas PAVEGEN son de procedencia británica, se ha cotizado la importación de estas por dos medios de transportes distintos; Aéreo y Marítimo. Para la importación de estos productos se está considerando el INCOTERM $2010 \mathrm{FOB}$, por lo cual se tendrán que asumir los costos de Flete, Seguro y los demás gastos aduaneros necesarios para su importación.

La partida Arancelarias para su importación es la "8541.60.00.00", la cual se refiere a cristales piezoeléctricos montados. Esta partida arancelaria localizada en la página web de la SUNAT, se encuentra en la sección XVI "MÁQUINAS Y APARATOS, 
MATERIAL ELÉCTRICO Y SUS PARTES; APARATOS DE GRABACIÓN O REPRODUCCIÓN DE SONIDO, APARATOS DE GRABACIÓN O REPRODUCCIÓN DE IMAGEN Y SONIDO EN TELEVISIÓN”, en el Capítulo 85 "Máquinas, aparatos y material eléctrico, y sus partes; aparatos de grabación o reproducción e sonido, aparatos de grabación o reproducción de imagen”. A continuación, se podrá observar los diversos costos de importación que se deben asumir al importar productos pertenecientes a dicha partida.

Figura N 58: Costos de Importación para la Partida Arancelaria "8541.60.00.00"

MEDIDAS IMPOSITIVAS PARA LAS MERCANCIAS DE LA SUBPARTIDA NACIONAL $\mathbf{8 5 4 1 . 6 0 . 0 0 . 0 0 ~ E S T A B L E C I D A S ~ P A R A ~ S U ~ I N G R E S O ~ A L ~ P A I S ~}$

\begin{tabular}{|c|c|c|}
\hline \multirow[t]{2}{*}{ TIPO DE PRODUCTO: } & \multicolumn{2}{|l|}{ LEY 29666-IGV 20.02.11 } \\
\hline & \multirow[t]{2}{*}{ Gravámenes Vigentes } & Valor \\
\hline Ad / Valorem & & $0 \%$ \\
\hline \multicolumn{2}{|c|}{ Impuesto Selectivo al Consumo } & $0 \%$ \\
\hline \multicolumn{2}{|c|}{ Impuesto General a las Ventas } & $16 \%$ \\
\hline \multicolumn{2}{|c|}{ Impuesto de Promoción Municipal } & $2 \%$ \\
\hline \multicolumn{2}{|l|}{ Derecho Especificos } & N.A. \\
\hline \multicolumn{2}{|l|}{ Derecho Antidumping } & N.A. \\
\hline \multicolumn{2}{|l|}{ Seguro } & $1.75 \%$ \\
\hline \multicolumn{2}{|l|}{ Sobretasa } & $0 \%$ \\
\hline \multicolumn{2}{|l|}{ Unidad de Medida: } & $(*)$ \\
\hline
\end{tabular}

N.A.: No es aplicable para esta subpartida

Fuente: SUNAT

A continuación, se presentarán las 2 cotizaciones realizadas para la importación de las baldosas desde Inglaterra hasta Perú y, posteriormente se realizará la selección del medio de transporte que será utilizado en base a un análisis de pros y contras en cuanto a cada una de las cotizaciones.

\subsubsection{Cotización Aérea}

Primero se presenta la cotización aérea, en la cual se puede observar un total a pagar valorizado en $\$ 33,888.09$ lo que equivale a $\mathrm{S} / 114,205.59$. 


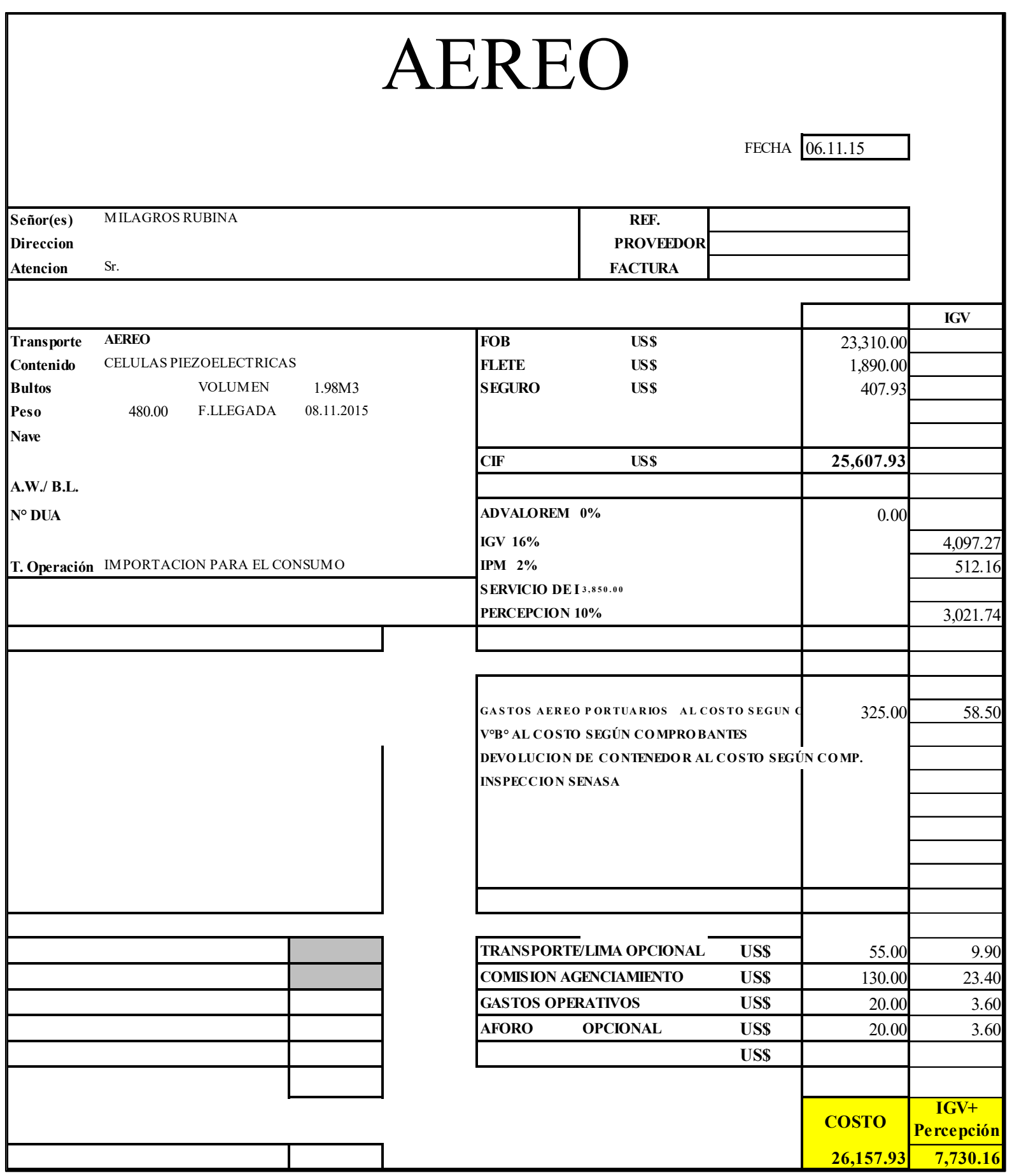

\subsubsection{Cotización Marítima}

Luego se presenta la cotización marítima, en la cual se puede observar un total a pagar valorizado en $\$ 32,332,38$ lo que equivale a $\mathrm{S} / .108,960.12$ 


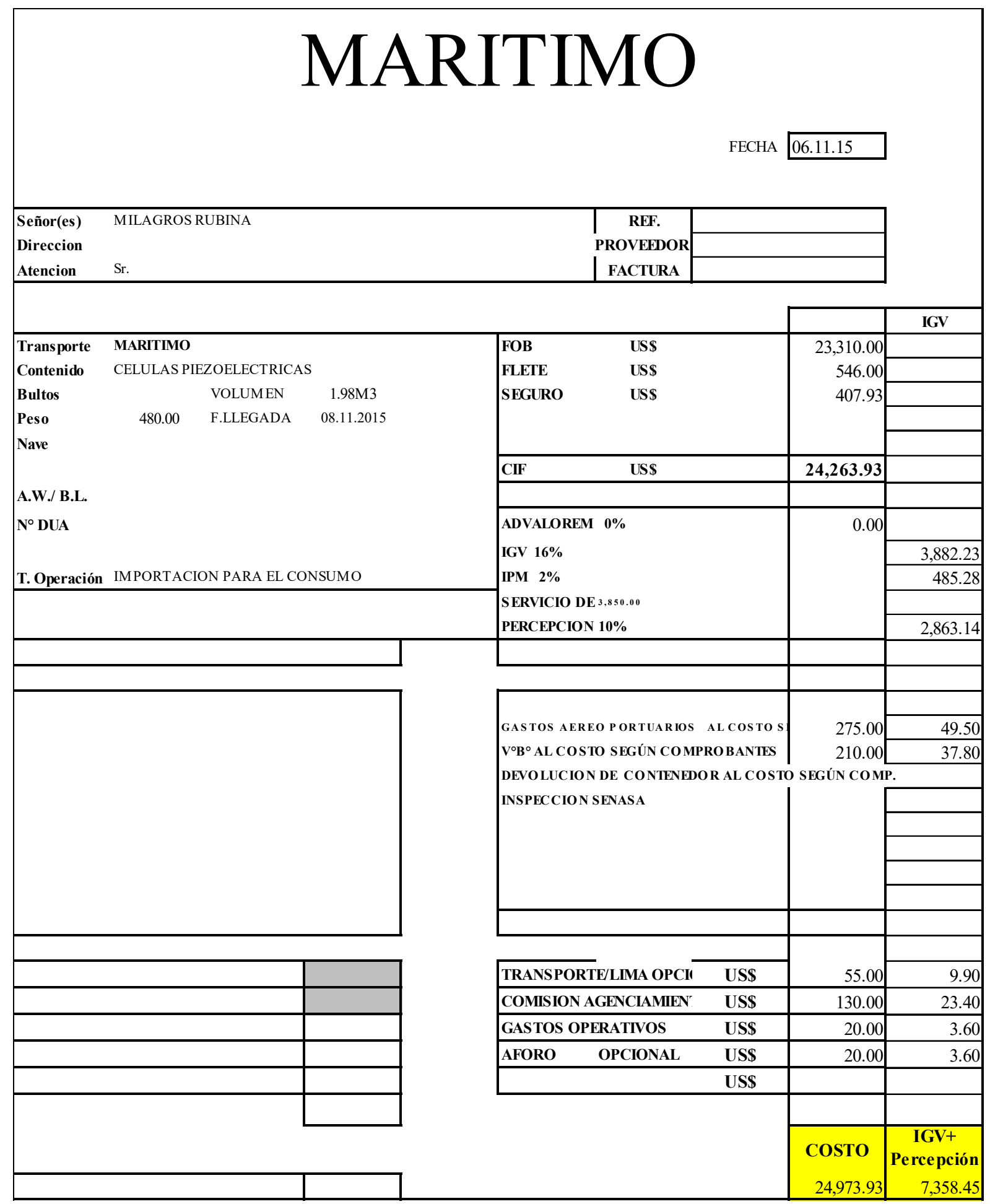

\subsubsection{Evaluación y Selección del Medio de Transporte.}

Como resultado de la comparación, la diferencia en costos entre la cotización aérea y marítima son solamente $\$ 1,555.71$, siendo la importación aérea más cara. Por lo cual, se 
analizaron los beneficios que cada uno ofrecía. Finalmente, se decidió utilizar la importación aérea por los siguientes motivos:

- Menor tiempo de entrega.

- Mayor seguridad en el transporte.

- Menos trámites aduaneros engorrosos.

Se concluye que los costos de importación de las baldosas son $\$ 33,888.93$ y se ha considerado una tasa de cambio del euro de S/ 3.37, lo cual representa S/ 114,205.69.

\subsubsection{Costos de Implementación}

Para la implementación de este proyecto, se deben incurrir en los siguientes costos, los cuales serán especificados a continuación y han sido calculados mediante el uso de una tasa de cambio de S/ 3.37 por dólar.

Tabla $N^{\circ}$ 28: Costos de Implementación del Proyecto

\begin{tabular}{|c|c|}
\hline Actividad & Costos (Nuevos Soles) \\
\hline Costo de las Baldosas e Importación & $114,202.87$ \\
\hline Costos Arquitectónicos & $3,370.00$ \\
\hline Costos Civiles & $67,400.00$ \\
\hline Costo Eléctricos & $10,000.00$ \\
\hline COSTOS TOTALES & $\mathbf{1 9 4 , 9 7 2 . 8 7}$ \\
\hline
\end{tabular}

\section{Fuente: Elaboración Propia}

- Costos de las Baldosas e Importación: 
Los S/ 114,202.87, mencionados anteriormente, incluyen la adquisición de las 60 baldosas mediante una importación vía aérea, la cual incluye los costos de flete, el seguro para la mercancía, el IGV, el IPM, la Percepción, los costos de agenciamiento, gastos operativos y todos los gastos que se deban incurrir en los procesos de desaduanaje.

La suma del IGV, el IPM y la Percepción son S/ 26,050.65 los cuales se convierten en crédito fiscal positivo para la empresa, el cual podrá ser aprovechado en el futuro al momento de tener que pagar impuestos.

\section{- Costos Arquitectónicos:}

El arquitecto Esteban Zupan ha de cobrar S/ 3,370.00 soles por el diseño de todos los planos arquitectónicos y las vistas 3D necesarias para la correcta implementación de este proyecto.

\section{- Costos Civiles:}

Según la cotización realizada a una empresa inmobiliaria, RERSA INGENIEROS S.A.C., los costos civiles para implementar el proyecto en una semana, laborando nocturnamente y asumiendo todos los costos requeridos para finalizar el proyecto en el tiempo establecido, es de $\$ 20,000.00$ los cuales son traducidos a $\mathrm{S} / 67,400.00$ nuevos soles.

\section{- Costos Eléctricos:}

Los costos eléctricos fueron estimados en base al asesoramiento de un Ingeniero Eléctrico, los cuales incluyen todo el cableado y las labores eléctricas que se deberán llevar a cabo para poder concluir la instalación correcta de las baldosas en la estación La Cultura. 


\subsubsection{Cronograma de Instalación}

En esta sección del proyecto de investigación, se elaborará un cronograma, el cual abarcará solamente la etapa de implementación del proyecto, utilizando el programa MS Project 2013 para así lograr un cronograma de implementación más estructurado y preciso en cuanto a la estimación de los tiempos requeridos.

Las fechas de inicio y fin no están establecidas, ya que hasta el momento no se cuenta con una fecha exacta para su inicio, pero se estima estar iniciando el proyecto a mediados del año 2016.

Tabla N²9: Cronograma de Implementación del Proyecto

\begin{tabular}{|c|c|c|c|}
\hline$N^{\circ}$ & NOMBRE DE TAREA & DURACIÓN & PREDECESORAS \\
\hline 1 & Implementación del Proyecto & 49 días & \\
\hline 2 & Adquisición de Baldosas & 35 días & \\
\hline 3 & Negociación de Baldosas & 21 días & \\
\hline 4 & Importación de Baldosas & 14 días & 3 \\
\hline 5 & Diseño Arquitectónico & 7 días & $2 \mathrm{CC}$ \\
\hline 6 & Obras Civiles & 35 días & \\
\hline 7 & Diseño Civil & 7 días & 5 \\
\hline 8 & Ejecución de obras civiles & 7 días & 7,4 \\
\hline 9 & Instalaciones Eléctricas & 7 días & $8 \mathrm{CC}$ \\
\hline 10 & Pruebas de Funcionamiento & 7 días & 9,6 \\
\hline
\end{tabular}

Fuente: Elaboración Propia 
Figura $N^{\circ}$ 59: Diagrama de Gantt

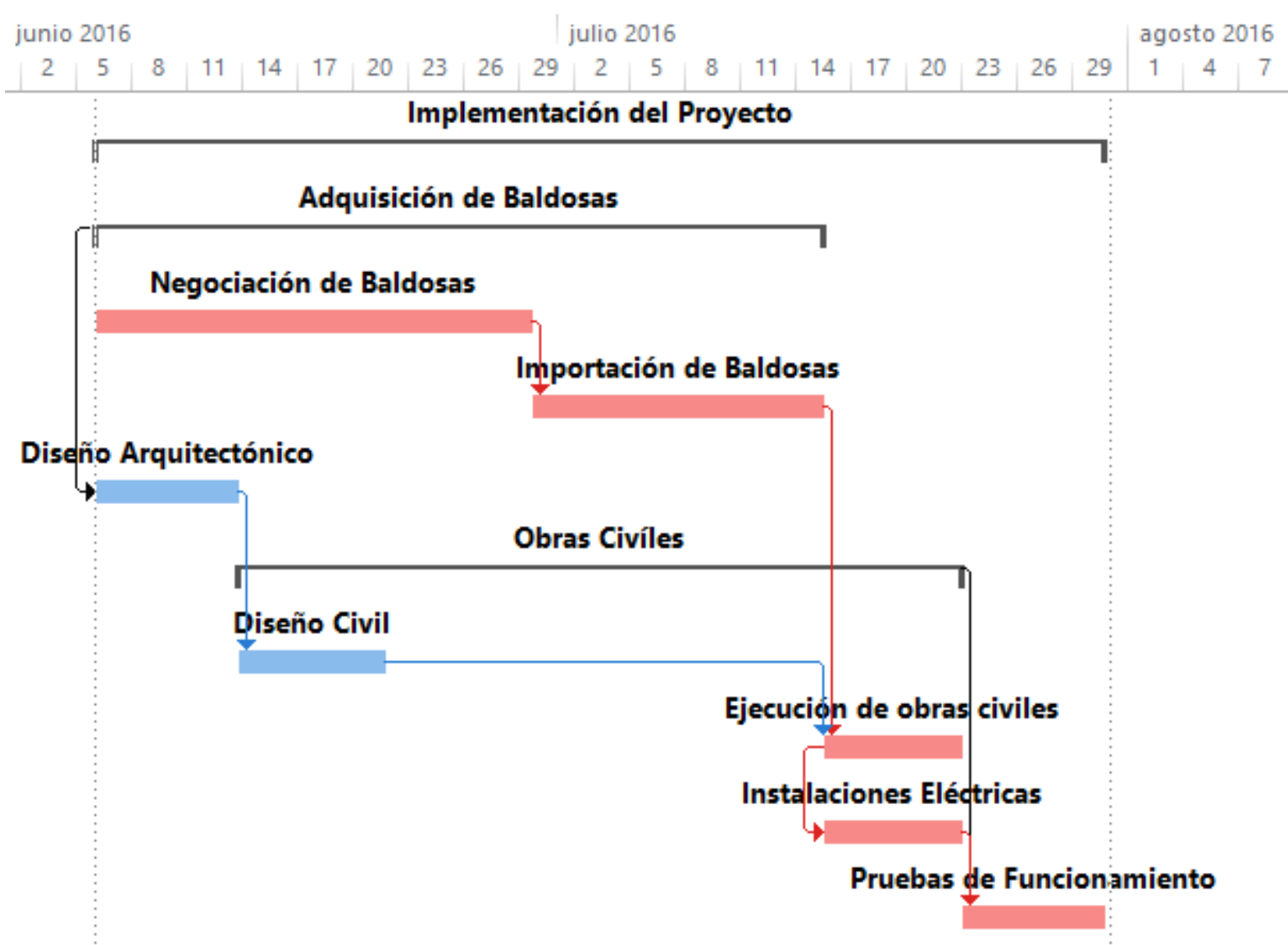

Fuente: Elaboración Propia

El tiempo estimado para la implementación del proyecto es de aproximadamente 49 días, en los cuales se llevarán a cabo las siguientes actividades: “Adquisición de baldosas, Diseño Arquitectónico, Obras Civiles, Instalaciones Eléctricas y Pruebas de Funcionamiento".

Las actividades de color rojo que se pueden observar en el Diagrama de Gantt, presentado anteriormente, hacen referencia a las actividades críticas que deben llevarse a cabo en el tiempo establecido para poder cumplir el plazo estimado de 56 días. Las actividades de color azul, las cuales incluyen tanto el diseño arquitectónico como el diseño civil, son actividades que pueden realizarse simultáneamente a otras las otras actividades. 
En primer lugar, la adquisición de baldosas incluye tanto la negociación de las baldosas con la empresa PAVEGEN como la importación de las mismas desde Londres hasta Perú.

En segundo lugar, el diseño arquitectónico puede ser realizado desde la primera semana, con la condición de terminar antes de culminar la negociación de las baldosas, para así brindar el tiempo necesario para elaborar un correcto diseño civil para su implementación.

En tercer lugar, las obras civiles incluyen tanto el diseño civil como la ejecución de las mismas, para así culminar la instalación de las baldosas. La instalación o ejecución de estas deben iniciarse solamente al momento que la importación y el desaduanaje se hayan culminado y se cuente con el producto en Lima.

En tercer lugar, las instalaciones eléctricas deben realizarse simultáneamente a la ejecución de las obras civiles, para así poder colocar el cableado necesario en el momento adecuado y no incurrir en costos extras de perforación o demolición para su instalación.

Por último, las pruebas de funcionamiento tomarán cerca de una semana, para así poder garantizar el correcto funcionamiento del sistema de generación de energía renovable y el éxito del proyecto.

\subsubsection{Horizonte de recuperación}

Para evaluar en cuánto tiempo se recuperará la inversión para la implementación del proyecto, se elaboraron los cálculos respectivos del horizonte de recuperación. Teniendo en cuenta que el proyecto tiene un costo estimado de implementación de S/. 194,972.87, se plantearon 2 escenarios para el cálculo. Los escenarios son los mismos que se usaron para calcular los ahorros de energía valorizados, S/ 134,028.69 y S/178,704.92 respectivamente.

Tabla N 30: Horizonte de Recuperación 


\begin{tabular}{|c|c|}
\hline AHORRO & $\begin{array}{c}\text { TIEMPO DE } \\
\text { RECUPERACIÓN }\end{array}$ \\
\hline Ahorro de $131,745.38$ & 17.7 Meses \\
\hline Ahorro de $175,660.52$ & 13.3 Meses \\
\hline
\end{tabular}

Fuente: Elaboración Propia

Los resultados obtenidos fueron de un periodo de recuperación de la inversión que fluctúa entre 13.3 y 17.7 meses. Esto quiere decir que en menos de un año y medio se empezaran a tener indicios de ganancias, ya que, a partir de este momento todos los ahorros energéticos obtenidos serán ahorros netos.

\subsubsection{Conclusión}

Según lo observado en este capítulo, la instalación del sistema de generación de energía renovable en la estación La Cultura del tren Eléctrico es viable y no requiere de una gran inversión con respecto a los ahorros que traerá consigo la implementación de este sistema. La distribución física de la estación se presta adecuadamente para maximizar la utilización las baldosas y así mejorar le eficiencia de la generación de energía renovable.

Los procesos o actividades más importantes para la instalación de este proyecto son los siguientes: "negociación e importación de las baldosas, diseño arquitectónico y civil, ejecución de las obras civiles y eléctricas, y finalmente las pruebas de funcionamiento". La semana destinada a pruebas de funcionamiento es sumamente importante para así garantizar el correcto funcionamiento del sistema de energía renovable. 


\section{CAPÍTULO 4: VALIDACIÓN DE LA PROPUESTA DE SOLUCIÓN}

En el presente capitulo se validará la funcionabilidad y cómo es que la propuesta planteada soluciona la problemática previamente identificada. Se validará el diseño conceptual de la implementación de un sistema de generación de energía renovable, y para ello se plantearán dos métodos de validación. En primer lugar, se validará el funcionamiento de la tecnología piezoeléctrica para generar energía con las pisadas de las personas, mediante el planteamiento y el desarrollo de un prototipo de baldosa. Luego, se simulará la implementación de la propuesta en el software Arena y para así validar su efectividad mediante los resultados brindados por el software.

\subsection{Prototipo de Energy Harvester}

Con el fin de validar el funcionamiento de la tecnología piezoeléctrica de las baldosas PAVEGEN, se elaboró un prototipo de Energy Harvester bajo la ayuda y supervisión de Renato Villavicencio Pezo, egresado en Ingeniería Electrónica y Automatización Industrial de la TECSUP. Inicialmente, bajo la solicitud y sugerencia del Sr. Villavicencio, se cotizó y adquirió la siguiente lista de materiales para la elaboración de la baldosa piezoeléctrica.

- 2 tablas de melamina de $18 \mathrm{MM}$ de $20.5 \times 24 \mathrm{~cm}$.

- 16 piezoeléctricos.

- 1 puente de diodos estándar.

- 1 condensador de 4700 microfaradios.

- 1 condensador de 3300 microfaradios.

- 4 resortes de fierro.

- 4 pernos de $1 / 2$ de espesor y $7 \mathrm{~cm}$ de largo. 
- 42 sujetadores de jebe.

- Focos LED.

- 16 tacos de goma.

\subsubsection{Etapas de desarrollo}

\section{Etapa 1: Construcción del Mecanismo}

Primero, se hicieron 4 orificios en las esquinas de las dos tablas de melamina para usarlas como base de las baldosas, y se atravesaron los 4 pernos con sus respectivas arandelas y resortes a través de estos huecos. Posteriormente, se enroscaron las 4 tuercas en cada perno para terminar la plataforma. Una vez listo, se probó el mecanismo con el fin de confirmar su funcionamiento. Obteniendo como resultado una plataforma que puede soportar "XX" kg de peso aproximadamente.

Figura $N^{\circ}$ 60: Elaboración Prototipo 2

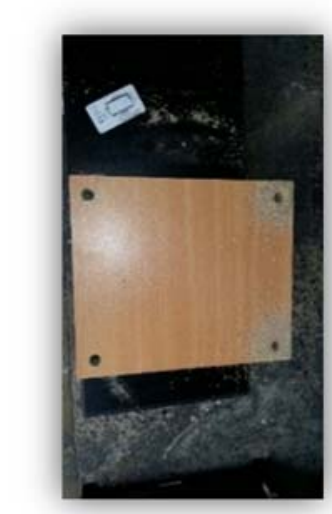

Fuente: Elaboración Propia 
Figura $N^{\circ}$ 61: Elaboración Prototipo 1

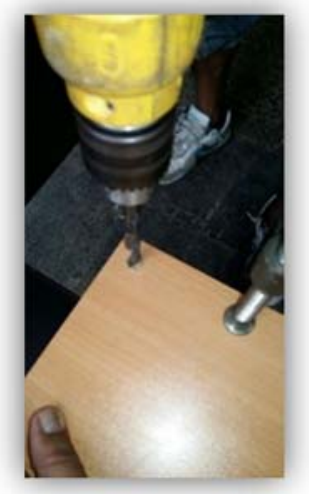

Fuente: Elaboración Propia

Figura N 62: Elaboración Prototipo 4

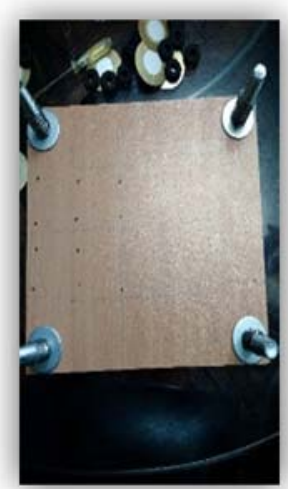

Fuente: Elaboración Propia 


\section{Figura $N^{\circ}$ 63: Elaboración Prototipo 3}

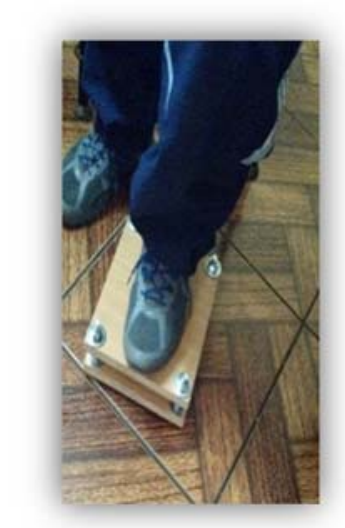

\section{Fuente: Elaboración Propia}

Posteriormente, se trazaron las líneas de medición necesarias para poder poner los 16 piezoeléctricos, en la base de abajo, de manera que más adelante se puedan realizar las conexiones del circuito sin ningún inconveniente.

\section{Figura $N^{\circ}$ 64: Elaboración Prototipo 5}

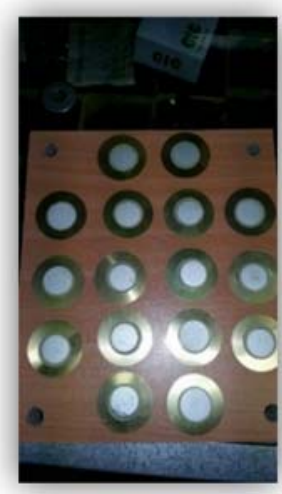

Fuente: Elaboración Propia 


\section{Figura $N^{\circ}$ 65: Elaboración Prototipo 6}

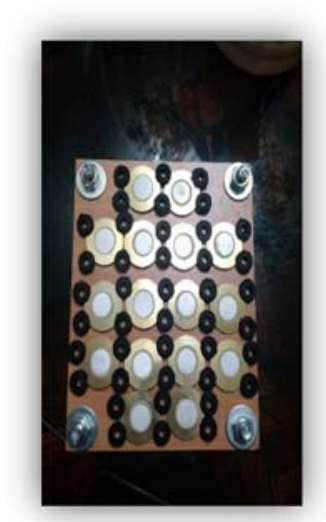

Fuente: Elaboración Propia

Figura N66: Elaboración Prototipo 7

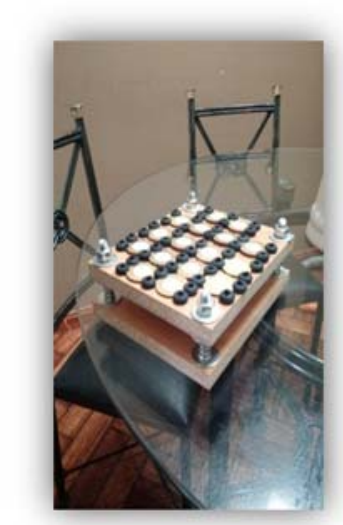

Fuente: Elaboración Propia

Una vez ubicados los piezoeléctricos, se entornillaron los jebes sujetadores para fijar cada elemento piezoeléctrico en la base de melamina. Previo a ello, se fijó la primera hilera alineada para empezar con las primeras pruebas del circuito. 


\section{Figura $N^{\circ}$ 67: Elaboración Prototipo 9}

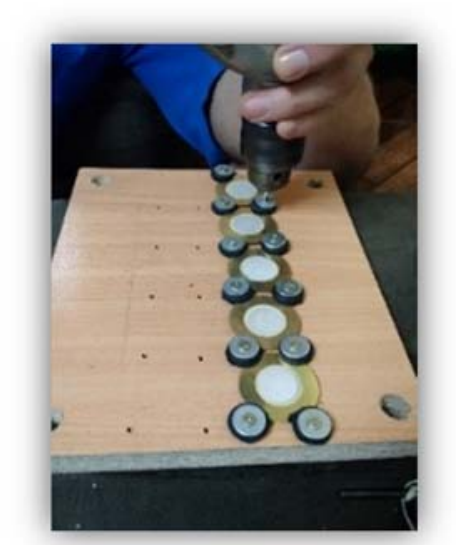

Fuente: Elaboración Propia

\section{Figura $N^{\circ}$ 68: Elaboración Prototipo 8}

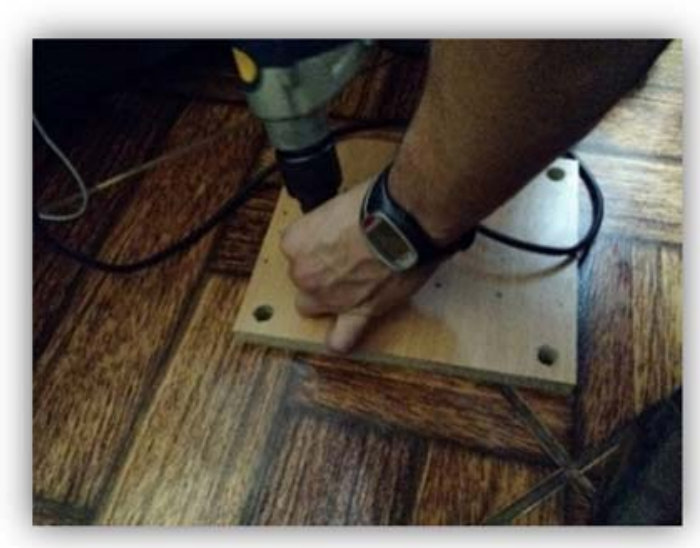

Fuente: Elaboración Propia

\section{Etapa 2: Construcción del Circuito y Pruebas}

Para poder realizar las primeras pruebas del recolector de energía, se construyó el circuito en un Protoboard piloto que tenía un circuito con la siguiente secuencia: Puente de diodosCondensador-Resistencia-Foco LED como se puede observar en la siguiente figura: 


\section{Figura Nº 69: Elaboración Prototipo 10}

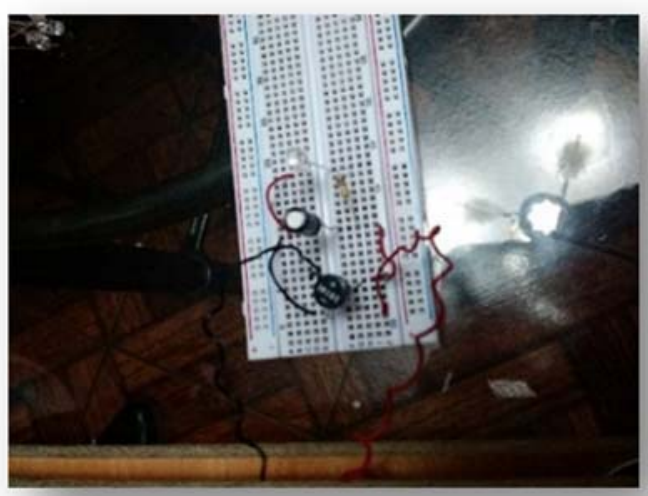

Fuente: Elaboración Propia

Este circuito utiliza el concepto de "Una fuente alterna Rectificada y Filtrada", la cual podrá verse explicada gráficamente a continuación:

Figura N 70: Rectificación y Filtrado de Energía

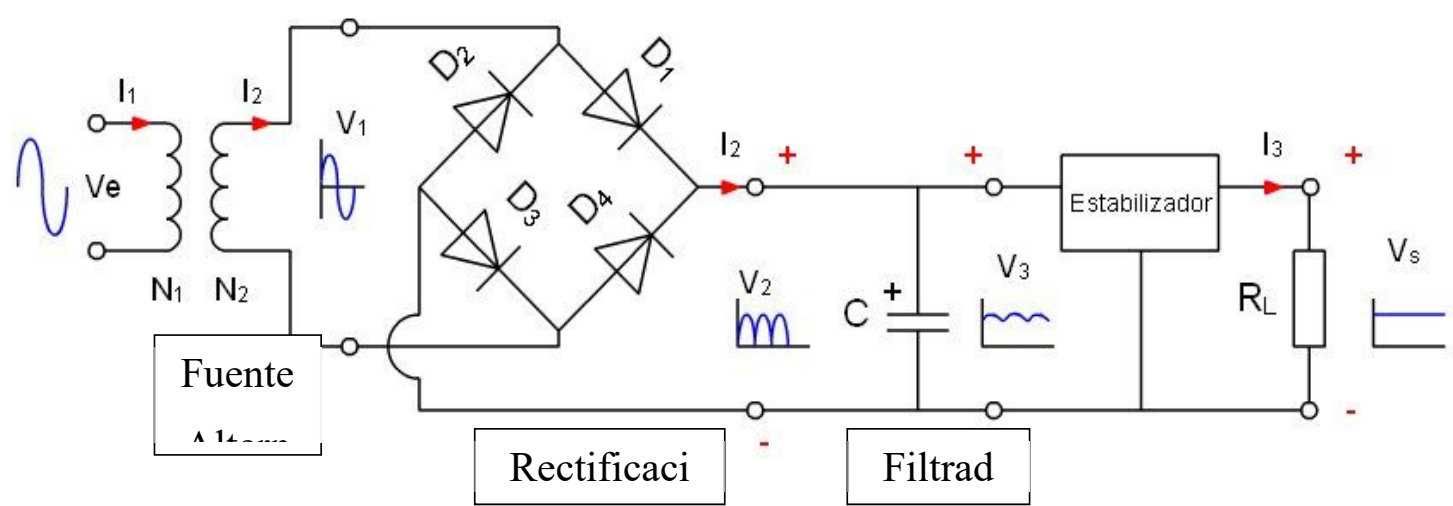

Fuente: Google, modificación Propia

Primero, ingresa una carga de una fuente alterna (Los piezoeléctricos), la cual tiene el inconveniente de presentar una carga inestable con comportamiento senoidal, en el cual la carga presenta variaciones positivas y negativas. 


\section{Figura $N^{\circ}$ 71: Comportamiento Senoidal}

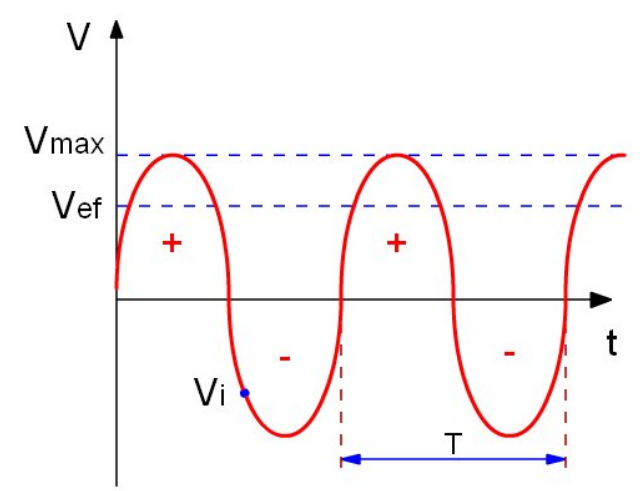

Fuente: Google, modificación Propia

Para esto, se aplicó el concepto de Rectificación con la ayuda de un puente de diodos, el cual estabiliza la carga volviéndola siempre positiva.

Figura No 72: Rectificación

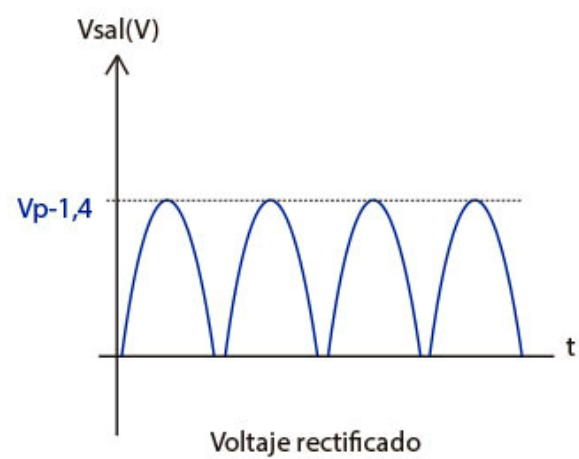

Fuente: Google, modificación Propia

Finalmente, la carga pasa por un proceso de Filtrado con la ayuda de un condensador de energía, el cual a su vez almacenará la energía recolectada con el dispositivo piezoeléctrico. 
Figura $N^{\circ}$ 73: Filtrado

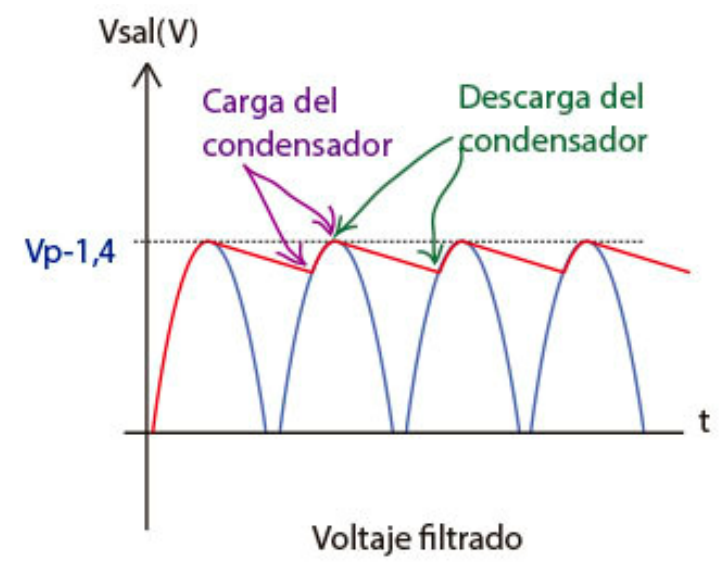

Fuente: Google, modificación Propia

Una vez listo el Circuito en el Protoboard, se conectaron los piezoeléctricos de la primera hilera en paralelo para conectarlo con este y realizar una primera prueba de funcionabilidad.

Figura No 74: Elaboración Prototipo 11

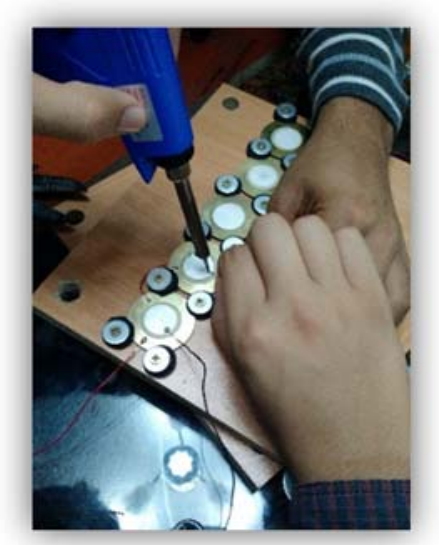

Fuente: Elaboración Propia 


\section{Figura Nº 75: Elaboración Prototipo 12}

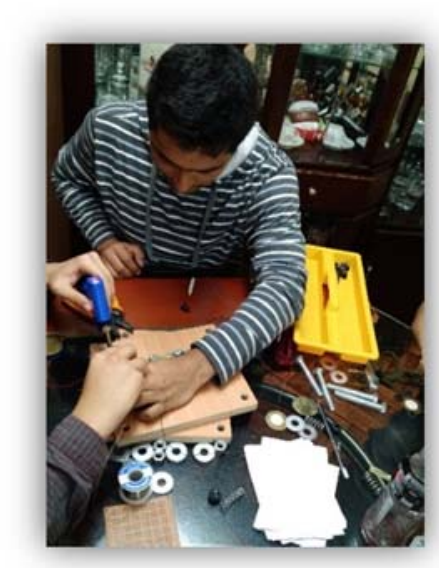

Fuente: Elaboración Propia

Luego de probar el funcionamiento del circuito en la primera hilera, se continuó fijando los demás piezoeléctricos por toda la base de melamina. Una vez que se terminó de fijar todos los piezoeléctricos, se conectaron en paralelo cada uno de ellos y se transfirió el circuito a una placa fija o galleta, adicionándole un terminal de entrada y un interruptor que permitirá abrir y cerrar el circuito libremente.

\section{Figura No 76: Elaboración Prototipo 13}

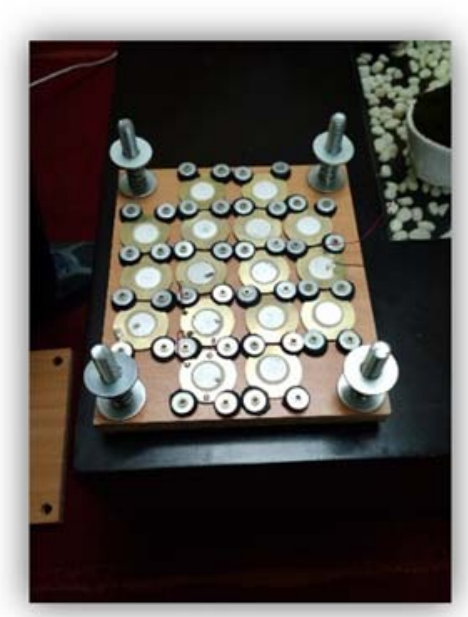

Fuente: Elaboración Propia 
Figura N ${ }^{\circ}$ 77: Elaboración Prototipo 14

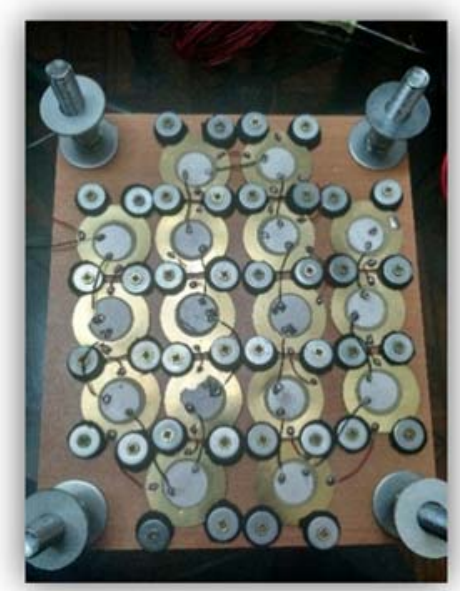

Fuente: Elaboración Propia

Figura No 78: Elaboración Prototipo 15

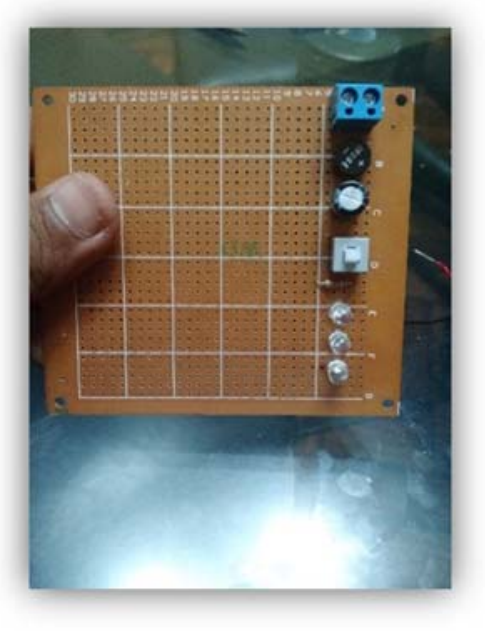

Fuente: Elaboración Propia 
Figura $N^{\circ}$ 79: Elaboración Prototipo 16

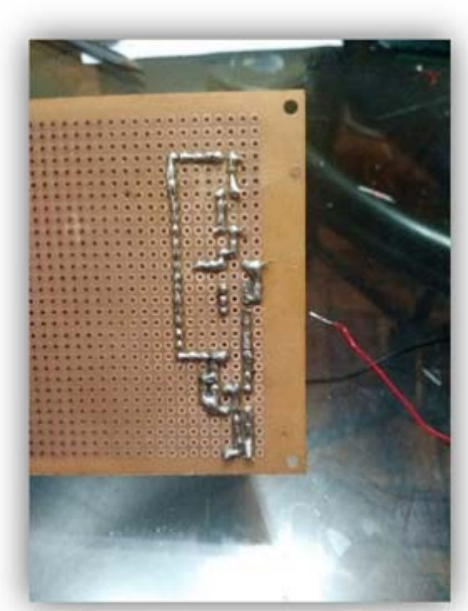

Fuente: Elaboración Propia

Figura Nº 80: Elaboración Prototipo 17

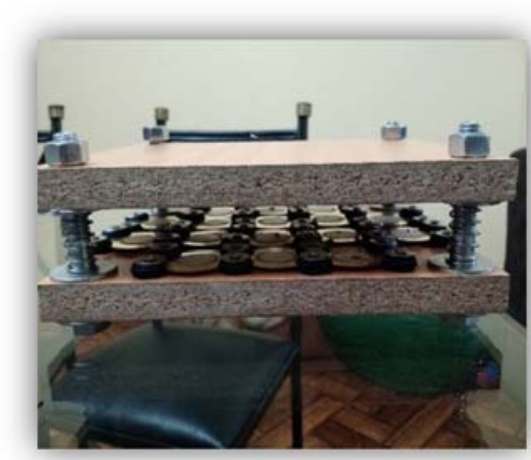

Fuente: Elaboración Propia

Figura $N^{\circ}$ 81: Elaboración Prototipo 18

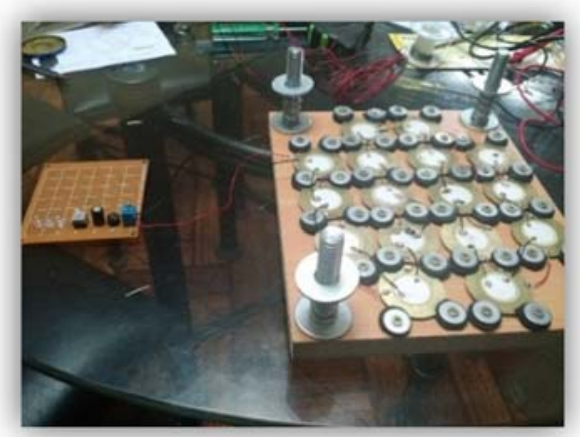

Fuente: Elaboración Propia 
Posteriormente, se ubicaron los tacos de goma en la plataforma superior para que hagan contacto con los piezoeléctricos al ejercer presión sobre estos.

\section{Figura Nº 82: Elaboración Prototipo 19}

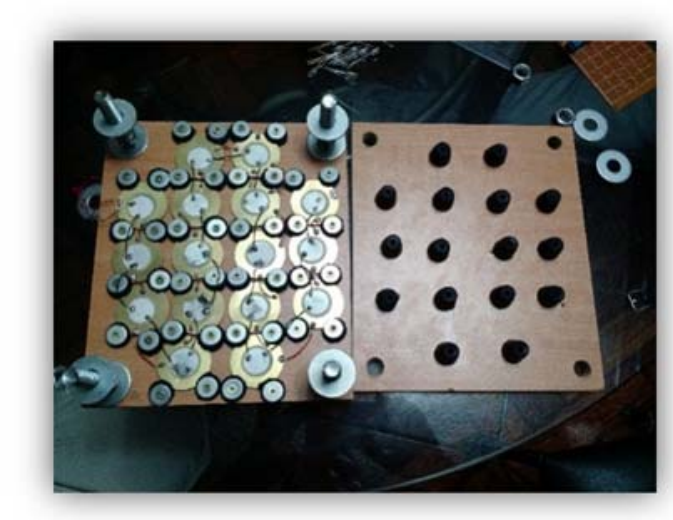

\section{Fuente: Elaboración Propia}

\section{Figura $N^{\circ}$ 83: Elaboración Prototipo 20}

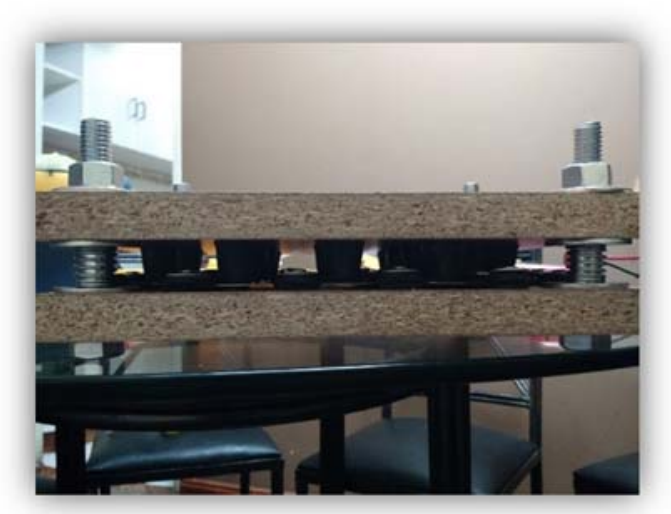

Fuente: Elaboración Propia

Por último, se realizaron las pruebas finales al prototipo y se demostró que el dispositivo efectivamente carga al condensador al hacer presión sobre la plataforma superior y los tacos de goma deforman los piezoeléctrico. Una vez cargado el condensador, se procede a activar el interruptor, lo cual conlleva a que los focos LED se enciendan con normalidad manteniéndose durante un tiempo considerable. Además, se evidencio que con cada pisada los focos LED seguían encendidos de manera constante. 
Figura Nº 84: Elaboración Prototipo 21

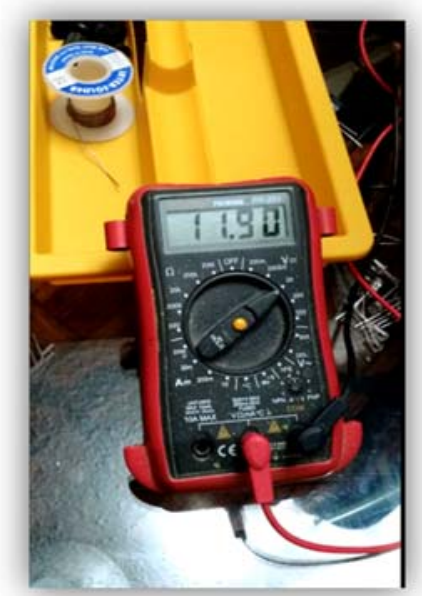

Fuente: Elaboración Propia

Figura $N^{\circ}$ 85: Elaboración Prototipo 22

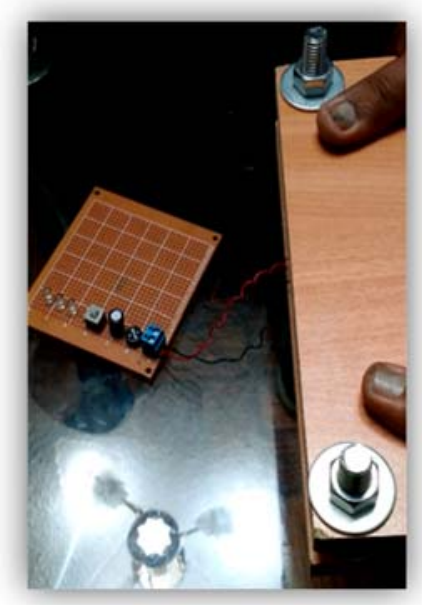

Fuente: Elaboración Propia 


\section{Figura $N^{\circ}$ 86: Elaboración Prototipo 23}

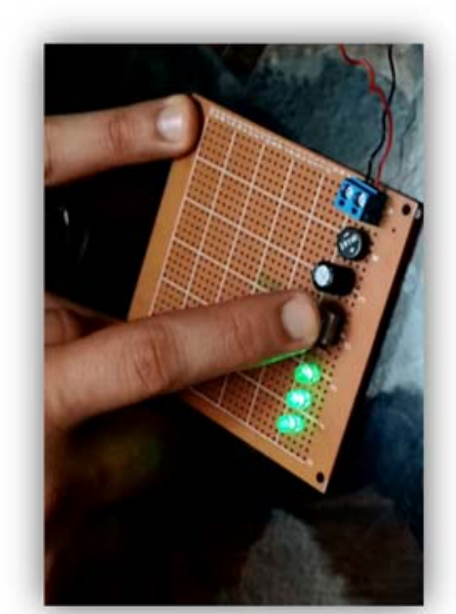

Fuente: Elaboración Propia

\section{Etapa 3: Mejoras}

Una vez terminado el Dispositivo Piezoeléctrico, se detectó cuáles eran los puntos críticos con respecto a su funcionabilidad, por lo cual se planteó propuestas de mejora que ayuden a que el dispositivo sea más funcional y presente menos errores.

Primero, se detectó que existía un constante problema en la conexión que se tenía entre la placa y el Dispositivo Piezoeléctrico; al hacer las pruebas de las pisadas siempre se desconectaban. Es por eso que se instalaron Terminales a ambos para cerciorar una buena conexión.

\section{Figura N87: Mejora Prototipo 1}

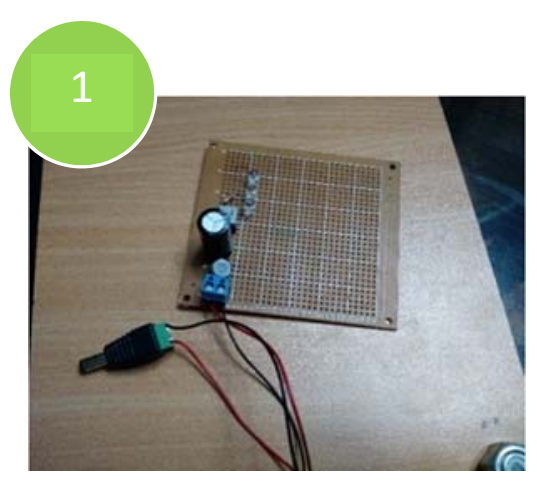

Fuente: Elaboración Propia 


\section{Figura N88: Mejora Prototipo 2}

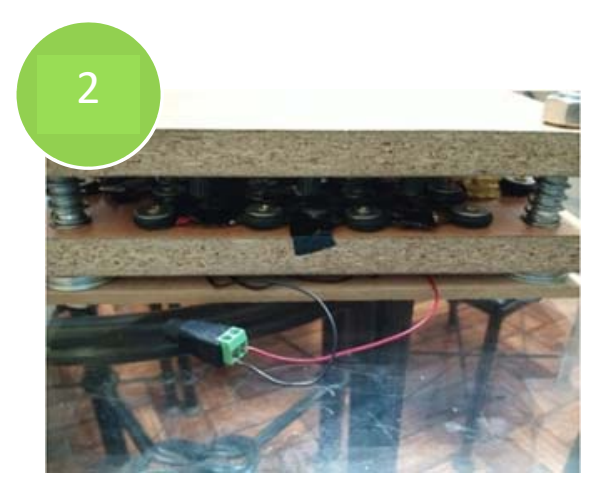

Fuente: Elaboración Propia

Otro punto crítico detectado fue el cableado y la conexión de los piezoeléctricos, que al ser presionados por las gomas superiores se desoldaban y desconectaban todo el circuito. Es por esto que se decidió hacer todo el cableado por debajo de la baldosa central y encasillarlo con un piso adicional inferior que los proteja. Adicionalmente, se cubrieron las conexiones de cada piezoeléctrico con cinta aislante para darle mayor protección.

Figura No89: Mejora Prototipo 3

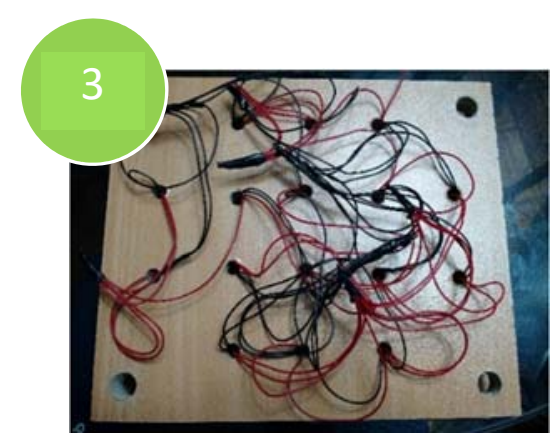

Fuente: Elaboración Propia

Figura N90: Mejora Prototipo 4 


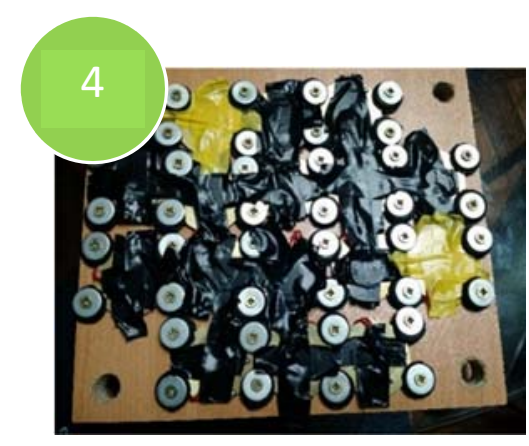

Fuente: Elaboración Propia

El último punto crítico detectado fueron las gomas que tocaban los piezoeléctricos, ya que estas no ejercían suficiente presión. Por este motivo, se cambiaron por unos más sólidos que puedan deformarlos con mayor fuerza.

\section{Figura No91: Mejora Prototipo 5}

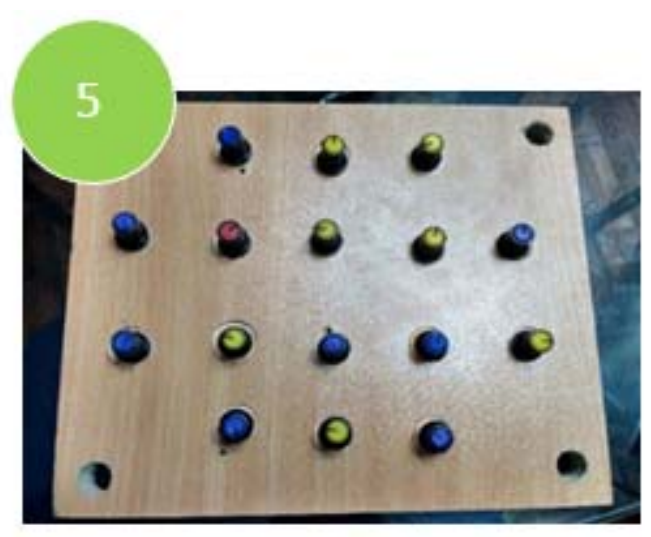

Fuente: Elaboración Propia

\subsubsection{Evaluación de Resultados}

Una vez elaborado el prototipo, se hicieron pruebas para determinar cuanta energía podría recaudar el Energy Harvester con cada pisada. Para este caso, se tomaron varias muestras con $5,10,15$ y 20 pisadas.

Para cada uno de los distintos escenarios planteados anteriormente, se tomarán 10 muestras, mediante las cuales se podrá verificar su funcionamiento y efectividad. Los resultados podrán visualizarse en la siguiente tabla: 
Tabla No31: Pruebas del prototipo

\begin{tabular}{|c|c|c|c|c|c|c|c|}
\hline \multirow{2}{*}{\multicolumn{2}{|c|}{$\begin{array}{c}\text { Categoría } 1 \\
\text { Prueba con } 5 \\
\text { pisadas }\end{array}$}} & \multicolumn{2}{|c|}{ Categoría 2} & \multicolumn{2}{|c|}{ Categoría 3} & \multirow{2}{*}{\multicolumn{2}{|c|}{$\begin{array}{c}\text { Categoría } 4 \\
\text { Prueba con } 20 \\
\text { pisadas }\end{array}$}} \\
\hline & & $\begin{array}{r}\text { Prue } \\
\mathbf{p}\end{array}$ & $\begin{array}{l}\operatorname{con} 10 \\
\text { das }\end{array}$ & $\begin{array}{r}\text { Prue } \\
\text { p }\end{array}$ & $\begin{array}{l}\text { con } 15 \\
\text { das }\end{array}$ & & \\
\hline $\begin{array}{c}N^{\circ} \text { de } \\
\text { prueb } \\
\quad \text { a }\end{array}$ & $\begin{array}{c}\text { Resultad } \\
\text { o } \\
\text { obtenido } \\
\text { (V) }\end{array}$ & $\begin{array}{c}N^{\circ} \text { de } \\
\text { prueb } \\
\quad \text { a }\end{array}$ & $\begin{array}{c}\text { Resultad } \\
\text { o } \\
\text { obtenido } \\
\text { (V) }\end{array}$ & $\begin{array}{c}N^{\circ} \text { de } \\
\text { prueb } \\
\text { a }\end{array}$ & $\begin{array}{l}\text { Resultad } \\
\text { o } \\
\text { obtenido } \\
\text { (V) }\end{array}$ & $\begin{array}{c}\mathrm{N}^{\circ} \text { de } \\
\text { prueb } \\
\text { a }\end{array}$ & $\begin{array}{c}\text { Resultad } \\
\text { o } \\
\text { obtenido } \\
\text { (V) }\end{array}$ \\
\hline 1 & 0,31 & 1 & 0,56 & 1 & 0,88 & 1 & 1,02 \\
\hline 2 & 0,30 & 2 & 0,62 & 2 & 0,79 & 2 & 1,02 \\
\hline 3 & 0,34 & 3 & 0,64 & 3 & 0,89 & 3 & 1,04 \\
\hline 4 & 0,32 & 4 & 0,57 & 4 & 0,82 & 4 & 1,09 \\
\hline 5 & 0,32 & 5 & 0,55 & 5 & 0,83 & 5 & 1,01 \\
\hline 6 & 0,33 & 6 & 0,68 & 6 & 0,88 & 6 & 0,92 \\
\hline 7 & 0,35 & 7 & 0,63 & 7 & 0,92 & 7 & 0,94 \\
\hline 8 & 0,32 & 8 & 0,60 & 8 & 0,85 & 8 & 0,99 \\
\hline 9 & 0,33 & 9 & 0,51 & 9 & 0,83 & 9 & 0,94 \\
\hline 10 & 0,28 & 10 & 0,59 & 10 & 0,81 & 10 & 0,94 \\
\hline Prom & 0,32 & Prom & 0,595 & Prom & 0,85 & Prom & 0,991 \\
\hline
\end{tabular}

\section{Fuente: Elaboración propia}

En el siguiente cuadro, se evaluarán los promedios obtenidos en cada una de las categorías anteriores, lo cual dará a conocer el voltaje promedio por pisada obtenido en cada categoría.

Tabla N³2: Cantidad de energía por pisada 


\begin{tabular}{|c|c|c|c|}
\hline \multirow{2}{*}{\multicolumn{2}{|c|}{$\begin{array}{c}\text { Categoría } 1 \\
\text { Prueba con } 5 \text { pisadas }\end{array}$}} & \multirow{2}{*}{\multicolumn{2}{|c|}{$\begin{array}{c}\text { Categoría } 2 \\
\text { Prueba con } 10 \text { pisadas }\end{array}$}} \\
\hline & & & \\
\hline $\begin{array}{c}\text { Cantidad de energía } \\
\text { por pisada }\end{array}$ & 0,064 & $\begin{array}{c}\text { Cantidad de energía } \\
\text { por pisada }\end{array}$ & 0,060 \\
\hline
\end{tabular}

\begin{tabular}{|c|c|c|c|}
\hline \multicolumn{2}{|c|}{ Categoría 3 } & \multicolumn{2}{c|}{ Categoría 4 } \\
\hline Prueba con 15 pisadas & Prueba con 20 pisadas \\
\hline $\begin{array}{c}\text { Cantidad de energía } \\
\text { por pisada }\end{array}$ & 0,057 & $\begin{array}{c}\text { Cantidad de energía } \\
\text { por pisada }\end{array}$ & 0,050 \\
\hline
\end{tabular}

Fuente: Elaboración Propia

Una vez obtenido los 4 resultados de cada categoría sobre la cantidad de energía almacenada por pisada, se ponderarán para obtener un resultado promedio que nos permita culminar el cálculo y poder concluir cual es la cantidad de energía que puede almacenar cada pisada en el prototipo elaborado.

Tabla N³3: Energía Promedio generada por el prototipo

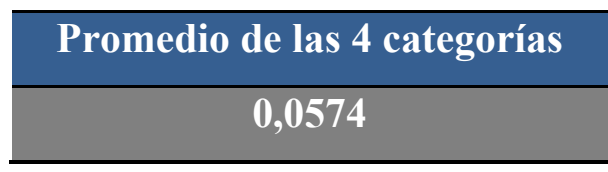

Fuente: Elaboración Propia

Finalmente, según el cálculo previo, se concluyó que por cada pisada en el prototipo de Energy Harvester, se puede almacenar 0,0574 Volts. El prototipo tiene un tamaño de $20.5 \times 24 \mathrm{~cm}$, quiere decir $0,0492 \mathrm{~cm}^{2}$. La baldosa PAVEGEN tiene un tamaño de 0,27 $\mathrm{cm}^{2}$, y si ponderamos, un prototipo con las mismas dimensiones podría almacenar 0,315 Volts por pisada. 
Esto no solo valida el funcionamiento de la tecnología piezoeléctrica y las baldosas PAVEGEN, también reafirma la funcionabilidad del uso de esta tecnología en la estación La Cultura del tren eléctrico de Lima para reducir sus costos energéticos.

\subsection{Simulación de la Propuesta de Solución}

Para poder validar que la implementación de un sistema de generación de energía renovable basado en la tecnología piezoeléctrica en la Estación La Cultura de la Línea 1 del tren eléctrico de la ciudad de Lima, se ha realizado una simulación utilizando el Software Arena de Rockwell. Esta simulación ha sido planteada siguiendo los lineamientos del diseño arquitectónico establecido en el capítulo 3.

La propuesta de solución planteada en este proyecto de investigación no busca mejorar los tiempos de servicio brindados en las diversas actividades del proceso de atención; sin embargo, se busca implementar un sistema de generación de energía, el cual pueda aprovechar la energía cinética de las personas que utilizan este medio de transporte, para así transformarla en energía eléctrica y consecuentemente poder reducir los costos energéticos de la estación sin distorsionar el servicio actual ni sus procedimientos.

Debido a que esta propuesta no busca mejorar los tiempos de servicio, se realizará la simulación con el objetivo de demostrar que la instalación de las baldosas PAVEGEN no perjudicarán el servicio brindado por el tren eléctrico. Lo único que traerá consigo la implementación de las baldosas será la generación de energía eléctrica y consecuentemente el ahorro energético para la estación La Cultura.

\subsubsection{Planteamiento de la Simulación}

En el siguiente modelo planteado en el Software, se les ha dado la oportunidad a los clientes de decidir que torniquete utilizar, siempre optando por el que tenga menor cantidad de gente en cola. En este flujo, el único tiempo de servicio crucial viene a ser el de los torniquetes, ya que estos son las compuertas que permiten el ingreso y salida de las personas a la estación.

A continuación de los torniquetes, se han colocado las baldosas, brindándoles un tiempo de atención de 0,63 segundos, ya que una persona promedio peruana realiza 6 pasos en 
3,5 segundos, lo cual conlleva a un tiempo promedio de 0,63 segundo por pisada. Según lo establecido en el capítulo 3, una baldosa equivale en promedio a un paso.

Figura N92: Modelo planteado en el Software Arena

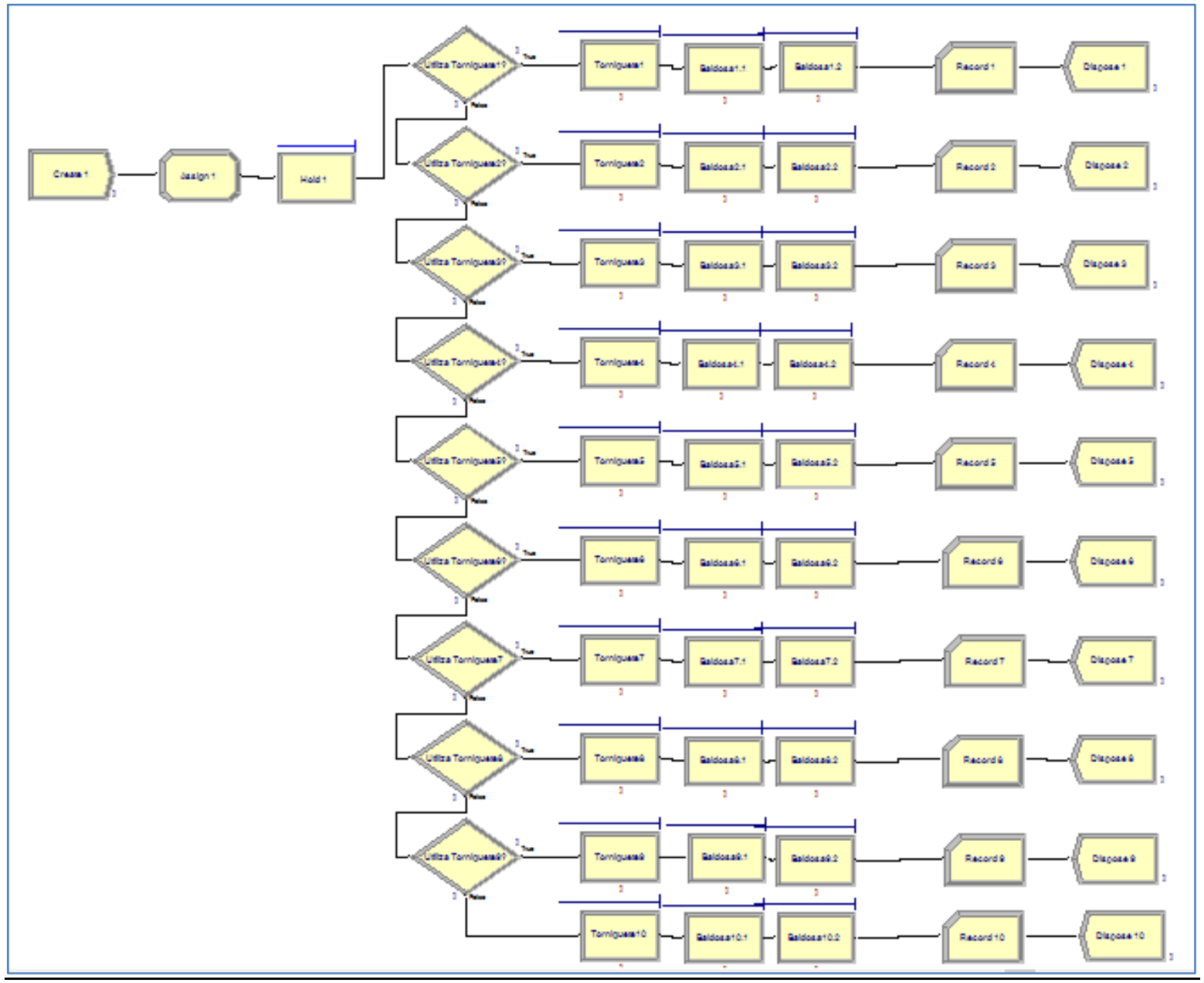

Fuente: Elaboración Propia

A continuación, se mostrarán imágenes de las características de la simulación, para así demostrar cuales han sido los atributos brindados a los clientes, las fórmulas establecidas para que los clientes siempre opten por el torniquete con menor cola, y los tiempos de servicio asignados a los torniquetes y a las baldosas.

Estos han sido establecidos mediante la exploración y adquisición de muestras respectivas para así hallar la data real para este problema. 
En primer lugar, se verá los atributos brindados a los clientes:

\section{Figura No93: Distribución del tiempo de llegada de los clientes}

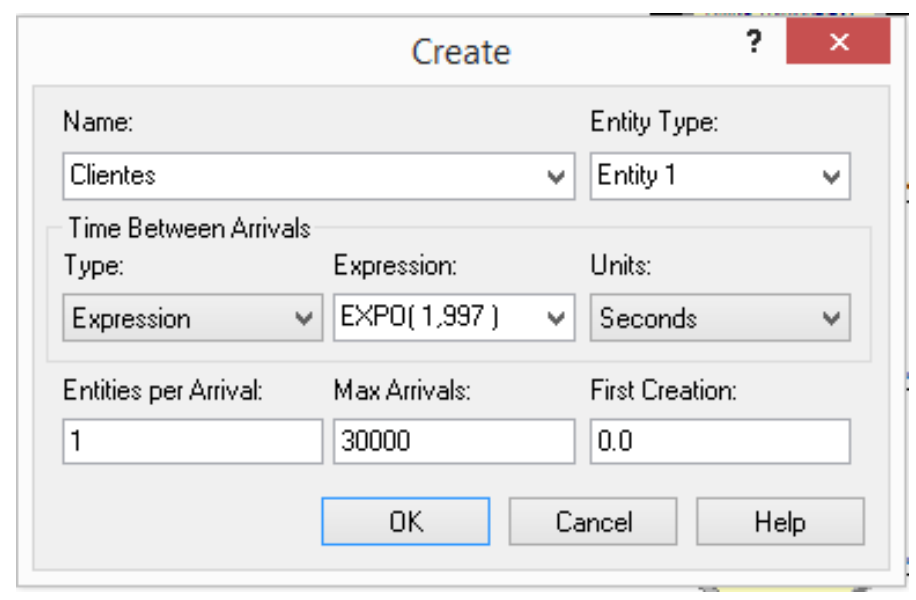

\section{Fuente: Elaboración Propia}

A los clientes se les brindo una distribución exponencial de 1,997 segundos para su tiempo de llegada, ya que esta fue calculada mediante los datos proporcionados por la empresa AATE. Además, debido a que diariamente la estación tiene un promedio de 29,413 personas, se designó un máximo de llegadas de 30,000 personas al día para así tener un pequeño margen de error.

A continuación, se podrá observar la distribución de los datos brindados por AATE y los cálculos realizados para poder corroborar que los clientes cuentan con una distribución exponencial de llegada de 1,997 segundos. 
Tabla N³4: Distribución de Tiempos entre llegadas

\begin{tabular}{|c|c|}
\hline $\begin{array}{c}\text { Tiempo entre } \\
\text { llegadas } \\
\text { Xi (segundos) }\end{array}$ & fi \\
\hline 0.8027 & 4,485 \\
\hline 0.8126 & 4,430 \\
\hline 0.9934 & 3,624 \\
\hline 1.14 & 3,158 \\
\hline 1.295 & 2,780 \\
\hline 1.8888 & 1,906 \\
\hline 2.7027 & 1,332 \\
\hline 2.765 & 1,302 \\
\hline 2.8823 & 1,249 \\
\hline 3.0822 & 1,168 \\
\hline 3.5468 & 1,015 \\
\hline 4.0134 & 897 \\
\hline 4.157 & 866 \\
\hline 4.5455 & 792 \\
\hline 5.3333 & 675 \\
\hline 5.5728 & 646 \\
\hline 11.215 & 321 \\
\hline
\end{tabular}

Fuente; AATE

\section{$\underline{\text { Resumen de Datos: }}$}

\begin{tabular}{|c|c|}
\hline \multicolumn{2}{|c|}{ Resumen de Datos } \\
$\begin{array}{c}\text { Tamaño de } \\
\text { Muestra }\end{array}$ & 30,646 \\
\hline Máximo & 11.215 \\
\hline Mínimo & 0.8027 \\
\hline Promedio( $\beta)$ & 1.997 \\
\hline K & 16 \\
\hline Rango & 10.4123 \\
\hline Ancho de Clase & 0.6508 \\
\hline
\end{tabular}

Fuente: Elaboración Propia 


\begin{tabular}{|c|c|c|c|c|c|c|}
\hline & LI & LS & fi & $\mathbf{P}(\mathbf{L i}<=\mathbf{X}<=\mathbf{L s})$ & $\begin{array}{c}\text { Frecuencia } \\
\text { Esperada }\end{array}$ & $\frac{(F O i-F E i)^{2}}{F E i}$ \\
\hline 1 & 0.80 & 1.45 & $18,477.00$ & 0.43 & $13,301.64$ & $2,013.61$ \\
\hline 2 & 1.45 & 2.10 & $1,906.00$ & 0.51 & $15,511.50$ & $11,933.70$ \\
\hline 3 & 2.10 & 2.75 & $1,332.00$ & 0.55 & $16,705.95$ & $14,148.16$ \\
\hline 4 & 2.75 & 3.41 & $3,719.00$ & 0.56 & $17,194.57$ & $10,560.95$ \\
\hline 5 & 3.41 & 4.06 & $1,912.00$ & 0.56 & $17,199.01$ & $13,587.56$ \\
\hline 6 & 4.06 & 4.71 & $1,658.00$ & 0.55 & $16,877.53$ & $13,724.41$ \\
\hline 7 & 4.71 & 5.36 & 675.00 & 0.53 & $16,342.81$ & $15,020.69$ \\
\hline 8 & 5.36 & 6.01 & 646.00 & 0.51 & $15,674.67$ & $14,409.30$ \\
\hline 9 & 6.01 & 6.66 & - & 0.49 & $14,929.36$ & $14,929.36$ \\
\hline 10 & 6.66 & 7.31 & - & 0.46 & $14,146.18$ & $14,146.18$ \\
\hline 11 & 7.31 & 7.96 & - & 0.44 & $13,352.29$ & $13,352.29$ \\
\hline 12 & 7.96 & 8.61 & - & 0.41 & $12,566.17$ & $12,566.17$ \\
\hline 13 & 8.61 & 9.26 & - & 0.39 & $11,800.11$ & $11,800.11$ \\
\hline 14 & 9.26 & 9.91 & - & 0.36 & $11,062.00$ & $11,062.00$ \\
\hline 15 & 9.91 & 10.56 & - & 0.34 & $10,356.62$ & $10,356.62$ \\
\hline 16 & 10.56 & 11.21 & 321.00 & 0.32 & $9,686.57$ & $9,055.21$ \\
\hline & & & 30,646 & & & 192,666 \\
\hline
\end{tabular}

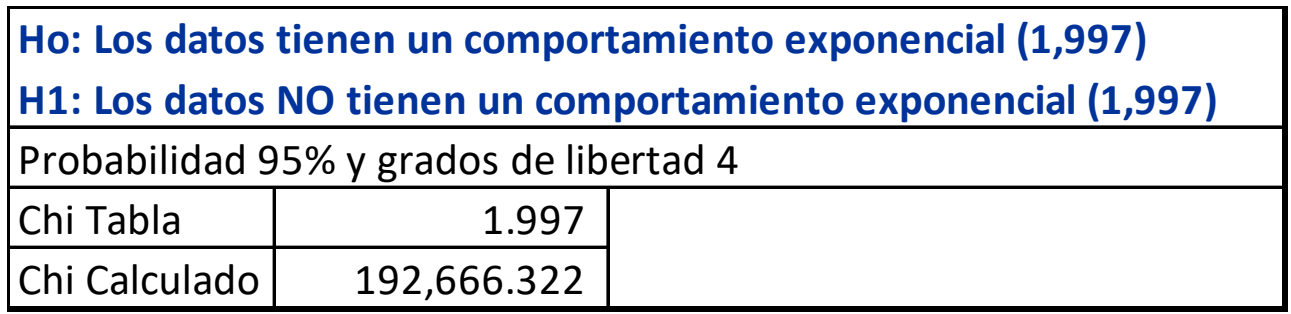

Mediante los cálculos realizados, se pude corroborar que la data brindada por la institución AATE cuenta con una distribución exponencial de 1,997 segundos.

En segundo lugar, se podrán visualizar las fórmulas establecidas para que los clientes siempre opten por seleccionar el torniquete con menor cola. 
Figura N94: Selección de torniquetes

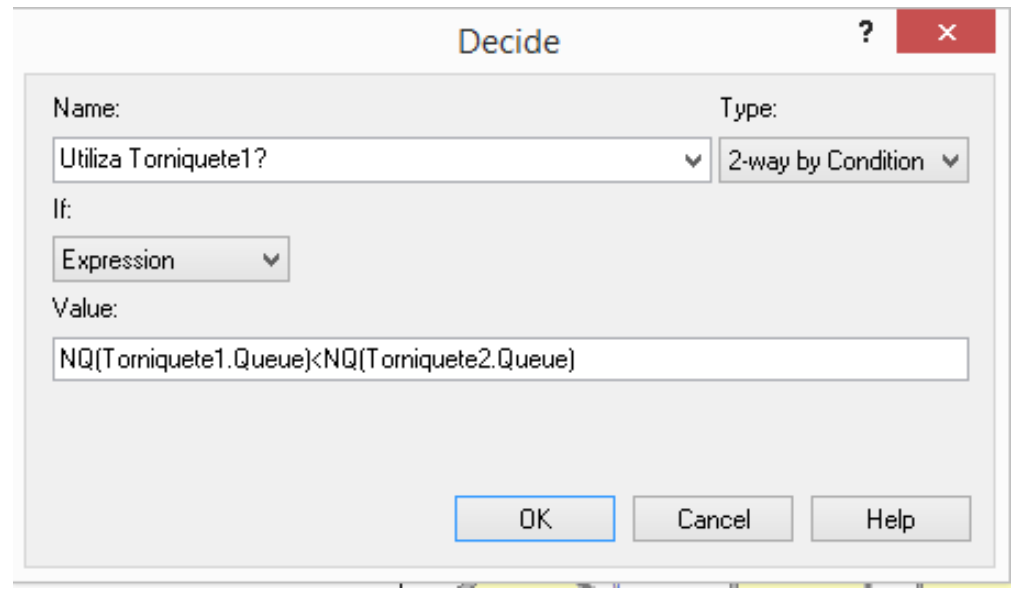

Fuente: Elaboración Propia

En el modelo planteado, se pueden encontrar 10 procesos de toma de decisión, los cuales seguirán el mismo patrón mostrado en la imagen anterior. Estos les darán la oportunidad a los clientes de elegir el torniquete con menor cola para así agilizar su flujo.

En tercer lugar, se podrá visualizar el tiempo de servicio brindado a los torniquetes y los datos de donde se han obtenido estos tiempos de servicio. 


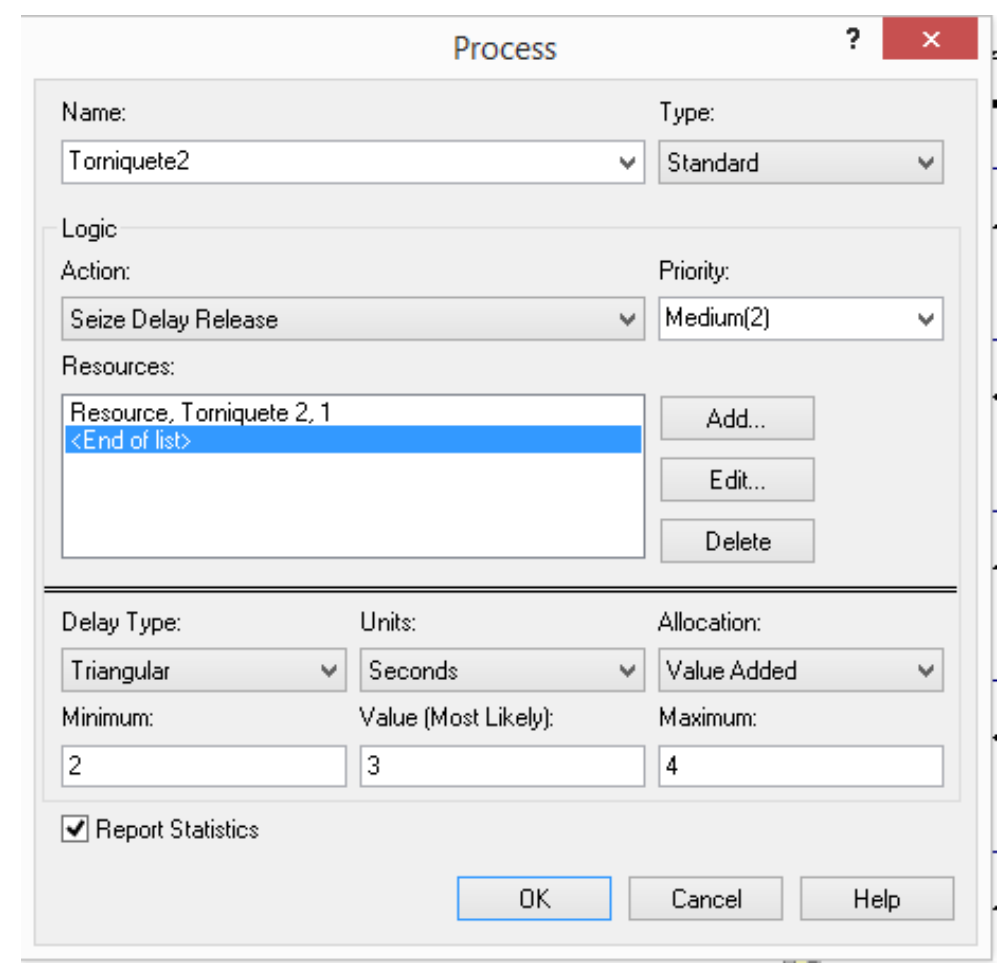

Fuente: Elaboración Propia

La distribución brindada a los torniquetes ha sido una distribución triangular de $(2,3,4)$ segundos, ya que todas las personas se demoran entre 2 y 4 segundos en poder atravesar estos torniquetes. Los torniquetes, como no son operados por ningún empleado, dependen estrictamente de los usuarios, los cuales a veces transitan de una manera eficaz y rápida, y algunos se toman un tiempo un poco mayor al usual. Debido a ello, es que se han considerado los tiempos de 2, 3 y 4 segundos.

Debido a que la tabla de toma de tiempos es muy extensa para colocarla en esta parte del documento, se colocará al final del proyecto de investigación como parte de los anexos, identificada como (ANEXO 3). En esta tabla se podrá corroborar que los tiempos de servicio de los torniquetes fluctúan entre 2 y 4 segundos.

Después de haber corrido la simulación un total de 10 veces, este brindó un reporte bien extenso el cual podrá ser visualizado en el (ANEXO 3). Proveniente de este resultado e informe, se elaboró una tabla con los tiempos de las colas formadas en las diversas entidades de este sistema, para poder así corroborar que las baldosas no generarán cola alguna. Esta tabla podrá ser visualizada a continuación. 


\section{Tabla N³5: Tiempo en Colas}

\begin{tabular}{|c|c|c|c|c|c|c|c|c|c|c|}
\hline \multirow[b]{2}{*}{ Simulación } & \multicolumn{10}{|c|}{ Tiempo de Espera en Segundos } \\
\hline & $\begin{array}{c}\text { Nro. } \\
1\end{array}$ & $\begin{array}{c}\text { Nro. } \\
2\end{array}$ & $\begin{array}{c}\text { Nro. } \\
3\end{array}$ & $\begin{array}{c}\text { Nro. } \\
4\end{array}$ & $\begin{array}{c}\text { Nro. } \\
5\end{array}$ & $\begin{array}{c}\text { Nro. } \\
6\end{array}$ & $\begin{array}{c}\text { Nro. } \\
7\end{array}$ & $\begin{array}{c}\text { Nro. } \\
8\end{array}$ & $\begin{array}{c}\text { Nro. } \\
9\end{array}$ & $\begin{array}{c}\text { Nro. } \\
10\end{array}$ \\
\hline Baldosa 1.2 & 0 & 0 & 0 & 0 & 0 & 0 & 0 & 0 & 0 & 0 \\
\hline Baldosa 10.1 & 0 & 0 & 0 & 0 & 0 & 0 & 0 & 0 & 0 & 0 \\
\hline Baldosa 10.2 & 0 & 0 & 0 & 0 & 0 & 0 & 0 & 0 & 0 & 0 \\
\hline Baldosa 2.1 & 0 & 0 & 0 & 0 & 0 & 0 & 0 & 0 & 0 & 0 \\
\hline Baldosa 2.2 & 0 & 0 & 0 & 0 & 0 & 0 & 0 & 0 & 0 & 0 \\
\hline Baldosa 3.1 & 0 & 0 & 0 & 0 & 0 & 0 & 0 & 0 & 0 & 0 \\
\hline Baldosa 3.2 & 0 & 0 & 0 & 0 & 0 & 0 & 0 & 0 & 0 & 0 \\
\hline Baldosa 4.1 & 0 & 0 & 0 & 0 & 0 & 0 & 0 & 0 & 0 & 0 \\
\hline Baldosa 4.2 & 0 & 0 & 0 & 0 & 0 & 0 & 0 & 0 & 0 & 0 \\
\hline Baldosa 5.1 & 0 & 0 & 0 & 0 & 0 & 0 & 0 & 0 & 0 & 0 \\
\hline Baldosa 5.2 & 0 & 0 & 0 & 0 & 0 & 0 & 0 & 0 & 0 & 0 \\
\hline Baldosa 6.1 & 0 & 0 & 0 & 0 & 0 & 0 & 0 & 0 & 0 & 0 \\
\hline Baldosa 6.2 & 0 & 0 & 0 & 0 & 0 & 0 & 0 & 0 & 0 & 0 \\
\hline Baldosa 7.1 & 0 & 0 & 0 & 0 & 0 & 0 & 0 & 0 & 0 & 0 \\
\hline Baldosa 7.2 & 0 & 0 & 0 & 0 & 0 & 0 & 0 & 0 & 0 & 0 \\
\hline Baldosa 8.1 & 0 & 0 & 0 & 0 & 0 & 0 & 0 & 0 & 0 & 0 \\
\hline Baldosa 8.2 & 0 & 0 & 0 & 0 & 0 & 0 & 0 & 0 & 0 & 0 \\
\hline Baldosa 9.1 & 0 & 0 & 0 & 0 & 0 & 0 & 0 & 0 & 0 & 0 \\
\hline Baldosa 9.2 & 0 & 0 & 0 & 0 & 0 & 0 & 0 & 0 & 0 & 0 \\
\hline Torniquete 1 & 0.94 & 1.06 & 1.01 & 1.06 & 0.94 & 1.04 & 1.04 & 1.01 & 1.09 & 1.05 \\
\hline Torniquete $\mathbf{1 0}$ & 1.41 & 1.41 & 1.4 & 1.41 & 1.41 & 1.42 & 1.41 & 1.43 & 1.42 & 1.4 \\
\hline Torniquete 2 & 1.03 & 1.03 & 1 & 0.99 & 1.07 & 1.03 & 1 & 1.08 & 1.09 & 1.03 \\
\hline Torniquete 3 & 1.01 & 1.01 & 1.03 & 1.02 & 1.05 & 1.05 & 1.01 & 1.02 & 1.05 & 1.03 \\
\hline Torniquete 4 & 1.03 & 1.03 & 1.01 & 1.04 & 0.99 & 1.01 & 1.01 & 1.06 & 1.02 & 1.03 \\
\hline Torniquete 5 & 1.06 & 1.04 & 1 & 1.06 & 1 & 1.04 & 0.99 & 1.03 & 1.03 & 1.03 \\
\hline Torniquete 6 & 1.01 & 1.03 & 1 & 1.02 & 1.02 & 1.05 & 1.02 & 1.02 & 1.05 & 0.99 \\
\hline Torniquete 7 & 1.02 & 1.01 & 1.03 & 1.03 & 1.03 & 1.03 & 1.04 & 1.02 & 1.01 & 1.04 \\
\hline Torniquete 8 & 1.06 & 1.05 & 1.05 & 1.05 & 1.06 & 1.05 & 1.05 & 1.06 & 1.05 & 1.05 \\
\hline Torniquete 9 & 1.17 & 1.18 & 1.17 & 1.17 & 1.17 & 1.17 & 1.17 & 1.18 & 1.17 & 1.18 \\
\hline
\end{tabular}

Fuente: Elaboración Propia

Como se pude visualizar en la tabla anterior, las colas generadas en los torniquetes tienen un tiempo promedio de 1,1 segundos, mientras que las baldosas no generan ninguna cola 
en lo absoluto. Esto se debe a que las personas solo caminan sobre ellas y esto no generará ninguna inconformidad ante los usuarios.

Por consiguiente, se puede validar que la implementación de las baldosas PAVEGEN en la estación La Cultura, solo conllevará a aprovechar la energía cinética desaprovechada de las personas, generar energía eléctrica y reducir los costos energéticos de la estación, mas no perjudicar el servicio brindado por el tren eléctrico. 


\section{CAPÍTULO 5: IMPACTOS DEL PROYECTO}

La implementación de este sistema de generación de energía renovable en base a la tecnología piezoeléctrica trae consigo diversos impactos positivos, tanto para la empresa misma donde se va a instalar "AATE" como también para la sociedad, ya que esta se ve involucrada directamente en la generación de este tipo de energía y son el input indispensable para el desarrollo de este proyecto.

La energía renovable piezoeléctrica no es muy conocida hoy en día por la sociedad, ya que, como se presentó en el capítulo 2, la sociedad limeña solo tiene conocimiento sobre los tipos de energía renovable más convencionales como la energía solar, hidroeléctrica, eólica y geotérmica, mientras que es casi nulo el conocimiento de la energía piezoeléctrica. Esta es una oportunidad sumamente importante para darle a conocer a la sociedad acerca de nuevas posibilidades de generación de energía limpia que hay disponibles en el mercado para poder contribuir con el medio ambiente al aprovechar la energía del entorno que se viene desperdiciando día a día.

Gráfico N³5: Conocimiento de la sociedad sobre tipos de energía

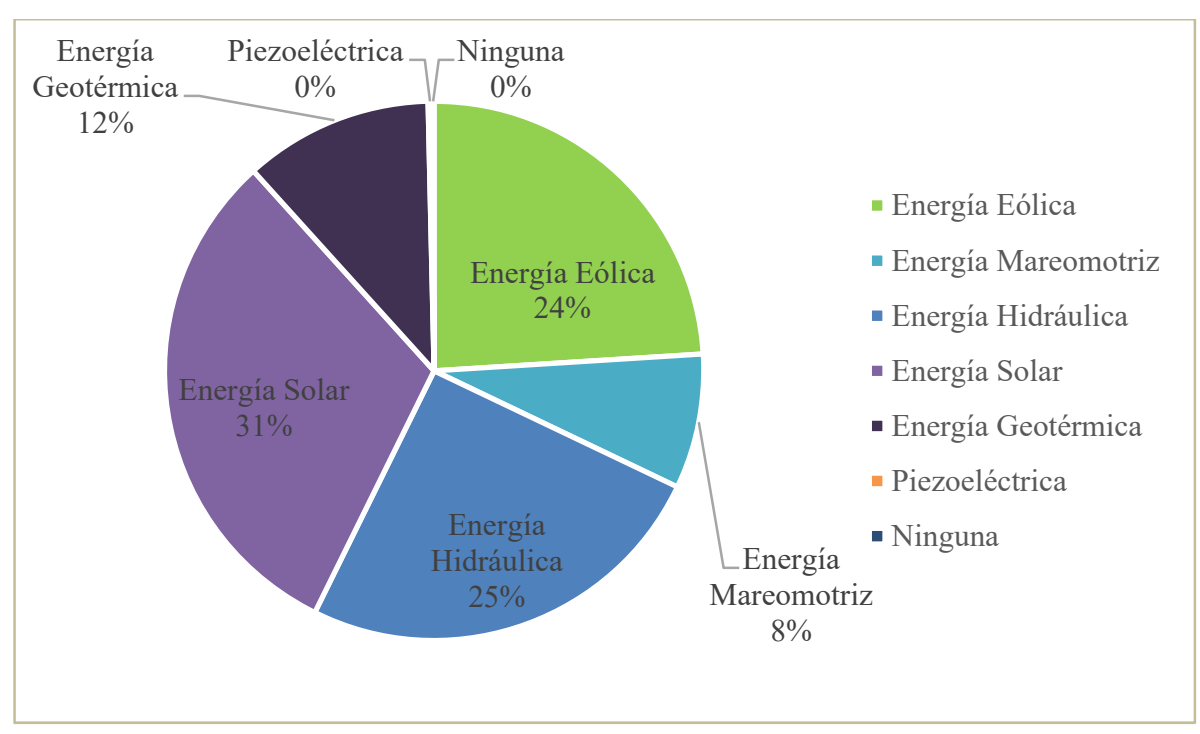

Fuente: Elaboración Propia 
Como se puede visualizar en la gráfica del resultado obtenido en las encuestas realizadas a la sociedad limeña, menos del $1 \%$ de la población limeña tiene conocimiento de la existencia de la tecnología piezoeléctrica. Esto refleja la incertidumbre de la sociedad limeña ante un tipo de tecnología que es de gran implicancia en nuestro entorno, el cual está caracterizado por la gran actividad vial de la sociedad en hora punta en diversos puntos de la ciudad, medios de transporte, centros comerciales, grandes eventos, etc.

A continuación, se evaluarán los impactos del proyecto relacionados a los 3 pilares de la sostenibilidad en los cuales se basa el proyecto, económico, social y ambiental.

\subsection{Impacto Económico}

En todo proyecto es sumamente importante evaluar cuáles serán los beneficios económicos que este puede traer consigo y cuál es el comportamiento de la inversión con respecto a los mismos. En cuanto al impacto económico generado para la empresa AATE, la implementación de las baldosas PAVEGEN en sus instalaciones, tienen un costo de $\mathrm{S} /$ 192,972.87, los cuales tienen un periodo de recuperación menor a 2 años.

El cálculo del beneficio económico se presentará a continuación con su respectivo horizonte de recuperación, además de indicadores que permitan corroborar la factibilidad de este proyecto.

\subsubsection{Ahorros Generados por la instalación de la tecnología piezoeléctrica}

Como se ha mencionado a lo largo del proyecto, una de las principales variables para la generación de energía es la gran afluencia diaria de la Estación La Cultura, donde se propone implementar este proyecto, (un promedio de 29,413 personas diarias) la cual permite el gran aprovechamiento de la energía cinética de las personas para generar energía renovable mediante la tecnología piezoeléctrica utilizando sus pisadas.

A continuación, utilizando solamente la información de afluencia brindada por AATE se verán tres escenarios, en los cuales se planteará distintos márgenes de ahorro dependiendo 
de la cantidad de pasos que se den en el tramo donde estarán instaladas las baldosas, los cuales se mostraran a continuación:

Tabla N’36: Cálculo de Ahorros en la Estación la Cultura 6 Pasos aprovechados por Usuario

\begin{tabular}{|l|r|}
\hline \multicolumn{2}{|c|}{ 6 PASOS POR PERSONA } \\
\hline \begin{tabular}{l|r} 
Afluencia Anual de la Estación La \\
Cultura
\end{tabular} & $\mathbf{1 0 , 7 3 5 , 8 3 0}$ \\
\hline Días al año & 365 \\
\hline Flujo de personas diario & 29,413 \\
\hline Numero de pasos (6 pasos/persona) & 176,479 \\
\hline Watt por paso = 7 W & $1,235,355.82$ \\
\hline kW generados por día & $1,235.36$ \\
\hline kWh generados al día. & 72.67 \\
\hline Porcentaje de Eficiencia Estimado & $70 \%$ \\
\hline Costo kW & 0.4174 \\
\hline Ahorro Diario S/. & 360.95 \\
\hline Ahorro Mensual S/. & 10828.39 \\
\hline Ahorro Anual S/. & $\mathbf{1 3 1 , 7 4 5 . 3 9}$ \\
\hline
\end{tabular}

Fuente: Elaboración Propia

Tabla N³7: Cálculo de Ahorros en la Estación la Cultura 7 Pasos aprovechados por Usuario

\begin{tabular}{|l|r|}
\hline \multicolumn{2}{|c|}{ 7 PASOS POR PERSONA } \\
\hline $\begin{array}{l}\text { Afluencia Anual de la Estación La } \\
\text { Cultura }\end{array}$ & $\mathbf{1 0 , 7 3 5 , 8 3 0}$ \\
\hline Días al año & 365 \\
\hline Flujo de personas diario & 29,413 \\
\hline Numero de pasos (7 pasos/persona) & 205,893 \\
\hline Watt por paso = 7 W & $1,441,248.46$ \\
\hline kW generados por día & $1,441.25$ \\
\hline kWh generados al día. & 84.78 \\
\hline Porcentaje de Eficiencia Estimado & $70 \%$ \\
\hline Costo kW & 0.4174 \\
\hline Ahorro Diario S/. & 421.10 \\
\hline Ahorro Mensual S/. & 12633.12 \\
\hline Ahorro Anual S/. & $\mathbf{1 5 3 , 7 0 2 . 9 5}$ \\
\hline
\end{tabular}

Fuente: Elaboración Propia 
Tabla N³8: Cálculo de Ahorros en la Estación la Cultura 8 Pasos aprovechados por Usuario

\begin{tabular}{|l|r|}
\hline \multicolumn{2}{|c|}{ 8 PASOS POR PERSONA } \\
\hline $\begin{array}{l}\text { Afluencia Anual de la Estación La } \\
\text { Cultura }\end{array}$ & $\mathbf{1 0 , 7 3 5 , 8 3 0}$ \\
Días al año & 365 \\
\hline Flujo de personas diario & 29,413 \\
Numero de pasos (8 pasos/persona) & 235,306 \\
Watt por paso = 7 W & $1,647,141.10$ \\
kW generados por día & $1,647.14$ \\
\hline kWh generados al día. & 96.89 \\
\hline Porcentaje de Eficiencia Estimado & $70 \%$ \\
\hline Costo kW & 0.4174 \\
\hline Ahorro Diario S/. & 481.26 \\
Ahorro Mensual S/. & 14437.85 \\
\hline Ahorro Anual S/. & $\mathbf{1 7 5 , 6 6 0 . 5 2}$ \\
\hline
\end{tabular}

\section{Fuente: Elaboración Propia}

Como se pudo apreciar, en el peor de los casos el ahorro mínimo anual sería de $\mathrm{S} / 131,745,39$ mientras que en el escenario optimo se podría conseguir un ahorro de hasta S/ $175,660.52$.

\subsubsection{Retorno Sobre la Inversión (ROI)}

Debido a que la implementación de las baldosas será permanente y este traerá consigo ahorros continuamente en el futuro, se calculará el ROI basándonos en un periodo de 2 , 3 y 4 años para los distintos escenarios planteados en el subcapítulo anterior. Cada uno de estos escenarios se diferencia por el número de pisadas promedio que puede generar cada usuario al transitar por el área donde serán instaladas las baldosas PAVEGEN. Mientras más pisadas se aprovechen de los usuarios, mayor energía será generada por las baldosas. 
Tabla N³9: Indicador ROI

\begin{tabular}{|c|c|}
\hline \multicolumn{2}{|c|}{ Escenario 1.1 } \\
\hline Periodo & 2 Años \\
\hline & \\
Inversión & $192,972.87$ \\
\hline & \\
Retorno & $263,490.78$ \\
\hline ROI & $\mathbf{3 6 . 5 \%}$ \\
\hline
\end{tabular}

\begin{tabular}{|c|c|}
\hline \multicolumn{2}{|c|}{ Escenario 2.1 } \\
\hline Periodo & $\mathbf{2}$ Años \\
\hline & \\
Inversión & $192,972.87$ \\
\hline & \\
Retorno & $307,405.90$ \\
\hline ROI & $\mathbf{5 9 . 3 \%}$ \\
\hline
\end{tabular}

\begin{tabular}{|c|c|}
\hline \multicolumn{2}{|c|}{ Escenario 3.1 } \\
\hline Periodo & 2 Años \\
\hline & \\
Inversión & $192,972.87$ \\
\hline & \\
Retorno & $351,321.04$ \\
\hline ROI & $\mathbf{8 2 . 1 \%}$ \\
\hline
\end{tabular}

\begin{tabular}{|c|c|}
\hline \multicolumn{2}{|c|}{ Escenario 1.2 } \\
\hline Periodo & 3 Años \\
\hline & \\
Inversión & $192,972.87$ \\
\hline & \\
Retorno & $395,236.17$ \\
\hline ROI & $\mathbf{1 0 4 . 8 \%}$ \\
\hline
\end{tabular}

\begin{tabular}{|c|c|}
\hline \multicolumn{2}{|c|}{ Escenario 2.2 } \\
\hline Periodo & 3 Años \\
\hline Inversión & $192,972.87$ \\
\hline & \\
Retorno & $461,108.85$ \\
\hline ROI & $\mathbf{1 3 9 . 0 \%}$ \\
\hline
\end{tabular}

\begin{tabular}{|c|c|}
\hline \multicolumn{2}{|c|}{ Escenario 3.2 } \\
\hline Periodo & 3 Años \\
\hline Inversión & $192,972.87$ \\
\hline & \\
Retorno & $526,981.56$ \\
\hline ROI & $\mathbf{1 7 3 . 1 \%}$ \\
\hline
\end{tabular}

\begin{tabular}{|c|c|}
\hline \multicolumn{2}{|c|}{ Escenario 1.3 } \\
\hline Periodo & 4 Años \\
\hline & \\
Inversión & $192,972.87$ \\
\hline & \\
Retorno & $526,981.56$ \\
\hline ROI & $\mathbf{1 7 3 . 1 \%}$ \\
\hline
\end{tabular}

\begin{tabular}{|c|c|}
\hline \multicolumn{2}{|c|}{ Escenario 2.3 } \\
\hline Periodo & 4 Años \\
\hline & \\
Inversión & $192,972.87$ \\
\hline & \\
Retorno & $614,811.80$ \\
\hline ROI & $\mathbf{2 1 8 . 6 \%}$ \\
\hline
\end{tabular}

\section{Escenario 3.3}

\begin{tabular}{|c|c|}
\hline Periodo & 4 Años \\
\hline Inversión & $192,972.87$ \\
\hline & \\
Retorno & $702,642.08$ \\
\hline ROI & $\mathbf{2 6 4 . 1 \%}$ \\
\hline
\end{tabular}

Fuente: Elaboración Propia

Como puede ser visualizado en las tablas anteriores, a partir del segundo año todos los indicadores ROI (Return of Invertion o Retorno sobre la Inversión) en cualquiera de los tres escenarios es positivo, ya que el periodo de recuperación es menor a los dos años. Este periodo de recuperación podrá ser visualizado nuevamente a continuación, ya que fue presentado también en el capítulo anterior. 
Tabla N40: Horizonte de Recuperación

\begin{tabular}{|c|c|}
\hline \multicolumn{2}{|c|}{ HORIZONTE DE RECUPERACIÓN } \\
\hline AHORRO & $\begin{array}{c}\text { TIEMPO DE } \\
\text { RECUPERACIÓN }\end{array}$ \\
\hline Ahorro de 131,745.38 & 17.7 Meses \\
\hline Ahorro de $175,660.52$ & 13.3 Meses \\
\hline
\end{tabular}

Fuente: Elaboración Propia

\subsection{Impacto Social y Ambiental}

En primer lugar, es importante determinar el impacto ambiental que se puede alcanzar con la implementación del proyecto.

La generación y utilización de energías renovables traen consigo la reducción de la contaminación ambiental producida por el uso convencional de las principales fuentes de generación de energía eléctrica que hay actualmente, ya que la mayoría de la energía proveniente de fuentes externas proviene de la quema del gas natural o la utilización de combustibles fósiles para su generación. En cuanto al Perú, la distribución de generación de energía está enfocada en cuanto a utilización de energía hidroeléctrica y la no renovable proveniente de la quema de combustibles fósiles. Sin embargo, provenga de donde provenga la energía externa, esta puede contaminar el medio ambiente, ya que, no únicamente proviene de la misma generación de esta energía, si no también puede producirse al momento de almacenarla o durante la operación de las compañías que administran esta energía.

El generar energía limpia siempre es beneficioso para la sociedad y para el mismo ecosistema, ya que la misma es generada con el input de las pisadas de las personas que son un recurso que se desperdicia diariamente, sin saber que de su aprovechamiento se podrían obtener grandes resultados sin necesidad de perjudicar al medio ambiente.

La implementación de la tecnología piezoeléctrica o los productos PAVEGEN en la Estación La Cultura, suplantara en una proporción la utilización de energía proveniente de fuentes externas, las cuales generan contaminantes para el medio ambiente. De esta 
forma, el proyecto impacta positivamente al medio ambiente y la conservación del mismo.

A continuación, se mostrarán los resultados de una encuesta realizada a los usuarios del tren eléctrico, la cual podrá demostrar que la mayoría de ellos se encuentra a favor de la utilización de energía renovable, pero no están informados de todas las tecnologías que se encuentran disponibles hoy en día.

\section{Gráfico No 36 : ¿Ha escuchado sobre las energías Renovables ?}

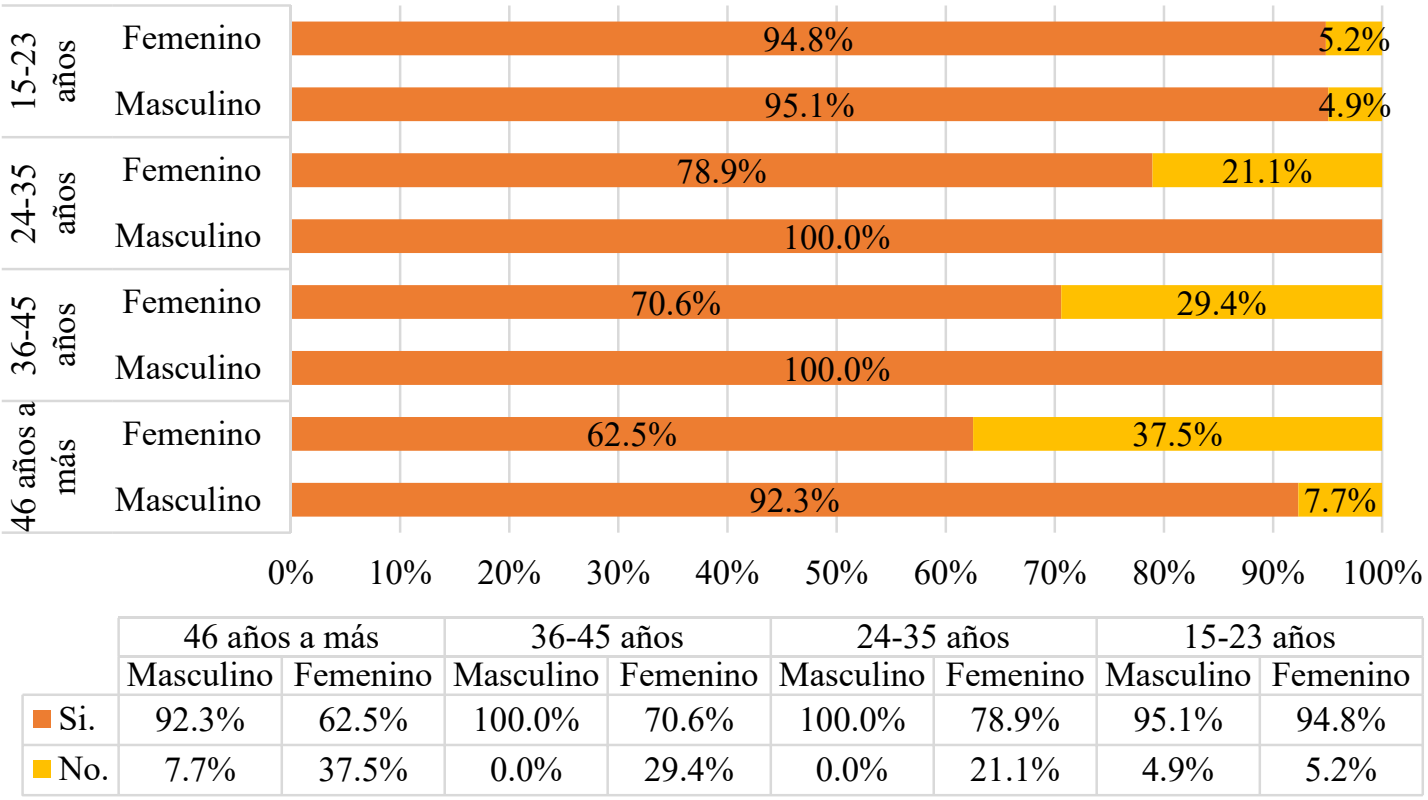

\section{Fuente: Elaboración Propia}

Según el resultado, el 90,9\% de todos los encuestados tienen conocimiento de las energías renovables. Además, este resultado da a conocer que este tipo de energías ha tomado mayor relevancia con el pasar del tiempo, ya que las personas van tomando conciencia de la contaminación por la cual está pasando el mundo de hoy en día. 


\section{Gráfico $N^{\circ} 37$ : ¿Estaría de acuerdo en el uso de Energías Renovables en la}

ciudad?

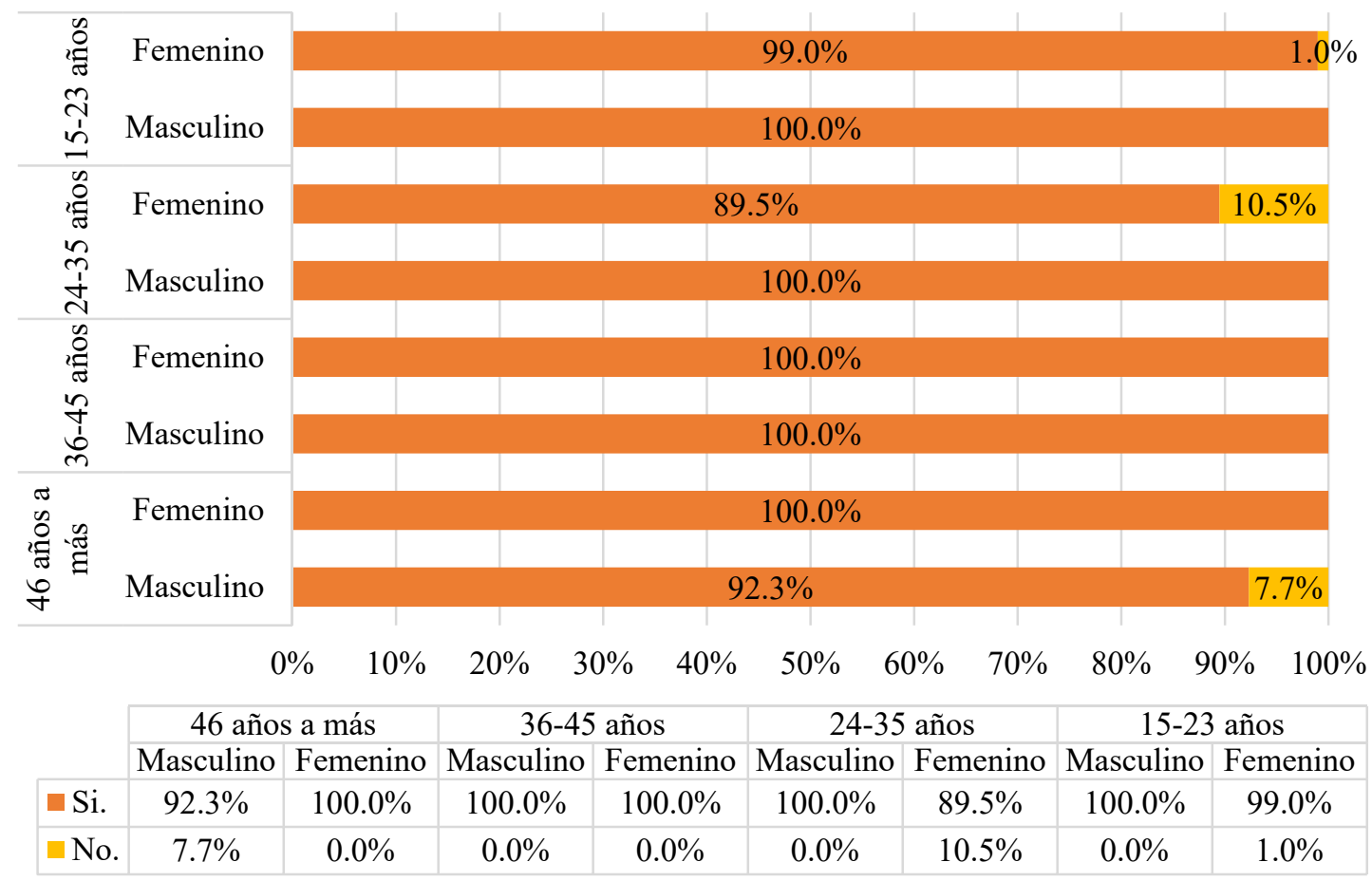

\section{Fuente: Elaboración Propia}

En esta grafica se refleja la casi unánime aceptación por el uso de energías renovables con un $98,5 \%$ de resultados afirmativos y reafirma lo mencionado en la gráfica anterior con respecto a la relevancia de las energías renovables en la sociedad. Es así como se puede concluir que la sociedad limeña es consciente de la existencia de las energías renovables y de su importancia e impacto que estas pueden traer consigo.

De estas personas sabemos que existe una incertidumbre sobre lo que es la tecnología piezoeléctrica, ya que, el 99,64\% de los entrevistados no han escuchado hablar sobre la generación de energía en base a esta tecnología. Si bien han escuchado hablar sobre otro tipo de energía renovable y están a favor de su uso en la ciudad, no conocen otro tipo de generación de energía alterna de alto impacto como la obtenida con los dispositivos piezoeléctricos.

Por este motivo, también se puede resaltar el impacto positivo que traerá consigo la implementación de las baldosas PAVEGEN en la Estación La Cultura, ya que así los 
mismos usuarios podrán darse cuenta que ellos están contribuyendo en la generación de esta energía limpia y son participes del cambio de nuestra sociedad.

Entonces, la implementación del proyecto traerá consigo un alto impacto ambiental y social, del cual los stakeholders tienen conciencia y conocimiento, tanto por ser partícipes, como por su compromiso en el desarrollo del mismo.

\subsection{Impacto Tecnológico}

Por último, como esta tecnología no es muy conocida a nivel global, se busca fomentar en las personas de la sociedad limeña la investigación y la curiosidad por informarse sobre nuevas tecnologías emergentes. Las nuevas tecnologías pueden ser sumamente valiosas para nuestra realidad, ya que pueden contribuir positivamente en cuanto al ahorro económico, reducir la contaminación ambiental y generar la cultura de ahorro energético. El Perú será un país pionero en cuanto a la utilización de la energía piezoeléctrica, pero se espera que no solo se instalen proyectos de este tipo en la capital peruana, se busca comenzar a instalar esta tecnología en lugares con gran afluencia de personas, que no se encuentren solo en Perú, sino que también se extienda esta tendencia por todos los países latinoamericanos.

Es por esto que la implementación de nuestro proyecto tendrá un impacto tecnológico sin precedentes para nuestro país y para la sociedad, debido a que en todo Latinoamérica solo se ha implementado un proyecto que utiliza esta tecnología en Brasil. Es así como se abriría un hito para nuestro desarrollo, al convertirnos en uno de los países pioneros en este rubro, y nos mostraría como una sociedad vanguardista y comprometida con la generación de energía limpia, el cuidado del medio ambiente y con el incentivo del ahorro energético en la sociedad. 


\section{CONCLUSIONES}

- Todo proyecto debe fundarse y estar orientado bajo los conceptos de los tres pilares de la sostenibilidad: económico, ambiental y social. Siendo así, estos factores trascendentales para asegurar el éxito de cualquier proyecto.

- Los resultados de la investigación muestran que el uso de energías renovables cuenta con gran aceptación por parte de la sociedad. Respaldando así el pilar social de la sostenibilidad en nuestro proyecto, el cual fomenta el uso de energías renovables, cultura de ahorro de energía y el cuidado del medio ambiente.

- Actualmente, el sistema de transporte de nuestro país está lleno de defectos e informalidad, los cuales ocasionan contaminación, congestión vehicular e insatisfacción en la población limeña.

- Las tendencias de consumo energético en el país presentan un comportamiento creciente exponencial a lo largo del tiempo debido a su fuerte relación con el crecimiento económico del país, la cultura consumista de la población y la dependencia a los combustibles fósiles para la generación de energía. De continuar esta situación, en los próximos años, el país enfrentará una inminente crisis energética, para la cual es necesaria gestionar planes de contingencia para mitigar este riesgo, tales como el uso de energías renovables.

- Hoy en día, las tecnologías aportan al desarrollo de la sociedad y el caso de la generación de energía no es la excepción. Motivo por el cual, este proyecto busca aprovechar la energía cinética de las pisadas de las personas para generar energía eléctrica mediante un dispositivo que utiliza tecnología piezoeléctrica.

- Las aplicaciones de diferentes métodos ingenieriles son indispensables para desarrollar el proyecto de la manera más óptima, tales como la distribución de planta, análisis de procesos, programación lineal, simulaciones, entre otros.

- Los sobrecostos asumidos por la empresa AATE, para que el servicio del tren eléctrico pueda seguir funcionando correctamente, se generan a causa de un déficit 
en la recaudación de dinero con el pasaje de los usuarios del servicio, los cuales no cubren los pagos de la concesión otorgada a la empresa G\&M; estos representan alrededor de S/. 26,870,506 anuales.

- Con el presente proyecto, se podría generar un ahorro en los costos energéticos de la Estación La Cultura de entre un 32,82\% y un 80,28\%. Lo cual representa un 0.5 y $1.2 \%$ del déficit de S/ 26,870,506 asumidos por el Estado. Esto respalda el pilar económico de la sostenibilidad.

- La implementación del proyecto tendrá un costo estimado de aproximadamente S/ 194,972.7. El mismo que se llevará a cabo en un tiempo estimado de 49 días. Este a su vez presenta un horizonte de recuperación que fluctúa entre los $7.3 \mathrm{y}$ 17.7 meses. A partir de ese momento, todo ahorro generado para la estación será neto.

- Con la elaboración del prototipo se ha logrado validar el funcionamiento de la tecnología piezoeléctrica, la cual es utilizada por la compañía PAVEGEN para el aprovechamiento de las pisadas de las personas en la generación de energía eléctrica.

- Mediante la simulación de la propuesta de solución implementada en la Estación La Cultura, se ha podido corroborar que la misma no traerá consigo ningún impacto negativo para el servicio brindado por el tren eléctrico ni demoras en su tiempo de atención. Es más, solo traerá consigo consecuencias positivas para la empresa AATE.

- La generación de energía renovable permitirá reducir los costos energéticos de la estación, el consumo de energía proveniente de fuentes externas, reducir la contaminación ambiental y fomentar el uso de la misma en la sociedad limeña.

- La tecnología piezoeléctrica es muy poco conocida en la sociedad limeña y en todos los países latinoamericanos, lo cual pondrá al Perú como un país pionero en cuanto a la utilización de energías renovables en la región, marcando un hito tecnológico para la sociedad. 
- Uno de los impactos más importantes que traerá consigo este proyecto es el impacto social, ya que fomentará a la sociedad limeña utilizar energías renovables y la cultura del ahorro energético. Además, el usuario se verá comprometido e involucrado con la generación de energía, siendo el protagonista de la viabilidad de este proyecto.

- La ejecución de este proyecto es totalmente viable y rentable, ya que su periodo de recuperación es menor a 2 años y posteriormente, se podrán generar ahorros sobre los S/ 130,000.00 soles anuales, lo cual es muy beneficioso para toda empresa. 


\section{RECOMENDACIONES}

- Se recomienda implementar este sistema de generación de energía renovable en todas las estacione del tren eléctrico, lo cual generaría ahorros mayores a los 2,85 millones de soles anuales. Esto representaría un ahorro del 10,6 y 14,2\% del déficit asumido por el Estado Peruano ante G\&M

- Se recomienda buscar la aplicación de este tipo de proyectos en los diversos puntos del país donde exista un nivel de afluencia de personas alto, tales como centros comerciales, grandes eventos, y otras zonas altamente transitadas. Principalmente se recomienda la aplicación de esta tecnología en las posteriores líneas del tren eléctrico y otros servicios de transporte masivos de la ciudad.

- Se recomienda mantenerse actualizado con los nuevos avances y tendencias con respecto a la tecnología piezoeléctrica, para así buscar constantemente nuevas alternativas y mejoras sobre el mismo.

- Se recomienda aplicar las dos propuestas de solución en la estación La Cultura, ya que, a pesar de que el tiempo de recuperación es mayor, el beneficio para la estación será mayor. Además, es necesario evaluar mejoras en la eficiencia del consumo de la estación, para reducir constantemente su consumo energético.

- El Perú debe de comenzar a utilizar más energías renovables, ya que debemos reducir la contaminación del ambiente para poder preservar el ecosistema. Además, es importante para posicionar al país como un pionero en la utilización de la tecnología piezoeléctrica en la región.

- Para todos los proyectos es necesario un diagnóstico, análisis, evaluación y ejecución independiente a la realidad y a las necesidades de cada uno para su aplicación. Es por esto que se recomienda utilizar esta investigación como punto base para la ejecución de proyectos futuros. 


\section{BIBLIOGRAFÍA}

Altiok, T. y Altiok, M. (2007). Simulation Modeling and Analysis with Arena. United States of America: Elsevier.

Baksh, A., Khan, F., Gadag, V., Ferdous, R. (2015) Network based approach for predictive accident modelling.Safety Science

Bustamante, G. y Zapata, D. (2012). Análisis de viabilidad para desarrollo de prototipo de acera que produce electricidad (Tesis de titulación de Ingeniería Industrial)

Dahiya, R. y Valle, M. (2013). Robotic Tactile Sensing: Technologies and System. Springer.

D.O. Akinyele, , R.K. Rayudu. (2014). Review of energy storage technologies for sustainable power networks. Sustainable Energy Technologies and Assessments

DOE/Oak Ridge National Laboratory. (2011, September 25). Amazing electrical properties in polymers discovered. ScienceDaily. Retrieved September 6, 2015 from (www.sciencedaily.com/releases/2011/09/110923102532.htm), Consultado el 3/08/2015

Dynamic energy storage control for reducing electricity cost in data centers.(2015) Mathematical Problems in Engineering

Empresa de Distribución Eléctrica Lima Norte (EDELNOR). (2015). Tarifa para la venta de energía $\quad$ eléctrica $\quad$ Recuperado de http://www.edelnor.com.pe/ES/INFORMACIONLEGAL/Tarifas/Pliegos\%20Edelnor\% 20040915\%20consumo\%20WEB.pdf. Consultado el 25/08/2015

Erturk, A., Inman, D.J. (2011) Broadband piezoelectric power generation on high-energy orbits of the bistable Duffing oscillator with electromechanical coupling. Journal of Sound and Vibration 
Escalera Siles, J. (12 de Julio de 2012). Simulación de estructuras mecámicas para UAVS. Recuperado el 25 de Octubre de 2012, Recuperado de http://upcommons.upc.edu/pfc/bitstream/2099.1/16028/4/memoria.pdf

Espitia, C y HERNANDE, E. (2011). Valoración de la capacidad de generación de energía eléctrica por medio de un dispositivo con efecto piezoeléctrico en las entradas vehiculares de la sede central de la UIS(Tesis de titulación de Ingeniería Eléctrica) Recuperado de http://repositorio.uis.edu.co/jspui/bitstream/123456789/3037/2/141033.pdf Consultado el 25/08/2015)

Fares Kahoul, Louanes Hamzioui, Ahmed Boutarfai. (2015). Microstructural, Dielectric, and Piezoelectric Properties of SFN-modified PZT. Ceramics. Energy Procedia.

Feng, X. , Gooi, H.B. , Chen, S. (2015). Capacity fade-based energy management for lithium-ion batteries used in PV systems.Electric Power Systems Research

Garcia, M., Ruina, A., Coleman, M., \& Chatterjee, A. (2010). Passive-dynamic models of human gait. Consultado el 20 de Octubre de 2012. Recuperado de http://citeseerx.ist.psu.edu/viewdoc/download?doi=10.1.1.46.185\&rep=rep1\&type=pdf

Geiyer, D., Kauffman, J.L. (2015). Chaotification as a means of broadband energy harvesting with piezoelectric materials. Journal of Vibration and Acoustics, Transactions of the ASME

Gestión. (2013). El 78\% de los peruanos utiliza transporte público para ir a trabajar. 3 de Octubre de 2015. Recuperado de: http://gestion.pe/tendencias/78-peruanos-utilizatransporte-publico-ir-al-trabajo-2056683

Giannakis, M. , Papadopoulos, T. (2014)Supply chain sustainability: A risk management approach. International Journal of Production Economics 
Gonzalez-L, E.C. , Adarme-Jaimes, W. , Orjuela-Castro, J.A. (2015). Stochastic mathematical model for vehicle routing problem in collecting perishable products. DYNA (Colombia)

Gu, L (2011) Microelectronics Journal Articles Low-frequency piezoelectric energy harvesting prototype suitable for the MEMS implementation.

Hayes, D. (2011). A Study Into the Harvesting of Energy from the Movement of Pedestrians. Recuperado de https://books.google.com.pe/books?id=9XCEF7xNLyQC\&pg=PA27\&dq=pavegen\&hl $=$ en $\&$ sa $=X \& v e d=0 C C M Q 6 A E w A W o V C h M I 5 f 3 A 4 P H i x w I V h \_2 A C h 01 k Q M j \# v=$ onepa ge\&q=pavegen $\& \mathrm{f}=$ false. . Consultado el 04/09/2015

Hillier, F. y Lieberman, G.. (2010). Introducción a la investigación de operaciones. México: MC. Graw Hill

Honoré, E., \& Mininni, P. (1996). Estudio del comportamiento de un material piezoeléctrico en un campo eléctrico alterno. Recuperado el 12 de Octubre de 2012, de http://www.fisicarecreativa.com/informes/infor_ondas/piezoelectr96.pdf Hua-Bin Fang, Jing-Quan Liu, Zheng-Yi Xu, Lu Donga, Li Wang, Di Chena, Bing-Chu Cai, Yue Liu

INEN. (2006). El INS y las acciones contra el dengue en Lima. abril 17, 2016, de INEN Recuperado de http://www.ins.gob.pe/insvirtual/images/boletin/pdf/ReporteEpidemiologicoINS2006$\underline{22 . p d f}$

Jiménez, B. (1995). Materiales piezoeléctricos: formas de presentación, ventajas y desventajas en las aplicaciones. Cerámica y Vidrio, 272-276.

Jiménez, J. de Frutos, D. Vázquez, M. (2015) Optimización de piezoeléctricos comerciales para su uso en sistemas de Energy. Harvesting. Boletín de la Sociedad Española de Cerámica y Vidrio 
Kirsch, P., Hine, A., Maybury, T. (2015). A model for the implementation of industrywide knowledge sharing to improve risk management practice. Safety Science

Kittel, C. (1995). Introducción a la física del estado sólido. Reverte.

Komurcugil, H. , Altin, N. , Ozdemir, S. , Sefa, I. (2015) An extended lyapunovfunction-based control strategy for single-phase UPS inverters. IEEE Transactions on Power Electronics

Kuo, A., Donelan, J. M., \& Ruina, A. (2005). Energetic Consequences of Walking Like an Inverted Pendulum: Step-to-Step Transitions. American College of Sports Medicine, 88-97.

Lindo Systems Inc. (2016). LINGO 15.0 - Optimization Modeling Software for Linear, Nonlinear, and Integer Programming. Abril, 15, 2016, de Lindo Systems Inc. Sitio web: http://www.lindo.com/index.php?option $=$ com content\&view $=$ article\&id=2\&Itemid $=10$

M. T. Penella y M. Gasulla, (2007). A Review of Commercial Energy Harvesters forAutonomous Sensors», en IEEE Instrumentation and Measurement Technology Conference Proceedings, 2007. IMTC 2007 , pp. 1-5.

Marsal-Llacuna, M.-L. (2015) City Indicators on Social Sustainability as Standardization Technologies for Smarter (Citizen-Centered) Governance of Cities. Journal of Springer Science Business Media Dordrecht

Mateu, 1. y Moll,F. (2011). Review of energy harvesting techniques and applications formicroelectronics», Proc SPIE 5837 VLSI Circuits Syst. II, pp. 359-373, jun. 2005. Mediavilla M. (2012). Una visión global de la crisis energética. El Ecologísta, 73, pp. 3034.

Mediavilla, M (2010) Crecer, decrecer, evolucionar: causas y consecuencias del crecimiento en un planeta limitado Recuperado de http://www.eis.uva.es/energiasostenible/wp-content/uploads/2011/11/Mediavilla-crecerdecrecer-evolucionar.pdf). Consultado el 23/08/2015) 
MEDIAVILLA PASCUAL, Margarita (2012) Una visión global de la crisis energética. Revista ecologista (Nº73) ,p. 30-34.Consultado el 25/08/2015

Michel, A. , Hudon, M. (2015). Community currencies and sustainable development: A systematic review. Journal of Ecological Economics

Microelectronics Journal (2006). Fabrication and performance of MEMS-based piezoelectric power generator for vibration energy harvesting.

Minazara, E, Vasic,D Y Costa, F. (2008). Piezoelectric generator harvesting bike vibrations energy to supply portable devices.Recuperado el 26 de Setiembre de 2015, de PRES UNIVERSUD. Recuperado de http://www.icrepq.com/icrepq-08/344$\underline{\text { minazara.pdf. }}$

Minazara, E. Vasic, D y Costa, F. (2008). Piezoelectric generator harvesting bike vibrations energy to supply portable devices.

MINEM (2010). Decreto Legislativo de Promoción de La Inversión para 1La generación de Electricidad con el uso de Energías Renovables. Consultado el 3 de Octubre de 2015, Recuperado de MINEM Sitio web.

MINISTERIO DE ENERGÍA Y MINAS (2014) Plan energético Nacional 2014-2025 (http://www.minem.gob.pe/ detalle.php?idSector=10\&idTitular=6397). Consultado el 28/08/2015)

Mitcheson, P., Yeatman, E., Rao, G. K., Holmes, A., \& Green, T. (2008). Energy Harvesting From Human and Machine Motion for Wireless Electronic Devices. Proceedings of the IEEE, 1457- 1486.

MOHEIMANI, S. O. R Y FLEMING, A. J., (2006), Fundamentals of Piezoelectricity, London: Springer

Ordóñez , P. (2011, diciembre). Estudio del comportamiento de una cerámica piezoeléctrica mediante elementos finitos. 
Organismo Supervisor de la Inversión en Energía y Minería. (2013). Sistema de información de energías renovables. 3 de octubre de 2015, de osinergmin Recuperado de http://www2.osinerg.gob.pe/EnergiasRenovables/EnergiasRenovables.html

P.M. Mayrhofer, , , H. Riedl, H. Euchner, M. Stöger-Pollach, P.H. Mayrhofer, A. Bittner, U. Schmid. (2015) Microstructure and piezoelectric response of YxAl1-xN thin films. Acta Materialia

Pajuelo, M. y Castro, J. (2014) PCR: Informe sectorial Perú: Sector Eléctrico. Recuperado de

http://www.ratingspcr.com/uploads/2/5/8/5/25856651/sector_electrico_peruano_201409 -fin.pdf). Consultado el 28/08/2015)

PAVEGEN. Recuperado de http://pavegen.com/technolog. Consultado el 28/08/2015 Richelli, A. , Colalongo, L. , Kovàcs-Vajna, Z. (2015) A 30 mV-2.5 V DC/DC converter for energy harvesting. Journal of Low Power Electronics

Roundy, S., Wright, P., \& Rabaey, J. (9 de Octubre de 2002). A study of low level vibrations as a source for wireless senser nodes. Consultado el 23 de Octubre de 2012, Recuperado de http://bwrc.eecs.berkeley.edu/publications/2003/presentations/Low Power_Elec Devic e/ComComRoundy.pdf

S. O. R. Moheimani y A. J. (2006). Fleming, «Fundamentals of Piezoelectricity», en Piezoelectric Transducers for Vibration Control and Damping, Springer London. pp. 935 .

Saadon, S. Othman Sidek. (2015). Micro-Electro-Mechanical System (MEMS)-Based Piezoelectric Energy Harvester for Ambient Vibrations. Procedia - Social and Behavioral Sciences

Sepúlveda, E. (2014) Diseño de un Colecto de Energía Piezoeléctrico (EnergyHaversting) Mediante Optimización Topológica que Maximice la Transformación de Energía Mecánica en Eléctrica Generada por un Ser Humano al Caminar (Tesis de Magister en $\begin{array}{lll}\text { Ingeniería } & \text { Mecánica). } & \text { Recuperado de }\end{array}$ 
http://www.bdigital.unal.edu.co/47308/1/1128267719.2015.pdf). Consultado 24/09/2015)

Shane Hickey. (2015). No need to tread lightly: the tile lighting up football in Rio and stations in France. Consultado el 27 de Setiembre del 2015, Recuperado de The Guardian Recuperado de http://www.theguardian.com/business/2015/feb/15/tile-light-football-rio$\underline{\text { stations-france-pavegen-kinetic-footfsteps-energy }}$

Sharapov, V.Piezoceramic sensors. Springer.

Sodano, H., \& Inman, D. (2005). Comparison of Piezoelectric Energy Harvesting Devices for Recharging Batteries. Journal of Intelligent Material Sustems and Structures, 799807.

Thomas K. Grose. (2012). Tiles May Help Shrink Carbon Footprint by Harnessing Pedestrian Power. Recuperado el 27 de Setiembre de 2015, de National Geographic News. Recuperado de

http://news.nationalgeographic.com/news/energy/2012/05/120518-floor-tiles-turnfootfalls-to-electricity/

Thomas, J., M. A. Qidwai, y J. C. Kellogg, «Energy scavenging for small-scaleunmanned systems», J. Power Sources, vol. 159, n.o2, pp. 1494-1509, sep. 2006.

TURIEL, A. (2012) El declive energético. Revista Mientras Tanto (No117), p. 11-26. Consultado el 25/08/2015.

Wang, D.-A. , Chang, K.-H. (2010) Electromagnetic energy harvesting from flow induced vibration. Microelectronics Journal ISSN: 00262692

Xiangdong Xie, Quan Wang. (2015). A mathematical model for piezoelectric ring energy harvesting technology from vehicle tires. International Journal of Engineering Science Yuri A. Genenko, Julia Glaum, Michael J. Hoffmann, Karsten Albe. (2015) Mechanisms of aging and fatigue in ferroelectrics. Materials Science and Engineering: B 
Yu-Yin Chen, Dejan Vasic. (2015). Electrical Interfacing Circuit Discussion of Galloping-based Piezoelectric Energy Harvester. Physics Procedia

Zhang, S., Yang, J., Shi, Y., Wu, X., Ran, Y. 


\section{ANEXOS}

\section{ANEXO 1 "Encuesta a los Representantes de AATE"}

\section{ENCUESTA REALIZDA A ALEJANDRO BALLESTA Y HUMBERTO COVARRUBIAS CON SUS RESULTADOS}

1. ¿Cuál es su cargo en AATE?

a. Alejandro Ballesta:

i. Gerente de Operaciones

b. Humberto Covarrubias:

i. Especialista en Mantenimiento de Sistemas Eléctricos de la Unidad Gerencial de Operaciones y Mantenimiento

2. ¿Tiene un grupo especializado en evaluación de Proyectos?

a. La institución AATE si cuenta con un área de evaluación de proyectos, pero éstos solo han sido financieros, publicitarios y de servicios.

b. Hasta el momento, los proyectos propuestos han sido un poco descabelladas, por lo cual no se han llevado a ejecución hasta el momento.

3. ¿Cuáles son los principales problemas del a operación del Servicio del Tren Eléctrico actualmente?

a. El principal problema del Tren Eléctrico son los sobrecostos que el Estado peruano debe cubrir para poder continuar su funcionamiento, ya que la suma de dinero recabada por los pasajes de los usuarios no alcanza para cubrir los costos de operación del Tren.

b. La Línea 1 del tren eléctrico se encuentra concesionada por la empresa Graña y Montero, a la cual se le debe pagar trimestralmente un monto acordado respecto a los kilómetros recorridos. Este monto siempre es superior al dinero recabado como fue mencionado anteriormente. 
4. ¿Cuáles fueron sus posibles proyectos para solucionar los altos costos operativos del Tren?

a. Se propuso la instalación de publicidad al interior de las estaciones para poder reducir el déficit entre lo recabado y lo pagado a Graña y Montero, pero esto no se vería bien y el servicio del tren perdería seriedad y su imagen se vería perjudicada.

b. Se vio la posibilidad de aumentar el pasaje del servicio de transporte, pero la población no lo aceptaría correctamente.

5. ¿Qué opina de las energías renovables?

a. Están a favor del uso de energía renovable, ya que es una forma muy buena de reducir costos y reducir la contaminación ambiental.

b. El Perú necesita de la implementación de estas energías para poder mantener su crecimiento económico sin perjudicar al medio ambiente.

6. ¿Tiene conocimiento de la tecnología piezoeléctrica?

a. No.

7. ¿Qué opinión tiene acerca de la implementación de energía renovable mediante la utilización de la tecnología piezoeléctrica en las Estaciones del Tren Eléctrico?

a. Les pareció súper interesante, ya que no tenían conocimiento de esta energía renovable y sus posibles aplicaciones y beneficios en las estaciones del tren eléctrico.

Al momento de haber culminado con la presentación del proyecto, comentaron que supusieron que el proyecto se basaría en la reutilización de la energía de los trenes eléctricos para alimentar al siguiente tren que viene en camino, lo cual ya lo estaban realizando.

8. ¿Qué consejos nos podría brindar? 
a. Se podría realizar una matriz energética para tener conocimiento exacto de los consumos eléctricos de la estación.

b. Implementar esta energía renovable en la Estación La Cultura como proyecto piloto para evaluar su efectividad.

c. Averiguar el hundimiento de las baldosas al ser pisadas, ya que las personas podrían caerse y causar accidentes.

\section{ANEXO 2 "Encuesta realizada a la comunidad limeña"}

\section{Encuesta Proyecto Tesis}

Agradecemos su participación en esta encuesta que es de vital importancia para nuestro proyecto de Tesis.

Muchas gracias de antemano.

*Obligatorio

1. ¿Tiene conocimiento del servicio de transporte público del Tren Eléctrico de Lima? *

*En caso que la respuesta sea NO, agradecemos su tiempo y colaboración para participar de esta encuesta, en caso contrario, por favor, continúe con las siguientes preguntas.

$\mathrm{Si}$

No

2. Género *

3. ¿Cuál es su edad? *

15-23 años

24-35 años

36-45 años

- 46 años a más

4. ¿Cuál es su ocupación?* *

Estudiante Universitario

Estudiante Escolar

- Empleado del Sector Privado

Empleado del Sector Público

$\checkmark$ Independiente

Desempleado

Jubilado 


\section{5. ¿Alguna vez ha utilizado el Tren Eléctrico en Lima Perú? *}

Marque una sola opción. En caso que la respuesta sea NO pase a la pregunta 7, en caso contrario, por favor, continúe con las siguientes preguntas.

$\mathrm{OSi}$

No

\section{6. ¿Con que frecuencia lo utiliza?}

Marque una sola opción.

Diariamente

De Lunes a Viernes

Interdiario

- 1 a 2 veces por semana

1 vez al mes

7. ¿Qué opina usted del actual costo del pasaje del Tren Eléctrico de Lima (S/.1.50), considerando el servicio que brinda? *

Es el adecuado.

Debería reducirse.

Debería ser más alto.

8. ¿Ha escuchado sobre las energías Renovables? *

$\circ \mathrm{Si}$

No. 


\section{9. ¿Qué Energías Renovables conoce? *}

Marque todas las que conozca y agregue en la casilla de otros si conocen algunas que no hayan sido nombradas

$\square$ Energía Solar.

$\square$ Energía Hidráulica.

$\square$ Energía Mareomotriz.

$\square$ Energía Eólica

$\square$ Energía Geotérmica

Otro:

10. ¿Está a favor del uso de Energías Renovables? *

$\mathrm{Si}$

No

11. ¿Estaría de acuerdo en el uso de Energías Renovables en la ciudad? *

$\mathrm{Si}$.

No.

12. ¿Cree usted que los ciudadanos de Lima tienen una cultura de ahorro de energía? *

Si.

No.

13. ¿Considera que la ciudad de Lima esta propensa a una crisis energética en los próximos 10 años? *
Si.
No.
No sabe. 
14. ¿Considera que la ciudad de Lima está atravesando una crisis energética actualmente? *

Si.

No.

No sabe.

15. ¿Considera que la ciudad de Lima tiene problemas de contaminación ambiental? *

$\mathrm{Si}$

No.

\section{Enviar}

Nunca envies contraseñas a través de Formularios de Google.

ANEXO 3 "Toma de tiempos de los Torniquetes"

\begin{tabular}{|c|c|c|c|c|c|}
\cline { 2 - 6 } \multicolumn{1}{c|}{} & Lunes & Martes & Miércoles & Jueves & Viernes \\
\hline muestra & $\begin{array}{c}\text { Tiempo por } \\
\text { atención (seg) }\end{array}$ & $\begin{array}{c}\text { Tiempo por } \\
\text { atención } \\
\text { (seg) }\end{array}$ & $\begin{array}{c}\text { Tiempo por } \\
\text { atención (seg) }\end{array}$ & $\begin{array}{c}\text { Tiempo por } \\
\text { atención } \\
\text { (seg) }\end{array}$ & $\begin{array}{c}\text { Tiempo por } \\
\text { atención } \\
\text { (seg) }\end{array}$ \\
\hline $\mathbf{1}$ & 2 & 3 & 3.5 & 2.5 & 3.5 \\
\hline $\mathbf{2}$ & 2.2 & 2.5 & 3.6 & 3.5 & 3 \\
\hline $\mathbf{3}$ & 2.5 & 2.5 & 2 & 3.6 & 2 \\
\hline $\mathbf{4}$ & 2.6 & 3.5 & 3 & 3 & 2.4 \\
\hline $\mathbf{5}$ & 3 & 3.6 & 3 & 3 & 4 \\
\hline $\mathbf{6}$ & 0.2 & 3.8 & 3.4 & 3 & 2 \\
\hline $\mathbf{7}$ & 3.15 & 3.9 & 3.6 & 3.6 & 2.4 \\
\hline $\mathbf{8}$ & 3.2 & 3.8 & 3.6 & 4 & 2 \\
\hline $\mathbf{9}$ & 3.1 & 2 & 3.6 & 3 & 3 \\
\hline $\mathbf{1 0}$ & 3.4 & 3.58 & 3.6 & 3 & 2.5 \\
\hline $\mathbf{1 1}$ & 3.58 & 4 & 3 & 3.6 & 3.5 \\
\hline $\mathbf{1 2}$ & 4 & 3.9 & 2.6 & 4 & 3.6 \\
\hline $\mathbf{1 3}$ & 3.9 & 3.8 & 2.4 & 3 & 4 \\
\hline $\mathbf{1 4}$ & 3.8 & 2 & 3 & 3.5 & 3 \\
\hline $\mathbf{1 5}$ & 2 & 3 & 3 & 3.6 & 3.4 \\
\hline $\mathbf{1 6}$ & 3.7 & 2.5 & 3 & 3 & 2.6 \\
\hline $\mathbf{1 7}$ & 2.5 & 2.5 & 2.6 & 2 & 3 \\
\hline $\mathbf{1 8}$ & 2.9 & 3.5 & 2.4 & 2.4 & 3 \\
\hline $\mathbf{1 9}$ & 3.6 & 3.6 & 3.5 & 2 & 3.6 \\
\hline
\end{tabular}




\begin{tabular}{|c|c|c|c|c|c|}
\hline 20 & 3.8 & 3.8 & 3.6 & 2 & 4 \\
\hline 21 & 2.4 & 3.4 & 2 & 3.6 & 3 \\
\hline 22 & 2.2 & 3.58 & 3 & 4 & 2.5 \\
\hline 23 & 2.1 & 4 & 3 & 2 & 2.8 \\
\hline 24 & 2 & 3.9 & 3.4 & 2.4 & 2.7 \\
\hline 25 & 2 & 3.8 & 3 & 2 & 1.9 \\
\hline 26 & 2.4 & 2 & 3 & 2.5 & 3.6 \\
\hline 27 & 3.5 & 2.4 & 3 & 3.5 & 4 \\
\hline 28 & 3 & 2.8 & 2.6 & 3.6 & 3 \\
\hline 29 & 3 & 3.8 & 2.4 & 3 & 4 \\
\hline 30 & 3 & 3.9 & 3 & 2 & 3.5 \\
\hline 31 & 2.6 & 4 & 3 & 3.6 & 2.6 \\
\hline 32 & 2.4 & 4.2 & 2.6 & 4 & 3.5 \\
\hline 33 & 2.8 & 1.9 & 2.4 & 3 & 3.8 \\
\hline 34 & 3.8 & 3.8 & 2 & 2 & 3 \\
\hline 35 & 3.9 & 2.5 & 3.7 & 2.4 & 3.6 \\
\hline 36 & 3 & 2.5 & 2.5 & 2 & 4 \\
\hline 37 & 3 & 3.5 & 2.5 & 2.5 & 3 \\
\hline 38 & 2.6 & 3.6 & 3.5 & 3.5 & 1.9 \\
\hline 39 & 2.4 & 3 & 3.6 & 3.6 & 4 \\
\hline 40 & 3 & 3 & 3 & 3 & 1.9 \\
\hline 41 & 2.6 & 3 & 3 & 3.6 & 4 \\
\hline 42 & 2.4 & 3.4 & 3 & 4 & 2 \\
\hline 43 & 2.8 & 3.58 & 2 & 3 & 2.4 \\
\hline 44 & 1.5 & 4 & 3.7 & 2 & 4 \\
\hline 45 & 2 & 3.9 & 2.5 & 2.4 & 2 \\
\hline 46 & $1 . .9$ & 3.8 & 2.5 & 2 & 2.4 \\
\hline 47 & 3.58 & 2.5 & 3.5 & 3.6 & 2 \\
\hline 48 & 4 & 2.5 & 3.6 & 4 & 3 \\
\hline 49 & 3.9 & 3.5 & 3 & 3 & 3 \\
\hline 50 & 3.8 & 3.6 & 3 & 3.5 & 3 \\
\hline 51 & 2 & 3.8 & 3 & 3.6 & 3 \\
\hline 52 & 3.7 & 3.4 & 2.6 & 3 & 3.6 \\
\hline 53 & 2.5 & 3.58 & 2.4 & 2 & 4 \\
\hline 54 & 2.5 & 4 & 3.6 & 2.4 & 3 \\
\hline 55 & 3.5 & 3.9 & 3 & 2 & 2.5 \\
\hline 56 & 3.6 & 3.8 & 3 & 3.5 & 3.4 \\
\hline 57 & 3.8 & 2 & 3 & 2.5 & 3 \\
\hline 58 & 2.4 & 3 & 3.4 & 3.5 & 3.5 \\
\hline 59 & 2 & 2.5 & 2 & 3.6 & 4 \\
\hline 60 & 3 & 2.5 & 3 & 3 & 3.9 \\
\hline 61 & 3 & 3.5 & 3 & 2 & 2.5 \\
\hline 62 & 2 & 3.6 & 2.6 & 2.4 & 3.8 \\
\hline 63 & 2 & 3.8 & 2.4 & 2 & 3 \\
\hline 64 & $1 . .9$ & 2 & 3.7 & 3.4 & 2 \\
\hline 65 & 3.58 & 2.4 & 2.5 & 2.5 & 4 \\
\hline
\end{tabular}




\begin{tabular}{|c|c|c|c|c|c|}
\hline 66 & 2 & 3.4 & 2.5 & 3.5 & 3.6 \\
\hline 67 & 3.7 & 3.58 & 3.5 & 3.6 & 4 \\
\hline 68 & 2.5 & 4 & 3.6 & 3 & 3 \\
\hline 69 & 2.5 & 3.9 & 3 & 3.6 & 3 \\
\hline 70 & 3.5 & 3.8 & 3 & 3.6 & 2.5 \\
\hline 71 & 3 & 2 & 2.6 & 4 & 2.5 \\
\hline 72 & 2 & 2.8 & 2.4 & 2 & 3.5 \\
\hline 73 & 2.4 & 3.8 & 3.5 & 2.4 & 4 \\
\hline 74 & 2 & 3.9 & 3.6 & 2 & 3 \\
\hline 75 & 3 & 4 & 2 & 2.5 & 2.5 \\
\hline 76 & 3 & 4.2 & 3 & 3.5 & 2.5 \\
\hline 77 & 2.5 & 1.9 & 3 & 3.6 & 3.5 \\
\hline 78 & 2.5 & 3.8 & 3 & 3 & 2 \\
\hline 79 & 6 & 3.4 & 3 & 2 & 2.4 \\
\hline 80 & 3 & 3.58 & 2.6 & 2.9 & 4 \\
\hline 81 & 3.8 & 4 & 3 & 3.6 & 2 \\
\hline 82 & 3.9 & 3.9 & 3 & 4 & 2.4 \\
\hline 83 & 4 & 2.5 & 2.6 & 2 & 2 \\
\hline 84 & 4.2 & 2.5 & 2.4 & 2.4 & 3 \\
\hline 85 & 3.9 & 3.5 & 2.5 & 2 & 4 \\
\hline 86 & 3.8 & 3.6 & 2.5 & 2.5 & 3 \\
\hline 87 & 2 & 3.8 & 3.5 & 3.5 & 4.1 \\
\hline 88 & 3.7 & 3 & 3.6 & 3.6 & 2.5 \\
\hline 89 & 2.5 & 3.4 & 4 & 3 & 2.5 \\
\hline 90 & 2.9 & 3.58 & 3.5 & 1.9 & 3.5 \\
\hline 91 & 3.6 & 4 & 3.6 & 3.6 & 2.8 \\
\hline 92 & 3.9 & 3.9 & 4 & 4 & 3 \\
\hline 93 & 3.8 & 3.8 & 3 & 3 & 2 \\
\hline 94 & 2 & 2 & 3 & 2 & 2.4 \\
\hline 95 & 3.7 & 3 & 3 & 2.4 & 4 \\
\hline 96 & 2.5 & 3.4 & 3 & 2 & 2 \\
\hline 97 & 2.9 & 3.58 & 2.6 & 3.6 & 2.4 \\
\hline 98 & 3.6 & 4 & 2.4 & 4 & 2 \\
\hline 99 & 3.8 & 3.9 & 4 & 3 & 3 \\
\hline 100 & 2 & 3.8 & 3 & 4.1 & 3.5 \\
\hline
\end{tabular}


ANEXO 4 "Número de veces que transitan la estación al día los pasajeros"

\begin{tabular}{|c|c|c|c|c|c|c|}
\hline & \multirow{2}{*}{\multicolumn{6}{|c|}{$\begin{array}{c}\text { RECUENTO DE PERSONAS QUE UTILIZAN LA ESTACION LA } \\
\text { CULTURA EN SU RUTA DE REGRESO } \\
\text { LUnes }\end{array}$}} \\
\hline & & & & & & \\
\hline & \multicolumn{3}{|c|}{ Personas que entran } & \multicolumn{3}{|c|}{ Personas que salen } \\
\hline & Regresan & No regresan & Total & Regresan & No regresan & Total \\
\hline $\begin{array}{c}\text { Cantidad de } \\
\text { personas }\end{array}$ & 142 & 18 & 160 & 155 & 25 & 180 \\
\hline \multirow[t]{4}{*}{ Proporción } & $89 \%$ & $11 \%$ & $100 \%$ & $86 \%$ & $14 \%$ & $100 \%$ \\
\hline & \multicolumn{6}{|c|}{ Martes } \\
\hline & \multicolumn{3}{|c|}{ Personas que entran } & \multicolumn{3}{|c|}{ Personas que salen } \\
\hline & Regresan & No regresan & Total & Regresan & No regresan & Total \\
\hline $\begin{array}{c}\text { Cantidad de } \\
\text { personas }\end{array}$ & 144 & 16 & 160 & 163 & 18 & 181 \\
\hline \multirow[t]{4}{*}{ Proporción } & $90 \%$ & $10 \%$ & $100 \%$ & $90 \%$ & $10 \%$ & $101 \%$ \\
\hline & \multicolumn{6}{|c|}{ Miercoles } \\
\hline & \multicolumn{3}{|c|}{ Personas que entran } & \multicolumn{3}{|c|}{ Personas que salen } \\
\hline & Regresan & No regresan & Total & Regresan & No regresan & Total \\
\hline $\begin{array}{c}\text { Cantidad de } \\
\text { personas }\end{array}$ & 124 & 32 & 156 & 132 & 27 & 159 \\
\hline \multirow[t]{4}{*}{ Proporción } & $79 \%$ & $21 \%$ & $98 \%$ & $83 \%$ & $17 \%$ & $88 \%$ \\
\hline & \multicolumn{6}{|c|}{ Jueves } \\
\hline & \multicolumn{3}{|c|}{ Personas que entran } & \multicolumn{3}{|c|}{ Personas que salen } \\
\hline & Regresan & No regresan & Total & Regresan & No regresan & Total \\
\hline $\begin{array}{c}\text { Cantidad de } \\
\text { personas }\end{array}$ & 138 & 22 & 160 & 155 & 32 & 187 \\
\hline \multirow[t]{4}{*}{ Proporción } & $86 \%$ & $14 \%$ & $100 \%$ & $83 \%$ & $17 \%$ & $104 \%$ \\
\hline & \multicolumn{6}{|c|}{ Viernes } \\
\hline & \multicolumn{3}{|c|}{ Personas que entran } & \multicolumn{3}{|c|}{ Personas que salen } \\
\hline & Regresan & No regresan & Total & Regresan & No regresan & Total \\
\hline $\begin{array}{c}\text { Cantidad de } \\
\text { personas }\end{array}$ & 115 & 25 & 140 & 161 & 26 & 187 \\
\hline \multirow[t]{4}{*}{ Proporción } & $82 \%$ & $18 \%$ & $88 \%$ & $86 \%$ & $14 \%$ & $104 \%$ \\
\hline & \multicolumn{6}{|c|}{ Sabado } \\
\hline & \multicolumn{3}{|c|}{ Personas que entran } & \multicolumn{3}{|c|}{ Personas que salen } \\
\hline & Regresan & No regresan & Total & Regresan & No regresan & Total \\
\hline $\begin{array}{c}\text { Cantidad de } \\
\text { personas }\end{array}$ & 147 & 23 & 170 & 157 & 26 & 183 \\
\hline Proporción & $86 \%$ & $14 \%$ & $106 \%$ & $86 \%$ & $14 \%$ & $102 \%$ \\
\hline
\end{tabular}

\begin{tabular}{|c|c|}
\hline \multicolumn{2}{|c|}{$\begin{array}{c}\text { PROMEDIO DE PERSONAS QUE UTILIZAN LA ESTACION LA } \\
\text { CULTURA EN SU RUTA DE REGRESO }\end{array}$} \\
\hline Personas que entran & $85.52 \%$ \\
\hline Personas que salen & $85.66 \%$ \\
\cline { 2 - 2 } & $\mathbf{8 5 . 6} \%$ \\
\hline
\end{tabular}

